\title{
Abstracts of the 38th Annual Meeting of THE JAPAN SOCIETY OF HUMAN GENETICS
}

October 21-23, 1993, Tokyo, Japan

President: Yukio FUKUYAMA, M.D., D.M.Sc.

(Professor, Department of Pediatrics, Tokyo Women's Medical College, Tokyo) 
The Japan Society of Human Genetics Award Lecture

AW 1-A 20

CYTOGENETIC STUDIES OF REPRODUCTION. Kazuya MIKAMO (Dept. Biol. Sci., Asahikawa Med. Col., Asahikawa)

The primary incidence of reproductive failure is known to be extremely high in humans. It is estimated that more than $75 \%$ of the ova in contact with spermatozoa are aborted due to abnormal development. In addition to this biologically unusual phenomenon, it has been postulated that more than half of these abnormal embryos have either numerical or structural chromosome aberrations.

Since it has been very difficult to directly karyotype human gametes, this hypothesis has not been proved to be scientifically acceptable. Owing to recent progress in developmental biology and medicine, however, the cytogenetic study of human oocytes and spermatozoa has become possible in the last ten years. Our studies, and those using our improved method, have shown clearly that the hypothesis is acceptable. Moreover, our controlled animal experiments have shown that incidences of spontaneous chromosome aberrations are much lower in animals. Thus, it is strongly suggested that this extraordinary phenomenon is generated by species specific properties of man.

In the present lecture, the causal mechanisms inducing the frequent chromosomal errors in human gametes and embryos were discussed with special reference to the characteristic nature of human reproduction.

\section{Junior Award Lecture}

\section{AW 2-A 19}

CLINICAL AND MOLECULAR ANALYSIS OF PEROXISOME-DEFICIENT DISORDERS Nobuyuki SHIMOZAWA

(Dept. of Pediatrics, Gifu University School of Medicine)

Zellweger syndrome is a fatal autosomal recessive disease, with clinical findings including dysmorphic features, hepatomegaly, multiple renal cysts and neuronal migration disorders. This disorder is characterized by the absence of peroxisomes, resulting in multiple metabolic disturbances such as defects in peroxisomal Boxidation and plasmalogen biosynthesis. We have recently found that ten complementation groups were identified by means of cell fusion and immunofluorescence analysis. No apparent relations were noted between complementation groups and clinical phenotypes. The primary defect was clarified in the one group (F) including a Japanese and an English patient of Zellweger syndrome, who were homozygote for the same point mutation that resulted in the premature termination of peroxisome assembly factor-1 (PAF-1).

Furthermore, we demonstrated the assignment of the human $\mathrm{PAF}-1$ gene to chromosome $8 \mathrm{q} 21.1$. 
Plenary Lectures (L 1-L 4)

\section{2-A 7}

PERSPECTIVE IN NEUROGENETIC RESEARCH

P.Michael CONNEALLY (Indiana University School of Medicine, Indianapolis, USA)

The advent of recombinant DNA allowed rapid advancement in understanding the etiology of inherited neurological diseases. The vast majority of the more common neurogenetic disorders have now been assigned to a specific chromosomal region and a significant proportion of the responsible genes have been cloned. This has led to a number of unique types of phenomena. For example, the dystrophin gene is the largest ever described in any organism (over 2 megabases) and mutations causing Duchenne muscular dystrophy are the results of very large deletions in the gene. The gene for neurofibromatosis is also very large (approximately $350 \mathrm{~kb}$ ) and furthermore there are three other genes contained within the NF1 gene and as far as is known they are unrelated to the disease. A group of neurological disorders which include myotonic dystrophy, fragile-X syndrome and Huntington disease are due to an expansion of trinucleotide repeats in the gene. The size of the expansion is highly correlated with age at onset and/or severity of symptoms. What other surprises lie in store is difficult to imagine. Though the molecular defect is known for a number of these disorders, treatment is turning out to be difficult in many cases.

These issues and an overview of molecular discoveries in neurogenetic diseases will be discussed.

\section{3-A 18}

CONCENTRATION OF VSV-G PSEUDOTYPED RETROVIRAL VECTORS TO VERY HIGH TITERS. T.Friedmann, J.Burns and J.-K.Yee(Center for Molecular Genetics and Dept. of Pediatrics, UCSD School of Medicine, La Jolla,Cal. 92093 USA)

The goal of many current studies of human gene therapy is the efficient delivery of transducing viral vectors directly to appropriate target cells in vivo. While retroviral vectors remain ideal for many ex vivo gene transfer models, it has been difficult to extend their use to in vivo applications, partly because of the difficulty in producing retroviral vectors of suitably high titers. Retroviruses are labile under most conditions of physical concentration, and while it is possible under some conditions to achieve a concentration of several fold, the yield of virus is poor, almost always less than $5 \%$. As part of our efforts to produce retroviral vectors of higher titers, our laboratory has recently shown that pseudotype particles of retroviral vectors can be produced in which the viral envelope gene product in the viral membrane can be replaced entirely by the $G$ protein of vesicular stomatitis virus (VSV). Such pseudotyped viral particles have the expanded host range characteristic of VSV and can infect cells from a variety of fish and other non-mammalian sources. More important for human gene therapy applications is the fact that VSV-G pseudotype virus is much more stable to sedimentation in an ultracentrifuge and can be concentrated by pelleting to titers of higher than $10^{\circ}$ infectious particles $/ \mathrm{ml}$. We are studying the use of VSV $-\mathrm{G}$ pseudotyped retroviral vectors to deliver potentially therapeutic genes directly in vivo. 


\section{4-A 29}

SYNDROMOLOGY AND CLINICAL GENETICS. John M. OPITZ (Shodair Hospital, Helena, Montana, USA)

Genetics arose out of embryology (Darwin 1859, the formal analysis of development) and, as a discipline, represents the causal analysis of development. All development is epigenetic and occurs in developmental fields which are the fundamental units of ontogeny and of phylogeny. In vertebrates, field development represents, in part, a long evolutionary history of reduction or subordination of metamerism while allowing the organism to retain many of the genetic systems that initiate morphogenesis in all higher organisms and that were elucidated recently by the methods of molecular biology. In view of the extraordinary paucity and conservatism of final common developmental paths and the large number of genes in humans, it is a given that many genes are involved in every developmental process, hence the phenomena of 1.)heterogeneity, 2.)pleiotropy, and 3.)polygenic/multifactorial determination. Syndromes, as causally defined entities, represent pleiotropy, i.e. multiple structural and functional effects of a single cause. Classically (Plate, 1910) the term was applied to mendelian mutations, but recently it has become applied also to the effects of aneuploidy and polyploidy. Teratogens give rise to disruption sequences. Associations are idiopathic patterns of multiple anomalies arising during blastogenesis.

\section{Symposia}

\section{S 1-A 1}

PREHISTORIC DISPERSAL OF HUMANS INFERRED FROM MITOCHONDRIAL DNA. Satoshi HORAI (Dept. Hum. Genet., Natl. Inst. Genet., Mishima)

By virtue of its rapid rate of evolution and maternal mode of inheritance, mitochondrial DNA (mtDNA) permits discrimination among closely related individuals of human. Restriction enzyme analysis has been a powerful tool in attempts to elucidate evolutionary relationships among human ethnic groups. However, in recent mtDNA analyses, it has become popular to employ the direct sequencing by means of PCR. Targeted was a major noncoding region (D-loop region) of mtDNA that has apparently evolved several times faster than other parts. Sequence analysis of this region therefore offers a high resolution that discriminate among even very closely related individuals of human. So far we have determined $482 \mathrm{bp}$ sequences of the major noncoding region of mtDNA for over 400 individuals from 8 different geographic populations; Africans, Europeans, Southeast Asians, East Asians, Aboriginal Taiwanese, Papuans, Siberians and Native Americans. Phylogenetic analysis in the entire human population indicates that Africans are much more diverse than other human populations. Moreover, some Africans came directly from the root of a phylogenetic tree, indicating that Africa is the initial place for diversification of modern humans. However, we found that some Papuans also had a deeper branch in the tree. It may indicate that ancestors of these Papuans were earliest migrants of Homo sapiens, who went out of Africa. I also discussed about the prehistoric dispersal of humans and the total scenario of peopling on a global basis. 


\title{
S 1-A 2
}

MOLECULAR GENETICS OF HLA. Akinori KIMURA (Dept. Genet., Med. Inst. Bioreg., Kyushu Univ., Fukuoka)

Human leukocyte antigens (HLA) are encoded by a multigene family in the HLA region spanning about $4,000 \mathrm{~kb}$ on the short arm of chromosome 6 . There are at least 30 functional genes in the HLA region, including genes for classical transplantation antigens (HLA class I molecules, HLA-A, B, C) and the genes for immune responses to exogenous antigens (HLA class II molecules, HLA-DR, DQ, DP) and other genes which may be involved in the immune system, such as C4 and TNFs. The HLA genes are extreamly polymorphic in the exons encoding for the distal extracellular domains of the HLA molecules and these polymorphisms are mainly found at the amino acid residues directly involved in the binding of antigenic peptides. The HLA genes, in addition, are polymorphic in their promoter regions and in the exons for cytoplasmic domains. The polymorphism in the promoter region determines the affinity to specific transcription factors and, in consequence, the allelic differences in the gene-expression are found for HLA class II genes. The polymorphic cytoplasmic region might play a role in the signal transduction via HLA class II molecules, leading to different inducible activity of adhesion molecules, such as B7. The polymorphisms in the HLA genes, therefore, may determine the allelic differences in immune responsiveness to self and/or natural antigens and, in turn, the susceptibility to autoimmune diseases should be analyzed in view of these polymorphisms and linkage disequilibria between alleles of HLA genes. I have discussed the role of the polymorphisms of HLA genes in determining the susceptibility to various diseases.

\section{S 1-A 3}

\author{
MOLECULAR ANTHROPOLOGY \\ Naovuki TAKAHATA (Dept. Genet., Grad. Univ. Adv. Studies, Yokohama)
}

Anthropology that has integrated molecular evolutionary study appears to have been experiencing an exciting time. Four main features relevant to the issue on the origin of Home sapiens are: (1) The extent of genetic variation at most loci in human populations is rather low, suggesting that the breeding population size has been about $10^{4}$. (2) The extent of genetic differentiation of contemporary human populations is also rather low, due to either continuous migration among the major human populations or the short period of isolation. (3) The gene genealogy is generally shallow. For mitochondrial DNA, the deepest branch point is $\sim 200,000$ years, whereas for nuclear genes, it rarely exceeds 1 my. (4) However, the extraordinary polymorphism at some of the major histocompatibility complex (Mhe) loci rules out the past action of severe bottlenecks, or the so-called founder principle which invokes only a small number of founding individuals when a new species emerges. This conclusion may be extended to the 35-million-year-old history of the human lineage, because some polymorphism at Mhc loci seems to have lasted that long. These impose important requirements for the hypotheses for the origin of modern humans; the moderate population size and the absence of long-term isolation among populations. Any hypothesis that assumes a small number of founding individuals throughout the Late Pleistocene can clearly be rejected. There is also some indication that natural selection has been relaxed since the human lineage underwent dramatic changes in brain size, way of life and culture about 2 my ago. 


\section{S 1-A 4}

A NotI RESTRICTION MAP OF HUMAN CHROMOSOME 21 AND ITS USE TO THE ANALYSIS OF GENE REARRANGEMENTS IN ACUTE MYELOID LEUKEMIA. Misao OHKI, ( Radiobiology Division, National Cancer Center Research Institute, Tokyo)

The $\mathrm{t}(8 ; 21)(\mathrm{q} 22 ; \mathrm{q} 22)$ translocation is one of the most frequent chromosome abnormalities in acute myeloid leukemia (AML) and is morphologically associated with the M2 subtypes. The $t(16 ; 21)(\mathrm{p} 11 ; \mathrm{q} 22)$ translocation has been found in chronic myeloid leukemia (CML) in the blastic crisis and myelodysplastic syndrome (MDS) evolved to AML as well as de novo AML. These breakpoints were analysed with the help of our own NotI restriction map of chromosome 21 which was constructed by using a NotI linking library including most of NotI sites on chromosome 21 . The use of the linking clones which arrayed along the chromosome provides a system to systematically survey chromosome aberrations such as translocation. This allowed the identification of the involvement of a new gene AML1 in $t(8 ; 21)$ and ERG in $\mathfrak{t}(16 ; 21)$ on chromosome 21 . Both of these translocations result in the formation of the fusion genes. Sequence analysis of cDNA showed that $\mathrm{t}(8 ; 21)$ translocation juxtaposes the AML1 gene with a novel gene, named MTG8, on chromosome 8 resulting in the synthesis of an AML1-MTG8 fusion transcript. In $\mathbf{t}(16 ; 21)$ translocation the breakpoints were clustered within a single intron in the coding region of the ERG gene, a member of the ets-oncogene superfamily.

\section{S 1-A 5}

A MOLECULAR BIOROGICAL APPROACH TO HUMAN GENETICS : MECHANISMS FOR CONTROLIING SPONTANEOUS MUTAGENESIS.

Mutsuo Sekiguchi, Masato Furuichi and Teruhisa Tsuzuki

(Med. Inst. Bioregulation, Kyushu Univ., Fukuoka)

To reveal a complex molecular mechanism in human cells, it is useful for analyzing the basic process in a model organism, such as Escherichia coli. Here we present an example of such an approach.

The MutT protein of E. coli possesses an enzyme activity to hydrolyze 8oxo-dGTP to the corresponding nucleoside monophosphate and this activity is responsible for preventing occurence of $A: T$ to $C: G$ transversion. Human cells contain an enzyme activity to degrade 8-oxo-dGTP in a fashion similar to that seen with MutT protein. We purified this particular human enzyme to physical homogeneity and then cloned the cDNA for huan 8-oxo-dGTPase. The human protein comprises 156 amino acid residues and has some sequence homology with the $E$. coli MutT protein. When the human cDNA was expressed in $E$. coli mut $T^{2}$ mutant cells, there was a siginificant amount of 8-oxo-dGTPase acitivity. In such cells, the frequency of spontaneous mutation was greatly reduced. We propose that the human 8-oxo-dGTPase protects genetic information from the untoward effects of endogenous oxygen radicals. 


\section{S 2-B 1}

GENETIC SERVICES IN CHILDREN'S MEDICAL CENTER. Ki yoshi IMAIZUMI (Div.Med.Genet., Kanagawa Child.Med.Centr.,Kanagawa).

Genetic services in Japan became more widely available with advance in medical genetics including molecular genetics, mapping of human genome and prenatal diagnosis. Genetic services in children's medical center consist of clinical services and medical researches. Clinical services include (1) clinical diagnosis of patients, (2) follow up of patients over a long periods, (3) genetic couseling. Follow up of patients make it possible to clarify natural histories of syndromes or diseases. We can present a good advice to improve patient's quality of 1 ife by natural histories.

In medical researches, (1)cytogenetic and molecular study, (2)establishment of new syndrome, (3) monitoring of congenital anomalies, (4) education of medical genetics, are included. Rapid advance in medical genetics created an recognition of the role of genetic factors even in common diseases and it increases demand for medical genetic services. Recently, education of medical genetics has been presented by Japanese Society of Human Genetics and it provides certification as specialists in medical genetics. In response to the need for an organization to coordinate activities, regional networks for genetic services among children's medical center should be established.

\section{S 2-B 2}

GENETIC SERVICES IN THE UNITED STATES.

Harold CHEN, Wladimir WERTELECKI (Department of Medical Genetics, University of South Alabama, Mobile, Alabama, USA)

Advances in medical genetics, including mapping of human genome, improved therapy for genetic disorders, and new screening tests for carrier detection and prenatal diagnosis have created a growing demand for clinical genetic services in the United States. Such services (diagnosis, management, and genetic counseling) received partial support from state, federal, and private sources and were mostly based in academic medical centers. Gradually, such programs evolved into regional or state-wide activities with an emphasis on outreach clinics. Now, an increasing number of for-profit corporations have entered into this field. Clinical genetic teams usually include clinical geneticists and other professionals with expertise in the diagnosis and management of genetic conditions and skills in information presentation and family support. The American Board of Medical Genetics, the newest member of the American Board of Medical Specialties, provides certification for five categories of genetics professionals and sets standards for training programs.

Based on personal experiences from the states of Alabama and Ohio and data from the Council of Regional Networks for Genetic Services, we show and compare trends of newborn screening programs and regional genetic services. The effects of economic and social trends as they impinge on genetic services are monitored by a routine use of several databases in our center. 


\section{S 2-B 3}

A COMPUTERIZED DATABASE (UR-DBMS) - USEFUL DIAGNOSTIC AID FOR THE MALFORMATION SYNDROMES AND GENETIC DISEASES. Kenji NARITOMI (Dept. Pediat., Univ. Ryukyus, Okinawa)

UR-DBMS (University of the Ryukyus-database for malformation syndromes), an original Macintosh-computerized database for malformation syndromes and genetic diseases using Filemaker II, was a product for six years by the author, because difference of DOS obstructed the availability of English databases in Japan. UR-DBMS includes the data of 4,250 diseases or alleli making total volume about $8 \mathrm{MB}$. The data from several famous textbooks and databooks were combined and summarized in each syndromes or diseases according to McKusick's catalog or original code numbers. The fields designed include syndrome name, mode of inheritance, clinical findings and codes for reference, comments (reported case numbers, gene locus and DNA information etc.), and almost all references since 1980 . The codes of findings to refer was composed by 24 major codes, middle codes, and 1986 minor codes to avoid failure of selection by difference of expression. Access time to refer is within one second. The UR-DBMS Ver. 2 (English version) had already been furnished at cost, and utilized in over 120 Japanese universities or institutes. UR-DBMS Ver. 2 was effective for diagnoses of genetic diseases in about $2 / 3$ of 400 patients applied in our clinic. The UR-DBMS should help and support the development of clinical genetics in Japan.

\section{S 2-B 4}

MEDICAL GENETICS AND THE SUPPORT OF PATIENTS AND THEIR FAMILIES.

Tomoko Hasegawa (Div. Clin. Genet. Shizuoka Child. Hosp., Shizuoka)

For the support of patients with genetic diseases and their families, medical geneticists play an important role in view of their medical and genetic knowledge. Medical geneticists are responsible for diagnosing anomalies, giving information about the cause and condition, the possibility of cure and care, the medical and social prognosis, and the genetic prognosis. They are also responsible for supporting the quality of life of the patients and their parents. For this purpose, their main role is to overcome the incorrect image of the disease, and the prejudice and discrimination that exists because of it, through education of the patients, family and general public with other involved professionals. In addition to this genetic service, it is necessary to support patient-parent associations. Although there are many of these associations in Japan, they are neither systematic nor clearly identified, compared with those in the U.S.A.. The reasons for this may be satisfaction and lack of necessity because of the guaranteed minimum standard of living and education, traditional dependence on the government together with a lack of sharing-caring spirit, and the lack of a concept of management and law related to non-profit organizations. Finally, we have to bring about a greater mutual understanding between medical and co-medical professions and members of patient-parent associations, since there seems to be much mutual misunderstanding, particularly with regard to genetic services. 


\section{S 3-C 1}

MOLECULAR ARCHITECTURE OF COLLAGENS AND THEIR GENE EXPRESSION. Yoshifumi NINOMIYA (Department of Molecular Biology and Biochemistry, Okayama University Medical School, Okayama)

The collagens constitute a superfamily of extracellular matrix proteins with repeated Gly-X-Y sequence which aggregate either alone or in conjunction with other extracellular matrix molecules. Fibrillar collagens(I, II, III, V, and XI) are expressed from genes with 50 exons interspersed by various length of introns. In other collagens, such as basement membrane collagens(IV) or FACIT collagens(IX, XII, XIV, XVI, and Y), several shorter triple-helical domains are separated by nontriple-helical domains. The formation of tissues and organs during development requires the assembly of matrices of precise threedimensional structure, and many of the collagens that have been described as minor collagens in a quantitative sense may play important roles in the assembly process.

In early developmental process collagen genes are expressed in a tissue specific fashion. The expression of collagen genes is controlled predominantly at the transcriptional level, although alternative transcription, alternative splicing, chromosomal arrangement of genes, and post-transcriptional controls are important as well. Transcriptional controls depend on gene regulatory proteins that bind to specific DNA sequences. These proteins can help to turn collagen genes either on or off.

\section{S 3-C 2}

\section{RECURRENCE OF OSTEOGENESIS IMPERFECTA DUE TO PATERNAL MOSAICISM.} Chisato NAMIKAWA $^{1}, \underline{\text { Kaoru SUZUMORI }}^{2}$, Yoshimitsu FUKUSHIMA $^{3}$, Makoto SASAKI $^{1}$, Akira HATA ${ }^{1,4}{ }^{1}$ Dept. Biochem., ${ }^{2}$ Dept. Ob. Gyn., Nagoya City Univ., ${ }^{3}$ Saitama Children's Medical Center, ${ }^{4}$ Dept. Public Health, Hokkaido Univ.)

Mutations in the type I collagen genes (COL1A1 AND COL1A2) have been found in many patients with osteogenesis imperfecta (OI), a heritable disorder of connective tissue. Recently, recurrent dominant forms of lethal OI were described and hypothesis of a parental mosaicism for a mutation in one of the type I collagen genes was demonstrated. Here we report a sibling with recurrent severe type of OI, whose mutation change Gly to Ser at position 862 caused by a G-to-A transition at nucleotide 3208 of the coding sequence in one allele of COL1A1 gene. We also demonstrated the presence of the same mutation in the leukocytes, the cultured fibroblasts and the sperm of their father in mosaic form.

The recurrence risk of OI has been empirically estimated to be $7 \%-8 \%$. This high value seems to be related the fact that somatic mosaicism may be tolerated with no resulting disease. Therefore, it is important that when a new heterozygous mutation has been detected in a family, germ line mosaicism should not be ignored when genetic counseling is given. 


\section{S 3-C 4}

アルポート症候群の遗伝子解析仲里仁史、服部新三郎、松浦稔展、遠藤文大、松目一郎 （熊本大学医学部小児科）、小板橋靖（聖マリアンナ医科大学小児科）、Gene analysis of Alport syndrome、 Hitoshi NAKAZATO、Shinzaburo HATTORI、Toshinobu MATSUURA、 Fumio ENDO、Ichiro MATSUDA (Dept. Pediatr. Kumamoto Univ. Kumamoto)、 Yasushi KOITABASHI (Dept. Pediatr. St. Marianna Univ. Kanagawa)

アルポート症候群は遺伝性腎炎の一つで、診断は1）血尿をもつ家族歴，進行性腎炎，2） 高音域の感音性難聴，3）眼科的異常，および4) 腎系球体基底膜の電顕所見によって行わ れる。家系によって臨床像は様々である。頻度は1/5000人。遺伝形式は，常染色体性 遺伝の報告もあるが伴性遺伝が最も多い。Hostikkaらは I V 型コラーゲン $\alpha 5$ 制遗伝子

(COL4A5）の一部をクローニングとそれがXq22に位置することを証明し、伴性遺伝型アル ポート症候群の責任遺伀子であることを示唆した。Zhouらはその全CDNA（約 $5 \mathrm{k} \mathrm{b}$ ) およ びそれが51エタソン，1685個のアミノ酸から構成されていることを解明した。我々は， $\alpha 5$ 鎖のnon-collagenous（NC1）ドメインをコードする第4 7 から 51 エクソンをP R R 一S S C P 一銀染色法により本症患者 40 例を解析した。 5 例に変異（3例に-.-塩基置換， 2例に一塩基挿入）が楒められ，いずれも今までの報告とは異なる新しい変異であった。現 在世界でCOL4A50変異が20 数例報告されてきている。なかでも splice siteの異常を含む一 塩基置換等minor変珙が多い。その変異部位は遺伝子上遍く存在しており、本症は遺伀的に も heterogenietyのある疾患であることがわかった。配偶子形成の異常も約 $15 \%$ \%みられた。 将来は臨床病型（遺伝形式、症状）と遺伝子解析の結果の両方で診断されることになるだろ う。また最近、 $\alpha 6$ 鎖の存在も明らかになり伴性遺伝型アルポート症候群の第 2 の責任遺伝 子之も考之られ、今後の研究が期待される。

\section{S 3-C 5}

CHONDRODYSPLASIA AND COLLAGEN.

Tomoatsu KIMURA, Ken NAKATA, Noriyuki TSUMAKI, Keiro ONO (Dept. Orthop. Surg., Osaka Univ., Osaka), and Bjorn R. OLSEN (Dept. Cell Biol., Harvard Med. Sch., Boston)

Chondrodysplasias are an extremely heterogeneous group of heritable disorders involving cartilage tissues. Although mutations in the genes for types II and X collagens have been reported in some variants of chondrodysplasias, causative mutations in many other variant forms are still unclear. To elucidate the possible consequences of mutations in other cartilage collagens, we have generated transgenic mice bearing type IX collagen mutations. In mouse tissues the transgene was expressed as mutant $\alpha \mathbf{l}$ (IX) chains that were associated with endogenous $\alpha$ chains forming abnormal heterotrimeric type IX collagen molecules. Examination of the offspring of independent founders revealed pathological changes similar to osteoarthritis. In addition, mice with certain types of mutation developed mild chondrodysplasia. The phenotypic severity was dependent on the position and nature of mutations and also on the level of transgene expression. Given these findings, it is possible that mutations in type IX collagen chains may act as dominant-negative mutation and cause certain forms of chondrodysplasia and osteoarthritis. 


\section{S 4-A 13}

RECENT PROGRESS IN GENE THERAPY TECHNIQUES

Takashi Shimada (Dept.Biochem.Mol.Biol.,Nippon Med.School, Tokyo)

Since the first human gene therapy protocol began in 1990, more than 100 patients have already been treated by this innovative therapeutic approach. Two patients with adenosine deaminase (ADA) deficiency have been successfully treated by transfusion of genetically modified lymphocytes. In adittion to many genetic diseases, cancer and AIDS are becoming important targets for somatic celi gene therapy. The development of a specific gene therapy protocol is dependent on the available gene transfer technique. Retroviral mediated gene transfer has been the principal procedure for clinical trials. Recently, new viral vectors derived from adenovirus, adeno-associated virus, herpes virus, and even HIV have been designed to improve gene transfer efficiency. Non-viral techniques such as liposomes and receptor mediated methods are also promising in some applications. The feasibility and specific problems in current gene transfer strategies will be discussed.

\section{S 4-A 14}

GENE EXPRESSION USING ADENOVIRUS VECTOR.

Izumu SAITO and Yumi KANAGAE

(Lab. Mol. Genet., Inst. Med. Sci., Univ. Tokyo)

Adenovirus vector is an efficient tool to introduce an expression unit of desired foreign gene into a wide variety of animal cells and tissues. Recently this vector system attracted much attention because this vector was used for gene therapy trials of cystic fibrosis in U.S.A. However, the useful range and limitations of this vector have not fully been investigated, mainly because the current method of constructing recombinant adenoviruses is extremely inefficient.

We have improved the construction method of recombinant adenoviruses (COS-TPC method). The new method employed a combination of parent adenovirus genome tagging viral terminal proteins at both ends and a cassette cosmid of $43 \mathrm{~kb}$ containing essentially entire adenovirus genome. Using the new construction method, we have newly constructed 39 recombinant adenoviruses within 14 months and distributed them to collaborators. Therefore, we now expect that adenovirus vector system by rapidly becomes popular both in basic research and in clinical application using the newly developed efficient method of constructing recombinant adenovirus. We will also present data about species and tissue specificities of adenovirus expression vector using LacZ-gene-expressing recombinant adenoviruses. 


\section{S 4-A 15}

IMMUNOGENE THERAPY AGAINST CANCER: Hirofumi HAMADA (Cancer Chemotherapy Center, Cancer Institute, Japanese Foundation for Cancer Research, Tokyo)

To provide insights for the development of effective cancer gene therapy, I review the strategic aspects of our studies in murine tumor models. Our strategies are summarized as follows: 1)Immunotherapy of cancer using genetically modified tumor cells; 2)Combined immunogene therapy using antigen-presenting cells (APC); 3)Enhancement of tumor-specific immune response using identified tumor-associated antigen peptides; 4)Adoptive immunogene therapy using tumor-specific T lymphocytes; 5)Combinations of immunomodulating drugs with these strategies. In the second part of this review, I make brief comments on some major obstacles encountered in the application of our strategies to clinical situations. The questions are whether it is possible or not to apply our immunogene therapies to 1)tumors located in the immunologically privileged sites (e.g., the central nervous system), 2)patients with large tumor burdens, or 3)"nonimmunogenic" tumors.

\section{S 4-A 16}

\section{GENE THERAPY FOR INBORN ERRORS OF METABOLISM} Fumio ENDO (Department of Pediatrics ,Kumamoto University, Kumamoto)

Many of inborn errors of metabolism are caused by the deficiency of hepatic enzymes. Among such disorders hyperammonemia caused by the deficiency of ornithine carbamyltransferase(OTC) is one of the most important disorders in Japan. Prognosis of severe form of the disease is poor and the patients did not respond to nutritional and pharmaceutical treatment. Gene therapy with introduction of functional OTC gene into hepatic cells seems only way to treat the patients.

We constructed recombinant adenovirus which carries human OTC cDNA driven by SRa promoter. Infection of the replication defective virus into cultured Cos 1 cells resulted in expression of human OTC activity and enzyme protein in the cells. We are attempting to infect the recombinant virus into epithelium of small intestine, since expression of OTC in the small intestine of OTC deficient mice by transgene resulted in clinical improvement of the phenotype.

We also study gene therapy for tyrosinemia type I (fumarylacetoacetate hydrolase deficiency) and type III (4-hydroxyphenylpyruvic acid dioxugenase deficiency) using the recombinant adnovirus and mouse models for the tyrosinamias. 


\section{S 4-A 17 \\ PRESENT STATUS AND PERSPECTIVE OF GENE THERAPY IN JAPAN.}

\section{Fumimaro Takaku(International Medical Center of Japan,} Tokyo)

Gene therapy of human beings had started in 1989 in the United Status. On the other hand, the Japanese guideline for gene therapy had been delivered from the Ministry of Health and Welfare of the Government on June of 1993. Although our Government is going to organize a central Committee for the approval of the protocol on human gene therapy in a very near future, the gene therapy in our country is far behind that of the United States.

Since our Government made the guideline and going to organize the Central Committee, it is hoped that the human gene therapy will start soon in our country. The Ministry and Welfare has started a research fund of 150 million yen for gene therapy this paper and this research fund is expected to increase every year.

Therefore, it is my belief that we have to prepare for the start the research on human gene therapy.

\section{S 5-B 14}

LI-FRAUMENI SYNDROME AND GERM-LINE MUTATIONS IN THE P53 TUMOR SUPPRESSOR GENE.

Yukiko. TSUNEMATSU(Div. Hematol./Oncol. Natl. Child Hospital. Tokyo)

Germ-line p53 point mutations have been reported in various families with Li-Fraumeni syndrome(LFS) characterized by a dominant increased susceptibility to the development of various neoplasms at early age in multiple family members. The original studies were performed on a series of LFS families obtained from Drs. Fred Li, Joseph Fraumeni and Louise strong. The original five families in which germline p53 mutations could be identified, all of these mutations were clustered in exon 7. We found novel germ-1ine p53 mutations in two Japanese cancer-prone families collected from childhood adrenocortical carcinoma. In both cases, mutations are located in exon 8 where germ-line p53 have not been reported previously. Subsequent studies have found germ-line mutations in some LFs families, but not in others. The discordant results could be due to the failure to the entire p53 gene. Another explanations that the syndrome is genetically heterogenous. Two International workshops, were held in 1991 to consider recommendations for p53 testing. The discuss focused on predictive testing, which for present purpose is the use of molecular genetic assays to detect inherited cancer-predisposing mutations in clinically healthy individuals. Predictive testing should be guided four ethical principles of respects:for autonomy, beneficence, confidetiality, and justice. 


\section{S 5-B 15}

\section{MOLECULAR MECHANISM AND ITS CLINICAL APPLICATION IN TRANSLOCATION-ASSOCIATED LEUKEMIAS.}

Nobuo MASEKI and Yasuhiko KANEKO (Hematology Clinic and Dept. of Lab. Med., Saitama Cancer Center, Saitama)

About a half of leukemias have nonrandom chromosomal translocations. Over 50 types of leukemia-specific translocations have been reported to date, and are known to be closely associated with specific morphologic and immunologic phenotypes of leukemia and clinical characteristics or prognosis of patients. Molecular analyses have discovered several leukemia-associated genes at the translocation breakpoints, and the involvement of such genes in leukemogenesis. The breaks usually occur in antigen-receptor genes such as Ig or TCR, in lymphoid leukemias, or transcription factor genes in myeloid leukemias; these events lead hemopoietic stem cells to the neoplastic process. We analysed the molecular mechanism of $t(8 ; 21)$-associated leukemia and identified the occurrence of a chimeric gene, AML1-MTG8(ETO), by the translocation. Minimal residual leukemia with $t(8 ; 21)$ can be detected by the RT-PCR method using a set of primers of the involved genes. The rearrangement of $M L L$ gene is detected using MLL CDNA probes in the leukemias with various types of 11q23-translocation although the translocation partners are different in each translocation. Molecular approach is useful for the diagnosis and clinical management of patients with translocation-associated leukemias.

\section{S 5-B 16}

GENETIC EVENTS INVOLVED IN ENDOMETRIAL CARCINOMAS AND CELL GROWTH INHIBITION BY ANTISENSE OLIGONUCLEOTIDE. Toshiro IMAMURA (Dept. Reproductive Physiology and Endocrinology, Medical Inst. Bioregulation, Kyushu Univ., Oita).

Endometrial carcinomas are the second most frequent female carcinomas in Japan. In the present study, we analyzed genetic events involved in endometrial carcinoma by investigating point mutations of ras genes and amplification of the Int-2 gene. In addition, we searched for tumor suppressor genes by whole-cell and microcell hybrid formations, and by analyzing losses of heterozygosity using restriction fragment length polymorphisms (RFLP). We obtained evidence that at least 5 genetic events including putative tumor suppressor genes locating on chromosomes 1 and 4, the DCC gene, p53 gene, and the point mutation at codon 12 of the Kras gene were implicated in endometrial carcinoma. Antisense oligodeoxynucleotides are specific inhibitors of gene expression. This potent activity of the oligonucleotides may be available for gene therapy to treat patients with cancer, because inhibition of the single target gene expression that plays a key role in tumorigenesis is able to revert transformed phenotypes of tumor cells. We examined the effect of antisense oligonucleotides targeted to the mutated K-ras gene at codon 12 on growth of endometrial carcinoma cells (HHUA), and found that the oligonucleotide inhibited proliferation of HHUA in a sequence dependent manner. However, the potent anti-proliferative activity exhibited by the oligonucleotide is incomplete. Modifications that strengthen the biological actions of the oligonucleotide, such as psoralen, are required for the application of antisense oligonucleotide to cancer therapy. 


\section{S 5-B 17}

SOMATIC MUTATION OF THE APC GENE IN TUMORS OF DIGESTIVE SYSTEM. Akira HORII (Dept. Biochem., Cancer Inst., Tokyo)

We have isolated $A P C$, the gene responsible for familial adenomatous polyposis (FAP), and reported that this gene is somatically mutated in colorectal and gastric cancers. We further analyzed somatic mutations of this gene in precancerous lesion of gastric cancer, and tumors of other organs in which frequent LOHs of APC locus have been reported and/or expression of $A P C$ are high. By means of an RNase protection analysis coupled with PCR, 42 brain tumors, 55 lung cancers, 50 esophageal cancers, 14 renal cell carcinomas (RCC), 5 hepatocellular cancers (HCC), 10 pancreatic cancers, and 10 gastric flat adenomas (precancerous lesion of intestinal type of gastric cancer) were analyzed. In these tumors, seven of 55 lung cancers and all of RCCs and HCCs were observed of LOH at APC locus. We detected somatic mutations in four pancreatic cancers and four gastric flat adenomas, but no mutation was detected in other tumors. Our results imply that (i) mutation of $A P C$ is playing a very important role in pancreatic carcinogenesis besides colorectal and gastric tumorigeneses, and (ii) somatic mutation of $A P C$ is involved in the initiating step of gastric carcinogenesis, as was observed in colorectal carcinogenesis.

\section{S 5-B 18}

ABROGATION OF TUMORIGENICITY VIA GENE TARGETTING OF KI-RAS IN HUMAN COLON CANCER CELL LINES.

Senji SHIRASAWA(Dept. Genetics, Med. Inst. Bioreg.,Kyushu Univ., Fukuoka).

The process of carcinogenesis in human colon cells consists of a multistep progression in gene mutations at various loci involved in the regulation of the growth and differentiation. A correlation between the loss of heterozygosity in chromosomes $5 q, 17 p, 18 q$, and $22 q$ and tumorigenesis in colon cancer has been suggested. We investigated the role of mutant Ki-ras in the process of tumorigenesis by using gene targeting methods to disrupt the mutant Ki-ras gene in human colon cancer cell lines, DLD-1 and HCT 116, which were known to be tumorigenic in nude mice. After disruption of the mutant and wild Ki-ras alleles, the cells lacking the mutant allele lost their tumorigenic properties in nude mice, whereas those cells lacking the wild type $\mathrm{Ki}$-ras but retaining the mutant allele remained tumorigenic. Changes in morphology and growth rate were also observed in the mutant knockout cell lines. In addition, comparison of the expression levels of c-myc between the parental cells and the gene targeted progeny demonstrated that genes downstream of Ki-ras that are involved in the tumorigenic process were also significantly downregulated in the absence of mutant Ki-ras. These results indicate that disruption of mutant oncogenes may be utilized as an efficient target for gene therapy for cancer. 


\section{S 6-C 15}

CURRENT TOPICS ON REPETITIVE SEQUENCES IN HUMAN GENOME. Masahira HATTORI (Human Genome Center, Institute of Medical Science, Univ. of Tokyo, Tokyo)

Most of mammalian genomes including human genome contain various kinds of repetitive sequences. These are classified into two types with respect to how these are positioned on the genome. Alu and L1 families are the representatives of the randomly dispersed sequences throughout the genome. Another type is the tandemly repeated sequences at the specific region such as satellite DNA and Y-specific repetitive sequence. Also, tandem repeats at the telomeres of the chromosomes, minisatellite sequences such as variable number of tandem repeats (VNTR) and microsatellite sequences such as di-, tri- and tetranucleotide repeats are found in most of mammalian genomes. These have been exclusively studied in relevance to the biological functions, the genome evolution and recently as highly polymorphic sites in linkage analysis.

In this symposium, I discuss on the structural feature, the mechanism for the generation and the functions of the repetitive sequences in the genome

\section{S 6-C 16}

TRINUCLEOTIDE REPEAT EXPANSION IN FRAGILE X SYNDROME. Yutaka NAKAHORI (Dept. Hum. Genet., School of International Health, Univ. Tokyo, Tokyo)

In 1991 the FMR-1 gene corresponding to the Fragile X syndrome was cloned. The molecular mechanism of the disease was different from ones that had been known before. 'The expansion of the trinucleotide repeat' causes the disease. Several people predicted that it may be the uniform mechanism for human diseases. After 2 years hunting for the genes that contain the trinucleotide repeat, 6 other diseases (Spinobulbar muscular atrophy, Myotonic dystrophy, Huntington's disease, Spinocerebellar ataxia type 1, Fragile X (FRAXE), Dentatorubral and pallidoluysian atrophy) have been found to have the common mechanism for the disease. The more we know about the diseases, the more the questions arise. I summarize the status of the studies on the disorders of trinucleotide repeat expansion. 


\section{S 6-C 17}

APPLICATION OF TANDEMLY-REPETITIVE POLYMORPHISM FOR PERSONAL, IDENTIFICATION.

Atsushi AKANE, (Dept. Legal Med., Kansai Medical Univ., Moriguchi).

Analyses of tandemly-repetitive polymorphisms (e.g., minisatellite and microsatellite) are now well applied for forensic works such as personal identification and parentage testing. The polymorphic markers are very informative but involve several problems. First, the hypervariability suggests high frequency of their mutation. Second, costs for the patents are too expensive for routine works. Third, reproducibility should be further investigated by standarizing the methodology. We thus analyze variable number of tandem repeat probes (established by Y. Nakamura, et al.) by Southern blotting for the routine tests. The cases of parentage testing, diagnosis of twin zygosity and career diagnosis of infantile hypophosphatasia are demonstrated.

S 7-A 24

PROSPECTS OF THE HUMAN GENOME PROJECT Nobuvoshi SHIMIZU (Keio University School of Medicine)

Human genome project, the mapping and sequencing of the entire genome, has been rapidly progressing since its official start three years ago. Mapping of marker probes at certain distances on each chromosome is well established. Discoveries of new genes associated with disease are reported almost every week. Now, genome analysis will proceed systematically from YAC contigs to cosmid contigs to cDNA cloning to sequencing. Through this process, the positional cloning method would often be utilized. Such methods, technology development and exchange of materials and information are essential for the success of the human genome project. Under these circumstances, it is important to review the current status of the Japanese human genome project as well as other projects around the world. At this symposium, I will give you an overview of the status of the international genome project and other symposists will present the progress reports of their research. It is my hope that the symposium will bring the prospect of success of the human genome project closer in terms of medical therapies/treatments, human genetics, and human biology. 


\section{S 7-A 25}

PHYSICAL ANALYSIS OF HUMAN CHROMOSOME 21: FROM YAC SYSTEM TO P1 SYSTEM Yoshiyuki SAKAKI, Hiroshi TANAHASHI, Masahira HATTORI (Inst. of Med. Sci, Univ. of Tokyo), Miyuki OHIRA(Saitama cancer Res. Inst.), Kousuke TASHIRO(Fac. of Sci., Univ. of Tokyo), and Misao OHKI (Natl. Cancer Ctr.)

Chromosome 21 is the smallest chromosome (estimated to be about $50 \mathrm{Mb}$ long) in the human genome and several severe disorders, such as familial Alzheimer disease, familial amyotrophic lateral sclerosis, progressive myoclpnic epilepsy and Down syndrome, have been mapped on this chromosome. To define the physical and genetical structures of the chromosome, great efforts have been made. Recently, Ohki and his colleagues have constructed Not I restriction map of the chromosome 21q and Chumakov and coworkers succeeded in generating yeast artificial chromosome contiguous unit of the long arm of the chromosome. However, for the detailed analysis the use of $E$. coli system (coupled with YAC system) is desirable. For this reason, we attempted to construct a chromosome 21-specific P1 library using a human/hamster somatic cell hybrid containing the long arm of the chromosome 21 (q11-qter) as its sole human component. We isolated 1516 Alu/L1-positive clones, amounting to 2 equivalents of chromosome 21q. For rapid clone identification we constructed a 3-dimensional library and PCR-based screening of the library enabled us to isolate 69 positive clones from 100 sequence-tagged sites (STSs) specific for chromosome 21. The library further allowed us to construct several P1 clone contings of $300 \mathrm{~kb}$ or more in a simple manner.

\section{S 7-A 26}

HUMAN GENOME ANALYSIS BASED ON THE CHROMOSOME SORTING. Shinsei MINOSHIMA, Jun KUDOH, Kosuke SAKAI, Shuichi ASAKAWA, Kazuhiko KAWASAKI, Yimin WANG and Nobuyoshi SHIMIZU (Department of Molecular Biology, Keio University School of Medicine, Tokyo)

Flow sorted chromosomes provide an ideal DNA resource for human genome analysis. We have refined and established the protocol of chromosome sorting using a conventional cell sorter. Genome study in our laboratory focuses on the smallest chromosomes, 21 and 22, and starting materials are consistently flow sorted chromosome. Our goal is to assemble the cosmid contigs covering entire region of these two chromosomes and to uncover all the existing genes. We report here the construction of two cosmid libraries to use for contig assembly.

The first library was made with 10 million pieces of flow-sorted intact chromosome 21 . The library consists of approximately 33,000 clones (18 times equivalent and $80 \%$ in purity). For efficient colony hybridization, high density replica (HDR) filter (1,536 clones/filter) was prepared. YAC clones assigned to Down syndrome chromosome region and progressive myoclonus epilepsy locus were applied to HDR filters. More than 900 cosmid clones were identified and divided into 15 sub-groups according to overlaps between YAC clones. These cosmids are being subjected to the cosmid finger-printing and a significant number of contigs have been obtained. The second library was prepared with 8 million pieces of cat eye syndrome marker chromosomes consisting of 2 copies of 22 pter-q11.2 region. The library covers 10 equivalents of the chromosome size $(9,200$ clones, $63 \%$ in purity). Isolation of YAC clones within the 22 cen-q11.2 region is under way. Along these lines of work, we have carried out the construction of cosmid contigs corresponding the $\operatorname{Ig} \lambda$ locus on chromosome 22 . More than 150 cosmids were assembled into 4 contigs. The total size of those contigs is over $770 \mathrm{~kb}$. Numerous $V \lambda$ and $c \lambda$ genes were assigned within these contigs. 


\section{S 7-A 27}

\section{ISOLATION AND CHARACTERIZATION OF EXPRESSED DNA SEQUENCES FROM DEFINED HUMAN CHROMOSOME REGION CONTAINING NUROGENETIC DISEASE LOCUS}

Joh-E IKEDA (Dept. of Mol. Med. Genet. , The Institute of Medical Science, Tokai University School of Medicine, Isehara, Kanagawa 259-11)

The isolation of regional chromosome specific cDNA clones appears to offer an additional powerful methodology to search specific genes underlying neurogenetic disorders including Huntington disease (HD) and Wolf-Hirschhorn syndrome. We have developed a novel approach for the isolation of expressed DNA sequences from defined region of human chromosome, which relies on the direct screening of cDNA libraries by using pooled microclones generated by a laser chromosome microdissection in conjunction with Single Unique Primer (SUP)-PCR (Genomics 11, 364, 1991). This method was applied to the terminal region of the short arm of the human chromosome 4 (4p16) containing HD locus. 960 microclones which carry unique DNA sequences were isolated from the 4p16-specific microdissected DNA library, and divided into 10 groups. After screening of $2-11 \times 10^{5}$ plaques from three human brain cDNA libraries (striatum, caudate and fetal brain) with 10 microclone-pools as probes, 203 positive cDNA clones in all were isolated. Among these clones, 46 clones, consisting of 21 non-overlapping clones, were assigned to the human chromosome 4 defined by the somatic cell hybrid panel. GenBank data base established no significant similarities of 21 cDNAs to previously cloned genes of the primates. Ten out of 21 independent clones were subregionally mapped within the 4p16. Furthermore, HD region specific seven $\mathrm{YAC}$ clones has allowed the identification of two novel cDNA clones (JF12 and BC2) within $2 \mathrm{Mbp} \mathrm{HD}$ region of 4p16.3. SUP-PCR products of HD specific YAC-DNAs are also prominent probes for fishing the genes encoded in the HD region.

\section{S 7-A 28}

BODY MAPPING OF EXPRESSING GENES: functional analysis of human genome.

Kousaku Okubo (Institute Mol. Cell Biology, Osaka Univ, Suita, Osaka)

Single run sequencing of cDNAs on a large scale has been considered as supportive effort to currently ongoing structural analyses by providing expressed sequence tags (ESTS). However, if a large scale single path sequencing is directed to the $3^{\prime}$ end of the cDNA molecules, the abundancy of each gene transcript in a given cell or tissue will be counted. Collection of gene signatures, the $3^{\prime}$ directed CDNA sequence defining a gene, with the abundance information determiners the expression profile that can not be obtained through other CDNA sequence collecting projects. Such analysis expanded to cover the whole human body, will help elucidate, the genes expressed in a tissue secific way. Along this line we have started a large scale collection of $3^{\prime}$ directed CDNA sequences, gene signatures, made from mRNIA of various human tissue under physiological or pathological conditions. More than 20,000 3'cDNA have been collected from 20 different libraries, and the results have been assembled into a data base that reflects the transcriptional control information of as many as 6,000 genes in 20 different tissues. Efforts to provide tissue specific expression control information on each gene as described above is called body mapping. The functional analyses of the human genome by body mapping to obtain, the expression information vital to all genes, characterized or novel, is complemental with the structual analysis of human genome. 


\section{S 8-B 19}

MYOTONIC DYSTROPHY. Eiji NANBA (Division of Child Neurology, Institute of Neurological Sciences, Tottori University School of Medicine, Yonago)

Myotonic dystrophy (DM) is an autosomal dominant disorder caused by a trinucleotide(CTG) amplification at 19q13.3. I studied the CTG repeat in myotonic dystrophy patients from San-in district at Japan. I used the Southern blot analysis and PCR-based examination constructed by non-radioisotope protocol. The repeats from the congenital DM were more amplified than that from the adult DM. The genetic anticipation was showed by the study from the 3 families from the congenital DM. A consanguineous family was extremely interesting and the intergenerational expansion from the members through 4 successive generations could be analyzed. The rare minimal expansions $(37,41$, and 59 repeats) were detected by the analysis from the family members that showed no clinical manifestation. Though the most minimal abnormality of 37 repeats in the members showed no amplification by the transmission from the female, the minimal amplification from 41 repeats to 59 repeats generated by a transmission from the male. The minimal amplification of the CTG repeat seemed to be generated in the male meiosis and the congenital DM was born from the mother after at least 4 successive generations from the original mutation.

\section{S 8-B 20}

Clinical varieties and their genotypes in Gaucher disease

Yoshikatsu Eto

Department of Pediatrics,

Tokyo Jikei University School of Medicine

Tokyo, Japan

Gaucher disease is most common lysosomal sphingolipid storage disorder, characterized by a deficiency of lysosomal glucocerebrosidase. Present studies deals with molecular analysis of Japanese Gaucher disease to characterize the molecular basis of Gaucher disease in Japan. We analyzed for the presence of the two known mutations (6433C and3548A) in the glucerebrosidase gene of 15 patients with Gaucher disease by selective amplification and restriction endonuclease analysis. We found that the $6433 \mathrm{C}$ and $3548 \mathrm{~A}$ mutations occurred in all three clinical phenotypes of Japanese Gaucher patients. Most prevalent mutation in type I and II was $6433 \mathrm{C}$ in Japanese patients, about $40 \%$ of 30 chromosomes, whereas the $3548 \mathrm{~A}$ mutation was $20 \%$ of 30 chromosomes, both in type I and II Japanese patients. There were no distinct difference in clinical phenotype to genotype between type I and II in Japanese patients with Gaucher disease. These results suggest that clinical phenotypes may be influenced by other genetic factors including intracellular environmental factors. 


\section{S 8-B 21}

RELATION BETWEEN GENOTYPE AND PHENOTYPE IN HYPERPHENYLALANEMIA. Shigeo KURE, Kazutoshi TAKAHASHI, Hiroyuki IKEDA, Yoichi MATUBARA, and Kuniaki NARISAWA. (Dept. Giochemical Genetics, Tohoku Univ. SOM, Sendai)

Hyperphenylalanemia is caused by defects in phenylalanine hydroxylase (PAH) gene or by defective biosynthesis of $\mathrm{BH} 4$, a cofactor of $\mathrm{PAH}$, which results from the defects in GTPCH, PTPS, and DHPR genes, causing the non-allelic heterogeneity of hyperphenylalanemia. In DHPR deficiency we studied two families including one sib case. Three affected sibs in the family were considerably different in severity and onset of the symptoms, suggesting the phenotypic heterogeneity in the patients with identical genotype. We examined 42 unrelated PKU families by direct sequencing of exon 7 and amplified cDNA fragments from the ectopically-transcribed PAH mRNA in lymphoblasts, and identified both alleles in 19 families, one allele in 15 families, and no allele in 7 families (66\% mutant gene alleles). The relation between genotype and phenotype was discussed from the view points of the intellectual phenotype of the untreated patients, phenylalanine tolerance, and the predicted activity of the mutant PAH cDNA.

\section{S 8-B 22}

\section{CLINICAL AND GENETIC HETEROGENEITY OF MAPLE SYRUP URINE DISEASE \\ Yasuhiro INDO (Department of Pediatrics, Kumamoto University, Kumamoto )}

Maple syrup urine disease (MSUD) is an autosomal recessive inborn error of metabolism in which the primary defect is that of oxidative decarboxylation of branched-chain $\alpha$-keto acids derived from three branched-chain amino acids: leucine, isoleucine and valine. The oxidative decarboxylation of these keto acids occurs by means of the branched-chain $\alpha$ keto acid dehydrogenase complex (BCKDH), which is composed of three component enzymes: E1, E2 and E3. The E1 is further composed of E1 $\alpha$ and E1 $\beta$ subunits. Several different phenotypes of MSUD have been distinguished on the basis of clinical features: classical, intermittent, intermediate and thiamine-responsive types. We studied patients with MSUD to determine possible relationships between clinical features and properties and mutation(s) of the BCKDH. A relationship between patient's tolerance for leucine and the BCKDH activities measured at a low substrate concentration was noticed. Typical classical and intermittent subjects showed activity below $1.0 \%$ and $8-10 \%$ of normal control, respectively. Intermediate subjects showed activity between these two figures. Kinetic and immunoblot analyses of the BCKDH revealed that, although there are a few exceptions, the enzyme properties of sigmoid and hyperbolic kinetics correspond to E1 and E2 component deficiency, respectively. Mutations of (E1 $\alpha, E 1 \beta$ and E2), E2 and $\mathrm{E} 1 \alpha$ genes were identified in typical classical, intermittent and intermediate subjects, respectively. Thus, mutations causing MSUD are heterogeneous, including missense, deletion, insertion and splicing abnormalities. 
S 8-B 23 Genotype and phenotype of HPRT deficiency Naoyuki Kamatani Institute of Rheumatology, Tokyo Women's Medical College Hypoxanthine phosphoribosyltransferase (HPRT) deficiency causes two different phenotypes; Lesch-Nyhan's syndrome (severe type) and partial HPRT deficiency (mild type). Mutations causing HPRT deficiencies have been investigated extensively. Of 76 germline HPRT mutations so far reported $48(63 \%)$ were base substitutions in the coding region while $28(37 \%)$ had other abnormalities. The latter mutations were associated with Lesch-Nyhan's syndrome except for 2 rare cases. Among the former mutations, all of those associated with partial HPRT deficiencies were missense substitutions while 23 of 26 base substitutions associated with Lesch-Nyhan's syndrome were missense mutations. The remaining 3 were nonsense mutations. As to the germline in vivo mutations at HPRT locus, 80 of 89 base substitutions in the coding region were missense mutations, the rest being nonsense mutations. There are 1953 possible base substitutions in the coding region of human HPRT locus, and $424(21.7 \%), 1448$ $(74.1 \%)$, and $81(4.1 \%)$ are synonymous, missense and nonsense substitutions. Therefore, 5.3\% of all HPRT deficiencies caused by the base substitutions in the coding region are expected to have nonsense substitutions. However, the percentage of nonsense substitutions among base substitutions in the coding region associated with Lesch-Nyhan's syndrome was $11.5 \%$. Comparison of the expected value with the value actually obtained indicates that $43 \%$ of missense substitutions cause Lesch-Nyhan's syndrome and 74\% cause either LeschNyhan's syndrome or partial HPRT deficiency.Taken together, both synonymous substitutions and about $26 \%$ of missense substitutions in the coding region do not cause any diseases, while about $43 \%$ and $31 \%$ of missense substitutions cause Lesch-Nyhan syndrome and partial HPRT deficiency, respectively. Both nonsense substitutions and major gene changes cause Lesch-Nyhan syndrome. Although the structure of HPRT has not been determined, homologous amino acid sequence commonly seen in 10 different phosphoribosyltransferases is thought to be the PRPP binding site.

\section{S 9-C 18}

APPLICATION OF DNA-PROFILE : CHEMILUMINESCENT SUBSTRATE FOR SINGLE LOCUS PROBES.

Hori MASAHIKO (Teijin Bio $\cdot$ Lab. Inc.,Tokyo)

The DNA-profile are very useful in forensic, paternity testing and in various other medical applications. The probes to detect minisatellite for DNA-profile was labeled with the radioactive reagents heretofore in use. However radioactive materials require special equipments and permissions. Then high sensitive non-isotopic methods are anticipated. The chemiluminescent method meets it's expectations. This method give rapid results and have at least the equivalent detection against the radioactive methods.

Now we apply this chemiluminescent system for detection of DNA-profile. The chemiluminescent substrate uses AMPPD (3-(2'-Spiroadamantane)-4-methoxy4-(3"-phosphoryloxy)-phenyl-1,2-dioxetane) with alkaline phosphatase. We could detect single copy gene in 40ng sample DNA or bloodstain of $5 \mu$ l. 
S 9-C 19

DIGITAL DNA TYPING

Yoshinao KATSUMATA (Dept. Legal Med., Nagoya Univ., Nagoya)

In personal identification using DNA analysis, the fragment length polymorphism of minisatellite DNA are usually detected. However, it is not easy to determine their exact lengths, especially when they are more than several kilobases long. In 1991, Jeffreys et al. devised a new method for detecting minisatellite variant repeats (MVR) at D1S8 (MS32) by polymerase chain reaction (PCR). This method is called MVR-PCR or digital DNA typing and shows approximately 50 repeat units of D1S8 from the $5^{\prime}$ end as a bar code-like ladder on an autoradiograph. We have shown in previous reports that MVR coding ladders at D1S8 are extremely variable in the Japanese population, and that 73 people could be differentiated with only 12 repeats from the $5^{\prime}$ end, although MVR-PCR with more than 50 repeats could have been easily detected. For this study, we obtained the exact same MVR coding ladders with DNA samples purified from various organs and body fluids of the same individual. Since this method does not require error-prone allele length determination and has a great ability to identify individuals, it is expected to be highly useful in the field of forensic science.

\section{S 9-C 20}

DETECTION BY PCR OF HYPERVARIABLE VNTR LOCI AND THEIR FORENSIC SCIENCE APPLICATIONS. Yoshihiro TAMAKI (Dept. Forensic Med., Oita Med. Univ., 0ita)

DNA typing of hypervariable loci by Southern blotting requires relatively large amounts of DNA, gives poor reproducibility, involves a difficulty in band sizing, is not applicable to degraded DNA, and is time-consuming. To avoid these drawbacks, forensic scientists are increasingly using PCR for detection of VNTR and HLA loci. The ampl ifiabie minisatellites include MCT118, YNZ22, COL2A1, ApoB, D4S43, and DXS52. Of these, MCT118, 16 bp repeats, is the most usueful because of the large number of alleles with a high heterozygosity rate. The recent discovery of microsatellites has had a great impact on genetic workers in various fields. Microsatellites, i.e., 2-5 bp repeats, are extremely useful because of their high informativeness, their abundance, their uniform distribution throughout the genome, and their easy detectability. So far, hundreds of microsatellite loci have been identified, and some have found forensic application. In our experience, tetranucleotide repeats, and not dinucleotide repeats, appear useful for forensic science applications. In particular, the ACTBP2, AluVpA, FGA, D8S320, D11S488, and D11S554 loci are suited for forensic scienc practice in that they have high heterozygosity rates, that two or more loci are co-amplifiable, and that accurate band sizing can be attained by denaturing polyacrylamide gel electrophoresis followed by Southern blotting with digoxigenin-labeled ol igonucleotide $(A A A G)_{5}$. 


\section{S 9-C 21}

Extraction and analysis of DNA from forensic materials Hirofumi FUKUSHIMA (Dept. Legal Med., Shinshu Univ., Nagano)

DNA genetic typing of forensic samples relies on the efficient recovery and quality of the DNA isolated from the subject material. DNA quality suffers considerably when materials are subjected to harsh conditions, such as a moist storage environment. This paper discusses methods of DNA isolation from a variety of materials including blood (blood stains), semen (semen stains), saliva (saliva stains), mixed vaginal swabs and sperm, and samples of tooth, hair, bone,urine, sperm or other tissue (e.g., liver,brain, kidney and muscle). In general, the isolation of genomic DNA from forensic materials typically involves digestion of nuclei with a combination of proteinase $\mathrm{K}$ and SDS followed by deproteinization with organic reagents such as phenol and chloroform. PCR is considered to require less stringent purifications techniques than other analytical methods such as RFLP analysis (Southern blotting). A number of PCR - based DNA extraction procedures have been developed for forensic materials. In this symposium, we report a comparison between different methods of extraction, including phenol - chloroform extraction, boiling with water, microconcentration (Centricon), Tween 20 extraction and use of chelating resins (Chelex) prior to the amplification.

\section{S 9-C 22}

DNA ANALYSIS IN FORENSIC PRACTICE.

Yoshihiro YAMADA (Dept. Forensic Med.,Univ.of Tokyo)

Since multilocus DNA fingerprints were first reported in 1985, DNA analysis has become widely used in the fields of forensic practice, and the results of such analysis have occasionally been used as important evidence in criminal investigation. We are doing at present two distinct approaches to genetic testing at the DNA level; (a) the DNA was digested with Hinf I and subjected to Southern blotting procedures labeled a multilocus probe Myo and a single locus probe pYNH24 and (b)the use of the polymerase chain reaction (PCR) to amplify segments of genetically informative DNA sequence. Generally, the DNA recovered from forensic specimens is frequently too degraded to analyze by using the southern analysis. Furthermore, the contaminated samples are difficult to discriminate the individual from other individuals. We established a method based on the hyper-variability in the human mitochondrial DNA (mtDNA) sequence. The mtDNA was amplified by PCR and cloned and each individual clone obtained was sequenced. Those procedures enabled us to analyze even trace amount of highly degraded forensic specimens. On the other hand the cloned PCR products sequenced separately proved to be advantageous to analysis of contaminated samples. 


\title{
Special Symposium
}

P 1-A 30

\author{
HUNTINGTON DISEASE \\ P.Michael CONNEALLY (Indiana University School of Medicine, \\ Indianapolis, USA)
}

\begin{abstract}
Huntington Disease(HD) is a dominantly inherited neurodegenerative disorder with variable age of onset. The primary symptoms are involuntary choreic movements and dementia which progress inexorably until death. The mean age of onset is approximately 38 years with a mean duration of illness of 19 years. The HD gene was mapped to the distal short arm of chromosome 4 in 1983. The first human disease gene to be assigned to a chromosomal region using recombinant DNA techniques. The HD gene, however, proved to be very difficult to clone, taking ten years to accomplish. Problems in cloning genes using the standard positional cloning methodology will be discussed. The HD gene mutation is due to the expansion of a trinucleotide repeat(CAG). The normal allele varies between approximately 10 to 35 repeats while the HD gene varies between 40 and 85 repeats. There is a high correlation between age at onset and repeat length; the greater the number of repeats in the HD gene the earlier the onset. Repeat expansion occurs primarily during male meiosis. This accounts for the predominance of affected fathers offspring with onset under 20 years of age. The precise mechanism leading to amplification in repeat length is unknown, several hypotheses have been suggested. These will be discussed. Presymptomatic diagnosis in HD using linked markers has been complicated. The discovery of the mutation makes diagnosis simple and also gives an approximate prediction for age of onset. The function of the HD gene product has not yet been determined.
\end{abstract}

\section{P 1-A 31}

HUNTINGTON'S DISEASE IN JAPAN.

Jun GOTO and Ichiro KANAZAWA (Dept. Neurol., Inst. for Brain Research, School of Med., Univ. of Tokyo, Tokyo)

Huntington's disease (HD) is a progressive neurodegenerative disease with an autosomal dominant inheritance. The disorder involves the caudate nucleus pathologically and clinically presents choreic movements, psychiatric symptoms and dementia. The HD gene was mapped to chromosome $4 p$ in 1983. After a decade of efforts for cloning, HD has been shown to be caused by the expansion of a CAG repeat in the huntingtin (IT15) gene. $\mathrm{HD}$ is rare in Japan and an estimated prevalence is approximately 4 in one million. We have collected more than $50 \mathrm{HD}$ families including more than 90 affecteds. Our linkage studies showed that Japanese HD families are tightly linked to D4S43/S127 and D4S95 (Hum.Genet.85:257,1990; Jpn.J.Human Genet.38:193,1993). We proceeded efforts for identification of transcribed sequences in the region between D4S180 and D4S95 and found a new transcript (Watanabe, manuscript in prep.). The normal CAG allele varies between 16 and 32 repeats and an observed heterozygosity is 0.83 . The HD allele varies between 38 and 99 repeats and age at onset correlates to repeat length inversely. The discovery of mutation makes presymptomatic diagnosis simple. Complicated cases of presymptomatic diagnosis using linked markers were presented. 
P 1-A 32

\author{
PRION DISEASES \\ Jun TATEISHI (Dept. of Neuropathology, Kyushu Univ., Fukuoka)
}

Abnormal isoform of prion protein $\left(\mathrm{Pr}^{\mathrm{PS}}\right)$ has been specifically found in prion diseases which include Creutzfeldt-Jakob disease(CJD), Gerstmann-Sträussler syndrome (GSS), kuru, scrapie in sheep and in other species infected from sheep. Cellular isoform of $\operatorname{PrP}$ $\left(\mathrm{Pr} \mathrm{P}^{\mathrm{C}}\right)$ is universally encoded by a cellular gene. We have found many mutations and polymorphism of PrP gene and correlated them with clinico-pathological features. Hydrolytic autoclaving pretreatment can markedly enhance immunoreactivity of $\mathrm{PrPsc}$ in routine autopsy materials and classify $\operatorname{Pr}^{P^{s c}}$ deposition into plaque-type and synapse-type. Plaque-type deposition takes place in extra-cellular spaces after a long clinical course over several years, and occurrs among patients with P102L, P105L, A117V, Y145stop, 168 bp insert and $129 \mathrm{~V}$ polymorphism. Synapse-type deposition is mainly observed in presynaptic terminal and causes short clinical course around one year. This deposition is seen in patients with wild type CJD, D178N, V180I, E200K and M232R. Experimental transmission to mice from almost all patients with wild type CJD and a few mutation cases was positive but negative from many mutation cases. Therefore, prion diseases have both characters of infection and hereditary metabolic errors.

\title{
P 1-A 33
}

GENETIC LINKAGE ANALYSIS OF MACHADO-JOSEPH DISEASE. Masatoyo NISHIZAWA (Dept. Neuro1., Jichi Med. Sch., Tochigi)

Machado-Joseph disease (MJD) is an autosomal dominant, multisystem, neurodegenerative disorder involving predominantly cerebellar, pyramidal, extrapyramidal, motor neuron, and oculomotor systems. In Japan, MJD is one of the most common hereditary spinocerebellar degenerations. With the use of highly polymorphic microsatellite DNA polymorphisms, we performed systematic linkage analysis in five Japanese MJD families. We found that the MJD locus is tightly linked to chromosome 14q markers D14S48 and D14S55. The maximal pairwise lod score between MJD and D14 S48 was 5.66 at a recombination fraction $=0$. Multipoint linkage analysis with the LINKMAP program resulted in a higher likelihood of linkage at D14S55 (Zmax=9.72). We also found significant differences between MJD and normal control populations regarding allele frequencies for D14S48, D14S53 and D14S43. Recombination events between the MJD locus and D14 S55/S48 were not observed in these families, whereas multiple recombination events were found at D14S53 and D14S45. These data demonstrate that the gene for MJD is thus located in the 29-centimorgan region between D14S53 and D14S45. 


\section{P 1-A 34}

DEVELOPMENTAL FIELD AND NEURAL TUBE DEFECTS. John M. OPITZ(Shodair Hospital, Helena, Montana, U.S.A.)

In view of homology of structure and development, causal heterogeneity and phylogeneity (i.e. the spontaneous occurrence of similar/ identical NTDs in different mammalian species, or teratogenic production of NTDs in different species with identical or different teratogens), NTDs fulfill all of the classical criteria of a developmental field. NTDs (mostly anencephaly/spina bifida) are midline defects that arise during blastogenesis (days 18-28). Thus, NTDs are polytopic field defects frequently associated with other midline anomalies, especially in (schisis) associations. NT closure is multifocal in mice and in humans, and different closure defects may represent causally different entities (Van Allen, 1993). Some $70 \%$ of non-syndromal NTDs appear to be folic acid-sensitive and -preventable closure defects; the fact that in the Hungarian controlled trials the incidence of all birth defects was reduced by $50 \%$ supports the contention that NT formation be regarded more as a defect of gastrulation than as a defect of neurulation sensu stricto.

\section{P 2-A 35}

DIAGNOSIS AND TREATMENT OF FAMILIAL AMYLOIDOTIC POLYNEUROPATHY (FAP)

Shukuro ARAKI (Neurological Center, Mitsui Omuta Hospital, Fukuoka, Japan.)

FAP is an inherited systemic amyloidosis transmitted by autosomal dominant trait, occuring in middle age, and characterized by sensory-dominant poyneuropathy, autonomic dysfunction, cardiac conduction disturbance, and emaciation. The amyloid protein is composed of variant transthyretin (TTR) with a substitution of methionine for valine at position 30 (TTR Met 30) in the FAP type 1, as reported in Japan, Portugal, and Sweden. Until up todate, molecular biology explored 41 new TTR genetic variants, and proved a genetic and clinical heterogeneity in the TTR associated amyloidosis. In Japan, beside a variant TTR Met 30, there have been mutations at position Leu 30, Gly 42, Arg 58, and Cys 114, after direct DNA tests have been developed.

For diagnosis of FAP, tissue biopsies of abdominal fat, gastric mucosa, and sural nerve are important to identify the amylod deposit. Although PCR test is now available for diagnosis at pre-natal, and presymptomatic level, this DNA diagnosis raises new ethical problems about the identifications of individuals doomed to have an untreatable disease. There are no specific therapy for FAP, and symptomatic treatments are being performed. Recently, liver transplantation has started in Sweden, Spain, and the United States, as a clinical trial. 


\section{P 2-A 36}

GENE MUTATION, PHENOTYPE AND THERAPY OF $\beta$-GALACTOSIDOSIS Akihiro OSHIMA(Dept. Clin. Gent. , Metropolitan. Inst. Med. Sci. , Tokyo)

A1lelic mutations of the $\beta$-galactosidase gene resulted in heterogeneous expression. They are classified mainly into four major clinical groups: infantile, late infantile/juvenile, adult/chronic, and Morquio B disease. Most of mutant gene products lose $\beta$-galactosidosis activity completely, and resulted in infantile GM-gangliosiuosis. On the other hand, three mutant gene products(I51T, R201C, and $\mathrm{W} 273 \mathrm{~L}$ ) possess 2-10\% residual enzyme activity, and

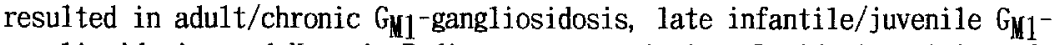
gangliosidosis, and Morquio $B$ disease respectively. Residual activity of I5IT mutant gene product seem to be closed the critical threshold value, below which the deposition of GM1-ganglioside occurs. Because a little increase of the residual activity may cure patients with adult $\mathrm{G}_{\mathbf{M}}$-gangliosidosis, they will be good candidates for gene therapy. R201C mutant gene product are rapidly degraded in the 1ysosome, the activity are restored by thiol protease inhibitors. if appropriate protease inhibitors are available, therapeutic approach should be considered.

\section{P 2-A 37}

ALTERED STRUCTURE AND EXPRESSION OF THE P53GENE IN HUMAN BRAIN TUMORS.

Kazuo TABUCHI, Kouzou Fukuyama, Toshihiro MINETA, Tetsuya SHIRAISHI, Katsuji HORI (Depts. Neurosurgery \& Biochemistry, Saga Med. School, Saga)

Several genetic alterations are associated with the development of certain human tumors arising from the central nervous system(CNS). The common alterations are deletions on the short arm of chromosome 17(17p13.1) and the long arm of chromosome 10. The p53 gene, a tumor suppressor gene, is located on chromosome 17p and encodes for a cellular 53 kd phosphoprotein(p53) now believed to be essential in the regulation of cell division. The structure and expression of the p53 gene were examined in both biopsied and cultured human brain tumors. Pulse-chase analysis showed an increased half-life of p53 in cultured glioma cells. Nucleotide substitutions in exon 5,7 or 8 of the p53 gene could be detected by PCR-SSCP analysis in 4 of $7(57 \%)$ human glioma cell lines, and 9 of 29 (31\%) biopsied specimens of brain tumors. The present results indicate that genetic alterations in the p53 gene are responsible for the tumorigenesis/development of certain tumors arising from the CNS. 


\section{P 2-A 38}

\section{NIEMANN-PICK DISEASE TYPE C}

Kousaku Ohno (Departmet of Neurobiology, School of Lile Sciences, Faculty of Medicine, Tottori Univ)

Diagnosis of Niemann-Pick disease type C (NP-C) is made based on extensive accumulation of free cholesterol, defective esterification of exogeneously added cholesterol and nearly normal activity of acid sphingomyelinase in cultured skin fibroblasts. Abnormal accumulation of free cholesterol can also be detected in characteristic foamy cells or in sea-blue histiocyte. The basic defect remain uncertain but defective trasport of cholesterol from lysosome to other membrane sites has been suggested. We have found the NP-C cells show a markedly increase in de novo cholesterol synthesis and that show altered sensitivities to inhibitors of the pathway, suggesting dependence on the de novo pathway for their requirement of cholesterol. This should be important as an additinal cellular marker of NP-C. We establish immortalized cell line from the sphingomyelinosis mouse and found the cells have the same abnormalities as NP-C cells. By a human chromosome transfer we have found the human chromosome restoring the abnormal phenotye of the cell line is \#18.

Recently, NP-C gene has been reported to be linked to chromosome 18, suggesting the gene restoring the mouse cell line is the same as defective gene in NP-C. The model mouse should be very useful for basic study of gene therapy in NP-C.

\section{P 2-A 39}

APPROACHES TO GENE THERAPY TO DISEASE AND OTHER DEFECTS IN THE MAMMALIAN CENTRAL NERVOUS SYSTEM. T.FRIEDMANN (Center for Molecular Genetics and Department of Pediatrics, UCSD School of Medicine, La Jolla,Cal. 92093,U.S.A.)

The concepts and tools of gene therapy for human disease have achieved a high level of acceptance in the medical, scientific, public policy and ethics communities. During the past several years, more than fifty experimental human gene transfer studies have been approved, principally aimed at cancer but also to a number of metabolic and infectious diseases. Disorders of the human CNS have not generally been considered obvious targets for gene therapy because of the relative inaccessibility of the CNS and the refractoriness of neurons to infection with the most popular gene transfer tools, the retroviral vectors. However, recent conceptual and technical advances have combined to make the human CNS an important and attractive target organ for gene therapy. These advances include the development of ex vivo approaches to Parkinson's and Alzheimer's diseases and other CNS disorders resulting from deficiencies of trophic factors and neurotransmitters, the use of adenoviral, adeno-associated and herpes viral vectors to transduce cells in the CNS to complement defects in CNS cells and the use of immortalized, genetically modified progenitor cells to reconstruct portions of the CNS and provide new functions to the CNS. 


\section{Workshops}

\section{W 1-A 8}

Linkage analysis and positional clononig of genes for neurodegenerative diseases. Haiime TANAKA Shoji TSUJI (Department of Neurology, Brain Research Institute, Niigata University, Niigata)

Linkage analyses have been employed to elucidate genes for various forms of hereditary neurolodegenertive disorders. Especially, developmet of highly polymorphic microsatellite markers has made linkage analyses far more effective. With use of a number of microsatellite markers we have succeeded in mapping the gene for Machado-Joseph disease (MJD) to chromosome 14(Takiyama et af).

Discoveries of unstable expansion of trinucleotide repeats in fragile $X$ syndrome, spinal and bulbar muscular atrophy, myotonic dystrophy, Huntington's disease and spinocerebellar ataxia 1 (SCA1) have shed light on the understanding of a new mechanism of human hereditary diseases. Taking advantage of directly screening genes with CAG repeats as candidates, we recently found unstable expansion of CAG repeat of a gene in dentatorubral-pallidoluysian atrophy (DRPLA)(Koide et al. Nature Genetics in press).

\section{W 1-A 9}

POSITIONAL CLONING OF THE HUMAN PAX3 FROM AN INVERSION BREAKPOINT IN A PATIENT WITH WAARDENBURG SYNDROME TYPE I (WSI), AND 2 ISOFORMS WITH ALTERNATIVE EXPRESSION IN ADULT TISSUES. Norio NIIKAWA (Dept. Hum. Genet., Nagasaki Univ. Sch. Med., Nagasaki)

We have isolated and characterized cosmid clones from an inversion breakpoint of chromosome 2 [inv(2)(q35q37.3)] in a patient with WSI. Genomic cosmid clones containing the human $P A X 3$, which was considered as a candidate for WSI, were isolated from a library constructed from the patient's DNA. One of the cosmids contained the inversion breakpoint and revealed signals at both $2 \mathrm{q} 35$ and $2 \mathrm{q} 37.3$ by fluorescence in situ hybridization (FISH), indicating disruption of $P A X 3$ by the inversion. Our result supported that $P A X 3$ is a candidate for WSI and is located at $2 \mathrm{q} 35$. We have then isolated two forms of cDNA clones from $P A X 3$. The gene product is considered to be one of transcription factors, and the two cDNA clones isolated, termed $\mathrm{HuP} 2 \mathrm{~A}$ and $\mathrm{HuP} 2 \mathrm{~B}$, were generated by a result of alternative splicing. The transcripts consisted of 215 and 206 amino acids, respectively, and shared 196 amino acids at the $\mathrm{NH}_{2}$-position. The sequence of amino acids in the common region (residues 1-196) showed a 100\% identity with that of exons 1 through 4 of the mouse Pax3. However, both of the PAX3-cDNAs lacked the DNA sequence corresponding to the paired-type homeodomain of the mouse Pax3. Analysis of gene expression in human adult tissues by reverse-transcriptase polymerase chain reaction (RT-PCR) revealed tissue-specific expression patterns of this gene; HuP2B was expressed in most of the tissues examined but HuP2A was detected in the cerebellum, esophagus and skeletal muscle. 
W 1-A 10

POSITIONAL CLONING OF THE GENE FOR LOWE SYNDROME

Ichiro OKABE (Department of Pediatrics, Jichi Medical School, Tochigi)

The Lowe's oculocerebrorenal syndrome (OCRL) is an X-1inked recessive disorder, characterized by congenital cataracts, mental retardation and renal tubular dysfunction. The OCRL locus has been mapped to $X q 25-q 26$ by linkage analysis and by finding de novo $X$; autosome translocations at Xq25-q26 in two unrelated females with OCRL. The complementary DNAs for OCRL have been isolated using yeast artificial chromosomes as probes which span the $X$ chromosomal breakpoint from a female OCRL patient. The transcript is absent in both female OCRL patients with $X$; autosome translocations and it is absent or abnormally sized in some unrelated male OCRL patients with no detectable genomic rearrangement. The open reading frame encodes a new protein with $71 \%$ similarity to inositol polyphosphate-5phosphatase. OCRL is now proposed to be an inborn error of inositol phosphate metabolism. Abnormalities in inositol metabolism or transport have been implicated in the pathogenesis of the cataracts and peripheral neuropathy in galactosemia and complications of diabetes mellitus.

W 1-A 11

Positional Cloning of Breast Cancer-Related Gene Mitsuru Emi \& Yusuke Nakamura ( Dept. of Biochemistry, Cancer Institute)

Allelic loss studies of sporadic breast and ovarian cancers have suggested the presence of a tumor suppressor gene(s) for these types of tumors at chromosome region 17q21. Linkage analysis has also located a locus for inherited form of breast and ovarian cancer to the same location. Through the combined use of the two approaches, we defined the location of putative suppressor gene within $500 \mathrm{~kb}$ on a physical map of 17q21.3. One of the cosmids covering this interval detected somatic rearrangements in two cases of breast cancer by Southern blot analysis. A novel gene was identified from this region that encodes a 524 amino acid protein with unexpected similarity to members of snake venom metalloprotease / disintegrin family and guinea pig sperm-surface protein $\mathrm{PH}-30$, that have been implicated in either interference or mediation of cell-cell or cell-extracellular matrix interaction. Both rearrangements in the tumors involved multiple exons and disrupted the coding region of this gene. 


\section{W 2-B 7}

Molecular genetics of Duchenne muscular dystrophy. Kayoko SAITO, Kiyoko IKEYA, Akemi YAMAUCHI, Reiko MORITA, Satoshi KOMINE, Izumi SAKUMA, Eri KONDO, Yukio FUKUYAMA.

The identification of the gene, and the subsequent description of its protein product -dystrophin- have opened several new fields of research and genetic diagnosis. Studies in our laboratory revealed that 35 out of 59 cases (59\%) of Duchenne/Becker muscular dystrophy(DMD/BMD) exhibited genomic deletion by means of polymerase chain reaction(PCR) analysis and Southern blot analysis. The reliability of the result of carrier detection increased by using Southern blot analysis, nested PCR and pulse field gel electrophoresis of DMD family with deletion of dystrophin gene. Carrier detection was performed based on Bayesian calculations, taking into account family history, serum creatine kinase value, and PCR-RFLP analysis for family members in whom deletion was not detected. Comparison between the clinical picture and the results of molecular genetic studies enables clarification of the relationship between the phenotype and genotype of $\mathrm{DMD} / \mathrm{BMD}$. Our investigation revealed 1) a case of congenital muscular dystrophy (non-Fukuyama type) clinically, with dystrophin deficiency and a genomic deletion, and 2) a case of deletion of the brain promoter in DMD gene in spite of normal intelligence, which proved to be a case of somatic mosaicism by autopsy. Extensive studies on dystrophin and the gene may lead to an understanding of the cause of the disease, and may allow a rational treatment of DMD to be developed.

\section{W 2-B 8}

\section{THE GENETIC ANALYSIS OF THE GENE FOR MYOTONIC DYSTROPHY.}

Tetsuro MIKI (Dept. Geriat. Med., Osaka Univ. Med. Sch., Osaka)

The myotonic dystrophy (DM) mutation recently identified as an unstable (CTG)n repeat which is present at a copy number of 3-35 repeats on normal chromosomes but is amplified to 50-2000 copies on DM chromosomes. Previous finding that DM has founder chromosomes raises a question about molecular events involved in the expansion mutation. To trace this ancestral event we have analyzed the copy number of the repeat in 89 Japanese DM families and 13 control families using PCR. Linkage disequilibrium between the (CTG)n repeat alleles on the normal chromosomes and the closely linked markers D19S63, p37.1 and an insertion/deletion polymorphism was detected. These data suggest that a common ancestral mutation in both caucasian and Japanese populations has originated by expansion of an ancestral 5 CTG repeat allele to between 18 and 20 copies. These data support recently proposed multistep models of triplet repeat expansion for both DM and fragile $\mathrm{X}$ linked mental retardation. 


\section{W 2-B 9}

GENETIC DIAGNOSIS OF FACIOSCAPULOHUMERAL MUSCULAR DYSTROPHY Kiichi ARAHATA, Hideo SUGITA (Natl. Inst. Neurosci., NCNP, Tokyo) Tetsuo FURUKAWA (Tokyo Medical and Dental College, Tokyo) Ko SAHASHI, Hiroshi SUOH (Aichi Med. Sch., Aichi) Yoshiko NOMURA, Masaya SEGAWA (Segawa Neurol. Clinic, Tokyo)

Facioscapulohumeral muscular dystrophy (FSHD) is an autosomal dominant muscular disorder, and shows highly variable clinical phenotypes from almost normal (abortive) to severe forms. In the present study, we analyzed four FSHD families ( 2 familiar, and 2 sporadic patients), using a p13E-11 probe, specific to the most teromeric locus at chromosome 4q (distal to the D4S139 locus). We found that p13E-11 probe detected an EcoRI fragments of smaller size $\left(16^{\sim} 27 \mathrm{~kb}\right)$ in the Japanese FSHD patients similar to those observed in Dutch patients, and thus co-segregated with FSHD. This study emphasizes the clinical importance of the p13E-11 probe for the accurate diagnosis and genetic counseling of FSHD patients and their family.

\section{W 2-B 10}

GENE THERAPY FOR MUSCULAR DYSTROPHY: CURRENT ACHIEVEMENT AND PROSPECT. Toshifumi TSUKAHARA, Shin'ichi TAKEDA and Kiichi ARAHATA (Dept. Neuromuscular Research, National Institute of Neuroscience, NCNP, Tokyo)

Since dystrophin, that is defected in Duchenne muscular dystrophy patient, is a myofibrillar and cytoskeletal protein present at the inner face of the sarcolemma, it is difficult to supplement it by pharmacological method. Therefore, the establishment of gene therapy for DMD has been expected.

Wolf et al. injected dystrophin cDNA intramuscularly into dystrophin deficient $m d x$ mice, and fund dystrophin positive fibers, but was counted only $1 \%$ of all fibers. Perricaudet et al. succeeded to transfer a truncated dystrophin minigene using of the adenovirus vector, and showed that muscle fibers were protected against the degeneration process. Recombinant dystrophin expressed in mdx muscle tissues up to 9 months after treatment. We attempt to develop an adenovirus vector which can carry a fulllength dystrophin cDNA. We also show that the myosin heavy chain IIB core promoter may help muscle specific expression of transfected foreign genes. 
W 3-C 8

GENOME MAPPING BY DIRECT R-BANDING FISH. Ei-ichi TAKAHASHI (Div. Genet., Natl. Inst. Radiol. Sci., Chiba) and Yusuke NAKAMURA (Dept. Biochem., Cancer Inst., Tokyo)

The construction of a high-resolution cytogenetic map is an essential step for positional cloning in which the genes responsible for genetic diseases and cancers are isolated. Furthermore, these mapping data provide many useful landmarkes for the construction of contig maps with YACs and cosmids. Direct R-banding FISH has proved powerful for the precise localization of markers on bands and allows more rapid and efficient construction of cytogenetic maps. With this system, we have constructed high-resolution cytogenetic maps with newly isolated cosmids of chromosomes 2, 5, 9 and 12 . The clones were distributed throughout the chromosomes, but sublocalized preferentially to R-positive bands. This bias may be due to the procedures used for colony-selection and/or the growth disadvantages of G-band DNA in bacteria host strains, but not by the procedures of R-banding. The average map distances are as follows: $0.7 \mathrm{Mb}, 1 \mathrm{Mb}, 0.7 \mathrm{Mb}$ and $0.7 \mathrm{Mb}$, respectively.

\section{W 3-C 9}

High resolution ordering of DNA markers by multi-color fluorescent in situ hybridization of prophase chromosomes. Johji INAZAWA (Dept. Hyg. Kyoto. Pref. Univ. of Med., Kyoto)

To improve resolution for physical ordering of adjacent DNA loci, prophase chromosomes were prepared for multi-color fluorescent in situ hybridization (FISH). The prophase chromosomes were obtained by culturing lymphocytes by the thymidine synchronization/bromodoxyuridine release technique and treating the cultures with topoisomeraseII inhibitors, ICRF154 or ICRF193. Almost all mitotic figures exhibited highly elongated prophase chromosomes without significant reduction of mitotic index. By multi-color FISH to these prophase chromosomes, we were able to delineate discernible signals for loci separated by as little as $50 \mathrm{~kb}$, and determine their orientation. Further, using this prophase ordering system, we confirmed the linear order and defined the orientation of seven cosmid markers within a $360 \mathrm{~kb}$ region surrounding D10S102 at locus that is closely linked to the disease locus in families segregating on allele causing MEN2A. This prophase FISH system, by rapidly and precisely providing the linear order of loci that are very close together, can expedite construction of fine cytogenetic maps and contribute to positional-cloning studies in which the precise ordering of DNA loci in a target region is critical. 


\begin{abstract}
W 3-C 10
SPECIFIC TRANSLOCATIONS IN HEMATOLOGIC MALIGNANCIES ARE DETECTED BY FLUORESCENCE IN SITU HYBRIDIZATION (FISH) WITH ALU-PCR AMPLIFIED YEAST ARTIFICIAL CHROMOSOME (YAC) CLONES AND WHOLE CHROMOSOME PAINTING (WCP) PROBES. Masafumi TANIWAKI (Dept. Med. Kyota Pref. Univ. Med., Kyoto)

\footnotetext{
We demonstrate the potential of two-color FISH studies using WCP-probes in combination with regional-specific DNA probes for unequivocal assignment of material in marker chromosomes from patients with leukemia. To further study cryptic translocation found in hematologic malignancies, we used YAC clones as probes for FISH analysis. YAC clones containing the human immunoglobulin heavy chain gene ( IgH) locus were successfully applied to detect cytogenetically invisible subtelomeric translocation of IgH gene to each partner site in various $14 \mathrm{q} 32$ translocations, e.g.. $t(3 ; 14), t(8 ; 14), t(14 ; 18)$, and $t(14 ; 19)$, and to identify their complex translocations. Remission state in patients with chronic myelocytic leukemia and with myelodysplastic syndrome was also confirmed through examining interphase nuclei by FISH using
} YAC clones containing the BCR and c-FMS.
\end{abstract}

\author{
W 3-C 11 \\ MOLECULAR DISSECTION OF THE PRADER-WILLI/ANGELMAN \\ SYNDROME REGION (15q11-13) BY YAC CLONING AND FISH ANALYSIS. \\ Akira Kuwano (Dept. Pediatr., Yamaguchi Univ., Ube) \\ Yeast artificial chromosome (YAC) clones were isolated from the \\ Prader-Willi/Angelman (PWS/AS) syndome region (15q11-13). \\ Muliti-color fluorescence in situ hybridization (FISH) analysis of \\ interphase nuclei provide the following order of markers: cen-IR39 \\ -ML34-IR4-3R-LS6-1-TD3-21-GABRB3-IR10-1-CMW-1-tel. Of 23 \\ cases of PWS, 13 cases were deleted in the interval IR4-3R to \\ GABRB3, while one case was deleted in the interval IR4-3R to TD3- \\ 21. Of 12 cases of AS, 4 cases were deleted in the same interval \\ as in PWS, while 2 familial AS cases showed the deletion from \\ Ls6-1 to GABR3. Further FISH analysis was done in the four \\ duplication cases, three were PWS and one was AS. Three cases \\ were duplicated in the interval IR39 to CMW-1, while one case \\ showed normal results for all YACs. These results indicate FISH is \\ an efficient method for sub-microscopic chromosomal \\ rearrangements in the microdeletion syndromes.
}




\section{W 4}

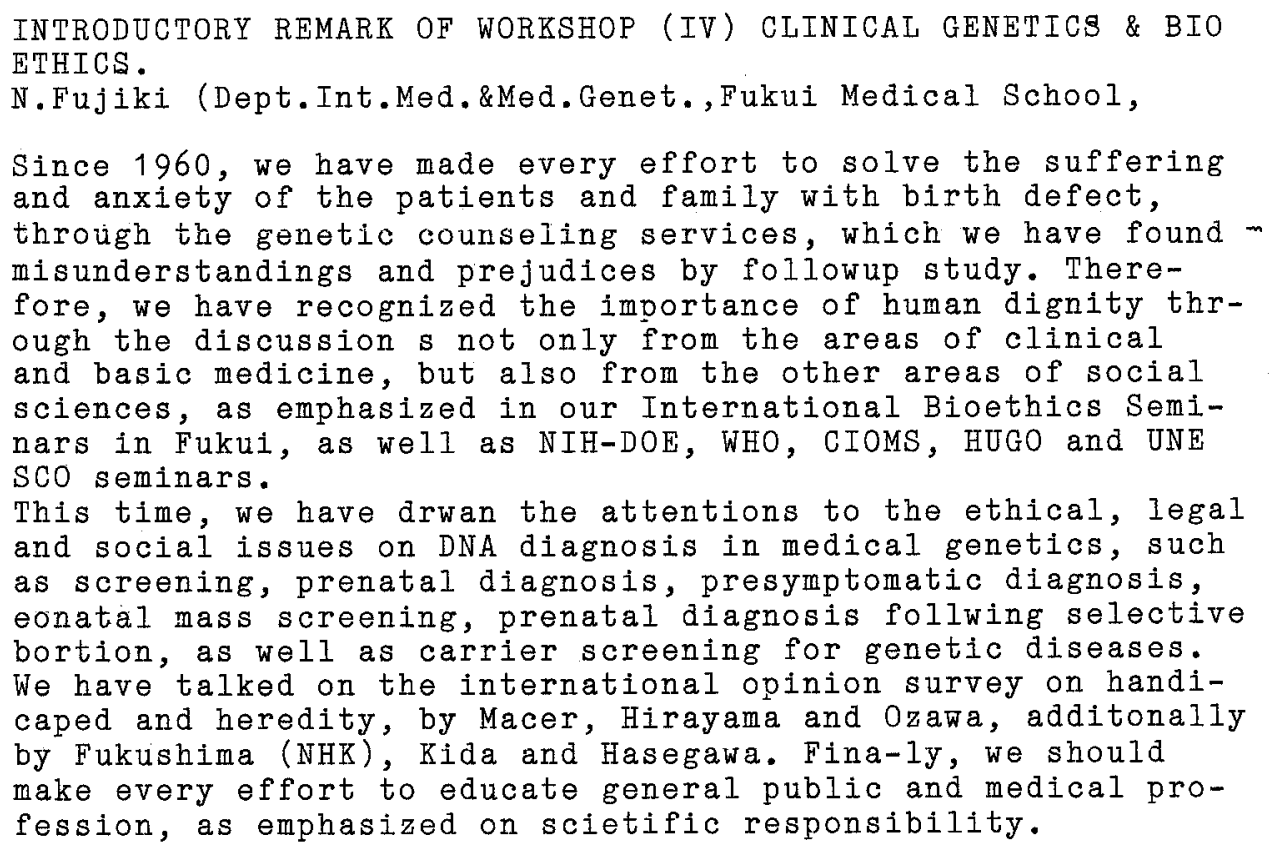

\section{W 4-A 21}

International comparions reveal Japanese have great support for gene therapy and strong support for prenatal genetic screening

\section{D.R. J. Macaer}

Institute of Biological Sciences, Univ. Tsukuba

Opinion surveys about altitudes to genctic screening and gene therapy of public, high school tcachers, and medical students in Japan, Australia, India, New Zcaland, Russia, Singaporc, and Thailand were conducted in 1993. These surveys included open responsc questions, and guestions about other biocthical issues. Further international comparisons to North Amcrica and Europe are made, and to previous surveys in Jipan.

The support for spceific thcrapeutic applications of gene therapy in Japan may be higher than in ollice countrics. All peoples show significant discretion over therapcutic and cosmctic applications of gene therapy. Japanesc people want prenatal screcning surveys $(0)$ be included under national health insurance. There is less opposition to prenalal genctic screcning in Japan than in the USA, the reverse of the myth that is perpeluated in Japan among the medical community that Japancse do not want such services. 
W 4-A 22

CONSENSUS SURVEY ON HANDICAPS AND HEREDITY

Mikio HIRAYAMA, Shigeaki NAKAZAKI, Norio FUJIKI (Dept. Int. Med. \& Med. Genet. Fukui Med. Sch., Fukui)

In 1993, we carried out the consensus survey on handicaps and heredity distributing the questionnaire to businessman, comedical students, comedical staff and medical students. $21 \%$ of businessman are interested in heredity. Those who consider heredity as predetermined comprised $68 \%$ in businessman, $16 \%$ in medical students. Those who consider it mysterious comprised $58 \%$ in comedical students, $49 \%$ in businessman, $34 \%$ in comedical staff and $16 \%$ in medical students. Those who consider it scientific comprised $51 \%$ in medical students, $24 \%$ in businessman. The frequency of congenital anomaly is 1 per 1000 10000 birth ; $75 \%$ in businessman, $60 \%$ in medical students ; One per 20 birth ; $6 \%$ in medical students, $4 \%$ in businessman. Even medical students underestimate the frequency of congenital anomaly. Those who know the term "prenatal diagnosis" comprised 58\% in medical students, and $24 \%$ in businessman. Its main source of information is television ; $43 \%$ in businessman. The reaction to carry a deleterious gene by oneself is shocked comprised $98 \%$ in businessman, $87 \%$ in medical students. In summary, the interest and knowledge of general public in heredity was rather low. The more time is needed for the education of genetic medicine at medical school and the general public.

\section{W 4-A 23}

Public perceptions of genetic counseling.

Makiko Osawa, (Dept of Pediatrics, Tokyo Women's Medical College)

Questionnaires were distributed to non-medical persons to ascertain the general public's view of genetic counseling(GC). Among 907 respond ents, $62 \%$ (all art students) had never heard of GC but $38 \%$ (41\% patient family members, 58\% art students) had, at some point, had inheritancerelated concerns. Ninety-four \% indicated the importance of helping individuals/couples cope with genetic problems as a goal of GC. As to the role of genetic counselors, $93 \%$ answered that support and understanding of medical facts are important, $95 \%$ that support for acceptance and disease countermeasures are important. As for appropriate behavior patterns of a genetic counselor, $92 \% \mathrm{felt}$ letting clients know the counselor is prepared to support selfdetermination was important. At the same time,giving practical advice on what the client should do was considered very important by $31 \%$ and somewhat important by $33 \%$, i.e. $64 \%$ felt this was an appropriate counselor attitude. Seventy-two \% indicated that GC with detailed gene analysis is necessary, though $23 \%$ were not sure and $4 \%$ gave negative responses. As to GC content, more than 56\% thought that gene analysis for patients and carriers, as well as prenatal diagnosis, were necessary. But few thought that discussing artificial fertilization, to prevent sex-linked disease, or adoption, as an alternative to having one's own children, were necessary in GC. 
Luncheon and Evening Seminars

\author{
N 1-B 6 \\ HUMAN BEHAVIORAL GENETICS AND TWIN METHOD. Juko ANDO ( Dept. Education, Faculty \\ of Letters, Keio Univ., Tokyo )
}

Human behavioral genetics is an interdiciplinary field between differential psychology and quantitative genetics, which aims at assessing comparative contributions of heredity and environment to individual differences of psychological characteristics, such as cognition, personality and psychopathology, through developmental processes. Large-scale longitudinal twin and adoption studies, as well as the research of twins reared apart, are being conducted, and, especially from the developmental point of view, several new findings are being made. "Heredity" does not mean "constancy", but sometimes regulates developmental changes of IQ and temperament. It does not mean "phenotypical succession" either, because non-additive genetic effects (or "emergenesis") have been shown in personality, schizophrenia, EEG, interest, talent and so on. An example of interaction between estinated genotype and environment, which was shown in cotwin controlled educational experiment, was presented, and a flexible structure model hypothesis was introduced.

\title{
N 2-C 6
}

TOWN GENETICIST-_-clinical dysmorphology from the view point of a radiologist

Gen Nishimura M.D. Department of Radiology, Shimizu City Hospital, Shmizu, Japan

Town geneticist is a word described by Dr. Toriello in Butterworth Hospital to designate her unique career which was started as a clinic coordinator in an non-academic hospital. Dr. Nagai and I have been engaged in the general medical services. In our professional life we have had a lot of opportunities to see handicapped children with birth defects. Naturally we have been involved in the work of clinical dysmorphology and clinical genetic services, so we entitle town geneticists to ourselves. In this lecture I deal with two topics as a radiologist. First the importance of correct diagnosis in birth defects is emphasized. In general there exist a lot of subclassifications in congenital malformations. Someone tends to think that those are jargons of the experts. The subclassifications of disorders, however, are settled to provide adequate medical services and genetic counseling for the patients and affected families, because each disorder has its own prognosis and recurrence risk. Second the concept of family of bone dysplasia is discussed. Family means a group of disorders sharing the common clinical and radiological features which remind us of the common pathogenesis. This idea represents only a logical basis of classical clinical practice. However, recent discoveries of type 2 collagen abnormality in a group of spondyloepiphyseal dydplasia have revealed that this concept would really work to classify bone dysplasias on the basis of the pathogenesis; in other words, that disorders of a same family could be caused by mutation of a same gene or a closely related gene. Furthermore, once mutation of the gene attributed to the disease were discovered, the careful clinical observation might make it possible to demonstrate the biological role of the substances synthesized by the gene. In conclusion the classic clinical skills, which make the correct diagnosis and classify the diseases adequately, permit us not only providing the proper medical services but also contributing to the progress of medical genetics. 


\begin{abstract}
$\mathrm{N} 2-\mathrm{C} 7$
TOWN GENETICIST : MEDICAL GENETICS AND CLINICAL DYSMORPHOLOGY FROM THE VIEW POINT OF A PEDIATRICIAN. TOShiro NAGAI (Dept. Pediatrics., Tokyo Metropolitan Kiyose Children's Hospital., Tokyo)

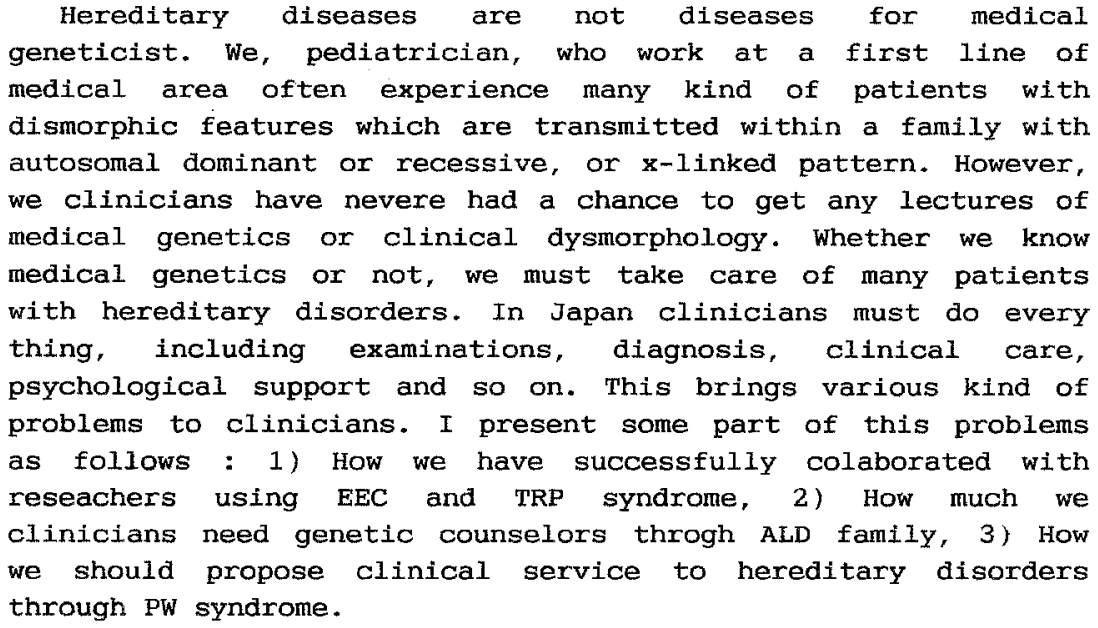

\title{
V 1-B 11
}

Molecular Studies in Lipidosis

Yoshikatsu Eto

Department of Pediatrics,

Tokyo Jikei University School of Medicine

Tokyo, Japan

The mutations in Japanese patients with metachromatic leukodystrophy(MLD) and Gaucher disease has been presented in detail. MLD is characterized by an accumulation of sulfatide in nervous tissues and kidney due to a deficiency of arylsulfatase A(ASA), Three known mutations in ASA gene have analyzed in 10 patients with MLD. Among 10 patients with Japanese MLD, we found alleles 445A mutation has moderately high incidence and also this homozygocity of this mutation. results in the late infantile form. Allele $2381 \mathrm{~T}$ was not found in Japanese MLD. Novel mutations, $1070 \mathrm{~A}$ and also three other missense mutations were identified in Japanese patients with late infantile and juvenile form of MLD. These mutations in Japanese MLD were different from those of Caucasian patients. On the other hand, we also present gene analysis of glucocerebrosidase in 15 Japanese patients with Gaucher disease. Most frequent mutations among them was the $6433 \mathrm{C}$ mutation, $40 \%$ of 30 chromosomes, whereas the novel mutation of the 3548A found in Japanese patients with neuronopathic Gaucher disease was found in $20 \%$. The characteristics of these mutations in Japanese patients with Gaucher disease is different from those of Caucasian population. 


\section{1-B 12}

THE CURRENT MOLECULAR STUDIES ON PEROXISOMAL DISORDERS Nobuyuki SHIMOZAWA (Dept. of Pediatrics, Gifu University School of Medicine)

Inherited metabolic diseases involving impairment of peroxisomal functions have been categorized into three subgroups: (1)Multiple metabolic disturbances and the absence of peroxisomes; (2)Various biochemical abnormalities and present peroxisomes; (3)Single enzyme deficiency. Peroxisome-deficient disorders included ten complementation groups, and the primary defect in one group (F) were clarified. The molecular defect of Japanese-type acatalasemia was a splicing mutation of human catalase gene. Mistargeting of peroxisomal L-alanine: glyoxylate aminotransferase to mitochondria in primary hyperoxaluria patients depends upon activation of a cryptic mitochondrial targeting sequence by a point mutation. A putative adrenoleukodystrophy gene was identified using positional cloning, and belonged to the ATP-binding cassette transporter protein superfamily.

\section{1-B 13}

Molecular genetics of methylmalonic acidemia and medium chain acyl $\mathrm{CoA}$ dehydrogenase(MCAD) deficiency Kuniaki Narisawa (Dept.Biochemical Genetics, Tohoku Univ.Sch.Med., Sendai)

Methylmalonic acidemia is an inborn error of organic acid metabolism caused by a functional deficiency of methylmalonyl CoA mutase (MCM). Molecular analysis of MCM deficiency among Caucasian and Japanese patients has revieled several mutations. These studies identified decreased amounts of MCM mRNA as well as various point mutations. We present here the identification of a novel nonsense mutation causing the instability of mRNA in a Japanese patient. This mutaion was found in 6 of 16 mutant alleles tested, suggesting that it might be a prevalent MCM mutation among Japanese patients.

MCAD deficiency is an inborn error of fatty acid metabolism which is known to cause Rey-like symdrome in children and sudden infant death. We identified Lys ${ }^{329}$-to-Glu substitution (K329E)in the MCAD gene as the most common cause of MCAD deficiency. The mutation was found to be responsible for 90\% of mutant MCAD alleles among Caucasians. In order to estimate the prevalence of the K329E mutation, we examined 1368 newborns in U.K., Australia, and U.S.A. using dried blood spots. For the three countries, the K329E carrir frequency is $1: 62$, and the incidence of homozygotes for this allele would be predicted to be 1 in 15,000 . Our simple DNA diagnostic method to detect the predominant MCAD mutation using Guthrie cards makes it feasible to consider the possibility of screening for this potentially fatal disorder. 


\section{2-C 12}

SEGREGATION ANALYSIS OF REARRANGED CHROMOSOMES USING EXPERIMENTAL MAMMALS. Shin-ichi SONTA (Dept. Genet., Inst. Develop. Res., Aichi Pref. Colony, Kasugai)

In the field of human reproduction, studies on cytogenetic problems have been based upon chromosomal data obtained from live-born children, aborted fetuses and gametes (especially sperm). However, only limited information is available from such materials. In experimental mammals, on the other hand, one can investigate directly chromosomes of meiotic cells and those of embryos at various stages from fertilization to early embryogenesis, which are almost impossible to observe directly in humans. Using Chinese hamsters with various chromosomal rearrangements which are similar to those seen in humans, the meiotic segregation, crossing-over and interchromosomal effects have been investigated in our laboratory. The results of chromosome analysis indicated that (1) chromosomally unbalanced gametes occurred usually at a high incidence by segregation from quadrivalents, (2) outward segregation ratios might influence by meiotic crossing-over, and (3) no interchromosomal effect was induced by the existence of reciprocal translocations and inversions. Problems in the field of meiosis, such as segregation, crossingover and interchromosomal effects, are discussed in comparison with other data obtained from investigation in humans and other experimental mammals.

\section{2-C 13}

\section{GENE TAGGING AS A TOOL IN MOLECULAR EMBRYOLOGY}

Ken-ichi Yamamura (Institute of Molecular Embryology and Genetics, Kumamoto University School of Medicine)

A strategy to monitor transcriptionally active regions of the genome was first described in bacteria in 1979. It involves the introduction of reporter constructs into the genome that require the acquisition of cis-acting DNA sequences to activate reporter gene expression. This approach has been applied more recently in higher organisms using modified vectors suitable for eikiaryotic transcription units. In the mouse unknown genes have been identified by insertional mutation in transgenic mice generated by retroviral infection or DNA microinjection. However, this approach is laborious and time-consuming. Through the use of embryonic stem (ES) cells, the enhancer traps as well as the gene trap are now possible in the mouse. Using the gene trap method, we demonstrated that new genes were identified in about $60 \%$ ES trap clones, and that the $3^{\prime}$ region of flanking mouse genome was either deleted or rearranged by insertion event. 


\section{2-C 14}

MOLECULAR BASIS OF A GENETIC DISEASE: ANALYSIS BY THE USE OF MICE CARRYING A TARGETED MUTATION. Shuichiro MAEDA (Dept. Biochem., Yamanashi Med. Univ., Yamanashi), Kiyoshi TAKAHASHI (Dept. Pathol., Kumamoto Univ. Sch. Med., Kumamoto), Ken-ichi YAMAMURA (Inst. Mol. Embryol. Genet., Kumamoto Univ. Sch. Med., Kumamoto) and Kazunori SHIMADA (Dept. Med. Genet., Res. Inst. Microbial Diseases, Osaka Univ., Osaka)

Familial amyloidotic polyneuropathy (FAP) is an autosomal dominant genetic disease caused by a point mutation in the transthyretin (ttr) gene. In the transgenic mice carrying the human mutant ttr gene, human TTR was deposited as amyloid fibrils in various tissues. Thus this transgenic mouse model of FAP can be used to elucidate the mechanism of amyloid deposition in FAP. These transgenic mice, however, do not develop peripheral neuropathy, which is the most prominent symptom of FAP. To elucidate the physiological function of TTR and the etiology of peripheral neuropathy in FAP, we have generated a unique strain of mice carrying a null mutation at the ttr locus by gene targeting. The levels of serum retinol, retinol-binding protein and thyroid hormone of the TTR-deficient mice were significantly depressed. We have used the TTR-deficient mice as recipients of the human mutant ttr gene. In the TTR-deficient mice carrying the human mutant ttr gene, amyloid began to deposit at the age of 11 months. These transgenic mice should be useful in elucidating the function of the human variant TTR and its role in the pathogenesis of FAP. 


\section{General Contribution}

\section{A-12}

LOCALIZATION OF A GENE FOR FUKUYAMA TYPE CONGENTTAL MUSCULAR DYSTROPHY TO CHROMOSOME 9q31-33. Tatsushi TODA1,2, IChiro KANAZAWA $^{2}$ and Yusuke NAKAMURA ${ }^{1}$ ('Dept. Biochem., Cancér Inst., Tokyo, ${ }^{2}$ Dept. Neurol., Tokyo univ., Tokyo)

Fukuyama type congenital muscular dystrophy (FCMD), which is the second most common form of childhood muscular dystrophy in Japan, is an autosomal recessive severe muscular dystrophy associated with an anomaly of the brain. Twenty-one FCMD families, 13 of them with consanguineous marriages, were analyzed by genetic linkage analyses with polymorphic microsatellite markers to map the FCMD gene. Significant lod scores were obtained with the markers D9S58 $\left(\mathrm{z}_{\max }=5.81\right.$ at $\theta=0.06)$, D9S59 $\left(\mathrm{Z}_{\max }=4.33\right.$ at $\left.\theta=0.02\right)$, and $H X B \quad\left(\mathrm{z}_{\max }=3.28\right.$ at $\theta=0.09$ ) on chromosome 9q31-33. Multipoint analysis placed FCND between D9S58 and D9S59, with a maximum lod score of 16.93 . These markers will be useful for presymptomatic, prenatal, and carrier diagnosis of family members carrying FCMD, and they represent important resources for the identification of a gene responsible for FCMD.

\section{1-D 1}

Locus-in and GeneView: NEW MAPPING DATABASE SYSTEMS WITH EXCELLENT USER INTERFACE FOR INTEGRATION AND FAST SEARCH. $\underline{S h i n s e i ~ M I N O S H I M A ~}^{1}$, Susumu MITSUYAMA ${ }^{1}$, Hiroshi DOHI ${ }^{2}$, Mitsuru ISHIZUKA $^{2}$ and Nobuyoshi SHIMIZU ${ }^{1}$ ( ${ }^{1}$ Department of Molecular Biology, Keio University School of Medicine, ${ }^{2}$ Faculty of Engineering, University of Tokyo, Tokyo)

Ever increasing mapping data are being compiled into a GDB (Genome Data Base) with the aid of numerous chromosome editors. The GDB is a character-based relational database constructed with Sybase and has been making significant contributions to the genome project. To facilitate more efficient use of the GDB, it is necessary to employ graphics to display maps and to simplify the user interface. We have constructed two prototype database systems, GeneView and Locus-in, which operate on a workstation with $\mathrm{X}$ - Window and have a smooth graphical user interface.

GeneView is a fast search system for gene mapping data. It offers the following features: (1) extremely fast access to data; (2) graphic display of chromosome idiograms giving a key and the results of a search; (3) bilingual operation in Japanese and English. Locus-in is a graphical system for entry and integration of raw mapping data. Locus-in has the following unique functions: (1) To zoom-in on a specific region of interest; (2) to generate a number of sub-windows associated with a specific region for entry and display of data (each sub-window accepts either ordered or not-ordered and either raw or published data); (3) to create new breakpoints. 
1-D 2

Construction of a human monochromosomal YAC library from human-rodent hybrid cells. Shigeo NAGAFUCHI, Takayuki TAKEDA and Masao YAMADA (Dept. Genet., NatI. Children's Med. Res. Ctr., Tokyo)

Human monochromosomal YAC libraries from human-rodent hybrid cells have been proved more useful resources for the human genome research than total human genomic YAC libraries. Because the rate of chimeric clones between human DNA is lower and the effort of screening the library is smaller. We have tried constructing a human chromosome 1-specific YAC library from human-mouse hybrid cell line A9Neo-4 (provided by Prof. M. Oshimura, Tottori University) by a similar method used in our previous experiment constructing a human chromosome 11 YAC library (Genomics 16: 580, 1993). We have obtained more than one thousand of transformants. The average insert length of transformants was estimated $350 \mathrm{~kb}$ by pulsed field gel electrophoresis. To date, however, most YAC clones have only the mouse genome and only a small number of YAC clones purely carry human DNA. The main reason for this finding may be a relatively low content of the human DNA in the original cells because of hyperploidy of the mouse genome. We are constructing another YAC library from subclones of the same cell line containing relatively high ratio of human DNA.

\section{1-D 3}

PHAGE/COSMID CLONES, POLYMORPHIC MARKERS AND STSS FROM MICRODISSECTED CHROMOSOMAL REGIONS.

Naomichi MATSUMOTO, Tatsuya KISHINO, Hidenobu SOEJIMA Rumiko KATO, Hiroshi SASAKI, Yoshihiro JINNO, Norio NIIKAWA (Dept. Hum. Genet., Nagasaki Univ. Sch. Med.), Tetsuro MIKI (Dept. Geriat Med., Osaka Univ. Sch. Med.), Naohiko SEKI (Div. Genet., Natl. Inst. Rad. Sci., Chiba), Shuichi IGARASHI, Shoji TSUJI (Dept. Neurol. Niigata Univ. Brain Res. Inst.)

We isolated corresponding phage/cosmid clones with/without polymorphisms and mapped to appropriate regions (Table).

\begin{tabular}{lrlllll} 
A & B & C & D & E & F & G \\
\hline $2 q 33-q t e r$ & 15 & $8(p)$ & 4 & FI & - & $2(R)$ \\
$8 p 22-p 11$ & - & 1 & 7 & H/L & - & $24(\mathrm{CA})$ \\
$8 q 23-q 24$ & 12 & 1 (p) & 1 & Del & - & - \\
$10 q 11-q 21$ & 43 & $2(c)$ & 24 & FI & - & $16(R)$ \\
$11 q 14-q 22$ & 33 & 5 (c) & 3 & FI & 29 & - \\
$11 q 23$ & 21 & $4(c)$ & 4 & FI & 10 & - \\
$11 q 23-q t e r$ & 44 & $5(c)$ & 2 & FI & 21 & - \\
$14 q 24-q 32.3$ & 277 & - & - & - & 5 & - \\
$15 q 11-q 13$ & 26 & $66(c)$ & 47 & FI & 12 & $6(\mathrm{CA})$ \\
- & & & & & &
\end{tabular}

A, dissected regions; B, no. of microclones; $\mathrm{C}$, no. of phages (p); cosmids (c); D, no. of cosmids mapped; $\mathrm{E}$, mapping method (F, FISH; H, hybrid cell panel, L, linkage; Del, deletion); $F$, no. of STSs; G, no. of polymorphic markers ( $R$, RFLP; CA, CA repeats; V, VNTR) 


\section{1-D 4}

CHROMOSOME MAPPING OF THE NERVOUS SYSTEM-SPECIFIC GENES AND IDENTIFICATION OF THE GENES RESPONSIBLE FOR THE HEREDITARY NEURAL DISEASE.

Shinsei MINOSHIMA, Yimin WANG, Mizuho TAKATA and Nobuyoshi SHIMIZU (Department of Molecular Biology, Keio University School of Medicine)

In the nervous system, a number of nervous type and developmental stagespecific genes are known to be expressed. We have recently mapped more than 30 human genes by a combination of spot-blot hybridization to flow-sorted chromosomes and fluorescence in situ hybridization. These include following 4 nervous systemspecific genes: glial fibrillary acidic protein (GFAP: chromosome 17), brain specific $\mathrm{S} 100$ protein $\alpha$ subunit (S100A: 1), $\beta$ subunit of the S100 (S100B: 21), brain-specific tyrosine, tryptophan-hydroxylase activator (YWHA: 22). In addition, we determined the localization of 4 more neuron-specific genes. These genes are listed below in the format: gene name, (gene symbol), [region] and <collaborators $>$.

1) Myelin P0 protein (MPZ) [1q22-q23] <K. Hayasaka et al.> 2) Myelin P2 protein (MP2) [8] <K. Hayasaka et al.> 3) Brain specific protein, drebrin (DRB) [5] $<$ M. Toda, T. Shirao, K. Uyemura et al.> 4) Myelin-associated 2', 3'-cyclic nucleotide 3'phosphohydrolase (CNP) [17] <Y. Takahashi, T. Kumanishi et al.>

Since MPZ was mapped to the same region as hereditary Charcot-Marie-Tooth type 1B (CMT-1B), we predicted the possibility that MPZ gene is responsible for the disease. This prediction was proved by the recent finding of the point mutations in the myelin $\mathrm{PO}$ genes of CMT-1B patients.

\section{1-D 5}

ISOLATION AND MAPPING OF 199 NEW DNA MARKERS ON HUMAN

CHROMOSOME 1. Hiroyuki KUGOH, Yuzuki NAKAGAWA, Kohzoh MITSUYA,

Tetsuo MITA, Mikio SUZUKI, Noriyuki SUZUKI, Hiroshi UEJIMA, Yoshihiro YUASA and Mitsuo OSHIMURA (Dept. of Mol. \& Cell Genet., Sch. of Life Sci., Faculty of Med., Tottori Univ.)

In order to obtain DNA markers on human chromosome 1, we first isolated 500 cosmid clones from mouse A9 cells containing a human chromosome 1 tagged with the pSV2neo. Of these, 199 were localized on each band on human chromosome 1 by the R-banding fluorescent in situ hybridization method (FISH); 129 on the short arm and 70 on the long arm. We performed RFLP analysis in these cosmid clones and in 45 of them, polymorphism were recognized with one or plural enzyme. Since several tumor supperssor genes and genes responsible for hereditary disorders have been suggested to exsit on this human chromosome, the DNA markers will be useful for RFLP analysis or isolation of new genes related to various disorders. 
A PHYSICAL MAP OF 26 LOCI OF COSMID MARKERS ON HUMAN CHROMOSOME 3p23-p21.3 BY MULTI-COLOR FLUORESCENT IN SITU HYBRIDIZATION.

Takeshi ARIYAMA ${ }^{1,2}$, Johji INAZAWA ${ }^{1}$, Kazuhiro YAMAKAWA ${ }^{3}$, Atsushi HORIUCHI $^{2}$, Yusuke NAKAMURA ${ }^{3}$, and Tatsuo $\mathrm{ABE}^{1}$

${ }^{1}$ Dept. of Hyg., Kyoto Pref. Univ. Med., Kyoto.

${ }^{2}$ Third Dept. of Internal Med., Kinki Univ., Med., Osaka.

${ }^{3}$ Dept. of Biochem., Cancer Inst. Tokyo.

In order to construct the fine cytogenetic map of the region of chromosome 3p23p21.3, we tried to physically order 26 cosmids markers (CI3) by two-color competitive fluorescent in situ hybridization (FISH) using prophase chromosomes. A pair of two cosmids was labeled with biotin and digoxigenin, respectively, and both signals were examined simultaneously on prophase chromosomes throuh a dual band-pass filter. The order of 26 cosmid markers could be determined as follows : 3cen-604-792-769-3829-810-785-940-470-533-917-771-848-524/708-401-717-878-911-718-1195-515905-818-872-245-ptel. Pulsed-field gel analysis of two cosmids of 524 and 708 provided that these two cosmids were overlapped. We could perform the preparation of the anchorpoints at intervals of about $1.0 \mathrm{Mb}$ on $3 \mathrm{p} 23-\mathrm{p} 21.3$. The fine cytogenetic map of 3p23-p21.3 constructed in the present study should provide an useful information in positional cloning of putative tumor suppressor genes responsible for renal cell carcinoma, lung carcinoma, and several other types of tumors.

\section{1-D 7}

ASSINMENT OF THE HUMAN $P A X 4$ TO CHROMOSOME $7 Q 32$ B Y FLUORESCENCE IN SITU HYBRIDIZATION.

Yoshinori IZUMIKAWA ${ }^{1,2}$, Toshiya TAMURA ${ }^{1,3}$, Tatyuya KISHINO ${ }^{1}$, Hidenobu $\underline{\text { SOEJIMA }}^{1}$, Yoshihiro $\underline{\text { INNO }}^{1}$, Norio NIIKAWA ${ }^{1}$

${ }^{1}$ Department of Human Genetics, Nagasaki University School of Medicine, ${ }^{2}$ Department of Pediatrics, University of the Ryukyus School of Medicine,

${ }^{3}$ Department of Child Development, Kumamoto University School of Medicine

Among nine members of a human paired box-containing gene family (PAX), precise localization of PAX4 has not yet been determined. We screened a cosmid library of human genomic DNA using polymerase chain reaction products for $P A X 4$ as a probe and isolated three positive cosmid clones. Sequence analysis revealed that at least two of them had exon-like sequences, and showed extensive homology to the mouse Pax4. These two cosmid clones were mapped to human chromosome $7 \mathfrak{q} 32$ by fluorescence in situ hybridization. 


\section{1-D 8}

ISOLATION AND MAPPING OF 111 COSMID CLONES ON 8 LOCI IN HUMAN CHROMOSOME $8 \mathrm{p} 12 \rightarrow \mathrm{q} 11.1$.

Akihiro KURIMASA, Norivuki SUZUKI, Mitsuo OSHIMURA

(Dept. of Mol. \& Cell Genet., Faculty of Med., Tottori Univ., Tottori)

Microcells which were isolated from mouse A9 cells containing a pSV2neotagged human chromosome 8 were fused with SV40 transformed mouse SCID fibroblasts (SCVA), and 70 microcell-hybrids were isolated following selection with the G418 antibiotics. Southern blot analyses revealed that 14 microcell-hybrids containing various regions of the transferred chromosome were formed during the microcell-fusion process.

A microcell-hybrid, $S C(-8)-10$, which retained a $8 \mathrm{p} 12 \rightarrow q 11.1$ region was used for constructing a human cosmid library, and a total of 111 cosmid clones was isolated. These cosmid clones were sublocalized to 8 different loci in the $8 \mathrm{p} 12 \rightarrow \mathrm{q} 11.1$ region using microcell-hybrid panel; Werner syndrome gene and the DNA-repair gene that can complement the mouse SCID mutation have been mapped to 2 of these loci.

Thus, these microcell-hybrids and cosmid clones are useful materials for positional cloning of important genes on $8 \mathrm{p} 12 \rightarrow \mathrm{q} 11.1$.

\section{1-D 9}

ISOLATION OF MICROSATELLITES FROM A LIBRARY MICRODISSECTED FROM THE WERNER'S SYNDROME REGION,8p11.2-p22. Lin YE, Jun NAKURA, Koichi KIHARA, Noriaki MITSUDA, Keiko NAGANO, Kouzin KAMINO, Toru OHTA*, Yoshihiro JINNO*, Norio NIIKAWA*, Tetsuro MIKI, Toshio OGIHARA (Dpt.Geriat. Med., Osaka Univ. Med. Sch. Osaka, *Dpt. Hum. Genet., Nagasaki Univ. Sch. Med., Nagasaki)

We have constructed a new genetic linkage map of the Werner's syndrome (WRN) region, using 7 (CA)n polymorphic microsatellites isolated from a microdissection library which has been recently developed by chromosome microdissection and enzymatic amplification method. From a total of 160 sequenced clones hybridized with (CA)n repeat probe, 104 had more than 10 (CA)n repeats. The remaining 56 clones were discarded because of unreliable sequences or misplaced microsatellites. Out of 104 clones, 46 were independent from each other because 58 clones were isolated more than twice. Primer pairs were synthesized for the 30 clones and 16 clones were discarded for the reason of primer sequences not found. Finally, we have isolated 24 polymorphic clones with (CA)n repeat sequence. These microsatellites were used to genotype the members of CEPH families. Two-point analysis was used to assign 7 markers relative to each markers and other markers reported in the CEPH public data base. Such microsatellites microdissected from the definite chromosome region would be useful for positional cloning. 


\section{1-D 10}

FLUORESCENCE IN SITU HYBRIDIZATION ANALYSIS OF CHROMOSOMAL LOCALIZATION OF THREE HUMAN CYTOCHROME P450 2C GENES (CYP2C8, 2C9, and 2C10) AT 10q24.1

Kiyoshi INOUE, Yasuhiko SUZUKI, Tsutomu SHIMADA, Hiroshi YAMAZAKI (Osaka Pref. Inst. Public Health, Osaka),

Johii INAZAWA, and Tatsuo ABE (Dept. Hygiene, Kyoto Pref. Univ. Med. , Kyoto )

Chromosomal localization of three human cytochrome $\mathrm{P} 450$ genes belonging to the CYP2C subfamily (CYP2C8, 2C9, and 2C10) was identified by fluorescence in situ hybridization (FISH) on R-banded human prometaphase chromosomes using PCR products subcloned into the pBluescriptIIKS $(+)$ vector as a probe. An original MP-8 clone was used as a DNA probe for the assignment of the CYP2C10 gene, while two cDNA probes, a $1.37 \mathrm{~kb}$ fragment of CYP2C8 and a $1.19 \mathrm{~kb}$ fragment of CYP2C9, were obtained after amplifying the predicted fragments (MP-20 and MP-4 clones, respectively) by $\mathrm{PCR}$ using a single human liver cDNA library. Of the signals examined for CYP2C8 clone, we observed the following chromosomal localizations at: $10 \mathrm{q} 23.3,8.7 \% ; 10 \mathrm{q} 24.1,82.6 \%$; and $10 \mathrm{q} 24.2,8.7 \%$. For the CYP2C9 clone, the signals were observed at: $10 \mathrm{q} 24.1,86.0 \% ; 10 \mathrm{q} 24.2,6.0 \%$; and $10 \mathrm{q} 24.3,8.0 \%$, and for the CYP2C10 clone, the signals were observed at: $10 \mathrm{q} 23.3,4.5 \% ; 10 \mathrm{q} 24.1,72.7$ $\% ; 10 \mathrm{q} 24.2,18.2 \%$; and $10 \mathrm{q} 24.3,4.5 \%$. Thus, the present results show that three human CYP2C8, CYP2C9, and CYP2C10 cDNAs were located at the same subchromosomal region, 10q24.1.

\section{1-D 11}

ISOLATION AND MAPPING OF YAC CLONES FROM THE q23 REGION OF THE HUMAN CHROMOSOME 11. Naohiko SEKI (Kazusa DNA Res. Inst.), Masatake YAMAUCHI, Toshiuki SAITO, Yoshi-nobu HARADA and Tada-aki HORI (Div. Genet., Natl. Inst. Radiol. Sci.)

A human genomic DNA library has been constructed by using a microdissection-microcloning method with polymerase chain reaction (PCR) techniques on DNA from the chromosome 1 lq23 region. A total of 450 recombinant microclones were isolated and their insert sizes ranged from 150 to $850 \mathrm{bp}$. Forty-two percent of them gave a unique (single-copy) positive signal in the Southern blot analysis with total human DNA and somatic cell hybrid DNA containing only a human chromosome 11 . The chromosomal location of these genomic clones were confirmed to be in q23 region of chromosome 11 by fluorescence in situ hybridization. (Seki et al., Genomics 16, 169172, 1993). Each sequence tag site (STS) designed for the unique microclones was used for PCRscreening of genomic DNA library constructed with yeast artificial chromosome (YAC). At present, twelve unique clones were desinged for STSs and thirteen YAC clones were isolated. These chromosomal region-specific genomic clones will be useful in the construction of physical contig map and also in the positional cloning of disease-related genes localized to the q23 region of chromosome 11 . 


\section{1-D 12}

IS OLATION AND MAPPING OF REGION SPECIFIC COSMID CLONES ON THE HUMAN CHROMOSOME 11q23 Motonobu KATOH, Yuzuki NAKAGAWA, Izumi HORIKAWA, Akihiro KURIMASA, Hiroyuki KUGOH, Mo toyuki SHIMIZU and Mitso OSHIMURA (Dept. of Mol. \& Cell Genet., Sch. of Life Sci., Faculty of Med., Tottori Univ., Yonago)

Cosmid clones containing DNA fragments from the $11 \mathrm{q} 23$ were isolated using radiation-reduced hybrids( $\mathrm{RH})$. Sixty $\mathrm{RHs}$ were isolated from a microcell hybrid containing human chromosome 11 tagged with pS V2neo at p11.2. Southern hybridization with Alu-DNA probe and Alu-primed PCR were performed to es timate the amount of human DNA in each RH. A set of 15 hybrids which contain different amount of human DNA were selected with an aim on preparing a hybrid panel to localize cosmid clones on chromosome 11. The presence or absence of fragments from the chromosome 11 in each RHs were examined by Southern hybridization with 28 known markers.

Of the $15 \mathrm{RHs}$, a hybrid $232 \mathrm{~A}$ was revealed to retain a $11 \mathrm{q} 23$ region in addition to the neo-tagged region. Chromosomal in situ hybridization revealed that the human chromosome fragments were inserted into a mouse chromosome in most of metaphases analyzed. Ninety-eight cos mid clones were isolated from the RH232A and mapped using the RH panel. Sixty-eight of 97 cosmids were mapped to the $11 \mathrm{q} 23$, and the remaining 29 were mapped to the region including $11 \mathrm{p} 11.2$. Three cosmids that were randomly selected were, in fact, mapped to the $11 \mathrm{q} 23$ by FISH. These new cosmid probes will serve resources to make a contig and isolate disease-associated genes on the 11q23 region.

\section{1-D 13}

DIRECT COMPARISON OF DNA BETWEEN GIEMSA DARK- AND LIGHT-BANDS OF HUMAN CHROMOSOME 11 BY MICRODISSECTION-MICROCLONING AND SEQUENCE ANALYSIS, AND THEIR DERIVED SEQUENCE-TAGGED-SITES. Hidenobu SOEJIMA, Koh-ichiro YOSHIURA Toshiva TAMURA Yoshihiro JINNO, Norio NIIKAWA (Dept. Hum. Genet., Nagasaki Univ., Nagasaki), Takashi TOKINO, Yusuke NAKAMURA (Dept. Biochem., Cancer Institute, Tokyo)

In order to know molecular basis of differentiation between Giemsa dark- and light-bands of human chromosome, 11q14-q22 (G-band) and 11q23-q25 (R-band) regions were microdissected, and their DNAs were amplified with the primer-linker PCR method and cloned into pUC19. Microclones from each library were compared regarding the proportion of single-copy and Alu/Kpn-I repetitive sequences, and GC content, by means of colony hybridization, Southern hybridization, and sequencing. Among G-band microclones, 43\% were single-copy sequences and $23.2 \%$ highly repetitive sequences, while in the R-band library, $54.2 \%$ and $20.3 \%$ were single-copy and repetitive elements, respectively. Although no statistically significant difference was observed in the proportion of Alu-repeats between G- and R-band libraries, Kpn-I sequences were significantly rich (4.1\%) in the G-band library. Sequence analysis revealed no significant difference in GC content and in a ratio of $\mathrm{CpG}$ sequence to GpC dinucleotide between the two bands. The present study provided direct evidence on the molecular construction between G- and R-bands of human chromosome. Using primer pairs designed according to the sequences of the single-copy microclones, DNAs from 5 human-mouse hybrid cells containing human chromosome 11 with various deletions of its long arm were PCR-amplified. Consequently, 50 of 67 microclones were mapped at five different regions ranging 11q13.4-q25. These 50 sequence-tagged-sites (STSs) are useful for human genome analysis. 


\section{1-D 14}

LOCALIZATION OF THE HUMAN COLLECTING DUCT WATER CHANNEL GENE TO CHROMOSOME REGION 12q13.11-q13.12 BY FLUORESCENCE IN SITU HYBRIDIZATION. Fumiko SAIT0 ${ }^{1}$, Sei SASAKI $^{2}$, Kiyohide FUSHIMI ${ }^{2}$, Fumiaki MARUMO ${ }^{2}$, Tatsuro IKEUCHI ${ }^{1}{ }^{1}{ }^{1}$ Dept. Cytogenet. Med. Res. Inst. , ${ }^{2}$ Dept. Int. Med., Sch. Med., Tokyo Med. Dent. Univ., Tokyo)

Human collecting duct water channel gene (WCH-CD), is related to the waterpermiability of kidney collecting tubule which is regulated with vasopressin, antidiuretic hormone, by its endo- and exo-cytos is from or to the apical membrane. By using the cDNA clone of rat WCH-CD (Fushimi et al., 1993), a 1.5kb human cDNA was isolated which contained $813 \mathrm{bp}$ open reading frame encoding 271 amino-acid protein with $91 \%$ homology to rat WCH-CD, and then a $15 \mathrm{~kb}$ human genomic DNA clone was obtained from human genomic DNA library by using this human CDNA as a probe. We performed a direct chromosome mapping of the gene by fluorescence in situ hybridization. High-resolution R-banded prometaphase chromosomes were prepared from PHA-stimulated lymphocyte cultures by cell synchronization with excess thymidine followed by BrdU incorporation. Identification of hybridization signals was based on the method by Takahashi et al. (1992). As a result, both the genomic and cDNA probes showed fluorescent signals on chromosome 12, q13.11-q13.12. This region is very close to the locus of MIP gene (12 cen-q14) (HGM11, 1991) whose amino-acid sequence is highly homologous to WCH-CD $(59 \%)$.

\section{1-D 15}

ISOLATION AND MAPPING OF COSMID MARKERS DERIVED FROM HUMAN CHROMOSOME 14. Masaharu Isobe, Fuminori Yamagishi, Hitomi Hori, and Konomi Iwaki (Dept. Patho-biochem., Toyama Med. \& Pharma. Univ., Toyama)

A cosmid library has been constructed from the mouse-human hybrid cells GM10479, which contain chromosome 14 as its sole known human component. Three hundred thousand colonies were produced, of which approximately 600 , or $0.2 \%$, contained human material. Each cosmids were regionally mapped by fluorescence in situ hybridization. The signals of 101 markers examined here were localized preferentially to R-positive bands of chromosome 14, particularly distal half of the long arm where major $\mathrm{R}$-bands are exist. To obtain more evenly distributed markers, we have isolated more than 1000 repeat-free clones from chromosome 14-specific flow-sorted library (ATCC 57706). Chromosome painting using a pool of these clones showed even distribution of probes throughout chromosome 14. This results suggested that the mapping of each clones will allow us to obtain the less biased map of chromosome 14 .

Our high-resolution cytogenetic map can facilitate the analysis of chromosomal and molecular aberrations in genetic disease such as Alzheimer's disease and MachadoJoseph disease. 


\section{1-D 16}

HUMAN 18TH CHROMOSOME GENE LIBR ARY AND GENE MAPPING. Hitoshi NAKASHIMA, Takashi IMAMURA(Dept.Hum.Genet., National Institute of Genetics)

For construction of high-resolution physical maps of the genome and characterization of disease-related genes, localization of many large DNA fragments on chromosome will be useful. We report herein the results of mapping 60 new cos mid clones on human 18th chromosome by FISH. A cosmid library was cons tructed from MS126-21 humanrodent hybrid cell line which was established by fusion between GM11010 and FSthy21 using thymidine synthetase as selection marker. The cosmid library was screened with human total DNA and 600 cosmids containing large human DNA inserts were isolated. Of the 200 cosmids thus far anaysed, a total of 60 cosmids have been mapped to metaphase chromosomes by FISH. To map the probes in terms of conventional cytogenetic bands, cosmid clones were hybridized to either R-banded or DAPI-banded metaphase chromosome spreads. We found that some of those cosmids which we were unable to localize on the R-banded metaphase spreads were clearly mapped on the DAPI-banded chromosome preparations. The results suggested that the probe derived from the Gimsa dark bands might well be localized on the DAPI-banded chromos ome spreads, but not on the R-banded chromosomes. These 60 cosmids were screened with oligonucleotide (CA) 20 and four PCR primer pairs were designed for detection of chromosome band specific microsatellites. Thes e cosmids and primers are thought to be useful physical and genetical DNA markers for further gene mapping.

\section{1-D 17}

MOLECULAR CLONING AND CHROMOSOMAL LOCALIZATION OF HUMAN HOLOCARBOXYLASE SYNTHETASE. Yoichi SUZUKI ${ }^{1}$, Yoko AOKI ${ }^{1}$, Yoshinori ISHIDA ${ }^{1}$, Yasushi CHIBA${ }^{2}$, Akihiro IWAMATSU ${ }^{3}$, Kuniaki NARISAWA' (Dept. 'Biochem. Genet. and ${ }^{2}$ Pediatr., Tohoku Univ. School of Medicine, Sendai; ${ }^{3}$ Kirin Brewery Co. Ltd., Central Laboratories of Key Technology, Yokohama)

Holocarboxylase synthetase (HCS) is an enzyme which catalyzes incorporation of biotin into apocarboxylases. Deficiency of HCS is known to cause neonatal form of multiple carboxylase deficiency (NMCD). To facilitate investigation on molecular basis of NMCD, isolation and characterization of cDNA for HCS is essential. We screened $\lambda$ gt10 human liver cDNA library and isolated 12 positive clones with inserts of 2 to $2.5 \mathrm{kbp}$ in size. The isolated cDNAs encoded a protein of 726 amino acids with molecular weight of 80,759 . The protein contained several sequences identical or similar to those of peptides derived from purified bovine liver HCS. The C-terminal region of this protein had $25 \%$ homology with BirA which was reported to act as HCS in E. coli. We expressed the protein using pET3a vector in E. coli. (BL21 strain) and raised antisera against the expressed protein. The antibody precipitated HCS activity in human lymphoblasts. These lines of evidence strongly suggest that the isolated cDNAs encode human HCS. The HCS gene was assigned to chromosome 21 by the analysis with PCR amplification of genomic DNA from human-hamster somatic cell hybrids. 


\section{1-D 18}

REGIONAL MAPPING OF HUMAN CHROMOSOME 21-SPECIFIC P1 CLONES TO CHIMPANZEE AND JAPANESE MACAQUE CHROMOSOMES BY FLUORESCENCE IN SITU HYBRIDIZATION. Fumiko SAITO $^{13}$, JUli SUZUKI ${ }^{2)}$, Hitoshi ICHIKAWA ${ }^{2)}$, Miki OHIRA ${ }^{23}$, Misao OHKI ${ }^{2)}$, Hiroshi TANAHASHI ${ }^{4)}$, Yoshiyuki SARAKI ${ }^{4)}$, Tatsuro IKEUCHI ${ }^{1)}{ }^{(1)}$ Med. Res. Inst., Tokyo Med Dent. Univ., ${ }^{2)}$ Primate Res. Inst., Kyoto Univ., ${ }^{3)}$ Saitama Cancer Ctr. Res. Inst. 4) Inst. Med. Sci., Tokyo Univ.)

Based on the studies of comparative banding, gene mapping, and recently, of painting with a human chromosome-specific DNA library, human chromosome \#21 shows homology with chromosome \#22 in great apes and with a half distal part of the short arm of \#2 in macaques. In order to understand more detailed chromosomal organization including very limited structural changes which might have occurred during evolution, we performed direct R-banding fluorescence in situ hybridization (FISH) on primate chromosomes using P1 phage clones originated from NotI-linking clones whose complete restriction mapp was made through the entire human \#21q (Ichikawa et al.,'93). So far, 16 P1 clones of human \#21q have been mapped to the homologous regions of chimpanzee \#22 and 18 clones to macaque \#2p. There was no evidence of minor rearrangements such as inversion in either of the two species, compared with the results of P1 clone mapping on human \#21. Of interest was the finding that the resulting order of $\mathrm{P} 1$ clones in macaque was in the opposite direction to that expected from the banding pattern.

\section{1-D 19}

EVALUATION OF THE CORRESPONDENCE BETWEEN THE NOTI RESTRICTION MAP AND CYTOGENETIC BANDING PROFILES ON HUMAN CHROMOSOME 21q, WITH SPECIAL REFERENCE TO THE DNA STRAND PACKING RATIO IN G- AND R-BAND REGIONS. Tatsuro IKEUCHI, Fumiko SAIT0, Mitsuaki A. YOSHIDA, Akihiro SHISHIKURA (Div. Genet., Med. Res. Inst., Tokyo Med. Dent. Univ., Tokyo), Hiroshi TANAHASHI, Yoshiyuki SAKAKI (Inst. Med. Sci., Univ. Tokyo, Tokyo), Hitoshi ICHIKAWA, Misao OHKI (Saitama Cancer Ctr. Res. Inst., Saitama)

By means of the FISH technique, we performed high-resolution chromosome mapping of 16 NotI- or SfiI-linking clones of the human chromosome 21q, and of $31 \mathrm{P} 1$ phage clones isolated using the NotI-linking clones. Highresolution $\mathrm{R}$-banded chromosomes were obtained from lymphocyte cultures by cell synchronization and subsequent BrdU and ethidium bromide treatments. The distribution pattern of the mapped clones was compatible with the order of clones in the NotI restriction map (Ichikawa et al., 1993), and the high density regions of NotI sites fairly corresponded to the R-band positive subbands. Based on the known physical distances between the clones in the map, identification of the clones at the boundaries of $R$ and $G$ bands enabled us to roughly estimate the packing ratio of DNA molecules in the given bands. Unexpectedly, there was no significant difference in the packing ratios between the $R$ (21q21) and $G$ (21q22) band regions. 


\section{1-D 20}

SYSTEMATIC ISOLATION OF COSMID CLONES FROM THE DOWN SYNDROME REGION OF HUMAN CHROMOSOME 21. Jun KUDOH $^{1}$, Susumu TSUJIMOTO ${ }^{1}$, $\underline{\text { Shinsei MINOSHIMA }}^{1}$, Yimin WANG $^{1}$, Eiichi SOEDA ${ }^{2}$, Ilya CHUMAKOV $^{3}$, Daniel COHEN $^{3}$, and Nobuyoshi SHIMIZU ${ }^{1}$. ('Dept. Mol. Biol., Keio Univ. Sch. Med., Tokyo, ${ }^{2}$ Tsukuba Life Sci. Center, RIKEN, Tsukuba, ${ }^{3} \mathrm{CEPH}$, Paris)

We have constructed a cosmid library using human chromosome 21 flow-sorted from Blymphoblastoid GM130B cells. To date, 33,000 independent cosmids, 18 times equivalents of chromosome 21, have been stored in 345 microtiter plates. Some of these clones were analyzed by FISH and approximately $80 \%$ were in fact localized to chromosome 21 . High density replica (HDR) filters consisting of 1,536 clones/filter were prepared using Beckman Workstation BIOMEK 1000. These HDR filters were hybridized with chromosome 21-specific DNA probes including D21S13, S16, S25, S40, S41, S42, S44, S46, S47, S48, S49, S52, S59, S82, D21F19S4, D21F20S4 and APP. A total of 206 cosmids were detected with these 17 probes with expected frequencies. These HDR filters are being used for systematic isolation of cosmids corresponding to specific YAC clones. To date, $>900$ cosmids have been identified using a set of overlapping YACs covering the Down syndrome Chromosome Region (DCR: D21S17-D21S55-ETS2), and these groups of cosmids were assigned to 19 sub-regions. The resulting cosmid groups will be particularly useful as the starting genomic material for the construction of cosmid contigs and isolation of the transcribed sequences from these regions.

\section{1-D 21}

HIGH-RESOLUTION REGIONAL MAPPING OF 103 PLASMID DNA CLONES ON HUMAN CHROMOSOME 22 BY FLUORESCENT IN SITU HYBRIDIZATION. Kaoru SAIJO ${ }^{1}$ Eiko ARAI ${ }^{1,2}$ Fumiko SAITO ${ }^{1}$ Yusuke NAKAMURA ${ }^{2}$ and Tatsuro IKEUCHI ${ }^{1}\left({ }^{1}\right.$ Dept. Cytogenet, Med. Res. Inst., Tokyo Med. Dent. Univ., Tokyo, ${ }^{2}$ Div. Biochem., Cancer Institute, Tokyo)

We have constructed a plasmid library from a human chromosome 22 specific phage library (ATCC). Nearly 2,000 plasmid clones were isolated from the library by colony hybridization using labeled human genomic DNA, and clones containing ribosomal DNA were eliminated. The clones showing an insert size of $10 \mathrm{~kb}$ or more were subjected to regional mapping by FISH. High-resolution banded late prophase or prometaphase chromosomes were obtained by cell synchronization followed by BrdU incorporation and treatment with ethidium bromide. So far 103 clones have been localized; 24 clones to band q11.2, 4 clones to q12, 28 clones to q13.1, 2 clones to $q 13.2,31$ clones to q13.3. And 18 clones to pericentromeric and $22 \mathrm{p}$ regions. Five clones were found to show distinct hybridization signals on the regions other than chromosome 22 . The ordering of these clones is in progress using multiple-colors FISH. These newly mapped and ordered DNA clones would contribute to a fuller understanding of the physical and molecular genetic of organization chromosome 22 . 
APPLICATION OF THE FLOW-SORTED DISEASE-ASSOCIATED MARKER CHROMOSOMES TO HUMAN GENOME ANALYSIS.

Shinsei MINOSHIMA ${ }^{1}$, Jun KUDOH ${ }^{1}$, Yimin WANG ${ }^{1}$, Kosuke SAKAI $^{1}$, Beverly S. EMANUEL ${ }^{2}$ and Nobuyoshi SHIMIZU ${ }^{1}$ ( ${ }^{1}$ Department of Molecular Biology, Keio University School of Medicine, ${ }^{2}$ The Children's Hospital of Philadelphia)

Certain diseases are known to be associated with the presence of a marker chromosome. These marker chromosomes are of great use for molecular analysis of the specific region involved in the chromosome alterations. Cat eye syndrome (CES) is a dysmorphic syndrome caused by trisomy or tetrasomy of the 22q11 region. The CES patients usually have a small dicentric marker chromosome retaining the $22 p$ and a proximal region of the 22q11. We isolated these marker chromosomes by flow-sorting and used as DNA source for construction of the specific cosmid library.

Eight million marker chromosomes were isolated from a B-lymphoblastoid cell line, CH91-157, derived from a CES patient using a FACS440 sorter. Spot blot hybridization analysis showed that the breakpoint locates between D22S57 and D22S36. DNA was partially digested with $M b o l$, ligated to SuperCos 1 vector and cloned with $E$. coli DH50MCR. More than 9,000 clones were stored individually in 96-well plates (10 times equivalents). FISH analysis revealed that $63 \%$ (33/52) of cosmids were definitely assigned to the CES marker chromosome. High density replica (HDR) filters consisting of 1,536 clones/filter were prepared, and hybridized with various DNA probes including D22F20S5, rDNA, D22F19S5, D22Z3, $\alpha X 1(1020), D 22 S 9, S 24, S 43$ and S57. A total of 874 cosmids were detected with each of these 9 probes at various frequencies. The CES marker chromosome-specific cosmid library and HDR filters are being used to construct cosmid contigs of the pericentromeric region of $22 \mathrm{q}$.

\section{1-D 23}

CROMOSOME MAPPING OF THE HUMAN GENE ENCODING THE MUTUAL SIGNAL-TRANSDUCING SUBUNIT $(\beta$-CHAIN) OF GM-CSF, IL3, AND IL5 RECEPTOR COMPLEXES BY FISH. Setsue TAKAI (Div. Genet., Natl. Med. Cent., Tokyo), Tadayoshi TANIYAMA, Nakami HIRAYAMA (Lab. Immunoreg., Dept. Immunol., NIH, Tokyo), Atsushi MIYAJIMA (Dept. Mol. Biol., DNAX Res. Inst., CA, USA), Kiyomi YAMADA (Div. Genet., Natl. Med. Cent., Tokyo)

Chromosome localization of the human gene for the mutual signal-transducing subunit ( $\beta$-chain) of GM-CSF, IL3, and IL5 receptor has been determined. Methods: <R-banded chromosomes> PHA stimulated peripheral blood lymphocytes were treated with thymidine and Brdu. (Probes A CDNA $(2.9 \mathrm{~kb})$ of the gene for the human GM-CSF receptor ( $\beta$-chain) was biotinlabeled. <In situ hybridization and signal detection> Hybrydization was performed at $37^{\circ} \mathrm{C}$ for $20 \mathrm{hr}$. Avidin-FITC was treated and the signal of FITC was enlarged after that. Results: Symmetrical double spots were detected on Chromosome 22. Sublocalization of the signals was determined to be 22q13.1. Discussion: Recently, the human gene for GM-CSF receptor ( $\alpha$-chain) has been mapped to the pseudoautosomal regions between $X$ and $Y$ chromosomes. It is interesting that the gene for $\beta$-chain has been mapped to the different region apart from $X$ or $Y$ chromosome in this study. 


\title{
1-D 24
}

\author{
ASSIGNMENT OF THE HUMAN MOESIN GENE TO Xq11.2-q12. \\ Tatsuya KISHINO, Hidenobu SOEJTMA, Tohru OHTA, Toshiya TAMURA, \\ Yoshihiro JINNO, Norio NIIKAWA (Dept. Hum. Genet., Nagasaki Univ. Sch. \\ Med., Nagasaki), Tadashi ARIGA, Yukio SAKIYAMA (Dept. Pediatr. Hokkaido \\ Univ. Sch. Med., Hokkaido) and Shoichiro TSUKITA (Dept. Information \\ Physiology, National Institute for Physiological Sciences. Okazaki)
}

The human moesin gene was mapped to Xq11.2-q12 by using colony hybridization, Southern blot hybridization and fluorescence in situ hybridization (FISH). Moesin, originally characterized as a possible receptor protein for heparan sulfate, is a member of the ezrin-radixin-moesin family (ERM) which has been postulated to provide a link between the cytoskeleton and the cell membrane. Recently, ERM was reported to be co-localized with sialophorin (CD43), which is deficient in lymphocytes of patients with Wiskott-Aldrich syndrome (WAS). We report the result of the moesin gene mapping by FISH and that the human moesin gene may be removed from candidacy for WAS whose putative gene has been mapped to Xp11.3-p11.22.

1-D 25

APPLICATION OF FISH (FLUORESCENCE IN SITU HYBRIDIZATION) TECHNIQUE TO YAC (YEAST ARTIFICIAL CHROMOSOME) SCREENING.

Takako TAKANO, Yasuko YAMANOUCHI (Dept. Hyg. \& Pub. Health, Teikyo Univ. School of Med., Tokyo), Yutaka NAKAHORI, Yasuo NAKAGOME (Dept. Hum. Genet. School of Internat. Health, Tokyo Univ., Tokyo)

We screened the CEPH \& Washington University YAC (yeast artificial chromosome) libraries by a three dimension PCR screening system assembled in the Cancer Institute (Tokyo) and colony hybridization to study detailed molecular structures of the $\mathrm{Y}$ specific and X-Y homologous regions. Fluorescence in situ hybridization (FISH) was carried out to know the chromosomal localization of isolated YAC clones and to avoid chimeric YACs. YAC clones were biotinylated by nick translation after digestion with EcoRI. In situ suppression hybridization was performed with 10-50 folds of human placenta DNA or Cotl to eliminate signals from repetitive DNA sequences such as Alu-sequences. Only one YAC was found to be chimeric, as the signals were detected on Yp11.2 and autosomal chromosomes (2p, 3q, 5q etc.). The signals of two YACs were detected on Yp11.2 and those of two YACs on both Yp11.2 and Xp22.31. The signals of two YACs were detected on Yq11.23. These YAC clones should be useful in the isolation of the azospermia gene and in the analysis of the amelogenesis imperfecta gene. 


\section{1-D 26}

STRUCTURAL ANALYSIS OF AMELOGENIN REGION VIA YAC CLONES. 1 Karo TANAKA, 'Bunkichi TSUNEKAWA, ${ }^{2}$ Yasuko YAMAUCHI, ${ }^{2 T a k a k o}$

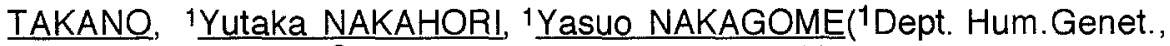
Tokyo Univ., Tokyo, 2Dept. Hygine and Public Health)

We have been analyzing the structure of $Y$ chromosome. We introduce a screening system using yeast artificial chromosome(YAC) to analyze long regions rapidly. In this study we cloned 5 YAC clones with Amelogenin region of either $X$ or $Y$ chromosome from $C E P H$ and Washington Univ. YAC libraries.

Analysis by pulse field gel electrophoresis revealed that each of these clones has one or two Not I sites. Two clones were mapped on both $X$ and $Y$ chromosomes indicating that these clones were located on $X$ and $Y$ homologous regions. We chose these clones to construct cosmid library to analize further details of these regions.

1-D 27

MOLECULAR ANALYSIS OF THE AZOOSPERMIC GENE REGION ON Y CHROMOSOME

Kazuhiro KOBAYASHI ${ }^{1}$, Kunihiko MIZUNO $^{1}$, Akiko HIDA ${ }^{1}$, IkumiMATSUSHITA $^{1}$, Karo TANAKA ${ }^{1}$, Rie KOMAKI ${ }^{1}$, Terutaka KODAMA ${ }^{1}$, Mikio NAMIKI $^{2}$, Yutaka NAKAHOR ${ }^{1}$, and Yasuo NAKAGOME ${ }^{1}$

( ${ }^{1}$ Dept. Hum. Genet., Tokyo Univ., Tokyo., ${ }^{2}$ Dept. Urol., Osaka Univ., Osaka.)

We have analyzed DNA from 62 Japanese men with azoospermia whose $Y$ chromosomes were cytogenetically normal. A total of 37 loci was examined in each patient. Of the 62 patients, 13 had small interstitial deletions, each of which was located within the Yq11.23 region, and 6 of the 13 patients lacked the same 2 loci.

We have constructed a YAC contig covering all the 13 deletions. A mega YAC $(\mathrm{CEPH})$, in fact, spanned most of the deletions and a phage library was derived from it. Analysis of these phage clones as well as screening of a cDNA library, using the mega $\mathrm{YAC}$ as a probe, are in progress. 


\section{1-D 28}

ANALYSIS OF CHROMOSOME ABERRATION BY WHOLE PAINTING TECHNIQUE. Ki ichi SHIMIZU, Tahahi ro MINESHITA, Toshihi ro GOTO(Shionog I Biomed.Lab., Osaka) and Yasushi SHIKISHIMA, Hidetoshi KAWAHARA, Koichiro NOSEC Dept. Pediatr . Kameda Sogo Hospital, Chiba)

Chromosome analysis by FISH technique is useful in the identification with chromosomal abnormality that isn't determined by morphology. We have studied FISH technique with painting probe in some cases. The patient is the third child to 30 -year-old father and 27 -year-old mother. He was referred to us because of asphxia of the newborn and multiple congenital anomalies:hypertelolism, saddle nose, low set ears, articular contructure, overlapping fingers. He deid of the acute heart failure on 50 days. An analysis was carried out using peripheral blood leukocytes. We used Chromosome analysis ( $G$-banding) and FISH with chromosome 14 painting probe (oncor). Cytogenetic study revealed trisomy 14 with $t(14 q 14 q)$ in 100 per cent of lymphocytes. Chromosome 14 painting probe detected this whole abnormal chromosome. We determined that karyotype of the patient was $46, X Y,-14,+t(14 q 14 q)$. Trisomy 14 without mosaicism is rare. We have studied FISH technique in other cases:t(21q21q)<\#21 paintig probe>, $t(8 ; 12 ; 14)<\# 14$ painting probe>,partial monosomy $7 \mathrm{q}<\# 7$ telomere probe>. We will analyze chromosome aberration by FISH technique in more other cases.

\section{1-D 29}

DETECTION OF CHROMOSOMAL CHANGES IN CULTURED PERIPHERAL LYMPHOCYTES BY FLUORESCENCE IN SITU HYBRIDIZATION.

Momoki HIRAI, Yumiko SUT0, Masumi 0HTA, Michiko KANO (Bept. Anthropol., Grad. Sch. Sci., Univ. Tokyo, Tokyo) and Tamiko SHINOHARA (Dept. Human Cytogenet., Japan Red Cross Med. Centr., Tokyo)

Analysis of chromosomal aberrations in cultured human peripheral blood lymphocytes is important for monitoring environmental mutagens. Newly devised molecular cytogenetic techniques may give further information on the chromosomal changes induced by such agents. Fluorescence in situ hybridization (FISH) using human alphoid DNA probes specific for chromosomes $17, X$ or $Y$ were performed to detect aneuploid cells in blood samples from newborns and 85-year-old populations in anattempt to establish baseline level of chromosomal aberrations. Elevation of the frequency of $X$-chromosome aneuploid cells was evident in 85 -yearold females (about $8 \%$ ). Most missing and additional $X$ chromosomes in their cells were found to be late replicating ones. The $Y$ chromosome did not show such an age dependent increase in males. Three-color FISH using chromosome-specific DNA libraries was found to be a powerful tool for the detection of stable types of structural aberrations. 


\section{1-D 30}

Characterization of chromosome rearrangements involving telomeric regions using the targeted chromosome-band painting technique. Hirofumi OHASHI, Keiko WAKUI, Yoshimitsu FUKUSHIMA (Saitama Children's Med Ctr), Kiyoshi IMAIZUMI (Kanagawa Children's Med. Ctr), Tatsuo MAEMOTO (Tokyo Women's Med. College), Mitsuaki YOSHIDA (Tokyo Med. Dent. Univ.) and Norio NIIKAWA (Nagasaki Univ., Nagasaki)

Chromosome microdissection-PCR amplification technique have facilitated to obtain FISH probe pools from targeted chromosome regions (targeted chromosome-band painting technique). We present here following two diagnostic applications of the technique for chromosome aberrations of unknown origin involving telomeric regions. [1] A probe pool was developed from the altered segment of unknown origin by microdissection-PCR. FISH with the probe pool was performed on a normal metaphase chromosomes to identify the origin of the altered segments. [2] A painting probe for a telomeric region of a normal chromosome was generated to diagnosis a "half cryptic translocation", in which one of the two reciprocal products cannot be detected. The diagnostic power of the targeted chromosome-band painting method for chromosome aberrations of unknown origin has currently been well documented. In addition, we would like to emphasize the usefulness of telomeric painting probes for characterization of chromosome aberrations involving telomeric regions. We have generated the following painting probes involving telomeric region: $3 \mathrm{p}, 4 \mathrm{p}, 4 \mathrm{q}, 5 \mathrm{p}$ and $8 \mathrm{p}$.

\section{1-D 31}

SPONTANEOUS INCIDENCE OF CHROMOSOME ABERRATIONS IN HUMAN SPERMATOZOA (THIRD REPORT). Yujiroh KAMIGUCHI, Hiroyuki TATENO and Kazuya MIKAMO (Dept. Biol. Sci., Asahikawa Med. Col., Asahikawa)

Using our interspecific in vitro fertilization system between human spermatozoa and zona-free hamster oocytes, a total number of 15,864 spermatozoa from 51 donors having normal semen quality were studied cytogenetically.

The incidence of aneuploidy was $1.4 \%$, consisting of the same incidences of hypohaploidy $(0.7 \%)$ and hyperhaploidy $(0.7 \%)$. This is a marked contrast to the previous data in which the former incidence was considerably higher than the latter. Nondisjunctional errors leading to the aneuploidy were distributed randomly among 8 chromosome groups (A-G and sex chromosomes), showing no significant difference from the expected frequencies which were calculated according to the assumption that the errors had taken place at an equal chance in each of 23 chromosomes. The incidence of spermatozoa with structural chromosome aberrations (14.1\%) was about 10 times higher than that of aneuploidy, showing a great individual variation (3.6-24.8\%). There was no positive correlation between the occurrence of these spermatozoa and the age of donors or the habit of smoking. It was evident in our material that annually averaged incidences of chromosome aberrations were fairly constant throughout the 7 years of survey. 
1-D 32

FAMILIAL TRANSMISSION OF RECIPROCALLY TRANSLOCATED CHROMOSOMES. Hidetsune 0ISHI(Dept. Genet., Inst. Develop. Res., Aichi Pref. Colony, Kasugai), Kaoru SUZUMORI(Dept. Obs. Gynec., Nagoya Ci ty Univ., Nagoya), Shigeki UEHARA (Dept. Obs. Gynec., Tohoku Univ. Sch. Med., Sendai), Ken HAYASHI(Dept. Obs. Gynec., Kyoto Univ. Sch. Med., Kyoto) and Tsutomu YAMANAKA(Cent. Hosp., Aichi Pref. Colony, Kasugai)

Familial reciprocal translocations ascertained for birth of malformed children were collected from our records and published papers. Of 603 cases examined, probands were shared equally for male and female, while their fathers and mothers with balanced translocation were 192 and 411 , respectively. By the pedigree analyses, 223 families with the same conditions of chromosomal rearrangements for two or more generations were listed, and it was found that the origin of balanced chromosomes of fathers was grandmaternal in 35 out of 61 cases (57.4\%), and that of mothers in 86 out of 140 cases $(61.4 \%)$. On the other hand, delivery records of parental sibs, cousins, aunts and uncles with balanced translocation were collected from these families. There were no sexual difference on their children with various chromosome constitutions, while fathers and mothers with balanced conditions were 89 and 143, respectively. From these data, one possible explanation could be presented that difference of fertility between wale and female carriers exerts influence on excess existence of the mother with balanced translocation.

\section{1-D 33}

Balanced chromosomal rearrangements with abnormal phenotypes: An important role of cytogenetics in human genome mapping. Yoshimitsu FUKUSHIMA, Hirofumi OHASHI, Keiko WAKUI (Saitama Children's Medical Center), Yusuke NAKAMURA (Cancer Institute), Norio NIIKAWA (Nagasaki University)

Recently, patients with mendelian disorders have been reported to have balanced chromosomal rearrangements, and their breakpoints gave definite information of gene loci. The effort of searching patients with both balanced rearrangement and a disorder is very important. Thus chromosome analysis should be performed on patients not only with multiple anomalies but with mendelian disorders or a single anomaly.

We have karyotyped about 2000 patients with birth defects in the latest 10 years, and found the following four patients with balanced rearrangements and abnormal phenotypes; 1) $\mathrm{t}(3 ; 4)(\mathrm{q} 23 ; \mathrm{p} 15.2)$ with blepharophimosis sequence [Am J Med Genet 40:485-487,1991], 2) inv(11)(p13p13) with aniridia [Hum Genet 91:205-209, 1993], 3) $\mathrm{t}(5 ; 17)(\mathrm{q} 11.2 ; \mathrm{q} 23)$ with Klippel-Feil anomaly,. and 4) inv(11)(q13q25) with polysplenia syndrome. Characterization of the breakpoint regions and cloning the gene of each disorders are under way.

This chromosomal rearrangement mapping will be a powerful tool if the following conditions are satisfied; 1) precise clinical estimation and diagnosis, 2) excellent cytogenetic techniques, 3) establishment of patients' cell-lines and 4) collaboration with laboratories for molecular genetics. 


\section{1-D 34}

IMPROVED HIGH-RESOLUTION R-BANDING METHOD IN LYMPHOBLASTIOD CELL LINES:

THE COMBINED USE OF CELL SYNCHRONIZATION AND ETHIDIUM BROMIDE TREATMENT.

Mei Hua YE, Fumiko SAITO, Tatsuro IKEUCHI (Dept. Cytogenet., Med. Res. Inst., Tokyo Med. Dent. Univ., Tokyo)

In lymphoblastiod cell lines (LCLs), high-resolution chromosome banding at more than 550-band levels is somewhat difficult, because of their condensed and shortened mitotic chromosomes. We have attempted to establish a reliable method for high-resolution R-banding in chromosomes of LCLs. The cell cultures were synchronized by either methotrexate (MTX) or thymidine (TdR), and the S-phase block was released by BrdU addition. In both the MTX and TdR experiments, the maximum mitotic index was obtained $6.5 \mathrm{hrs}$ after the start of BrdU treatment, in contrast to 5-5.5 hrs when the usual peripheral blood cultures were used. However, the frequency of early mitotic cells was not neccessarily high in these prepasations. Therefore, ethidium bromide $(\mathrm{EB}, 7.5 \mu \mathrm{g} / \mathrm{ml}, 1.5 \mathrm{hr})$ treatment method was applied to the cells cultrued in the presence of BrdU for $6.5 \mathrm{hrs}$ following the TdR-cell synchronization, and frequencies of late pro- or prometaphase cells were found to be drastically increased (over $60 \%$ of mitotic cells). The method combining cell synchronization with $\mathrm{EB}$ treatment can readily applied to the FISH mapping in high-resolution R-banded chromosomes of LCLs.

\section{1-D 35}

MOLECULAR CYTOGENETIC ANALYSIS OF HUMAN CHROMOSOME 6 USING COSMID DNA MARKERS.

Yumiko SUT0, Masumi 0HTA, Momoki HIRAI (Dept. Anthropol., Grad. Sch. Sci., Univ. Tokyo, Tokyo), Susumu SAITO and Yusuke NAKAMURA (Dept. Bio chem., Cancer Inst., Tokyo)

A total of 270 cosmid clones containing DNA inserts derived from human chromosome 6 were localized using direct $\mathrm{R}$-banding fluorescence in situ hybridization. (FISH). Of them, 75 were condfirmed their locations by the new ly devised direct G-banding FISH technique. The ordering of clones localized to p21.3 was analyzed by 2-color FISH. Two major histocompatibility complex (MHC) genes, HLA-B7 and $C 4$, were used as anchor genes for constructing the precise physical map of this region. Comparative mapping with 41 cosmid clones were made for four nonhuman primates (chimpanzees, hamadryas baboons, cynomolgu monkeys and African green monkeys) for the better understanding of the organization of this chromosome. Our results sugest the presence of complicated rearrangements in this chromosome during karyotype evolution in primates. 


\section{1-D 36}

A STABLE ACENTRIC MARKER CHROMOSOME DERIVED FROM DISTAL 8p: REACTIVATION OF A LATENT ANCIENT CENTROMERE AT 8p22. Hirofumi OHASHI, Keiko WAKUI, Kiyoshi OGAWA, Yoshimitsu FUKUSHIMA (Div. Med. Genet., Saitama Children's Med Ctr., Iwatsuki), Tetsuroh OKANO (Kitazato Univ.) and Norio NIIKAWA (Dept. Hum Genet., Nagasaki Univ., Nagasaki)

Centromere is considered to be an essential chromosomal component where microtubule-kinetochore interaction occurs to segregate sister chromatids faithfully, and acentric chromosomes are unstable and lost through cell divisions. We report a novel acentric marker chromosome that was stable through cell divisions. The patient was a 2-year-old girl with mental retardation, PDA and frontal bossing. Chromosome analysis revealed an additional small marker chromosome in all 100 cells examined. Using the microdissection and PCR-amplification method, the marker was found to originate from $8 \mathrm{p} 22$-pter involving no centromeric region. By FISH, an a-satellite sequence was not detected on the marker, while telomere sequences were detected at its each end. Two color FISH using cosmid probes 8-1(8p22) and 8-1198 (8p23) showed an 8-1 signal sandwiched between two 8-1198 signals on the marker, indicating that the marker was rearranged as 8pter-p22-8pter.

Recently, there has been some evidence for the presence of ancient centromeric sequences other than centromeric regions. The patient may provide direct evidence

\section{1-D 37}

STUDY OF $X$ AND $Y$ BEARING SPERM RATIO USING THREE COLOR FLUORESCENCE IN SITU HYBRIDIZATION. Norio MIHARU, Etsuji OKAMOTO, Osamu SAMURA, Yoshiharu NAKAOKA, Koso OHAMA (Dept. OB/GYN., Hiroshima Univ. of Med., Hiroshima), R G.BEST, S R. YOUNG (Dept. OB/GYN., Univ. of South Carolina., SC., USA)

Three color fluorescence in situ hybridization (FISH) was applied to study X-and Ybearing sperm ratio, frequencies of sex chromosome disomies and diploidy in sperm nuclei. Semen samples were obtained from nine men. To enhance penetration of sperm nuclei for DNA hybridization, fixed semen slides were pretreated with dithiothreitol and lithium diiodesalicylate. We utilized a cocktail of alpha-satellite DNA probes (Oncor Inc.) for chromosome X (DXZ1; digoxigenin), chromosome Y (DYZ1; biotin), chromosome 18 (D18Z1; biotin and digoxigenin). A total of 18866 sperm nuclei were analyzed and $18465(98 \%)$ were clearly scorable with 50.1 X-bearing and $49.9 \mathrm{Y}$ bearing. Frequencies of disomic nuclei were $0.06 \%$ for $\mathrm{X}-\mathrm{X}, 0.08 \%$ for $\mathrm{X}-\mathrm{Y}, 0.06 \%$ for $\mathrm{Y}-\mathrm{Y}$ and the diploidy frequency was $0.22 \%$. FISH is a useful method to distinguish disomic sperm nuclei from diploid sperm nuclei and to study X- and Y-bearing sperm ratio. 


\section{1-D 39}

HIGH FREQUENT INACTIVATION OF THE WT1 GENE IN WILMS' TUMORS FROM JAPANESE PATIENTS. Masao YAMADA, Keiko TADOKORO, Shigeo NAGAFUCHI (National Children's Medical Research Center, Tokyo 154) and Yasuhide HAYASHI (Dept. of Pediatrics, Univ. of Tokyo, Tokyo).

Wilms' tumor is an embryonal nephroblastoma and has been thought to result from two mutational events. At least 3 loci $(11 \mathrm{p} 13,11 \mathrm{p} 15$ etc.) have been implicated by cytogenetic and molecular analyses. The WT1 gene at 11p13 was cloned in 1990 on the basis of interstitial deletion, but mutations of the gene in tumors have rarely been described to date except for cases with Denys-Drash syndrome. We have analyzed DNA from Japanese Wilms' tumors. Nine polymorphisms in the WT1 gene (Tadokoro et al. Hum. Mol. Genet., in press) detected high frequency (50-60\%) and a distinct pattern of loss of heterozygosity in Japanese tumors. Several point mutations were detected by PCR-SSCP followed by sequencing. Including of a case of intragenic homozygous deletion (Tadokoro et al. Oncogene, 7:1215-1221, 1992), at least 7 out of 42 tumors were accounted for by inactivation of the WT1 gene on both alleles. Since incidence of Wilms' tumor in Japan is about $1 / 2$ to $1 / 3$ of that in Caucasian, our result suggests that involvement of the WT1 gene is higher in Japanese on the basis of the number of tumors, but almost same on the basis of the number of birth. Our result also suggests that genetic differences among ethnic groups are important in studies of predisposition to tumors.

\section{1-D 40}

WILMS TUMORS IN JAPAN

Masako TANIMURA, Ichiro MATSUI (Dept. Child Ecology, Natl. Children's Medical Research Center), Noboru KOBAYASHI (Natl. Children's Hospital)

\footnotetext{
Heterogeneity of Wilms tumors and its characteristics in the Japanese population were studied based on 1,090 cases with Wilms tumor in the Japan Children's Cancer Registry diagnosed during 1969 and 1990. Forty-six Wilms tumor cases had multiple congenital malformations and 104 cases had a single malformation. There were no Wilms tumor cases having both aniridia and hemihypertrophy. Most of 18 Wilms tumor cases with aniridia had more congenital malformations and mostly diagnosed at 1 year of age. Ten Wilms tumor cases with hemihypertrophy or EMG syndrome were mostly diagnosed at 3 years of age and half of them were accompanied with urogenital malformations. These results support the cytogenetic results that WT1 gene is linked to aniridia and WT2 gene may be associated with both Wilms tumor and EMG. Wilms tumor cases with horseshoe kidney or other urogenital malformations were mostly diagnosed at 4-5 years of age, implying the possible existence of another type of Wilms tumor different from either WT 1 or WT2.

The peak of age distribution at diagnosis of Wilms tumor was 1 year old in Japanese and 0-3 years in Caucasians. Wilms tumor was most frequently accompanied with aniridia in Japanese but with hemihypertrophy in Caucasians. WT 1 seems to be more frequent in Japanese than in Caucasians.
} 


\section{1-E 1}

POSSIBLE ROLE OT THE RB GENE IN PREVENTION OF PROGRAMMED CELL DEATH. Tomoko HASHIMOTO1), Tatsuo MORIMURA ${ }^{2}$ ), Hideki SEINDO ${ }^{3}$ ), Yasuhiro SOTOZONO ${ }^{1} 4$ ), Ei-ichi TANI ${ }^{3}$ ), Rei TAKAHASEI ${ }^{5}$ ) and Jun-ichi FURUYAMA ${ }^{1}$ ) (1)Dept. Genetics, Hyogo Coll. Med., Nishinomiya, 2) Dept. Neurosurg., Udano Hosp., Kyoto, 3 lDept. Neurosurg., Hyogo Coll. Med., Nishinomiya, 4)Dept. Pediatr., Kyoto Pref. Univ. Med., Kyoto, 5) Dept. Pathol., Kyoto Univ., Kyota)

In order to study the role of the $\mathrm{RB}$ gene in vivo, we converted the $\mathrm{RB}$-negative human bladder carcinoma cell line, HTB9, into an RBpositive cell line, H-CL2, by transfecting an RB expression vector, PBARB. H-CL2 cells require serum for growth, have a longer population-doubling time than HTB9, and are unable to form colonies in soft agar. H-CL2 cells were contact inhibited at confluency, whereas S-phase and mitotic cells were present in ATB9 cells. At confluency, HTB9 cells were accumulated in Gl phase and detached from the plate. The floating cells were trypan-blue dye exclusive and contained fragmented nuclei. DNA extracted from those cells showed DNA ladder formation characteristic of programmed cell death. On the other hand, almost all H-CL2 cells at confluency were in Go phase, none of the phenomena associated with HTB9 cells was observed. These results suggest that the $\mathrm{RB}$ protein could prevents programmed cell death of HTB 9 cells.

\section{1-E 2}

VNTR POLYMORPHISM OF RBI GENE INTRONS AND ITS APPLICATION TO GENETIC COUNSELING IN HEREDITARY RETINOBLASTOMA. Shinsuke NINOMIYA, Kouji NARAHARA, Yuji YOKOYAMA, Kazushiro TSUJI, Satoko ITOH, Masae MURAKAMI, Yoshiki SEINO (Dept. Pediatr., Okayama. Univ. Med. Sch., Okayama)

Risk estimation of siblings or offsprings is important in genetic counseling of patients with hereditary retinoblastoma. The RB1 gene spans approximately $200 \mathrm{~kb}$ in length, containing 27 exons. The use of polymorphic markers within the RBI gene will eliminate the need of laborious specification of a mutation. We determined types and frequencies of VNTR polymorphisms of the 17 th and 20 th introns of the $\mathrm{RBI}$ gene in 50 unrelated Japanese, using PCR amplification. In the 17 th intron VNTR, there were 4 alleles, which ranged from 1400 to 1550 bp. The most common allele was 1400 bp with a frequency of $73 \%$, and the heterozygosity rate wags $46 \%$. In the 20 th intron VN'R, there were at least 9 alleles, which ranged from 192 to 240 bp. The alleles were more evenly distributed than those of the 17 th intron VNTR, and the heterozygosity rate was $64 \%$. These VNTR polymorphisms were successfully applied to the prediction of retinoblastoma or the determination of parental origin of a chromosome deletion in 3 families with hereditary retinoblastoma. Analysis of VNTR polymorphisms in the RBl gene proved to be practical and efficient for risk estimation in hereditary retinoblastoma. 


\section{1-E 3}

SEMI-QUANTITATIVE ASESSMENTS OF AMPLIFICATION OF THE N-MYC GENE USING PCR. Yasuhiro SOTOZONO ${ }^{1}, 2$ ), TOmoko HASHIMOTO ${ }^{2}$ ), Jun-ichi FURUYAMA ${ }^{2}$ ), Tohru SUGIMOTO ${ }^{3}$, and Tadashi SAWADA ${ }^{3)}$ (1)Dept. Pediatr., Kyoto Pref. Univ. Med., Kyoto, 2 lDept. Genet., Hyogo Coll. Med., Nishinomiya)

Amplification of the $\mathrm{N}-m y c$ gene in neuroblastoma (NB) cells is considered to be related to an advanced stage of disease and poorer prognosis. To determine a protocol of the treatment of NBs, it is essential to find the number of copies of the $\mathrm{N}-m y c$ gene. If the copy number of the N-myc gene is determined by southern or dot blot analysis, it is not possible to determine a therapeutic protocol immediatly after surgical treatment based on amplification of the $\mathrm{N}-m y c$ gene. Therefore, we used semi-quantitative PCR for analysis of the N-myc locus. PCR was performed with 25 or 35 cycles using $0.1 \mu \mathrm{g}$ of DNA samples, and the amount of the PCR products were determined by densitometry after agarose gel electrophoresis. Two other loci with no amplification in NB cells were used as controls to adjust tne amount of DNA tested. Using several NB cell lines, the copy number of the N-myc gene determined by our PCR method is almost identical to that determined by southern blotting, suggesting that our method is efficient for choosing the first therapeutic protocol for NBs after surgical operation.

\section{1-E 4}

DETECTION OF ALTERNATIVE SPLICING OF THE SRC GENE BY PCR. TOhYU SUGIMOTO ${ }^{11}$, Yasuhiro SOTOZONO $\left.{ }^{1}, 2\right)$, Tomoko HASHIMOTO2), Misa NAKAMURA ${ }^{2}$ ), Tetsuro KURAOKA $^{2}{ }^{3)}$, Fumihiko IKOMA ${ }^{3}$, Tadashi SAWADA ${ }^{1)}$, and JUn-ichi FURUYAMA ${ }^{2}$ ) (1)Dept. Pediatr,, Kyoto Pref. Univ. Med., Kyoto, 2)Dept. Genet., 3 )Dept. Urol., Hyogo Coll. Med., Nishinomiya)

Human and rodent cells originated from nervus system express three forms of sre gene transcripts, C-srC and two types of src-N, N1 and N2. SrC-N1 and N2 are generated by alternative splicing and longer than c-src by 18 and 51 bp, respectively. We investigated the expression of the src gene using RTPCR with primers corresponding to either sides of the alternative splice site of the three types of src transcripts in relation to neuronal differentiation of neuronal tumor cells. To prevent heteroduplex formation of PCR products, we performed PCR reactions using a combination of primers, one 5'-biotinylated and the other non-biotinylated, electrophorased the PCR products on a denaturing acrylamide gel, and visualized the bands with the streptoavidin-PPD method. This technique allows complete separation of the three types of transcripts and quantification of each band by densitometer. Using this method, we analyzed sro expression in a human neuroblastoma cell line, RTBM1, and a rat pheochromocytoma cell line, PCl2, before and after treatment with retinoic acid and NGF, respectively. We found that these cell lines expressed a larger amount of src-N2 after neuronal differentiation than before. Moreover, highly differentiated tumor cells of neuronal origin expressed more src-N than pooly differentiated tumor cells. 


\section{1-E 5}

CHROMOSOME $3 p$ DELETIONS IN RENAL CELL CARCINOMAS FROM PATIENTS WITH VON HIPPEL-LINDAU SYNDROME. Mitsuaki A. YOSHIDA ${ }^{1}$, Kazunori KIHARA ${ }^{2}$, Yukio KAGEYAMA $^{2}$, Hiroyuk i OHSHIMA ${ }^{2}$, Hideyuki OGASAWARA ${ }^{3}$, Shoich i UEDA ${ }^{3}$, Takashi ISHIMATSU $^{4}$, Shinichi TAKANO $^{4}$, Naoki SAKAI ${ }^{5}$, Taro SHOTN ${ }^{5}$ AND Tatsuro IKE$\overline{\text { UCHI }}^{1}{ }^{1}{ }^{1}$ Dept. Cytogenet., Med. Res. Inst., ${ }^{2}$ Dept. Urol., Sch. Med., Tokyo Med. Dent. Univ., Tokyo, ${ }^{3}$ Dept. Urol., Sch, Med., Kumamoto Univ., ${ }^{4}$ Dept. Urol., Kumamoto Red-Cross Hosp., Kumamoto, ${ }^{5}$ Dept. Urol., Sch. Med., Yokohama City Univ., Yokohama)

Von Hippel-Lindau (VHL) disease is a familial cancer syndrome that is dominantly inherited and that predisposes affected individuals to a variety of benign and malignant tumors. Chromosome studies were performed on six renal cell carcinomas (RCC) from 3 patients (2 sporadic and 1 familial). Detailed analyses demonstrated monosomy of chromosome 3 in 4 tissues from sporadic cases and partial deletion of the short arm of chromosome 3 in one tissue from a familial case as highly clonal abnormalities. Trisomy or partial trisomy of chromosome 5 was also identified in four tissues. Moreover, \#7-trisomy was observed in 3 tissues. These chromosome abnormalities in VHL-RCCs are in general similar to those found in sporadic RCCs. The literature study including the present cases indicated that the commonly deleted region on \#3p in VHL-RCCs was p14pter, which includes the sites of putative tumor suppressor genes, 3p14p21 and p21-p22 associated with the development of sporadic RCC.

\section{1-E 6}

ACCUMULATION OF MALTIPLE DELETIONS INVOLVING SPECIFIC CHROMOSOMAL SITES, PARTICULARLY 1p AND 9p, IN HUMAN MALIGNANT MESOTHELIOMA. Takahiro TAGUCHI (Dept. Anat., Kochi Med Sch., Kochi) S.C. JHANWAR (SloanKettering Cancer Ctr., N.Y.), J.M. SIEGFRIED (Univ. Pittsburgh, PA), J.R. TESTA (Fox Chase Cancer Ctr., PA)

Detailed cytogenetic analyses were carried out on primary tumor specimens and cell lines from 23 patients with pleural malignant mesothelioma (MM). Clonal abnormalities were identified in 20 of 23 cases. In three cases, karyotypic data were compiled from harvests of both short-term cultures (1-3 days) and primary cultures grown on murine feeder layers for several weeks. The karyotypes obtained with these two different culture methods were very similar, although polyploid versions of abnormal clones were found only in the long-term cultures. The two most frequent changes were chromosomal losses of specific regions on $1 \mathrm{p}$ (18 cases) and $9 \mathrm{p}$ (16 cases). The shortest regions of overlap of these losses were at 1p21-p22 and 9p21-p22, respectively. Other common abnormalities included partial losses of $3 p$ (13 cases) and $6 q$ (9 cases) and numerical losses of chromosomes 14, 16, 18 and 22 (each observed in 10-133 tumors). In many MM, most of these recurrent changes occur in combination, suggesting the involvement of a multistep pathogenetic cascade in this malignancy. The pattern of recurrent chromosomal losses, particularly of $1 \mathrm{p}$ and $9 p$, suggests that these regions represent the sites of tumor suppressor genes whose loss may have a pivotal role in mesothelioma tumorigenesis. 


\title{
1-E 7
}

\begin{abstract}
A NORMAL HUMAN CHROMOSOME 2 INDUCES CELLULAR SENESCENCE IN A HUMAN CERVICAL CARCINOMA CELL LINE (SiHa). Hiroshi UEJIMA, Kohzoh MITSUYA, Izumi HORIKAWA, Hiroyuki KUGOH and Mitsuo OSHIMURA. (Dept. of Mol.\& Cell Genet., Sch. of Life Sci., Faculty of Med., Tottori Univ.)
\end{abstract}

We have identified a normal human chromosome that suppresses in vitro growth or tumorigenicity by microcell-mediated chromosome transfer to various tumor cell lines. By means of the technique, chromosomes that induce cellular senescence were also identified, e. g., chromosomes 1 and 11 . In this study, we transferred a normal chromosome 2 or 11 to a human cervical carcinoma cell line SiHa, in order to identify another chromosome that is associated with cellular senescence. Seventy-five \% (158/207) of clones with the transferred chromosome 2 showed a remarkable morphological change (Flat), and $93 \%$ of clones of them showed growth-arrest prior to $6 \sim 8$ population doublings. At least 3 markers, pSV2neo, HPV-genome and GArepeats on 2qwere present in the clones with the flat morphology similar to that of senescent clones. SiHa (\#11) clones contained the intact transfer chromosome 11, whereas $\mathrm{SiHa}$ (\#2) clones that didn't senesce or escaped senescence contained a deleted chromosome 2 . These results indicate the presence of a putative gene associated with the induction of senescence of some tumor cells on normal human chromosome 2.

\section{1-E 8}

FAMILIAL CANCER AGGREGATION AND SEX RATIO IN GYNECOLOGIC CANCER : DOES CANCER CAUSE INFERTILITY?

Takahiko SONODA (Dept. Gynec., National Cancer Center, Tokyo)

Masao KANAMORI (Dept. Hyg., Toho Univ., Tokyo)

Two hundred newly diagnosed cases of endometrial cancer $=\mathrm{EmC}$ and fifty cases of breast cancer $=\mathrm{BrC}$ at National Cancer Center Hospital during a 10-year-period were analysed with regard to the occurrence of cancer in three-degree relatives. The families of uterine cervical cancer $(\mathrm{N}=120)$ were analysed as controls. Cancer Aggregation : The cancer occurrence rates were as follows : paternal grandfathers(GFp) and grandmothers $(\mathrm{GMp})$ and maternal grandfathers $(\mathrm{GFm})$ and grandmothers $(\mathrm{GMm})$ were $3.6 \%(\mathrm{EmC}) / 9.5 \%(\mathrm{BrC})$, 8.4/6.8\%, 7.4/16.7\% and 5.6/6.4\%, respectively. Fathers(F) $17.0 \%(\mathrm{EmC}) / 34 \%(\mathrm{BrC})$, mothers(M) $18 \% /$ $24 \%$. Up (paternal uncles) $9.0 / 4.7 \%$, Ap (paternal aunts) 6.2/8.6\%. Um(maternal uncles) 8.0/8.4\%, Am(maternal aunts) $6.2 / 7.9 \%$. Brothers $6.8 / 8.5 \%$, sisters $6.4 / 11.1 \%$, sons $0.0 / 0.0 \%$, daughters $1.7 / 0.0 \%$. Sex Ratio of Children : GMp(except F) $=123(\mathrm{EmC}) / 121(\mathrm{BrC})$. GMm(except $\mathrm{M})=104 / 73$. Mothers (except proband) 101/73. Probands(P) $=102 / 109$.

Number of children : In EmC, average number of children of GMp, GMm, M and P were 3.59, 3.85, 4.11 and 1.85 , respectively and average abortion frequency of $\mathrm{P}$ was 0.69 . In $\mathrm{BrC}$, average number of children of GMp, GMm, $M$ and $P$ were 3.30, 4.10, 3.06 and 1.60, respectively and average abortion frequency of $P$ was 0.50 .

The above findings suggest that a hereditary factor, including sex chromosomal factor, is involved in a significant proportion of endometrial and breast cancer.

A hypothesis "cancer with unexplained infertility" is proposed. 


\section{1-E 9}

LONG-RANGE MAPPING OF CHROMOSOME 11 BAND q23 ( 11q23) REGION INVOLVED IN CHROMOSOME ABERRATIONS IN HUMAN TUMORS

Yukihiro AKAO

(Anatomy and Biology, Osaka Med.Coll. Osaka, JAPAN)

We cloned the RCK gene involved in $t(11 ; 14)(q 23 ; q 32)$ and the $M L L / A L L-1$ gene involved in $t(4 ; 11)$ and $t(11 ; 19)$ on 11q23. The gene mapping of these traslocation associated genes and the marker genes on $11 \mathrm{q} 23$ was conducted. The RCK and the more centromeric $M L L / A L L-1$ are localized on the different adjacent Notl fragments by pulsed-field gel electrophoresis (PFGE) analysis with the YAC clone yB22B2. The PFGE analysis using the YACs of YTY 17 containing the Porphobilinogen deaminase (PBGD), $C B L-2$ and $T H Y-1$ genes and yB22B2 allowed the following ordering of genes and breakpoints from $C D 3$ to $T H Y-1$ on 11q23: cent-CD3- $A L L / M L L-1-A C K-P B G D-C B L-$ 2- $T H Y-1$ and the establishment of a long-range restriction map covering these genes. In addition, the $F L 1-1$ region involved in the $t(11 ; 22)$ in Ewing's sarcoma was shown to be more telomeric region than the THY -1 gene by analyzing somatic cell hybrids carrying the 11q- and/or $14 q+$ chromosome of the $t(11 ; 14)$ translocation and by PFGE analysis of the YAC clone YTY17.

\section{1-E 12}

Ph TRANSLOCATION AND 5q- ARE DETECTED BY FISH USING YEAST ARTIFICIAL CHROMOSOME (YAC) CLONES CONTAINING THE BCR and C-FMS. Yutaka UEDA. Masafumi TANUWAKI. Kohichi HURAKANA, Yuke KUZUYAMA, Hiroyuki NAKAI, Shigeo HORIIKE, Shouhei YOKOTA. Shinichi MISANA, kei KASHIMA, Tatsue ABE (Depts. Med. and Hygiene, Kyoto Pref. Univ. Med., Kyoto)

Using YAC clones containing the BCR and $c-F M S$, we detected Ph chromosome in patients with chronic myelocytic leukemia(CML) and in those with myelodysplastic syndrome(MDS), respectively. The normal chromosome 22, $\mathrm{Ph}$, and the der (9) are clearly labeled in CML, indicating that the signal of BCR YAC was split by this translocation. In addition to the analysis of metaphase spreads, we identified these specific chromosomal abnormalities directly in interphase nuclei through demonstrating three signals in CML, and only one signal in 5q-syndrome. The ability to detect specific chromosomal abnormalities, particularly structural abnormalities, at single cell level makes interphase cytogenetics useful to study heterogeneous cell populations. The YAC clones are kindly provided by Dr. Thomas Cremer. Heildelberg University. 


\section{1-E 13}

ALTERNATIVE SPLICING OF THE p53 GENE, A POSSIBLE NOVEL MECHANISM OF p53 INACTIVATION IN BLAST CRISIS OF CHRONIC MYELOGENOUS LEUKEMIA (CMI). Hiroyuki NAKAI, Hiroto KANEKO, Shinichi MISAWA, Yutaka Ueda, Makoto NAKAO, Kouichi HIRAKAWA, Yuko KUZUYAMA, Taku SERIU, Shigeo HORIIKE, Shouhei YOKOTA, Masafumi TANIWAKI, Kei KASHIMA (3rd. Dept. Int. Med., Kyoto Pref. Univ. Med., Kyotol and Kanji ISHIzAKI (Radiation Biology Center, Kyoto Univ., Kyoto)

We found three truncated p53 transcripts in a patient with chronic myelogenous leukemia (CML) in blast crisis (BC) by reverse transcriptase (RT)-polymerase chain reaction (PCR)-based analysis. Sequencing of these three transcripts revealed complete absence of the entire exons 7,8 and 9 in one, absence of the entire exons 8 and 9 in another, and absence of the entire exon 10 in the other. However, PCR-single-strand conformation polymorphism (SSCP) analysis on genomic DNA sequences of exons 2 to 11 including a small part of flanking intron sequences revealed no abnormality in this case. We also confirmed normal sequences of exons 6 to 10 and their flanking introns by DNA sequencing. These results suggest that the three aberrant p53 transcripts in this case were not produced by splicing mutation but by alternative splicing, a possible novel mechanism of inactivation of the p53 gene.

\section{1-E 14}

MUTATIONS OF THE $p 53$ GENE IN T CELL- AND PRE B-CELL ACUTE LYMPHOBLASTIC LEUKEMIA. Machiko KAWAMURA, Yasuhide HAYASHI, Shigehiko KAMOSHITA (Dept.Pediat., Tokyo Univ.,Tokyo), Yasuhiko KANEKO (Saitama Cancer Ctr.,Saitama) and Takao SEKIYA (Natl.Cancer Ctr.,Tokyo)

Aberrations of the p53 gene were examined in T cell- and Pre-B cell acute lymphoblastic leukemia (ALL) by polymerase chain reaction-single strand conformation polymorphism (PCR-SSCP) analysis.Aberrations of p53 gene were found in 3 of 24 fresh samples, in 7 of 8 cell lines in T cell-ALL in and in 4 of 19 fresh samples, and in 3 of 4 cell lines in pre B-ALL with $t(1: 19)$. In one case ,we detected the same point mutations at diagnosis and relapse, while another case had no mutation at diagnosis but had the same point mutations in leukemic cells at relapse and in cell lines obtained from leukemic cell at diagnosis. Two of 3 cases with p53 gene mutations died in Tcell-ALL, while 4 of $5 \mathrm{t}(1 ; 19)$-ALL cases who died had mutations in the p53 gene. The mutations of the most cases were clustered at the highly conserved domains III (171181) and IV (236-258) , and included missense mutations at codon 177,179 and 248 in pre B-ALL, 175 and 248 in T-ALL. The Tcell-ALL cases with TAL1 gene rearrangement had no muattion in p53 gene.These observations suggest that the cases with p53 mutations had a poorer prognosis than cases without p53 mutations. The presence of p53 mutation in childhood ALL may suggest to be associated with poor prognosis. 


\section{1-E 15}

ANALYSIS OF HTLV-I PROVIRAL DNA INTEGRATIONS IN PERIPHERAL BLOOD LYMPHOCYTES FROM PATIENTS WITH ADULT T-CELL LEUKEMIA. Muneou SUZUKI, Hisamitsu UNO Takanori TOYAMA Kiyoshi YAMASHITA, Youko KUBUKI, Kouichi MAEDA, Hitoshi MATSUOKA, and Hirohito TSUBOUCHI (2nd. Dept. Int. Med. Miyazaki Med. School, Miyazaki)

We examined integration patterns of HTLV-I proviral DNA in peripheral blood mononuclear cells (PMNC) from patients with adult T-cell leukemia (ATL) (21 acute types, 6 chronic types, 6 lymphoma types, and 3 smoldering types) and HTLV-I carriers ( 3 asymptomatic carriers and $2 \mathrm{~B}$-cell lymphomas) by Southern blot analysis technique. We used probes, PHT-1(M)3.9 for env $\sim \mathrm{pX}$ region and pATK32 for gag pol region, to detect HTLV-I proviral DNA. We detected monoclonal bands of HTLV-I proviral DNA in 34 cases among all subjects examined $(83 \%) ; 0 \%, 33.3 \%, 100 \%, 100 \%, 83.5 \%$ and $50 \%$ in asymptomatic carriers, smoldering types, chronic types, acute types, lymphoma types and B-cell lymphomas, respectively. Six patients had 2 or more clonal bands. There were no statistically significant differences of laboratory data and prognosis between patients with single clonal band and those with 2 or more clonal bands. One patient experienced transformation of HTLV-I proviral DNA with laboratory data unchanged in the clinical course. Defective viruses were observed in 2 patients. We detected HTLV-I proviral DNA in PMNC from a patient with $0.5 \%$ morphological abnormal cells suggesting that there are more ATL cells than morphological abnormal cells.

\section{1-E 16}

FINE MAPPING OF THE PUTATIVE GENE FOR TRANSIENT ABNORMAL MYELOPOIESIS (TAM)

Tohru OHTA, Yoriko WATANABE, Kyohko ABE Norio NIIKAWA (Dept. Hum. Genet, Nagasaki Univ. Sch. Med., Nagasaki), Yoshivuki SAKAKI (Inst. Med. Sci.,Univ. Tokyo)

TAM is a leukemoid reaction that occurs occasionally in newborn infants with Down syndrome (DS) and rarely in karyotypically normal infants. Our previous study suggested that a mechanism responsible for the occurrence of TAM is disomic homozygosity of the mutant putative TAM gene which is most likely located to 21q11.2, according to the findings of molecular analysis and in a DS/TAM patient an inv(21)(q11.2q22.13) at which the TAM gene locus was suspected. Here, we present the result of a fine mapping study of the TAM gene.

A total of 40 cosmids were isolated from 7 loci at $21 \mathrm{q} 11.1-\mathrm{q} 11.2$ region, using sequence-tagged sites (STSs) (G51G10, G51E07, D215S15, 26EF3R, GA2G07, G52A04, G52E12, GA7C10, D21S120, D21S16, and D21S13) for YAC contigs that cover a segment between 21q11.1-q11.2. With these cosmids, FISH study was carried out on metaphase chromosomes of the inv(21q) patient whether their fluorescence signals appear at a proximal region to a breakpoint (21q11.2) or at a nearby region of the other breakpoint (21q22.13). The analysis revealed that the breakpoint involving the putative TAM gene is situated within about $1 \mathrm{Mb}$ between the 2 markers, G51E07 and G52A04. 
1-E 17

ANGIOTENSINOGEN AS A RISK FACTOR FOR ESSENTIAL HYPERTENSION AND HYPERTENSIVE PREGNANCY IN JAPAN.

Akira HATA $^{1,2}$ Gen KOBASHI $^{1}$, Chisato NAMIKAWA ${ }^{2}$, Takamichi NAKAMURA ${ }^{3}$,

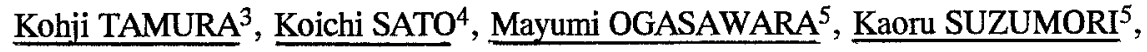
Shoii TOMODA $^{6}$, Makoto SASAKI ${ }^{2}$, Kivotaro KONDO ${ }^{1}$, J-M LALOUEL $^{7}\left({ }^{1}\right.$ Dept. Pub. Health, Hokkaido Univ. ${ }^{2}$ Dept. Biochem., ${ }^{4}$ Dept. Med., ${ }^{5}$ Dept. Ob. Gyn., Nagoya City Univ. ${ }^{3}$ Dept. Med. Yamanashi Med. Univ. ${ }^{6}$ Dept. Ob. Gyn., Osaka City Univ. ${ }^{7} \mathrm{HHMI}$, Univ. Utah)

An involvement of angiotensinogen in the pathogenesis of essential hypertension was suggested in caucasians. Angiotensinogen gene (AGT) genotype was determined with respect to residue 235 variant (M235: methionine, T235: threonine). A sample of 105 subjects with hypertensives was compared to 81 control subjects with normotensives. Allele T235 was significantly more common among hypertensives than in controls $(0.89$ vs. $0.75, \chi^{2}=11.3$ ). The frequency of the allele T235 in normotensive Japanese was much higher than observed in normotensive caucasians $\left(0.75\right.$ vs. $\left.0.36, \chi^{2}=62.1\right)$. A sample of 41 subjects with pregnancy induced hypertension (PIH) was compared to 80 control subjects. Allele T235 was significantly more common among PIH subjects than in controls ( 0.90 vs. $\left.0.71, \chi^{2}=11.9\right)$. The association of T235 with hypertension in two populations so distantly related suggests that this allele may behave as a global risk factor.

\section{1-E 18}

INSERTION/DELETION POLYMORPHISM IN THE GENE FOR ANGIOTENSIN CONVERTING ENZYME IS ALSO A POTENT RISK FACTOR FOR ISCHEMIC HEART DISEASE IN JAPANESE POPULATIONS. Tetsuro MIKI*, Yoshiko TABATA, Emiko MIYAZAKI, Masakatsu FUKUSHIMA, Yuichi KUMAHARA, Toshio OGIHARA* (* Dpt. Geriat. Med., Osaka Univ. Med. Sch.,Osaka, Sakuragaoka Hospitel)

It was reported that the deletion polymorphism in the gene for angiotensin-converting enzyme (ACE) is a potent risk factor for myocardial infarction in Caucasian populations. We have introduced the similar study to Japanese populations who have less risk factors for ischemic heart disease compared to Caucasian. Of 1644 individuals who admitted to receive routine health examinations, $102(6.2 \%)$ showed positive electrocardiogram pattern against stress testing and then were diagnosed as a silent ischemic heart disease. An insertion/deletion polymorphism in intron 16 of the ACE gene was easily detected by agarose gel electrophoresis of PCR products. We compared the genotypes in cases and controls and then we chose alow risk group from both populations. The low risk group consisted of subjects with a $B M K<26 \mathrm{~kg} / \mathrm{m} / \mathrm{m}$ and those a plasma total cholesterol level lower than $220 \mathrm{mg} / \mathrm{dl}$. In both the whole populations and the low risk groups, the frequency for the genotype insertion/insertion (II) was significantly lower that for the two genotypes $\mathrm{ID}$ and DD. This result seggests that insertion/deletion polymorphism in the gene for angiotensin-converting enzyme is also a potent risk factor for silent ischemic heart disease in Japanese populations 


\section{1-E 19}

GENETIC POLYMORPHISM OF APOLIPOPROTEIN(a) AS A RISK FACTOR FOR CORONARY HEART DISEASE. Shuichi KIKUCHI, Hideo HAMAGUCHI (Dept. Med. Genet., Univ. Tsukuba, Ibaraki), Hiroshi AMEMIXA (Tsuchiura Kyodo Hosp., Ibaraki), Yoshiyuki NAKAJIMA (Dept. Int. Med., Univ. Fukuoka, Fukuoka) and Yuichi NOGUCHI (Tsukuba Medical Center Hosp., Ibaraki)

High plasma lipoprotein(a) [ $\mathrm{Lp}(\mathrm{a})]$ levels are an independent risk factor for coronary heart disease (CHD). There is size polymorphism in apolipoprotein(a) [apo(a)], which is a major component of $\mathrm{Lp}(\mathrm{a})$, and there is an inverse correlation between the size of apo(a) and plasma $\mathrm{Lp}(\mathrm{a})$ levels. This study was conducted to clarify the role of plasma $\mathrm{Lp}(\mathrm{a})$ levels and apo(a) size in CHD. Subjects consist of 369 patients with CHD, whose onset were under 65 y.o. and 389 unrelated apparently healthy controls. The subjects with plasma $\mathrm{Lp}(\mathrm{a})$ levels above $30 \mathrm{mg} / \mathrm{dl}$ were significantly increased in CHD patient (27.4\%) compared with controls $\left(12.3 \%, \chi^{2}=27.1, \mathrm{P}<0.0001\right)$. Subjects with small apo(a) (smaller than $680 \mathrm{kD}$ ) were also significantly increased in CHD patient $(16.0 \%)$ compared with controls $\left(6.9 \%, \chi^{2}=15.4, \mathrm{P}<0.001\right)$. High $\mathrm{Lp}(\mathrm{a})$ levels were a stronger discriminator than apo(a) sizes. Inverse correlation between apo(a) sizes and plasma $\mathrm{Lp}(\mathrm{a})$ levels, but plasma $\mathrm{Lp}$ (a) levels were higher in the patient group than in the control group, when compared between the same apo(a) size groups. These results suggest that small apo(a) sizes are a genetic risk factor for CHD, and that there is (are) other factor(s) different from apo(a) sizes that associate with CHD through elevating the plasma $\mathrm{Lp}(\mathrm{a})$ levels.

\section{1-E 20}

SEQUENCE ANALYSIS OF APOLIPOPROTEIN E5 VARIANT (E5s) Yasuko YAMANOUCHI ${ }^{1}$, Yoshihide ISHIKAWA ${ }^{2}$, Katsushi TOKUNAGA ${ }^{2}$, Takeo JUI $^{2}$, Tadao ARINAMI ${ }^{3}$, Hideo HAMAGUCHI ${ }^{3}$, Shigeru TSUCHIYA ${ }^{4}$, Ryunosuke MIYAZAKI ${ }^{5}$, Takako TAKANO ${ }^{1}{ }^{1}$ Dept. Hyg. \& Pub. Health, Teikyo Univ. School of Med., Tokyo, ${ }^{2}$ Japanese Red Cross Central Blood Center, Tokyo, ${ }^{3}$ Dept. Med. Genet, Inst. Basic Med., ${ }^{4}$ Inst. Comm. Med., Univ. of Tsukuba, Ibaraki, ${ }^{5}$ Kudanzaka Hosp., Tokyo)

Apolipoprotein E (apo E) plays an important role in determining triglyceride-rich lipoprotein catabolism. It has been shown that a part of apo $E$ variants lead to hyperlipidemia. Assessment of apo E phenotype by two-dimensional gel electrophoresis of 819 Japanese males who visited a hearth care center in Tokyo, identified a rare apo E phenotype $(\mathrm{E} 3 / 5 \mathrm{~s})$. His levels of TG $(365 \mathrm{mg} / \mathrm{dl})$ and apo CIII $(33.8 \mathrm{mg} / \mathrm{dl})$ were elevated. Two-DE pattern showed this aberrant spot had a slower migration rate than E5 in spite of the same PI position as E5. In order to further characterize the E5s, we have studied its DNA sequence by T-vector cloning after PCR amplification and an automatic sequencing. In the first, second and third exons, the present sequence did not include the base substitutions reported for the apo E variants, and identical with the common type E3. Although the sequencing of the remaining fourth exon is yet to be completed, our preliminary results indicate that the apo E5s is a new apo E variant. 
1-E 21

AUTOSOMAL DOMINANT HYPOALPHALIPOPROTEINEMIA DUE TO A COMPLETELY DEFECTIVE APOLIPOPROTEIN A-I GENE

$\underline{\text { Katsunori NAKATA }}^{1}$, Kimiko KOBAYASHI ${ }^{1}{ }_{2}$ Hisako Yanagi ${ }^{1}$, Yae SHIMAKURA ${ }^{2}$ Shigeru TSUCHIYA $^{3}{ }^{2}$, Tadao ARINAMI ${ }^{1}$, and Hideo HAMAGUCHI ${ }^{1}{ }^{1}$ Department of Medical Genetics, Institute of Basic Medical Sciences, 2Institute of Clinical Medicine, and ${ }^{3}$ Institute of Community Medicine, University of Tsukuba, Tsukuba 305, Japan

Primary hypoalphalipoproteinemia is associated with atherosclerosis and exhibits significant familial aggregation. To reveal the presence of autosomal dominant hypoalphalipoproteinemia due to a completely defective apolipoprotein A-I gene, the apolipoprotein A-I gene was analyzed in a Japanese family with low levels of HDL cholesterol and apolipoprotein A-I. An insertion of a C in the region of the seven C run between codons 3 and 5 was detected in the apolipoprotein A-I gene. The heterozygous state for the mutation was associated with approximately $50 \%$ of the normal HDL cholesterol levels and of the normal apolipoprotein A-I levels. The data suggest that a part of familial hypoalphalipoproteinemia might be an autosomal dominant trait due to a completely defective apolipoprotein A-I gene.

\section{1-E 22}

THE MUTANT LDL RECEPTOR GENES IN THE JAPANESE PATIENTS WITH FAMILIAL HYPERCHOLESTEROLEMIA. Kimiko YAMAKAWA-KOBAYASHI, Hisako YANAGI, and Hideo HAMAGUCHI (Dept. Med. Genet., Inst. Basic Med. Sci., Univ. Tsukuba, Tsukuba )

The mutant LDL receptor genes in the Japanese patients with familial hypercholesterolemia (FH) were analyzed. In 40 pedigrees with $\mathrm{FH}, 13$ different mutant LDL receptor genes were thus far identified. They include five large deletions, one large insertion, two frameshift mutations, one single-amino acid deletion, three kinds of missense mutations, and a complex mutation resulting in single-amino acid deletion together with three amino acid substitutions. All the 13 mutant LDL receptor genes have not been reported in other countries. Four out of the 13 mutant genes were detected in two apparently unrelated families, respectively. These data indicate that the mutant LDL receptor genes for FH in Japanese have a tendency to differ among different families but some of them spread in different families. With regard to the mechanism responsible for the generation of mutations, a strand slipped mispairing by short direct repeats is considered to be the most likely mechanisms in two frameshift mutations and one single-amino acid deletion. 
1-E 23

MASS-SCREENING OF HEREDITARY HYPERLIPIDEMIA AMONG SCHOOL-AGE CHILDREN. Hisako YANAGI, Kimiko KOBAYASHI, Hideo HAMAGUCHI (Dept. Med. Genet., Inst. Basic Med. Sci., Univ. Tsukuba, Ibaraki), Yae SHIMAKURA (Dept. Pediatr., Univ. Tsukuba) and Shigreru TSUCHIYA (Inst. Comm. Med., Univ. Tsukuba)

For the carly diagnosis of hereditary hyperlipidemia associated with premature atherosclerosis (eg familial hypercholesterolemia and familial combined hyperlipidemia), we conducted the family studies of hypercholesterolemic children in Ibaraki, Japan. The frequency of hypercholesterolemia in children (total cholesterol levels $\geqq 200 \mathrm{mg} / \mathrm{dl}$ ) was about $7 \%$ in this area. Two hundred and forty seven pairs of the parents of hypercholesterolemic children were examined, and five families of classical familial hypercholesterolemia (with xanthomas) were diagnosed, indicating that heterozygotes of familial hypercholesterolemia (FH) number about one in 700 persons in Japanese. This frequency is similar to that of Caucasian's (about one in 500 persons). In other 242 families (non FH families), familial aggregations of hypercholesterolemia were observed at a rate of $20 \%$, suggesting that other type of hereditary hyperlipidemia such as familial combined hyperlipidemia (FCHL) are also common in Japanese. Our data also suggested that hypercholesterolemia expresses itself in childhood in a part of FCHL.

\section{1-E 24}

CLINICAL GENETIC STUDIES ON FAMILIAL COMBINED HYPERLIPIDEMIA IN CHILDREN. Yae SHIMAKURA, Natsuki IMOTO, Chiaki HIRANO, Hitoshi TAKITA (Dept. Pediatr., Univ. Tsukuba, Ibaraki), Hisako YANAGI, Kimiko KOBAYASHI, Tadao ARINAMI, Hideo HAMAGUCHI (Dept. Med. Genet., Inst. Basic Med. Sci., Univ. Tsukuba)

Two hundred and sixty seven children were diagnosed to be hypercholesterolemia (HC) from school survey of 3,113 children. Family studies of these hypercholesterolemic children indicated that thirty families were hereditary hypercholesterolemia. Based on clinical features, thirteen families were diagnosed as familial combined hyperlipidemia(FCHL). The average age of the probands with FCHL was at 10.5 years old. The relationship between hyperlipidemia and RFLP haplotypes in the apo AICIII-AIV gene cluster was examined in nine FCHL families: hyperlipidemia and the RFLP haplotypes were co-segregated in three families, but were not co-segregated in two families. The relationship was not informative or was not determined in four familes. The data suggest that the onset of hypercholesterolemia in FCHL was about age ten or earlier in considerable parts of children and genetical causes of FCHL were heterogeneous. 


\section{1-E 25}

MOLECULAR ANALYSIS OF THE C3-HYPOCOMPLEMENTEMIC FAMIL, Yoshihisa WATANABE ${ }^{1,3}$, Naomi MATSUI ${ }^{1}$, Kunimasa YAN' ${ }^{1}$, Hiroaki NISHIMUKAI $^{2}$, Katsushi TOKUNAGA $^{3}$, Takeo JUJI ${ }^{3}$, Noboru KOBAYASHI ${ }^{4}$, and Takao KOHSAKA ${ }^{1}$ ). ('Department of Immunology, National Children's Medical Research Center, ${ }^{2}$ Department of Legal Medicine, Ehime University School of Medicine, ${ }^{3}$ Japanese Red Cross Central Blood Center, ${ }^{4}$ National Children's Hospital.)

Molecular basis of the mRNAs in a case with C3-hypocomplementemia was revealed. We have found a novel C3 allotype (C3'F02') which is associated with familial hypocomplementemia. To define the mutation on the C3'F02' molecule, C3 mRNAs from the patient and her family members were analyzed. PCR-SSCP analysis revealed that mutation occurred in the region surrounding two cleavage sites for factor I. An amino acid substitution of Arg ${ }^{1298}$ (encoded by CGA) to $\operatorname{Gln}^{1298}$ (CAA) was deduced from cloning and sequencing of the C3 cDNA. This substitution occurred at one of the two Arg-Ser sequences which are recognized and cleaved by factor I. Inactivation of $\mathrm{C} 3 \mathrm{~b}$ and alteration to $\mathrm{iC} 3 \mathrm{~b}$ by factor I may be inhibited by this substitution and C3-hypocomplementemia may be caused by the overconsumption of serum $\mathrm{C} 3$.

\section{1-E 26}

CDNA CLONING OF THE P100 COMPONENT OF A NEW COMPLEMENT ACTIVATING FACTOR RaRF., Fumio TAKADA ${ }^{1,2)}$, Yoshinaga TAKAYAMA ${ }^{2)}$, Hiromi HATSUSE ${ }^{2}$, Masaya KAWAKAMI ${ }^{2)}$, ('Dept. Pediatr. and ${ }^{2}$ Mol. Biol., Kitasato Univ. Sch. Med., Kanagawa)

The Ra-reactive factor(RaRF) found in vertebrate sera binds to lipopolysaccharides(LPS) of enterobacteria and to the surfaces of fungi, yeasts and retroviruses, and activates the $\mathrm{C} 4$ and $\mathrm{C} 2$ components of complement. The LPS binding component (28-kDa C-type lectin) of RaRF was already identified as the mannose binding protein (MBP). The C4/C2activating component is $100-\mathrm{kDa}$ serine protease, called P100. In the present study, we cloned the cDNA of P100 from a human liver cDNA library, using mouse RaRF P100 as a probe. An open reading frame of 2097 nucleotides encoding a protein of 699 residues was found in the cloned cDNA of 4489 nucleotides. The characteristic modules and domain of $\mathrm{Clr}$ and $\mathrm{Cls}$ subcomponents of complement were highly conserved in this protein. However this protein exhibited low amino acid homologies with them. We confirmed the presence of a new complement activation pathway and advocate to call it "The Lectin Pathway". Recently an association was found between low levels of serum MBP and an increased frequency of recurrent infections in infants. However only a part of MBP allotypic variants have been reported to reveal recurrent infections in infancy. To analyze the predisposing cause of the recurrent infections, it is necessary to examine the levels of not only MBP gene but the P100 gene as well. 
1-E 27

EFFECT OF INTERLEUKIN-10 ON SUPEROXIDE ANION PRODUCTION AND GENE EXPRESSION OF NADPH OXIDASE COMPONENTS IN HUMAN MONOCYTES. Seiji KUGA, Takeshi OTSUKA, Hiroaki NIIRO, Yoshiaki NEMOTO, Teruaki NAKANO and Yoshiyuki NIHO (The First Dept. Int. Med., Kyushu Univ., Fukuoka)

Various cytokines have recently been shown to modulate the respiratory burst of human monocytes. In this study, we have examined the effects of IFN- $\gamma$ and IL-10 on superoxide anion $\left(\mathrm{O}_{2}^{-}\right)$production by monocytes and their gene expression of the $91-\mathrm{kD}$ heavy chain of cytochrome $\mathrm{b}, \mathrm{a}$ component of the NADPH oxidase. After 1 to 3 days of culture, $\mathrm{O}_{2}^{-}$production was measured by the superoxide dismutase inhibitable ferricytochrome $c$ reduction method using phorbolmyristate acetate (PMA) as the trigger. Total RNA was isolated from cytokine-treated monocytes and mRNA accumulation was determined by Northern blot analysis. Treatment of monocytes with IFN- $\gamma$ resulted in substantial increase in $\mathrm{O}_{2}^{-}$production and $91-\mathrm{kD} \mathrm{mRNA}$ accumulation. When monocytes were treated with both IFN-y and IL-10, O2production and $91-\mathrm{kD}$ mRNA accumulation were rather reduced as compared to IFN- $\gamma$ alone. Taken together, these results suggest that IL-10 may play important roles in immune responses via down-regulating monocyte activation by IFN- $\gamma$.

\section{1-E 28}

PHYSICAL MAPPING OF THE HUMAN IMMUNOGLOBULIN $\lambda$ GENE LOCUS. Kazuhiko KAWASAKI, Shinsei MINOSHIMA, Jun KUDOH, Nobuyoshi SHIMIZU (Dept. Molec. Biol., Keio Univ. Sch. Med., Tokyo), Toshihiko EKI, Eiichi SOEDA (RIKEN, Tsukuba)

Using YAC and cosmid clones, a physical map of the human immunoglobulin $\lambda$ gene $(\operatorname{Ig} \lambda)$ locus on chromosome 22 is being constructed. DNA markers used were isolated from a 1.4-Mb NotI fragment containing the $\operatorname{Ig} \lambda$ locus. With these markers and other Ig $\lambda$ locus-specific probes, six YAC clones were isolated. Southern hybridization analysis revealed that these YAC clones formed a contig, containing the entire $\mathrm{C}$ gene cluster and $\sim 95 \%$ of the $\mathrm{V}_{\mathrm{I}}$ and $\mathrm{V}_{\mathrm{III}}$ segments. In order to construct a fine map, a chromosome 22 specific cosmid library was screened using the YAC clones and $\mathrm{V}$ segment clones as probes. DNA from each of cosmid clones positive for the $V_{I}$ and/or $\mathrm{V}_{\mathrm{III}}$ segments was digested with various restriction enzymes. Comparison of the restriction fragment lengths allowed us to assemble these cosmids into 4 contigs. Contig $\mathrm{I}$ is $\sim 400 \mathrm{~kb}$ in length and spans from a region distal to the $\mathrm{C}$ gene cluster to a region proximal to BCRL4. Contig II is $\sim 180 \mathrm{~kb}$ in length and covers a region proximal to contig I. Contig III and IV are about $90 \mathrm{~kb}$ in length and their locations are currently under investigation. Contigs I and II contain most of the $\mathrm{V}_{1}$ and $\mathrm{V}_{\mathrm{III}}$ gene segments. 


\section{1-E 29}

THE CYNOMOLGUS MONKEY DPB1 ALLELES IN RELATION TO THE ORIGIN OF POLYMORPHISM OF HLA-DPBl GENES. Katsuko HASHIBA, Atsuo NOGUCHI (Inst. Basic Med. Sci., Univ. Tsukuba, Tsukuba), Tadashi IMANISHI (Dep. Anthrop., Fac. Sci., Univ. Tokyo, Tokyo), Shigeki MITUNAGA, Katsushi TOKUNAGA, Kenji TADOKORO, and Takeo JUJI (Jpn. Red Cross Central Blood Center, Tokyo)

The nucleotide sequences of cynomolgus monkey MHC Mafa-DPB1 were compared with those of human HLA-DPB1 to clarify the time of occurrence of polymorphism of HLA-DPBI genes in the second exon. METHOD: The nucleotide sequences of two homozygote cynomolgus monkeys selected by the PCR-SSCP method were determined directly, while those of two heterozygotes were determined after cloning. RESULTS: (1) On the phylogenetic tree of HLA-DPB1 and Mafa-DPB1 genes, all 32 HLA-DPB1 alleles formed a single clade. (2) HLA-DPB1 genes have the smallest within-species variation as measured from the numbers of nucleotide substitutions among DRBI and DQA1 genes of human, chimpanzees and rhesus macaques, and Mafa-DPB1 genes. (3) The numbers of the nonsynonymous substitutions were 2.7 times larger than those of synonymous substitutions in HLA-DPB1 genes, but 0.67 in Mafa-DPB1, and in DRB1 $(1.2,1.4,1.3)$ and in DQA1 $(0.87,0.69,0.83)$ of human, apes and macaques. DISCUSSION: It is assumed that the present polymorphism of HLA-DPB1 genes occurred during the evolution towards the hominoid line after diverging from the old world monkeys. This is in marked contrast with the cases of HLA-DRB1, DQA1 and DQB1. It is also assumed that a strong selective force operates on the HLA-DPB1 genes.

\section{1-E 30}

\section{A POLYMORPHIC AMINO ACID RESIDUE OF HLA-DR MOLECULE DETERMINED MAGNITUDE OF IMMUNE RESPONSE TO A STREPTOCOCCAL PEPTIDE IN A T CELL CLONE. Yasuharu NISHIMURA ${ }^{1}$, Yu-Chen CHEN $^{1}$, Katsushi TAKAHASHI ${ }^{2}$, and $\underline{\text { Sho }}$ MATSUSHITA ${ }^{1}{ }^{1}$ Div. Immunogenet., Kumamoto Univ. Grad. Sch. Med. Sci., Kumamoto, 2 Teijin Inst. Biomed. Res., Hino)}

HLA-DR molecule is a membrane protein consisted of monomorphic $\alpha$ and highly polymorphic $\beta$ chains. The HLA-DR molecule has an pocket on the top of extracellular domains in which antigenic peptide is accomodated. Polymorphism of DR $\beta$ chain determines structural polymorphism of peptide binding pocket and restrict the structure of peptides to be accomodated. CD4 $\mathrm{T}$ cells recognize non-self antigenic peptide in the context of polymorphic amino acid residues of HLA-DR molecule and are subsequently activated to proliferate and produce lymphokines. We investigated an interaction between a particular antigenic peptide(M12p50-72) derived from a streptococcal M12 protein and two HLA-DR4 associated molecules, DRB1*0406 and 0403. Between these two DRB1 only one amino acid residue 37 is different and it is Serine in DRB1*0406 whereas it is Tyrosine in DRB1*0403. A T cell clone specific to M12p50-72 was established from a donor heterozygous for DRB1*0406 and recognized the peptide in the context of allogeneic DRB1*0403 as well as DRB1*0406. Furthermore allogeneic DRB1*0403 presented peptide to the $T$ cell clone more efficiently than autologous DRB $1 * 0406$ did. These observations indicated that the polymorphic amino acid residue 37 of HLA-DR determined the magnitude of immune response to the peptide in the T cell clone. 


\section{1-E 31}

ANALYSIS OF A STRUCTURAL MOTIF OF THE HLA-DRB1*0405BINDING SELF PEPTIDES. Sho MATSUSHITA ${ }^{1}$, Katsushi TAKAHASHI ${ }^{2}$, Keiii KOMORIYA', and Yasuharu NISHIMURA' ('Div. Immunogenet., Kumamoto Univ. Grad. Sch. Med. Sci., Kumamoto, ${ }^{2}$ Teijin Inst. Biomed. Res., Hino)

HLA-DRB $1{ }^{*} 0405$ is primarily associated in Japanese with autoimmune diseases such as rheumatoid arthritis and type I diabetes. To elucidate a structural motif of peptides bound to DRB1*0405 molecule, self peptides have been eluted from peptide-binding grooves of the DRB1*0405 molecules purified from $10^{10}$ of EB virus-transformed $B$ lymphoblastoid cells (EBWa). The Nterminal sequencing analyses of major peaks on reversed-phase HPLC showed 8 independent sequences of self peptides. All the peptides synthesized from the sequencing results bound to acid-treated "empty" DR4. Furthermore, core residues inevitable to binding ( $F X X L X N)$ were identified by using synthetic peptides with non-conservative single amino acid substitutions. Extended substitution analyses of the 3 important positions ( $F, L$, and $N)$ on polyalaninebased AAFAALANAA demonstrated an unequivocal structural motif "( $F, Y, W, I$, or $M)-X X-(W, L, M, F$, or $V)-X-(K, R, H, N, S, F, I, V, \text { or } L)^{\prime \prime}$. These sets of information should allow us to identify possible fragments of autoantigens or foreign antigens recognized by $T$ cells in the context of DRB1*0405.

\section{1-E 32}

Analysis of HLA-B52 associated peptides. Nobuhiro Kamikawaji, Tohru Sudo, Takehiko Sasazuki (Dept. Gent.,Med.Inst.Bioreg.,Kyushu Univ. Fukuoka)

A pool of endogeous peptides bound to the human HLA-B52 has been isolated. Microcapillary high-performance liquid chromatography-electrospray ionization-tandem mass spectrometry was used to fractionate and sequence peptides isolated from the MHC molecule. Seven were sequenced and two were found in cellular proteins. Two were ten residue long, one was nine residue long and four were eight residue long. Four peptide had gulatamine in the second position and all peptide had hydrophobic residue at $C$ terminus, suggesting HLA-B52 had a distinct binding motif. 


\section{1-E 33}

\section{POLYMORPHISMS OF TAP GENES IN JAPANESE.}

Shoji KUWATA, Masami YANAGISAWA, Yoichi SHIBATA (Dept. Transfusion Med. Univ. of Tokyo), Katsushi TOKUNAGA, Takeo JUJI (Japan Red Cross Central Blood Ctr.), Yutaka HONDA (Seiwa Hsp.), Yasuko UCHIGATA, Yasue OOMORI, Yukimasa HIRATA (Diabetes Ctr., Tokyo Womens' Med. College)

We investigated TAP (transporter aasociated with antigen processing) gene polymorphisms in narcolepsy and insulin autoimmune syndrome. TAP1 and TAP2 genes encode a heterodimer protein responsible for active transport of antigenic peptide across the endoplsmic reticulum. These genes are mapped between HLADQB1 and -DPB1 loci in a region where recombination has been observed. TAP gene are reported as four possible alleles for TAP1 and eight possible alleles for TAP2. Polymorphis regions of TAP1 and TAP2 genes were amplified by PCR. Amplified products were digested with restriction endonucleases tom determine TAP gene alleles. We failed to find any differences in their frequencies between the patients and controls. Analysis of TAP gene polymorphisms will be useful for better understanding of susceptibility loci in HLA class II associatted disease.

\section{1-E 34}

MICE TRANSGENIC FOR HLA-DR51 ACQUIRED DR51-RESTRICTED T CELL RESPONSE TO SYNTHETIC PEPTIDE ANTIGEN. Ken YAMAMOTO, Yoshinori FUKUI, Yukio ESAKI, Kazuaki YAMANE, Tsutao TAKESHITA, Akinori KIMURA and Takehiko SASAZUKI (Dept. Genet., Inst. Bioreg., Kyushu Univ.)

To investigate whether human major histocompatibility complex (MHC) class II antigen, HLA-DR molecules function as Ir gene product in mice across species barrier, mice transgenic for HLA-DR51 were generated in $\mathrm{C} 57 \mathrm{BL} / 6$ background. In double transgenic mice carring both DRA and DR51B transgenes, HLA-DR51 molecules were expressed on B cells, macrophages and dendritic cells by flowcytometry. Immunization with influenza hemagglutinin derived peptide 307 - 319 (HA 307) revealed that DR51 transgenics but not B6, DRA- and DR51B- single transgenics acquired $\mathrm{T}$ cell response to this peptide. $\mathrm{CD} 4{ }^{+} \mathrm{T}$ cell line specific for $\mathrm{HA}$ 307 from the DR51 transgenics could recognize this peptide in the context of only DR51 molecule expressed on L cell, indicating not only this response is strictly restricted to DR51 molecule but functional interaction of mouse CD4 with HLA-DR molecule exists. These findings provide the first evidences that mouse $C D 4^{+} T$ cells could be generated to use HLA-DR molecule as a restriction element in transgenic mice across species barrier in the interaction between mouse CD4 and HLA-DR molecule. 


\section{1-E 35}

RG: $-1,-2$ PHE NOTYPE IN JAPANESE.

Hatsue TSUNEYAMA, Makoto UCHIKAWA, Katsushi TOKUNAGA, Tatsuya AKAZA, Takeo JUJI (Japanese Red Cross Central Blood Center, Tokyo), Mitsue HIRAYAMA, Chiaki SATO, Atsushi SHIBUYA, Yohichi ICHIKAWA. (Saitama Med. School, Saitama)

Rodgers ( $\mathrm{Rg}$ ) determinants of human $\mathrm{C} 4$ (C4d fragment) have been defind by human anti-Rg in hemagglutination inhibition assay (HAI) . 3,088 random Japanese donors have been studied by HAI using anti-Rg1+2. 9 donors were $\operatorname{Rg}:-1,-2$, and no $\operatorname{Rg}: 1,-2$ was found.

C4 protein allotyping of 8 out of the $9 \mathrm{Rg}:-1,-2$ donors showed C4AQO, QO in the 5 donors and C4A variant in the other 3 donors by immunofixation and hemolytic overlay assay after agarose gel electrophoresis.

The results of specific amplification of genomic C4 (C4A, C4B) and 21-hydroxylase (21-OHA, 21-OHB) by PCR showed no reaction products of $\mathrm{C} 4 \mathrm{~A}$ and $21-\mathrm{OHA}$ in all C4AQ0, Q0 samples.

6 examples of $\mathrm{Rg}:-1,-2$ were performed in HLA typing. All of tested donors found to have B67 antigen. There was an extremely strong association of C4AQ0 with $B 67$ antigen of HLA in Japanese.

\section{1-E 36}

HLA-DR RESTRICTED T-CELL EPITOPES FOR SYNTHETIC HEPATITIS B SURFACE ANTIGEN. Wei-ping MIN, Nobuhiro KAMIKAWAJI, Reiping DONG and Tajehiko SASAZUKI (Dept. Genet., Med. Inst. Bioreg., Kyushu Univ., Fukuoka)

One hundred and twenty-seven unrelated healthy volunteers were immunized with recombinant $H B$ vaccine three times subcutaneously. Five weeks after the last vaccination, specific antibody (by ELISA), proliferative response of PBL and HLA typing (by both serological and PCR-SSOP method) were done.The frequences of DR B 1*0101, DR B 1*0803, DR B 1*1502 were increased in high responders, and the frequences of DR B 1*0405, DR B 1*0901 were increased in low responders. Peptides spanning the sequances of HBsAg (adr subtype, 1622 mer, 10 amino acids overlapping) were synthesised and purified by reverse phase high performance liquid chromatogrphy. HBsAg specific T-cell lins were established after 2 weeks generation in the condition of $10 \%$ pooled male serum, $10 \mu \mathrm{g} / \mathrm{m} 1 \mathrm{HBsAg}, 100 \mathrm{U} / \mathrm{m} 1 \mathrm{IL}-2,1 \mathrm{U} / \mathrm{m} 1 \mathrm{IL}-4$. Proliferations of above Tcell lines to varous synthetic peptides were assaied in the presence of allogeneic PBL (3000 rad) whose HLA haplotype was half-matched as feeder cells. We found that pep-2 (residure 16-31) was the epitope of T-cell restricted by DR B 1*0101 or DR B 1*0803, and pep-14 was the epitope of the T-cells restricted by DR $B 1^{*} 1502$ or DR B 1*0901. Proliferative responses to the synthetic peptides were restricted by HLA-DR molecules becuase addition of anti-HLA-DR but not anti-HLA-DQ or anti-HLA-DP inhibited the response. 
1-E 37

ASSOCIATION OF SPECIFIC AMINO ACID SEQUENCE OF HLA DR WITH KOREAN RHEUMATOID ARTHRITIS. Gi Hyun HONG (Dep. Med. \& Phy. Ther., Univ. Tokyo, Tokyo; Dep. Biol., Sungshin Wom. Univ, Seoul), Fuiio TAKEUCHI, Hirofumi YAMADA, Keiichiro NAKANO, Kunio MATSUTA (Dep. Med. \& Phy. Ther., Univ. Tokyo, Tokyo), Myoung Hee PARK, Myoung-don oH (Dep. Clin. Path., Univ. Seoul, Seoul), Ratsushi TORUNAGA (Dep. Res., Jpn. Red Cross, Tokyo), Kyung Sook PARK (Dep. Biol., Sungshin Wom. Univ., Seoul) Koji ITO (Dep. Med. \& Phy. Ther., Univ. Tokyo, Tokyo)

The association of sequences on HLA DR genes with rheumatoid arthritis (RA) was examined in 61 Korean patients with RA and 82 controls using sequence specific oligonucleotide probes. The frequency of HLA-DR4 was significantly increased in RA patients (RR $\approx 4.3$, $p<0.0001$ ) and no significant difference was noted for that of HLA-DR1.

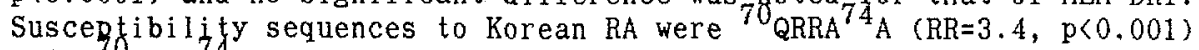
and $70_{Q K R A}{ }_{A} \quad(R R=8,8, \quad p \leq 0.05)$. These epitopes were epcoded by $\mathrm{DRB} 1 * 0405$ et al. $\left({ }_{\mathrm{QRRA}}{ }^{74}\right)$ and by DRBI $\left.* 0401{ }^{70} \mathrm{QRRA}_{\mathrm{A}}\right)$. HLA DR4/Dw15 was common type associated with RA in East Asia but was not main type in Caucasian. HLA DR4/Dw4 was associated with Rorean RA but not strongly associated with Japanese RA. indicated, Considering other reports including Chinese, the importance of conformation of $D R$ as well as epitope was assumed. Our observcation indicated detection of "QRRAA" increased the probability of diagnosis of early RA.

\section{1-E 38}

HLA-DQA GENE CONTRIBUTES TO THE HOST'S RESPONSE AGAINST HELICOBACTER PYLORI INFECTION.

Takeshi AZUMA, Junichi KONISHI, Yoshihiro KOHLI, and Norio FUJIKI. Second Dept. of Internal Medicine, Fukui Medical School, Fukui, Japan.

Helicobacter pylori infection is widely accepted as the predominant cause of chronic gastritis, and is strongly associated with duodenal ulcer disease and gastric cancer. The pathogenic mechanisms whereby $H$. pylori causes human disease remain poorly understood. Immunological factors for susceptibility or resistance to the disease caused by $H$. pylori may exist in the patients. Immune responses are controlled by genes of the major histocompatibility complex which encode the human leucocyte antigens (HLA). Individuals of different HLA types should differ in their susceptibility or resistance to infectious pathogens. In the present study, we typed the HLA-DQA1 locus in patients with chronic gastritis or duodenal ulcer harboring $H$. pylori . Twenty $H$. pylori positive patients with chronic atrophic gastritis, $37 \mathrm{H}$. pylori positive patients with duodenal ulcer, and $13 \mathrm{H}$. pylori negative healthy controls were subjected to the examination of $H$. pylori infection and HLA-DQA typing. HLA-DQA typing was carried out by polymerase chain reaction-restriction fragment length polymorphism (PCR-RFLP) method. The allele frequency of DQA ${ }^{*} 0102$ was significantly higher in $H$. pylori negative controls than in $H$. pylori positive patients with chronic atrophic gastritis or duodenal ulcer. The allele frequency of DQA $1 * 0301$ was significantly lower in $H$. pylori negative controls than in $H$. pylori positive patients with duodenal ulcer. These results suggest that HLA-DQA gene may contribute to the host's immune response against $H$. pylori infection. 
1-E 39

MODIFICATION OF ALLERGEN PEPTIDE BOUND TO HLA-DR MOLECULE INDUCED THE INCREASE OF GAMMA INTERFERON PRODUCTION IN A T CELL CLONE.

Yasuharu NISHIMURA $^{1}$, Shuji IKAGAWA ${ }^{1}$, Takeru ISHIKAWA ${ }^{2}$, and Sho MATSUSHITA ${ }^{1}$ (Div. Immunogenet., Kumamoto Univ. Grad. Sch. Med. Sci., ${ }^{2}$ Dept. Otorhinolaryngol., Kumamoto Univ. Med. Sch., Kumamoto)

Allergy to Japanese cedar pollen is induced by production of immunoglobulin $\mathrm{E}$ (IgE) specific to cedar pollen. Production of interleukin 4 (IL-4) by $\mathrm{CD} 4^{+}$helper T cell is essential for IgE production by $\mathrm{B}$ cells and $\mathrm{T}$ cells produce $\mathrm{IL}-4$ by recognition of allergen peptide in the context of HLA-class II molecules. We have established a T cell clone specific to the major allergen of Japanese cedar pollen (Cry jI) from a patient with cedar pollinosis. The T cell clone produced $\mathrm{IL}-4$ and a small amount of interferon- $\gamma$ (IFN- $\gamma$ ) by recognition of Cry jI p335-346 peptide in the context of HLA-DRB3*0301 molecule. Substitution of each one amino acid residue of Cry jI p335-346 to nonconservative amino acid revealed that substitution at the amino acid residues 338,340 , 341,344 or 345 abrogated $\mathrm{T}$ cell recognition indicating that these residues were important for antigen presentation to the $\mathrm{T}$ cell clone. On the otherhand, several mutant peptides having relatively conservative amino acid substitution stimulated the $\mathrm{T}$ cell clone . One of such mutant peptide Cry jI p335-346 (339 Val) stimulated the T cell clone to produce more IFN- $\gamma$ than wild type peptide (339Thr) did. Because IFN- $\gamma$ is a potent inhibitor of $\operatorname{IgE}$ production by $\mathrm{B}$ cells, this analog peptide derived from allergen peptide may be a good candidate of a medicine for cedar pollinosis.

1-E 40

MULTIPLE ALTERNATIVE SPLICE ISOFORMS OF PARATHYROID HORMONE-RELATED PEPTIDE mRNA IN TUMOR CELLS. Misa NAKAMURA ${ }^{1,2}$, Tomoko HASHIMOTO ${ }^{2}$, Yasuhiro SOTOZONO $^{2,3}$, Yasushi ISHIHARA ${ }^{1}$, Nariaki MATSUURA ${ }^{1}$, Kennichi KAKUDO ${ }^{1}$, and Junichi fURUYAMA ${ }^{2}$ (1Dept. Pathol., Wakayama Med. Coll., Wakayama, 2Dept. Genet., Hyogo Coll. Med., Nishinomiya, 3Dept. Pediatr., Kyoto Pref. Univ. Med., Kyoto)

Parathyroid hormone-related peptide(PTHrP) is thought to be responsible for hypercalcemia in cancer patients. PTHrP has been found in various tissues and cell lines. It has been reported that there are three types of PTHrP products, but tissue specificity of their expression is not known. The PTHrP gene has 7 exons, giving rise to 4 types of mRNAs through alternative splicing. We studied the expression of mRNAs in 12 cell lines and 3 primary tumor samples using the RT-PCR method. All cell lines and primary tissues examined expressed PTHrP transcripts. Most samples expressed all 4 types of mRNA. However, a rhabdomyosarcoma cell line, RD, showed only one type of PTHrP mRNA. A bladder carcinoma cell line, T24, and a glioma cell line, T98G, expressed two and three types of mRNA, respectively. These results suggest that PTHrP mRNA expression is not tissue-specific. 


\section{1-E 41}

MOLECULAR GENETIC ANALYSIS OF TRIIODOTHYRONINE RECEPTOR IN A FAMILY AFFECTED WITH GENERALIZED THYROID HORMONE RESISTANCE

Ryo $i$ HIRAMATSU, Masako ABE, Tomokazu SUZUKI (Dept. Clin. Genet., Med. Inst. of Bioregulation, Kyushu Univ., Beppu), Mitsuo MORITA and Shiro NOGUCHI (Noguchi Thyroid Clin. and Hosp. Foundation, Beppu)

Generalized resistance to thyroid hormone (GRTH) is an inherited disorder characterized by impaired tissue responsiveness to thyroid hormone. We have evaluated a family with GRTH for abnormalities in the thyroid hormone nuclear receptors by molecular genetic technique. We investigated the thyroid hormone nuclear receptor $\beta$ (c-erbA $\beta$ ) gene in this family by sequencing a major portion of the hormone-binding domain and the hinge domain after amplification by PCR. A single cytosine to adenine replacement was detected in the codon for amino acid 450 from the N-terminal causing a phenylalanine to leucine substitution in the c-erbAß from the propositus. Her mother who also showed GRTH had the same mutation. The in vitro translation product of this mutant gene demonstrated a significantly reduced $\mathrm{T}_{3}$-binding affinity. The prediction of the secondary structure of the mutant protein by Chou and Fasman method revealed a drastic change in the hormone-binding domain of the c-erbAß. This novel mutation is considered to be responsible for GRTH in this family.

\section{1-F 1}

AN RFLP IDENTIFIED WITHIN EXON 1 OF THE HUMAN GH-N GENE: SEQUENCE ANALYSIS OF 18 PATIENTS WITH DWARFISM

Takako OTSUKA Toshiya TAMURA Noritaka IWATANI, Teruhisa MIIKE (Dept. Child Neurol., Kumamoto Univ. Sch. Med., Kumamoto), Norio NIIKAWA (Dept. Hum. Genet., Nagasaki Univ. Sch. Med., Nagasaki)

Total deletion of the human growth hormone gene $(G H-N)$ causes isolated growth hormone deficiency (IGHD) type IA. There are reports that some patients with IGHD have various point mutations in $G H-N$. We analyzed the sequence of $G H-N$ in 18 patients with unknown dwarfism. One patient had an $A \rightarrow G$ substitution in the 47 th nucleotide of exon 1 , while the remaining 17 patients showed no evidence of mutations. The substitution found in the patient predicts an encoded Ala residue instead of $\mathrm{Thr}$, and produces a PstI restriction site. PstI-digests of genomic DNA from the patient gave 259bp (allele A) and $143 \mathrm{bp}+116 \mathrm{bp}$ (allele B) fragments. In order to know whether the mutation is related to the growth deficiency, we then analyzed 44 unrelated normal Japanese individuals with regard to the PstI site. PstI-digestion of their PCR products revealed that four persons had such a site: three were heterozygous and one homozygous for allele B. Thus, the allele frequency and heterozygosity among the Japanese were estimated at 0.057 and 0.75 , respectively. Co-dominant segregation was demonstrated in one family ( 3 individuals). This RFLP identified within exon 1 of $G H-N$ is hitherto undescribed and is useful for family analysis on the $G H-N$ expression. 


\section{1-F 3}

CORRELATION BETWEEN THE DEGREE OF CTG REPEAT EXPANSION AND CLINICAL FEATURES OF MYOTONIC DYSTROPHY

I. Eguchil R. Koike 1, O. Onodera1, H. Kondo 2 , N. Yamagata3, M.Momoi3, S. Tsuji1. 1 Dept. Neurol., Brain Res. Inst, Niigata Univ, Niigata, Japan, 2 Department of Neurol., Niigata National Hospital, Kashiwazaki, Japan, 3 Dept. Pediat, Jichi Medical School, Tochigi, Japan.

The mutation of myotonic dystrophy has been identified as unstable trinucleotide CTG repeat, located with the 3 -untranslated region of myotonin-protein kinase gene. We report correlation between the degree of CTG expansion and clinical features in 57 affected patients. CTG repeat expansion was analyzed with Southern blot hybridization. Genomic DNA from peripheral blood leukocytes was digested with Pst $\mathrm{I}$, and hybridized with radiolabelled pM10M-6 ( provided by Dr.Brook). The tendency was clearly observed when patients were categorized by clinical severities for the present analysis including ADL or mental deficiency. Intergenerational analysis of CTG expansion revealed that the small expansion in parents are proven to large expansions in the offsprings. The large CTG expansion in congenital form indicated that the size of the expansion was a significant determining factor. But the overlap in the range of repeat sizes between congenital and non congenital forms suggest that other factors, probably intrauterine effects on fetus, are also involved as well.

1-F 4

MECHANISM OF CTG EXPANSION IN MYOTONIC DYSTROPHY. Hidehisa YAMAGATA, Naoki YAMANAKA, Tetsuro MIRI and Toshio OGIHARA (Dept. Geriat. Med. , Osaka Univ. Med, Sch., Osaka)

Recently the myotonic dystrophy (DM) mutation was found to be an expansion of an unstable CTG repeat located in the $3^{\prime}$-UTR of the putative protein kinase gene. The absolute linkage disequilibrium was observed in both Caucasian and Japanese patients, between the DI mutation and a two-allele insertion/deletion polymorphism located $5 \mathrm{~kb}$ upstream from the CTG repeat, suggesting a single common origin of the mutation.

To trace this ancestral event, we have analysed the copy number of the repeat in 89 Japanese DII families and 13 control families using PCR. The associations of CTG repeat alleles on the normal chromosomes and the closely linked markers D19S63, p37.1 and an insertion/deletion polymorphism were investigated. The results strongly suggest that (CTG) $11-13$ alleles are independent and (CTG) $17-35$ may act as a predisposing allele (reservoir). 


\section{1-F 5}

Three unique mutations found in the dystrophin gene : dystrophin Kobe, dystrophin Yakumo and dystrophin (G-T) (1810). Masafumi Matsuo, Yasuhiro Takeshima, Naoko Narita, Yoko Hagiwara, Yoshihiko Kitoh, Hisahide Nishio, Hajime Nakamura, Mitsuhiro Yokoyama (ICMR, Dept Pediatr and Dept Int. Med., Kobe Univ.) Yukitoshi Ishikawa, Yuka Ishikawa and Ryoji Minami (National Sanatorium Yakumo Hospital).

We have identified three rather small mutations in the exon sequence of the dystrophin gene. In dystrophin Kobe 52 bp deletion was found in exon 19 in a patient with Duchenne muscular dystrophy. By skipping of exon 19 the resulting translational reading frame shifted (J. Clin. Invest. 87:2127-2131,1991). In dystrophin Yakumo a truncated $\mathrm{L} 1$ element was inserted into the sequence of exon 44 of a patient with Duchenne muscular. And the exon skipped durign splicing (J. Clin. Invest. 91:18621867,1993). In dystrophin (G-T)(1810), a point mutation at the 3' end of exon 13 sequence was found in Becker muscular dystrophy. The mutation induce skipping of exon 13 during splicing; but the resulting translational reading frame was maintained (Am. J. Hum. Genet. in press).

Every mutation induced exon skipping during splicing. However, only one mutation found in the last nucleotide of the exon changed the consensus sequence for splicing. In two other mutations no change was found in the consensus sequence for splicing, and other factor than the consensus sequence is suggested to control the splicing site selection.

\section{1-F 6}

A CASE OF DMD PATIENT WITH A BASE DELETION OF EXON 65.

Hiroko TSUKAMOT0 ${ }^{1.2}$. Hisao FUKUSHIMA? ${ }^{2}$, Itaru YANAGIHARA2, Tarou MATSUOKA ${ }^{2}$, Junko TANAKA ${ }^{2}$, Koji INUI ${ }^{2}$ and Shintaro OKADA ${ }^{2}$ ('Momoyama Memorial Hosp. for Infectious Dis., 0saka, ${ }^{2}$ Dept. Ped., Osaka Univ., 0saka)

$65 \%$ of DMD patients show a deletion or a duplication of one or more exons of the dystrophin gene. The other $35 \%$ of DMD patients are probably considered due to a point mutation or very small deletion or duplication. To detect such small mutations, we analyzed exon 65,67 , $68,70,75$ considered functionally important domein by single strand conformation polymorphism (SSCP) method and heteroduplex method in 10 typical DMD patients with no deletion detected by PCR method. In a DMD patient with synodactyly and polydactyly, and mental retardation, a band shift in SSCP and a heteroduplex conformation for exon 65 were obserbed. A base deletion in exon 65 generating a stop codon has been detected in this patient and his brother by direct sequencing. Their mother was also diagnosed as a carrier. Both SSCP method and heteroduplex method are very useful to screen for small mutations in large DMD gene. 


\section{1-F 7}

HIGHLY EFFICIENT JUNCTION FRAGMENT DETECTION METHOD FOR AN ACCURATE CARRIER DIAGNOSIS IN DUCHENNE (DMD) AND BECKER (BMD) MUSCULAR DYSTROPHY

Hiroyuki YAMAGISHI ${ }^{1}$, Shingo KATO $^{2}$, Yoshiyuki HIRAISHI ${ }^{2}$, Jun-ichi HATA ${ }^{3}$, Nobutake MATSUO ${ }^{1}$ and Toshiya TAKANO ${ }^{2}$ (Dept. ${ }^{1}$ Pediatr., ${ }^{2}$ Microbiol., ${ }^{3}$ Pathol.,

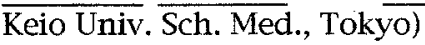

The junction fragment $(J F)$, occurring as a consequence of alteration in the structure of the dystrophin gene, allows unambiguous carrier diagnosis of $\mathrm{DMD} / \mathrm{BMD}$. However, detection of $J F$ is possible in only a small fraction of the patients by conventional analysis. We have developed a Southern blot-based JF detection method, using the four rare-cutting restriction enzymes (ApaI, BstPI, EcoRV, and KpnI) and the "Single strand DNA electrophoresis" to study twenty-seven DMD/BMD patients from 27 families with known mutations (20 deletions and 7 duplications) and the two families. The novel JFs were detected in 21 of the 27 patients ( 14 deletions and 7 duplications) in whom no $J F$ had been detected by previous conventional analysis. Using such JFs as markers, carrier diagnosis without dosage analysis was made in the two families. Since the gene deletion or duplication is known to occur in about $60-70 \%$ of $\mathrm{DMD} / \mathrm{BMD}$ patients, our data suggest that this method yields JFs in about $45-55 \%$ of all the patients and provides each respective family member with specific $J F$ to allow for simple and definitive carrier diagnosis.

\section{1-F 8}

CARRIER STATUS OF FEMALES IN FAMILIES WITH SPORADIC, DELETIONUNDETECTED DMD/BMD PROBANDS BASED ON PEDIGREE ANALYSIS, SERUM CK LEVEL AND HAPLOTYPE Reiko MORITA, Kayoko SAITO, Akemi YAMAUCHI, Takayo HARADA, Mayumi MISHIMA, Kiyoko IKEYA, IzUmi SAKUMA, Satoshi KOMINE, Eri KONDO and Yukio FUKUYAMA(Dept. Pediatr., Tokyo Women's Medical College, Tokyo)

Carrier detection for 24 at-risk females in 12 pedigrees of DMD/BMD patients was performed with PCR for non-isotopic analysis of intragenic PERT87-RFLPs and of polymorphism at a CA repeat located in the $3^{\prime}$ untranslated region of the human dystrophin gene Xp21. Carrier detection was performed based on Bayesian calculations of three information sources(DNA analysis, CK, and family history).

It was concluded that the above methods were useful because of the high heterozygosity present in $79 \%$ of at-risk females. Four of the 12 mothers of affected males were confirmed to be carriers, and the carrier risk of the other 8 was $25 \sim 75 \%$. Seven of other 12 female relatives who did not have affected offspring were confirmed to be non-carriers and the carrier risk of the other 5 was $10 \sim 73 \%$. 
Dystrophin Gene Expression in Hereditary Cardiomyopathic Hamster

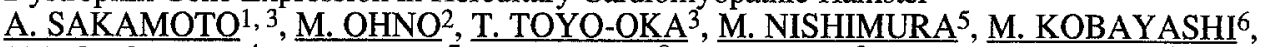

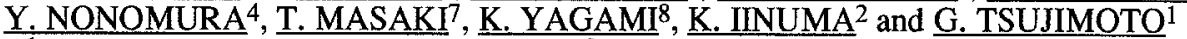

( ${ }^{1}$ Dept. of Pediatric Pharmacology and 2Teratology Lab., National Children's Medical Research Center: ${ }^{3}$ Second Dept. of Internal Medicine and ${ }^{4}$ First Dept. of Pharmacology, Univ. of Tokyo: ${ }^{5}$ Inst. of Experimental Animal, Hamamatsu Univ. School of Medicine: ${ }^{6}$ First Dept. of Pathology, Tokyo Women's Medical College: 7First Dept. of Pharmacology, Kyoto University: ${ }^{8}$ Inst. of Basic Medical Sciences, Univ. of Tsukuba )

Syrian Hamster BIO14.6 is known as animal model of human idiopathic cardiomyopathy and the phenotype transmits as autosomal recessive mode. The causal gene, however, remains to be elucidated. The animal also exhibits histopathological changes in skeletal as well as cardiac muscles, similar to Duchennne Muscular Dystrophy (DMD). So we analyzed the gene expression and intracellular localization of dystrophin, the product of the DMD gene, in this model animal by comparing with congenic normal control. First we revealed by $Q$ banding method that BIO14.6 has the same set of chromosomes as normal, without any gross abnormalities such as deletion or translocation. Northern blot analysis by using full-length cDNA for human dystrophin showed that, in both heart and skeletal muscle of BIO14.6, the transcripts exist as much as those of normal control. Furthermore, we found that immunofluorescences againt dystophin proteins localize at the peripherals of cardiac and skeletal muscle cells of not only normal but also affected hamster. These evidences suggest that the degenerative changes of this disease is quite akin to DMD but the genetic defect is different from dystrophin gene and confined to very tiny area of the chromosome.

\section{1-F 10}

CASES WHICH WE ENCOUNTERED DIFFICULTY OF DIAGNOSIS IN PRENATAL CHROMOSOME ANALYSIS OF 345 AMNIOTIC FLUID CASES.

Kiyomi YAMADA, Midoriko KASAMA(Div of Genetics, Clin Res Inst), Shigeki MINOURA. and Takashi WAGATSUMA (Dept of Obstetrics, Natl Med Cent Hosp, Tokyo 162)

During our 7-yrs-experience in amniotic fluid cases, we diagnosed 21 pregnant women as having chromosomally abnormal fetuses. However, we encountered some difficulties to diagnose fetuses according to fetal cytogenetic information alone. We had 10 cases with cytogenetic problem being apt to lead misdiagnoses: 4 fetuses were diagnosed as having normal variant chromosomes by confirmation of parental karyotypes; 13p-, 14p-, inv(1), and inv(Y), respectively. One fetus was a chimera of $46, X X / 47, X Y,+21$ which was confirmed in materials of cord blood and skin after abortion. In one case diagnosed prenatally as normal, a minute extra band on $8 \mathrm{p}$ was revealed by banding analysis after birth. One case showed trisomy -20 cells in a frequency of $18 \%$, but was informed to clinicians as normal by the reported evidence of similar cases. A t $(3 ; 9)$ translocation mosaics was found in one case, that was interpreted as a product of mutation in vitro from discordant findings between two culture dishes. In a wife of translocation carrier due to an exchange between terminal small bands without alteration of both chromosome lengths, the translocation chromosomes were precisely identified in subsequent 4 pregnancies by the chromosome painting method. Adoption of recent methods such as the high resolution banding and the chromosome painting are needed in addition to obtaining parental information on karyotypes and reproductive history. 


\section{1-F 11}

CHROMOSOME ANALYSIS OF AMNIOTIC ELUID CELLS IN HYOGO COLLEGE OF MEDICINE. Hiromi SAKAMOTO, Masafumi HANDA, Yoshie SUGAHARA, Hiroko MIMURA, Jun-ichi EURUYAMA (Dept. Clin. Genet., Hyogo Col. of Med. Hosp., and Dept. Genet. Hyogo Col. of Med., Nishinomiya)

We have been analyzing the karyotypes from amniotic fluid cells of 1048 cases in the second trimester and 49 cases in the third trimester, total 1097 cases. The indications for amniocentesis are as below: advanced maternal age $847(81 \%)$, previous Down $107(10 \%)$, previous chromosome abnormality 44(4\%), carrier of chromosome translocation $22(2 \%)$, carrier of $\mathrm{X}$-linked disorder 4(0.4\%), neural tube defect $14\left(1.4 \frac{\circ}{0}\right)$, fetal abnormality detected ultrasonically in the third trimester $49(5 \%)$, the other $31(3 \%)$. The indication of the advanced maternal age is increasing remarkably. We detected 32 abnormal karyotypes. The autosomal trisomy were found in 22 cases (trisomy 21: 11 cases, trisomy 18: 7 cases, trisomy 13: 2 cases). The sex chromosome aneuploidy were 5 cases. We diagnosed 6 true mosaicism and 13 pseudomosaicism. We failed to cultivate amniotic cells in 22 cases $(0.1 \%)$. We also experienced 2 cases with the normal chromosome which had been diagnosed prenatally but with abnormal phenotypes.

\section{1-F 12}

\section{A STUDY ON TRUE MOSAICISM, PSEUDOMOSAICISM AND MATERNAL CELL CONTAMINATION IN PRENATAL CHROMOSOME ANALYSIS OF AMNIOTIC FLUID CELLS.}

Kyohko ABE, Naoki HARADA. Kazuo NODA (Kyushu Medical Science Nagasaki Labo., Nagasaki), Norio NIIKAWA (Dept. Hum. Genet., Nagasaki Univ. Sch. Med., Nagasaki)

Cell lines with different chromosome constitutions are sometimes observed in prenatal cytogenetic diagnosis of amniotic cells. It is significant to differentiate whether they are true or pseudo mosaicism, chimerism, and/or maternal cell contamination. Among available cell culture techniques, the in situ method has been thought to be appropriate for the detection of such mosaicism. However, we are adopting a flask method, since it is simple and reliable and has advantage to detect fine structural abnormalities. We thus compared the frequency of mosaicism observed in our flask method and that in reported studies with the in situ method.

A total of 1,950 cases were analyzed with the flask method. At least 3 flasks were prepared for each case. When mosaicism was observed in only a flask and in 2 or more independent flasks, it was defined as pseudomosaicism and true mosaicism, respectively. Whenever pseudomosaicism was suspected, it was confirmed by in situ cultures. True mosaics were found in 4 cases $(0.21 \%)$ and pseudo mosaics in 16 cases $(0.82 \%)$. Of the 1,950 cases, 1,001 males (XY) were examined whether they were chimera or had maternal cell contamination. At least 20 mitotic cells were analyzed in each case. When $\mathrm{XX} / \mathrm{XY}$ karyotypes were found, the parental origin of each cell was ascertained using QFQ heteromorphisms as markers. Maternal cell contamination was observed in 6 males $(0.60 \%)$, but no chimeras were found in our series. Although the detection rate of pseudomosaicism was lower in our series than those with the reported in situ method, the frequencies of true mosaicism and maternal cell contamination were not different between them. 


\section{1-F 13}

A CYTOGENETIC STUDY OF 1,070 PRENATAL DIAGNOSES USING AMNIOCENTESIS: CONCERNING THE FREQUENCY OF CHROMOSOME ABNORMALITY.

Tamiko SHINOHARA (Dept. Hum. Cytogenet., Japan Red Cross Med. Centr., Tokyo) and Haruyoshi URANO (Dept. Obst. \& Gyne., Japan Red Cross Med. Centr., Tokyo)

We examined 1,070 cases with consecutive amniocentesis procedures, from January 1981 to March 1993, Japan Red Cross Medical Center. Indications for the examination were classified as: (A) implication in chromosome abnormality, (B) advaned maternal age, and (C) others. (A) consist of (1) carrier of translocation, (2) having previous child with chromosome abnormality and (3) having the patient with chromosome abnormality in fami1y. The corresponding figures were (A) 247 including (1) 25, (2) 180 and (3) 42 , (B) 799 , and (C) 24. The results of the examinations showed that the frequencies of chromosome abnormality were $2.8 \%(7 / 247)$ in (A) and $2.0 \%(16 / 799)$ in $(B)$. With regard to only (1) in (A), it was very high $20 \%(5 / 25)$, and all 5 cases were derived from maternal carrier. In (B), 8 cases were Down' syndrome: one mosaic type at maternal age of 36,2 standard types at 40,2 at 41,2 at 42 , and 1 at 44 , with the frequencies of each maternal ages, $1.8 \%, 2.5 \%, 3.7 \%, 5.5 \%$ and $25 \%$, respectively. We consider that the range of risk at advanced maternal age may be over 37 years old in our Center Hospital, though our data are small.

\section{1-F 14}

Changes in the frequency of fetal nucleated cells in maternal peripheral blood during pregnancy and after delivery.

Hiromi HAMADA, Tadao ARINAMI*, Satoshi SOHDA, Hideo HAMAGUCHI* and Takeshi KUBO (Dept Obstet Gynecol, Inst Clin Med, and *Dept Med Genet, Inst Basic Med Sci, Univ Tsukuba, Ibaraki)

To determine the frequency of fetal nucleated cells and their changes in maternal peripheral blood nucleated cells during pregnancy and after delivery, 50 primigravidas and 37 primiparas, a total of 245 blood samples, were investigated by observing cells with the $Y$ chromosome microscopically using fluorescence in situ hybridization (FISH) of Y-specific repetitive sequences of the DYZ1 family. Polymerase chain reaction (PCR) amplifying the same part of the DYZ1 used as the probe in FISH and a single-copy Y-specific fragment was also carried out for genomic DNA from the same samples. Cells with the hybridization signal were detected by FISH at and after 15 weeks of pregnancy in all pregnant women who gave birth to boys. The ratio of cells with the signal to those without the signal ranged from $1: 144,000$ to $1: 4,000$ with a tendency to increase as the pregnancy advanced. The frequency of these cells decreased with time, dropping below detectable levels 3 months after delivery. The frequency of fetal cells estimated by the PCR experiments were significantly and positively correlated with that found by FISH. The present study suggests that fetal nucleated cells increase in maternal peripheral blood with advancing gestation, from less than one in 100,000 nucleated cells in the first trimester to around one in 10,000 at term, and that these cells decrease in frequency with time after delivery and disappear from maternal circulation 3 months after delivery in most, if not all, mothers. 


\section{1-F 16}

DNA ANALYSIS MADE IT POSSIBLE TO DENY A NORMAL TRANSMITTING MALE IN A FAMILY WITH FRAGILE $X$ SYNDROME. Satoshi ISHIKIRIYAMA (Div. Med. Genet., Chiba Children's Hospital, Chiba), Naohiko SEKI, Masatake YAMAGUCHI, Tada-aki HORI (Div. Genet. National Institute of Radiological Sciences, Chiba)

In a genetic counselling, three men, who were two brothers and a maternal uncle of a male client, suffered from severe mental retardation. All of the mentally retarded members had long facies, prominent forehead, prognathism and macro-orchidism. We suspected fragile $X$ syndrome because of their phenotype and pedigree. Chromosome analysis under eiter folic acid deficient media or FUdR added media revealed fragile sites at Xq27.3 in the three patients and their moter, but no fragile sites in the client and their father. RFLP analysis utilizing PCR prodacts downstream to (CGG)n in FMR-1 revealed normal almost one-kilo-base Pst I fragments in the client and their father, normal one-kilo-base ones and 1.3 -kilo-base ones in their mother, and fragments with variable length ranging from 2.0 $\mathrm{kb}$ to $3.8 \mathrm{~kb}$ in the three patients. We concluded that the patients had full-mutations, that the mother a premutation, and that the client and thefather normal alles.

We can deny the possibility of a normal transmitting male in the client. We have comfirmed the efficaciuosness of DNA diagnosis in genetic counselling concerning fragile X syndrome, especially in distinguishing a normal male from a normal transmitting males.

\section{1-F 17}

MOLECULAR EVOLUTION OF ABO BLOOD GROUP GENES.

SAITOU Naruya (National Institute of Genetics, Mishima), YAMAMOTO Fumiichiro (Biomembrane Institute, Seattle)

There are three common alleles $(A, B$, and $O)$ for the human $A B O$ blood group locus, and these encode $A$ transferase, $B$ transferase, and a non-functional $O$ protein, respectively. We compared nucleotide sequences of these alleles and found relatively large numbers of nucleotide differences among them. These differences correspond to the divergence time of at least a few million years, that are unusually large for human alleles under neutral evolution. We also constructed phylogenetic trees for common and rare human alleles and for various non-human primates $A B O$ alleles. Trees thus obtained suggest that $A$ and $B$ polymorphism may be older than human-ape divergence and that the coexistence of $A$ and $B$ alleles evolved at least twice in primate evolution. These results suggest that some kind of balancing selection is operating at the $A B O$ blood group locus. If so, this may help us in elucidating the biological role of the $\mathrm{ABO}$ sugar antigens. 


\section{1-F 18}

COMPARISON OF DNA MARKER GENE FREQUENCY DISTRIBUTION AMONG JAPANESE REGIONAL POPULATIONS.

LEE SuBog, Shinji HARIHARA, Akira WATAHIKI, Momoki HIRAI (Dept. Anthropol., Grad. School. Sci., Univ. Tokyo, Tokyo), Koji SHIMIZU (Nat. Sci. Education, Naruto Univ. Education, Naruto), Shoji HARADA, Takako NAKAMURA (Inst. Commun. Med. , Univ. Tsukuba, Tsukuba) and Keiichi OMOTO (Dept. Anthropol., Univ. Tokyo, Tokyo)

Polymorphism of mitochondrial DNA was surveyed among the five regional populations: Hokkaido, Ibaraki, Tokushima, Shimane and Yamaguchi. A 9 bp deletion was detected by PCR and the following polyacrylamide gel electrophoresis of the PCR products. RFLPs by a restriction enzyme, HincII, were surveyed by the Southern hybridization method. The frequencies of the 9 bp deletion were 13 to $19 \%$ and there is no significant difference among them. The frequencies of HincII morph 1 , which has been reported to be a marker of South east Asians, were 4 to $9 \%$ and we cannot notice any significant difference among the frequencies. One of nuclear DNA polymorphisms, STR variation of GLUT2 intron 1, was also surveyed among the two Japanese populations, Ibaraki and Tokushima. PCR products were separated on polyacrylamide gel electrophoresis and size of each amplified fragment was measured. The length of amplified fragments were highly polymorphic and a total of 22 alleles were detected and 8 of them have not been reported in USA Caucasians. The allele frequency distribution was not so different among the two populations.

\section{1-F 19}

VERIFICATION OF A PROPOSED GENETIC CLADOGRAM FOR THE PRINCIPAL ALLELES OF HUMAN PHOSPHOGLUCOMUTASE 1 (PGM1) BY DNA SEQUENCING; REPORT 2. *Norio Takahashi, Junko Kaneko, Hideo Omine, Chiyoko Satoh (Dept. Genet., RERF, Hiroshima) and J.V. Neel (Dept. Human Genet., Univ. of Michigan, Ann Arbor, MI)

PGM1, which has diversities easily detectable by electrophoreses, is a particularly useful marker for human genetic research and forensic medicine. We proposed a genetic cladogram concerning the formation of eight types of the most common alleles among Japanese. The cladogram postulated that the eight alleles may be explained by three base substitutions and four recombinations between the substitutions. That is, intragenic recombination plays as significant a role as base substitution in the generation of allelic diversity of PGM1. Following the four types of alleles ( $\left.P G M 1^{*} 1+, 1-, 2+, 2-\right)$ reported at the last meeting of this society, DNA sequences were also determined for four other types of alleles $\left(P G M 1{ }^{*} 7+, 7-, 3+, 3-\right)$. In summary, only three different base substitutions $\left({ }^{265} \mathrm{~A} \rightarrow \mathrm{T},{ }^{723} \mathrm{C} \rightarrow \mathrm{T}\right.$, ${ }^{1320} \mathrm{~T} \rightarrow \mathrm{C}$, when $P G M I^{*} 1+$ was taken as the reference allele), were identified in cDNA obtained from Japanese in which eight types of genes are presumed to exist from electrophoresis. At the amino acid level, these substitutions correspond to ${ }^{67} \mathrm{Lys} \rightarrow \mathrm{Met}$, ${ }^{220} \mathrm{Arg} \rightarrow \mathrm{Cys}$, and ${ }^{419} \mathrm{Tyr} \rightarrow \mathrm{His}$, respectively. Subsequent recombinational events resulted in the remaining four alleles. These results demonstrated the propriety of the proposed genetic cladogram at the DNA level. 


\section{1-F 20}

IDENTIFICATION OF VARIATIONS IN RARE VARIANTS OF PHOSPHOGLUCOMUTASE 1 (PGM1) *Norio Takahashi, Yasukazu Kimura, Akiko Miura, Chiyoko Satoh, (Dept. Genet,, RERF, Hiroshima)

Starch gel electrophoresis of erythrocyte PGM1 obtained from 25,713 Japanese from Hiroshima and Nagasaki was performed, and 16 types of rare variants were encountered in this population. mRNAs obtained from 22 individuals, in which nine types of the rare variants were presumed to exist from electrophoresis, were amplified by RT-PCR, and their base sequences were determined. The types of amino acid substitutions were derived from the base substitutions observed. The results are shown in the right table. Since different base substitutions were identified by sequencing analysis for two different individuals known to have 4HR3 from electrophoresis, one of them was newly named "4HR4." The substitutions observed in residue 419 of $5 \mathrm{HR} 1$ and $6 \mathrm{HR} 3$ were identical to the variation identified in all variants of type "-" (PGM1 1-, PMG1 2-, etc.). These results of ten rare variants provide interesting information about the correlation between the protein structure and activity of this

\begin{tabular}{|c|c|c|}
\hline \multirow[b]{2}{*}{ Alleles } & \multicolumn{2}{|c|}{ Amino Acid Substitution } \\
\hline & Position & Types \\
\hline $4 H R 2$ & 74 & Ala $\rightarrow$ Pro \\
\hline $4 H R 3$ & 69 & Ala $\rightarrow$ Val \\
\hline $4 H R 4$ & 87 & $\mathrm{Ile} \rightarrow \mathrm{Val}$ \\
\hline $4 N G 1$ & 284 & $\mathrm{Ala} \rightarrow \mathrm{Thr}$ \\
\hline $5 H R 1$ & $\Gamma 419$ & Tyr $\rightarrow$ His \\
\hline & L 451 & $\mathrm{Arg} \rightarrow \mathrm{Cys}$ \\
\hline $6 H R I$ & 410 & $\mathrm{Asp} \rightarrow \mathrm{Val}$ \\
\hline $6 H R 2$ & 445 & $\mathrm{Glu} \rightarrow \mathrm{Lys}$ \\
\hline $6 H R 3$ & {$[419$} & Tyr $\rightarrow$ His \\
\hline & L 495 & $\mathrm{Asp} \rightarrow \mathrm{Gly}$ \\
\hline $6 N G 2$ & 368 & Ser $\rightarrow$ Arg \\
\hline $8 N G I$ & 53 & Glu $\rightarrow$ Lys \\
\hline
\end{tabular}
enzyme.

\section{1-F 21}

GENETIC POLYMORPHISM OF $\alpha$-L-FUCOSIDASE (FUCA1) DETECTED IN HUMAN SERA. Haruo TAKESHITA, Daita NADAÑO, Reiko IIDA, Koichiro KISHI (Dept. Legal Medicine, Fukui Med. Sch., Fukui) and Masao NAKANAGA (Dept. 2nd Int. Med., Fukui Med. Sch., Fukui)

Main isozyme patterns of desialylated blood plasma or serum $\alpha-[-$ fucosidase were almost identical to those of semen, urine, placental extracts and leukocyte lysates, when detected by polyacrylamide gel isoelectric focusing and activity staining using the fluorogenic substrate 4 -methylumbelliferyl$\alpha$ - - -fucopyranoside. Three phenotypes (1,2-1 and 2) determined from serum samples were the same from urine and leukocyte lysates from the same individuals: no discrepancy has been found. A population study of serum samples collected from 485 Japanese individuals indicated that the frequencies of the FUCA1*1 and FUCA1*2 alleles were 0.7505 and 0.2495 , respectively. The mean serum enzyme activities ( \pm S. D.) of the three phenotypes were $318.8 \pm 116.7 \mathrm{nmol} / \mathrm{ml} / \mathrm{h}$ for type $1,268.0 \pm 108.3$ $\mathrm{nmol} / \mathrm{ml} / \mathrm{h}$ for type $2-1$, and $233.2 \pm 84.4 \mathrm{nmol} / \mathrm{ml} / \mathrm{h}$ for type 2 from 485 normal Japanese individuals, respectively. The mean activities of types 1 and 2 suggest that, on average, the $F U C A 1^{*} 1$ gene product in the serum has about 1.4 times the activity of FUCA1*2. 


\section{1-F 22}

DETECTION OF $O$ GENE BY ALLELE-SPECIFIC AMPLIFICATION. Takasumi MATSUKI, Tamiko NAKAJIMA and Ken FURUKAWA (Dept. Legal Med., Gunma Univ. School of Med., Maebashi)

O gene of ABO blood group system was detected by polymerase chain reaction (PCR) using allele specific (AS) primers.

Twenty-three $O$ phenotype blood specimens and seven $A B$ phenotype blood specimens were analyzed by extracting genomic DNA by phenol method. PCR buffer, 5-50ng genomic DNA and primers were mixed in a PCR tube and boiled on water bath for 5 min. The boiled sample was rapidly cooling down on ice bath and was added $2.5 \mathrm{U}$ of Taq DNA polymerase from Pharmacia or Boehringer. PCR was carried out on Astec PC-700 by thirty cycles of denaturing $95^{\circ} \mathrm{C}$ for $40 \mathrm{sec}$, annealing $56^{\circ} \mathrm{C}$ for 40 sec, synthesizing 30 to $60 \mathrm{sec}$ and the last synthesis was for 5 min. Amplified samples were stored at $-20^{\circ} \mathrm{C}$ untill use and DNA was detected by $15 \%$ polyacrylamide gel electrophoresis with Tris-borate-EDTA buffer system and silver nitrate staining.

Amplified DNA band was observed in all 0 phenotype blood samples tested and no amplified band was shown in all $A B$ phenotype blood samples. In this study no exception was discovered by this AS-PCR method.

\section{1-F 23}

POLYMORPHISM OF THE "a" SUBUNIT OF COAGULATION FACTOR XIII AND NUCLEOTIDE DIFFERENCES BETWEEN ALLELES. Koichi SUZUKI, Misa IWATA, Atsuko UCHIDA, Yasuhiko MIZOI (Dept. Legal Medicine, Osaka Medical College, Takatsuki) Shigenori ITO (Dept. Chemistry)

Nucleotide differences between four common and two rare variant alleles of the "a" subunit of coagulation factor XIII (F13A) were determined by using PCR direct sequencing. A total of 14 coding exons were sequenced for both of double strands. A C to $\mathrm{T}$ transition in exon 12 which replaces a CCG codon encoding Pro564 by a CTG codon (Leu) was found to define the "A"/"B" difference. The first nucleotides of contiguous codons, GTT650 $\cdot \mathrm{GAG} 651$ (Val $\cdot \mathrm{Glu}$ ) in exon 14 for $F 13 A^{*} 1 A$ and $* 1 B$ were replaced by ATT $\cdot$ CAG (Ile $\cdot$ Gln) specifying $F 13 A * 2 A$ and $* 2 B$. Thus, combination of two allelic versions of each of exon 12 and 14 corresponded to four common alleles. These findings indicated that point mutations at two separate sites generated two new alleles and an intragenic crossing over event gave the fourth allele. Two rare alleles, $F 13 A * 4 I$ and $* 4 W$ were defined by GAA468 (Glu) for CAA (Gln) in exon 11 , and by CAG (Gln) for CGG (Arg) in exon 12, respectively, after SSCP analyses demonstrating putative exons harboring mutations. Further characterization of exon 12 and 14 of the two variant alleles showed that $F 13 A^{*} 4 I$ and $* 4 W$ mutated from $* I A$ and $* I B$, respectively. Because $F 13 A^{*} 4 I$ and $* 4 W$ were initially identified as the same $F 13 A^{*} 4$ by plasma typing, sequence data suggested that analysis on nucleotide differences is required for further characterization of conventional polymorphic markers. 


\section{1-F 24}

APPLICATION OF PCR-RFLP ANALYSIS TO GM TYPING

Kiyoshi FUJITA, Tokiko MIYAZAKI, Kiyoshi MATSUI, Shigenori ITO, Hideo Matsumoto and Yasuhiko MIZOI (Dept. Legal Med., Osaka Med. Coll., Takatsuki).

Gm allotypes, which have been found in the IgG heavy chains, are one of the most valuable genetic markers for paternity testing or personal identification. We established $\mathrm{Gm}$ typing system using PCR-RFLP analysis. Genomic DNA was purified by phenol/chloroform extraction from isolated buffy coat cells. Amplified fragments were subjected to polyacrylamide gel electrophoresis after digestion with appropriate restriction enzymes. At the same time we performed conventional $\mathrm{Gm}$ typing using hemagglutination inhibition test to detect nine phenotypes. Consequently, the results by conventional typing are in full agreement with those by the PCR-based procedure. Furthermore, we could discriminate between ag/axg and axg/axg that were impossible to be determined by conventional method. The frequencies of the two genotypes, ag/axg and axg/axg, were estimated at $13.7 \%$ and $2.0 \%$, respectively. No statistically significant deviation was estimated between the observed and the expected frequencies of ag and $\operatorname{axg}\left(\chi^{2}=0.5598\right.$, d.f. $\left.=1 、 0.25<\mathrm{P}<0.5\right)$.

\section{1-F 25}

FAMILIAL ALZHEIMER'S DISEASE IN JAPANESE POPULATION. Keiko NAGANO, Tomohiro KATSUYA, Kouzin KAMINO, Tetsuro MIKI, Toshio OGIHARA (Dept. Geriat. Med. Osaka Univ., Osaka)

We ascertained 56 kindreds with early onset familial Alzheimer's disease (EOFAD; mean onset age $<65$ years) and 10 kindreds with late onset familial Alzheimer's disease (LOFAD; mean onset age > 65 years) through questionnaire administered to neuro-psychiatric and medical school hospitals in Japan and through a review of cases in Japanese literature . Mean age of onset and death $( \pm$ S.D.) of EOFAD were $43.4 \pm 8.6$ years $(n=94)$ and $51.1 \pm$ 10.5 years $(n=85)$, respectively. Distributions of the age-onset is relatively constant within a family and significantly different between families. Our result may suggest that clinical differences between families represents genetic heterogeneity at the molecular level.

Six out of 32 kindreds with EOFAD showed the $717 \mathrm{Val} \rightarrow$ Ile mutation of $\mathrm{b} / \mathrm{A} 4$ amyloid precursor protein (APP) gene . This result suggests that the frequency of this mutation in Japanese population is higher than in Caucasian and allelic heterogeniety is existence in Japanese EOFAD. 
1-F 26 Statistical analysis as to why APRT deficiency is common among the Japanese. Naoyuki Kamatani, Chihiro Terai, Hisashi Yamanaka, Masayuki Hakoda, and Sadao Kashiwazaki Institute of Rheumatology, Tokyo Women's Medical College

Adenine phsophoribosyltransferase (APRT) deficiency is an autosomal recessive genetic disease, and the homozygotes develop urolithiasis and renal insufficiency. We performed a statistical analysis on cases whose samples have been sent to our laboratory for the diagnosis. We have so far diagnosed 110 homozygous individuals which comprise the majority of the reported cases in Japan. 120 cases with homozygous APRT deficiencies have been reported among Japanese representing about $70 \%$ of all the reported cases in the world. Therefore, this disease seems to be more common among Japanese than other ethnic groups. Among the cases whose samples were sent to us for the diagnosis, the genotypes were determined in 90 patients from 73 families. 70 cases from 55 families exhibited the type 2 (partial deficiency) deficiency, while 20 cases from 18 families had the type 1 (complete deficiency) deficiency. As to the genotypes, 48 , 8 and 18 families were with $A P R T^{*} J / A P R T^{*} J, A P R T^{*} J / A P R T^{*} Q 0$, and $A P R T^{*} Q O / A P R T^{*} Q 0$. In the remaining two families, the accurate genotypes could not be determined. The ages at diagnosis were $31.4+19.5(n=37), 33.3+$ $28.1(\mathrm{n}=7)$, and $24.1+17.6(\mathrm{n}=16)$ for individuals with genotypes, $A P R T^{*} J / A P R T^{*} J, A P R T^{*} J / A P R T^{*} Q 0$, and $A P R T^{*} Q O / A P R T^{*} Q 0$, respectively; thus, suggesting a higher onset age for the type 2 patients than the type 1 patients. According to the above data, the frequency of homozygotes for APRT deficiency would be $1 / 5$ of the current value if $A P R T * J$ allele were not present. If the population is in the Hardy-Weinberg's equilibrium, then the frequency of the homozygotes would be $1 / 10$ if $A P R T^{*} J$ allele were not present. Taken together our analysis suggests that the presence of $A P R T * J$ allele among the Japanese but not in other populations explains the high incidence of APRT deficient individuals among this population.

\section{1-F 27}

PEPSINOGEN C GENE POLYMORPHISMS IN THE JAPANESE POPULATION Zentaro YAMAGATA, Shinichi SHINOZAKI, Toshihiro MIYAMURA, Sumio IIJIMA and Akio ASAKA (Dept. of Fealth Sciences, Yamanashi Medical University)

Human pepsinogens are classified into two biochemically and immunologically distinct groups of isozymogens: pepsinogen A (PGA) and pepsinogen $\mathrm{C}$ (PGC). Recently pepsinogens have been considered to be effective markers of terminal differentiation of stomach mucosa, and also good markers of preneoplastic and neoplastic changes of the stomach mucosa. PGA and PGC gene have been localized to 11q13 and 6p21.1-pter respectively. Though polymorphisms in both genes have been reported, there are few reports about relation between polymorphisms and gastric diseases. We have tried to detect the genetic back ground for stomach cancer by using PGC gene polymophisms. The polyorphisms of PGC gene are identified by PCR which amplfies DNA in the region within the intron between exon 7 and exon 8 (Asuma, 1988; Bowcock, 1992) and 6\% polyacrylamide gel (no urea) electrophoresis. 6 alleles were observed in the Japanese population. The six alleles were: $0.50,0.48,0.45,0.43,0.40$, $0.31 \mathrm{~kb}$. Frequencies for these alleles in 200 unrelated Japanese chromosomes were: $0.061,0.038,0.205,0.333,0.015$ and 0.348 , respectively. Two alleles $(0.50$ and $0.43 \mathrm{~kb})$ of them are de novo alleles because they have never been identified in Caucasoids. These PCR products were cloned in plasmid vectors and sequenced. 


\section{1-F 28}

Gm ALLOTYPE FOUND IN ABORIGINES OF SOUTHAMERICAN SOUTHERN AREA Shinya MUTO, Tokiko MIYAZAKI, (Dept. Laboratory of Legal Medecine, Osaka Medic al College Takatsukí Osaka) Hideo MATSUMOTO (President Osaka Medical Coll lege)

The Gm allotype was unknown in the inhabitants of Southamerican southern area. The authors collected and analysed their blood of the five populations there in from January to April this year. The studies provide for defection of Gm allotype in the inhabitants domiciled in Southamerican southern area. The results showed that the Mapuches of Chile, and Aimaras of Bolivia were at values of $\mathrm{Gm}$ ag $0.7725, \mathrm{Gm}$ axg 0.0204 , Gm ab ${ }^{3}$ st $0.0, \mathrm{Gm} \mathrm{fb}^{1} \mathrm{~b}^{3} 0.2071$ and Gm ag 0.8683 , Gm axg 0.0317 , Gm $a b^{3}$ st 0.0313 , Gm $\mathrm{fb}^{1} \mathrm{~b}^{3} 0.0688$, respectively. The Chipayas of Bolivia and the Alacarufes and Yaganas of Chile were, however, at a $100 \%$ value only of $\mathrm{Gm} \mathrm{Ag}$ and at zero all of the $\mathrm{Gm}$ axg, Gm afb $\mathrm{b}^{3}$, $\mathrm{Gm} a b^{3}$ st and Gm $\mathrm{fb}^{1} \mathrm{~b}^{3}$.

Thus, the presence at $100 \%$ of $\mathrm{Gm}$ ag in the race was first found by us in the world. These suggest either the carrier of both the Gm ag and Gm axg lost axg due to the so-called bottle neck effect the population genetics or the single carrier of Gm ag originally migrated through Bering Str. which conbinued to the mother land 40 thousands years ago. These details are historically unknown.

\section{1-F 29}

DEATH RATE, MEAN AGE AT DEATH, AND MARITAL STATUS OF GENETIC DISEASES IN JAPAN, 1979-1985. Yoko IMAIZUMI (Institute of Population Problems, Ministry of Health and Welfare, Tokyo)

The paper deals with death rates of genetic diseases, the mean age at death, and the proportion of unmarried. Data on the deaths from genetic diseases were taken from the death certificate records from all of Japan, 1979-1985. Genetic diseases were peroneal muscular atrophy (ICD356.1; 49 cases) Huntington disease (ICD 333.4; 125 cases), chondrodystrophy (ICD756.4; 84 cases), tuberous sclerosis (ICD759.5; 38 cases), cystic fibrosis (ICD277.1; 27 cases), mucopolysaccharidosis (ICD277.5; 58 cases), Friedreich ataxia (ICD334.0; 10 cases), Schilder disease (ICD341.1; 26 cases), and ichthyosis congenita (ICD757.1; 8 cases). As for marital status, the corresponding proportion of unmarried in each disease was $29 \%, 26 \%, 99 \%, 92 \%, 93 \%, 95 \%, 50 \%, 77 \%$, and $88 \%$, respectively. As for the mean age at death, the corresponding value in each disease was $55,48,1,26,6,19,45,26$, and 9 years, respectively. Age-specific death rate of genetic disease was computed in each disease. 


\section{1-F 30}

EPIDEMIOLOGICAL STUDY OF LIMB REDUCTION DEFECTS IN KANAGAWA BIRTH DEFECT MONITORING PROGRAM (KAMP). Yoshikazu KUROKI, KiyOshi IMAIZUMI, Hiroshi KONISHI (Div. Med. Genet., Kanagawa Child. Med. Cent., Yokohama)

Limb reduction defects (LRD) are congenital malformations characterized by total or partial absence or severe hypoplasia of skeletal structures of the limbs. LRD are a very important group of malformations to be monitored because of its sensitivity to environmental causes known since the old episode of thalidomide. Epidemiological study of LRD was performed in Kanagawa Birth Defects Monitoring Program (KAMP) during the period 1981-1992. An overall prevalence rate of LRD in KAMP was 5.0 in 10,000 births, ranging from 3.1 through 7.3. It was almost the same to that in other similar studies in the world. About $60 \%$ cases fitted into the transverse type, followed by intercalary and preaxial types, 10-13\% each, multiple type, postaxial and unclassifiable types. Forty $\%$ were isolated LRD and $60 \%$ were associated with other non-limb malformations. Though maternal ages at birth were normal, paternal ages were slightly elevated. Gradually decreasing trends in the prevalence of LRD were noticed in recent 5 years. Wide-spread prenatal diagnosis probably plays an important role in recent decrease of LRD.

\section{1-F 31}

SEXING OF MOUSE PREIMPLANTATION EMBRYOS BY THE PCR METHOD AND EMBRYO TRANSFER

Tomone YANO, Yutaka SASABE, Susumu KATAYAMA, Naoki TAKESHITA, Yukiko KATAGIRI, Harumi KUBO, Shun HIRAKAWA (1st. Dept. Obstet. \& Gynecol., Toho Univ., Tokyo)

The feasibility of the dual PCR method in embryo sexing was examined using mouse pre-embryos obtained by in vitro fertilization. The Sry and the myogenin gene sequences were amplified as the $\mathrm{Y}$-specific and internal control sequences, respectively. Amplification of $10 \mathrm{pg}$ of mouse genomic DNA was possible with the dual PCR method, the sensitivity being 10-fold greater than that of the single PCR method. The sex was identified in $100 \%(24 / 24)$ and $96 \%(23 / 24)$ of the pre-embryos tested at the 16- and 4-cell stages, respectively. In addition, the sex of all four single blastomeres dissociated from 4-cell pre-embryos agreed in 76\% $(16 / 21)$ of the specimens tested and $94 \%(79 / 84)$ of dissociated blastomeres could be sexed. The sex of single blastomeres biopsied from pre-embryos at the 8-cell stage could be identified. After transfer of 13 male and 25 female sexed pre-embryos, six viable fetuses were obtained. Histological examination showed that all these fetuses were of the predicted sex. Sexing of biopsied single blastomere by the dual PCR method was rapid and reliable, suggesting its feasibility for preimplantation diagnosis of in vitro-fertilized human pre-embryos. 


\title{
1-F 32
}

\author{
PREMATURE CHROMOSOME CONDENSATION (PCC) AFTER IN VITRO \\ FERTILIZATION (IVF) . \\ Yoshiharu NAKAOKA, Etsuji OKAMOTO, Koso OHAMA (Dept. Obstet. Gynecol., \\ Hiroshima Univ. Sch. of Med., Hiroshima) and Yujiroh KAMIGUCHI (Dept. Biol. \\ Sci., Asahikawa Med. Col., Asahikawa)
}

Premature chromosome condensation (PCC) is a phenomenon whereby sperm nuclei which penetrate immature oocytes undergo chromosome condensation in the absence of pronuclei formation. This phenomenon is induced by maturation promoting factor in immature oocytes. During IVF cycling, follicle stimulation may produce an abundance of immature oocytes. In this study, we investigated the incidence of PCC in oocytes which fail to fertilize. A total of 501 oocytes were obtained from IVF patients following follicle stimulation. Oocytes which did not undergo pronuclei formation or were arrested prior to cleavage at day 2 after insemination were evaluated as unfertilized oocytes. A gradual fixation-air drying method was utilized to perform a cytogenetic analysis. Of 436 metaphase II oocytes, 30 oocytes (6.9\%) had PCC. The incidence of PCC in this study was similar to that of previous reports. This is the first report to study the incidence of PCC in human oocytes in JAPAN.

\section{1-F 33}

SCREENING FOR HUMAN IMPRINTED GENES USING HYDATIDIFORM MOLE AND NORMAL VILLI: THE TUMOR SUPPRESSOR GENE, WT1, IS PATERNALLY IMPRINTED

Yoshihiro JINNO, Takeo KUBOTA, Kunihiko NISHIWAKI, Norio NIIKAWA (Dept. Hum. Genet., Nagasaki Univ. Sch. Med., Nagasaki)

Genomic imprinting is implicated in an ever-increasing number of diseases including tumors. Only 4 mouse-genes have been known to be imprinted, and the two human genes, IGF2 and H19, are confirmed to represent paternal, monoallelic expression in the human. We took advantage of hydatidiform mole, an androgenetic product, in which transcripts of maternally expressed genes should not be detected. The cDNAs were prepared from poly(A)+ RNAs of a 13 weeks' mole, and 11 weeks' and 14 weeks' normal chorionic villous tissues, using oligo (dT) primer. Transcript levels were semiquantified by PCR amplification. Based on the imprinting map of the mouse, 28 human genes including IGF2 and IGF2R were chosen to be screened for the possibility of imprinting. Among them, 4 genes showed differential expression. IGF2 was expressed much more abundantly in the mole than in normal villi. $W T 1, G A B R B 3$ and $T P X 1$ were preferentially expressed in normal villi. Monoallelic (maternal) expression of $W T 1$ was confirmed using a dinucleotide repeat polymorphism in the $3^{1}$ UTR in 5 cases of 7 normal pre-term placentae. Although its expression was biallelic in fetal kidneys, monoallelic expression was observed in fatal brains. $I G F 2 R$ was equally expressed in both tissues. This may represent tissue-specificity. Alternatively, it may not be imprinted in the human. 


\section{1-F 34}

A cluster of testis-/embryo-expressed genes in the mouse $\mathrm{H}-2 \mathrm{~K}$ region.

Kuniya Abe ${ }^{1}$, Karen Artzt ${ }^{2}$, Ken-ichi Yamamura ${ }^{1}$

( ${ }^{1}$ Inst. of Mol. Emb. Genet., Kumamoto Univ., ${ }^{2}$ Univ. of Texas at Austin )

Majorhistocompatibility complex ( MHC) is known to contain genes important in immune system: the highly polymorphic class I and class II genes, the class III components of the complement cascades, and a newly found peptide transporter gene. In the MHC a striking number of transcription units of unknown function have also been revealed. There are several reasons for scrutinizing this complex. First, some MHC haplotypes are known to be involved in susceptibility to diseases. In some cases, it is possible that the genetic predispositon is associated with as yet unidentified genes closely linked to the class I or II loci. Second, the MHC is embedded in the middle of the $t$ complex. In mutant $t$ haplotypes, at least three recessive early embryonic lethal genes are contained in or near the MHC. Especially, $t c l-w 5$ is genetically inseparable from $H-2 K$. Lastly, knowledge of the detailed genomic organization of the MHC should allow an in-depth understanding of the evolutionary history of a sizable segment of mammalian chromosome. Here we describe an extended chromosomal walk started from the $\mathrm{H}-2 \mathrm{~K}$ gene. Detailed structural analysis of the cloned DNA and characterization of transcription units embedded in this region revealed highly polymorphic nature of the entire segment surrounding the $H-2 \mathrm{~K}$ and the presence of at least 13 novel transcripts. Most of these genes are found to be expressed in embryonic cells and/or germ cells.

\section{1-F 35}

SUPPRESSION OF DIABETES IN NOD-A ${ }^{\mathrm{K}}$ MICE. Fumi TASHIRO ${ }^{1}$, Masatoshi ISHII ${ }^{1}$, Ken-ichi YAMAMURA ${ }^{2}$ and Jun-ichi MIYAZAKI ${ }^{1}$ ('Dept. Disease-related Gene Reg. Res. (Sandoz), Univ. of Tokyo, Tokyo, ${ }^{2}$ Inst. of Mol. Embryol. \& Genet., Kumamoto Univ., Kumamoto)

Transgenic expression of the MHC (major histocompatibility complex) class II I-A $\mathrm{A}^{\mathrm{k}}$ molecule was previously shown to effectively reduce the incidence of insulitis in non-obese diabetic (NOD) mice at the age of 20 weeks. We have further characterized the expression and function of the $I-A^{k}$ molecule and examined its effects on the incidence of diabetes in NOD mice. FACS analyses showed that the $\mathrm{I}^{-\mathrm{A}^{\mathrm{k}}}$ transgene was expressed on peripheral blood lymphocytes (PBL) at the same level as in control $\mathrm{C} 3 \mathrm{H}$ mice, and that the levels of endogenous $\mathrm{I}-\mathrm{Ag} 7$ expresion on PBL were not affected by the transgene expression. To examine the effect of transgene expresssion on the population of PBL, we stained spleen cells of NOD- $\mathrm{A}^{\mathrm{k}}$ and control NOD mice by several cell surface markers. The result showed that the transgene expression did not significantly affect the population of lymphoid cells. I- $A^{k}$ transgenic NOD mice were completely resistant to spontaneous diabetes, but the treatment by cyclophosphamide, which effectively induces diabetes in normal NOD mice, caused diabetes although at a much lower incidence than that of normal NOD mice. 


\section{1-F 36}

TRANSGENIC MICE EXPRESSING ANTI-SENSE GLUCOKINASE RNA IN $\beta$ CELLS. Jun-ichi MIYAZAKI, Fumi TASHIRO, Koichi IKUTA (Dept. Dis.-rel. Gene Reg. Res., Univ. Tokyo, Tokyo), Hisamitsu ISHIHARA and Yoshitomo OKA (The Third Dept. Int. Med., Univ. Tokyo, Tokyo)

Recently, mutations in the glucokinase gene have been found in patients with maturity-onset diabetes of the young (MODY), which has raised the possibility that a decrease in glucokinse activity may impair the glucosestimulated insulin secretion in $\beta$ cells, leading to diabetes. To test the effect of a reduced glucokinase activity in $\beta$ cells on $\beta$-cell function and thier ability to maintain glucose homeostasis, we generated transgenic mice expressing an anti-sense glucokinase mRNA in $\beta$ cells. The transgene construct contains the human insulin promoter linked to a $5^{\prime}$ part of glucokinase cDNA of $\sim 280 \mathrm{bp}$ long including the start codon and is designed to produce an RNA that hybridizes specifically to glucokinase mRNA molecules, resulting in reduced levels of glucokinse mRNA in cells expressing the transgene. Fourteen mouse lineages were generated. Their fasting blood glucose levels were significantly higher that those of negative littermates. Studies are underway to determine the glucokinase activity in islets isolated from these mice. These mice are likely to provide insights into the role of glucokinase in glucose sensing in $\beta$ cells under various physiological conditions. These results also demonstrate the potential of applying antisense RNA for cell-specific reduction in gene expression in vivo.

\section{1-F 37}

CHARACTERIZATION OF ORNITHINE TRANSCARBAMYLASE ENHANCER IN TRANSGENIC MICE. Masaki TAKIGUCHI, Atsushi NISHIYORI, Kiwamu AKAGI*, Ken-ichi YAMAMURA* and Masataka MORI (Depts. Mol. Genet. and *Der. Genet., Kumamoto Univ. School Med., Kumamoto)

The ornithinc-urea cycle is the major pathway for detoxication of ammonia formed in amino acid melabolism. The cycle is also involved in biosynthesis of arginine. Ornithine transcarbamylase (OTC) catalyzes the second among the five enzymatic steps of the cycle. The enzyme is present in the liver and to a lesser extent in the small intestine. OTC deficiency is known in humans and mice, as an inborn error of metabolism that results in protein intolerance and hyperammonemia. The rat and human OTC genes span a region of $70-75 \mathrm{~kb}$ on the $\mathrm{X}$ chromosome. In transgenic mice, the promoter of the rat OTC gene directed liver- and small intestine-specific expression, but the expression of the transgene in the liver was very low. We found a hepatoma-specific enhancer region of $\sim 110$ bp located $11 \mathrm{~kb}$ upstream of the transcription start site. In transgenic mice, an OTC enhancer/OTC promoter/OTC cDNA transgene was expressed more strongly in the liver than in the small intestine, thus resembling the expression of the endogenous gene. This enhancer-containing plasmid may be useful for gene therapy of OTC deficiency. 


\section{1-F 38}

Structure and Expression of the mouse Neurofibromatosis type1-GTPase activating protein-related domain. Akio MANTANI, Shoji. WAKASUGI, Yoshifumi. YOKOTA, Kuniya. ABE Ken-ichi. YAMAMURA (Inst. Molec. Embryol. \& Genet., Kumamoto Univ. Med. Sch., Kumamoto) and Yukitaka. USHIO (Neurosurg., Kumamoto Univ. Med. Sch., Kumamoto)

Von Recklinghausen neurofibromatosis, or neurofibromatosis type 1 (NF1), is a common autosomal dominant disorder characterized by abnormalities in multiple tissues derived from the embryonic neural crest. The previous report revealed two types of NF1-GTPase activating proteinrelated domain (NF1-GRD) transcript which appear to be generated by an alternative splicing mechanism. To produce a mouse for this disease by targeting, we examined structure and expression of mouse NF1-GRD. Four types of cDNA encoding for NF1-GRD have been cloned. One of these isoforms was newly identified form termed type IV. Analysis on the genomic structure of the mouse NF1-GRD revealed two exons (23A and 23B) between exons 23 and 24, leading to the production of four types of NF1-GRD cDNA by alternative splicing mechanism. Amino acid sequences encoded by NF1-GRD are highly conserved between human and mouse. Analysis on expression of these transcripts in various tissues of adult mouse revealed that the type I transcript is predominantly expressed in neural tissues such as brain and spinal cord. Other forms, termed type II, III and IV are also expressed in various tissues. The type I and type II transcripts are expressed equivalently in undifferentiated P19 mouse teratocarcinoma cells, whereas the type I expression becomes predominantly during neuronal differentiation by retinoic acid treatment. Expression of type I is also shown to be correlated with cessation of cell proliferation in P19 cells. These, together with other results, suggest that four types of NF1-GRD transcript generated by alternative splicing have some important biological role in cell differentiation and proliferation.

The Guidlines for Topics on the National Medical Licensing Examination, which is prepared by the Ministry of Health and Welfare(MHW), has a major influence on the medical knowlege of doctors. In the 1993 revision of the Guidelines, subject of pediatrics has been eliminated and simultaneously subjects related to human genetics appear only seen in frequently.

As human genome analysis has progressed, genetic medicine has become increasingly important in actual clinical practice. Knowlege of genes has outgrown the sphere of genetic diseases and expanded to include recognition of human exsistence itself. Recently a number of current tests and diagnostic methods, such as chromosomal testing, amniotic fluid testing, and DNA diagnosis, were examined by the nonofficial medical examination centers. Society desires that medical training is not remain obedient to conventional therapies but rather evolve toward $s$ a more patient-oriented perspective that incorporates recent understanding of the nature of life. In this sence, it is necessary to comprehensively evaluate medical training. Given the role that children play in society's future and the essential importance of human genetics, medicine's current failure to emphasize pediatrics and genetics seems misdirected. 


\section{1-F 40}

POPULAR IMAGE OF THE TERM "GENETIC DISEASE"

Tomoko Hasegawa, Keiko Iwasaki, Jun Kouji, Takeyasu Igarashi (Div. Clin. Genet., Shizuoka Child. Hosp., Shizuoka)

An attempt was made to grasp the types of attitudes toward genetic disease, in comparison with those toward cholelithasis as a representative hereditary disease. Methods: The 424 participants in this survey (398 for the term cholelithasis) were nursing students, midwives, professionals in the training and education of handicapped children, medical students and non-medical students, ranging in age from 19 to 85 years. They described the images they held of these terms, and took one minute to describe each.

Results: Most participants said that their image of genetic disease was a feeling of dreadfulness, pity, hate or avoidance, and that there was no treatment or prevention. Objective images of genetic disease included a heavy burden on the family and serious disease for which there was no cure. Many participants, however, stated diseases that are not so serious medically, such as hemophjlia and color blindness, as examples of individual diseases. In contrast to the bad image of "genetic disease", that of "cholelithiasis" was quite mild, even though it has a hereditary background. These results show that the Japanese public have insufficient knowledge of medical genetics, and that education in this field is badly needed in Japan.

\section{2-D 1}

PARTIAL MONOSOMY FOR THE 4q DISTAL REGION ASSOCIATED WITH ROBIN SEQUENCE: MOSAICISM OF TWO CELL TYPES SHOWING DIFFERENT DELETED REGIONS. Tatsuro IKEUCHI ${ }^{1}$, Toshiaki SHIMIZU ${ }^{2}$, Ryoko NORINAGA ${ }^{1}$, Satoru NAGATA ${ }^{2}$, Ke ijiro YABUTA ${ }^{2}$ ( ${ }^{1}$ Dept. Cytogenet., Med. Res. Inst., Tokyo Med. Dent. Univ., ${ }^{2}$ Dept. Pediat., Juntendo Univ., Sch. Med., Tokyo)

The patient was a 5-month-old female infant who showed Robin sequence (micrognathia, glossoptosis and cleft palate). She also showed large ears, saddle nose, overlapping fingers in both feet, hypotonia and DQ $75 \%$. Chromosome analyses in blood cultures showed a deletion on the $4 \mathrm{q}$ distal region. Both parents were healthy and chromosomally normal. High-resolution G- and $\mathrm{R}$-band analyses by the ethidium bromide technique and by the method of cell synchronization followed by BrdU treatment, respectively, demonstrated the two cell types, one (51\%) with a deletion of larger segment (identified as $\mathrm{q} 31.3 \rightarrow \mathrm{q} 35.1$ by G-banding, and $\mathrm{q} 32 \rightarrow \mathrm{q} 35.2$ by R-banding), and the other (49\%) with a smaller deletion ( $\mathrm{q} 33 \rightarrow \mathrm{q} 35.1$ by $\mathrm{G}^{-}$, and $\mathrm{q} 34 \rightarrow \mathrm{q} 35.2$ by $\mathrm{R}$-banding). The different identification of the breakpoints by the two staining methods would be explained by the possibility that the breakpoints are located at the boundaries of $G$ and $R$ subbands. The mosaic cases of cells showing the 2 different deleted segments are quite rare, and possible mechanisms for the genes is of such chromosomal structural anomalies were discussed. 


\section{2-D 2}

DOMINANTLY INHERITED 4p DISTAL DUPLICATION DETECTED BY MICRODISSECTION-PAINTING METHOD. Tatsuo MAEMOT0 (Dept. Pediatrics. Tokyo Women's Medical College. Tokyo; Dept. Pediatrics, Asahi General Hosp., Chiba), Norihisa USUI, Chinatsu SEKI. Ayako MUTOU, Akemi YAMAUCHI (Dept. Pediatrics, Tokyo Women's Medical College, Tokyo), Humihiro OHASHI, Yoshimitsu FUKUSHIMA (Division of Medical Genetics, Saitama Children's Medical Center, Saitama), Yukio FuKuYAMA (Dept. Pediatrics. Tokyo Women's Medical College, Tokyo)

The proband was a 6 -month-old male infant. He was born at gestational age of 37 weeks with birth weight of $2554 \mathrm{~g}$ by cesarean section. He immediately underwent operation for omphalocele. When we first examined him at 6 months of age, he showe growth retardation, mild psychomotor retardation, mild hypotonia, frontal bossing, hypertelorism, upward slanted palpebral fissures, low and broad nasal bridge, retrognathia, high arched palate, blunt mandibular angle, short neck, clinodactyly, cryptorchidism, omphalocele, hypoplasia of the pelvis and hypogenesis of the corpus callosum on MRT. Both his mother and elder sister also showed short stature and the same facies as him. His sister was the daughter of a different father. His mother also showed bilateral hearing disturbance and dislocation of the hip joints. Chromosomal analysis with G-differentiation only showed unknown original insertion in $4 \mathrm{p}$. Mmicrodissection-painting method revealed that his karyotype was 46, XY, dir dup (4) (pl3 $\rightarrow$ pl5.2) mat. His mother and sister had the same duplication, and his grandparents had normal karyotype. This is the first case report of dominantly inherited $4 p$ duplication.

\section{2-D 3}

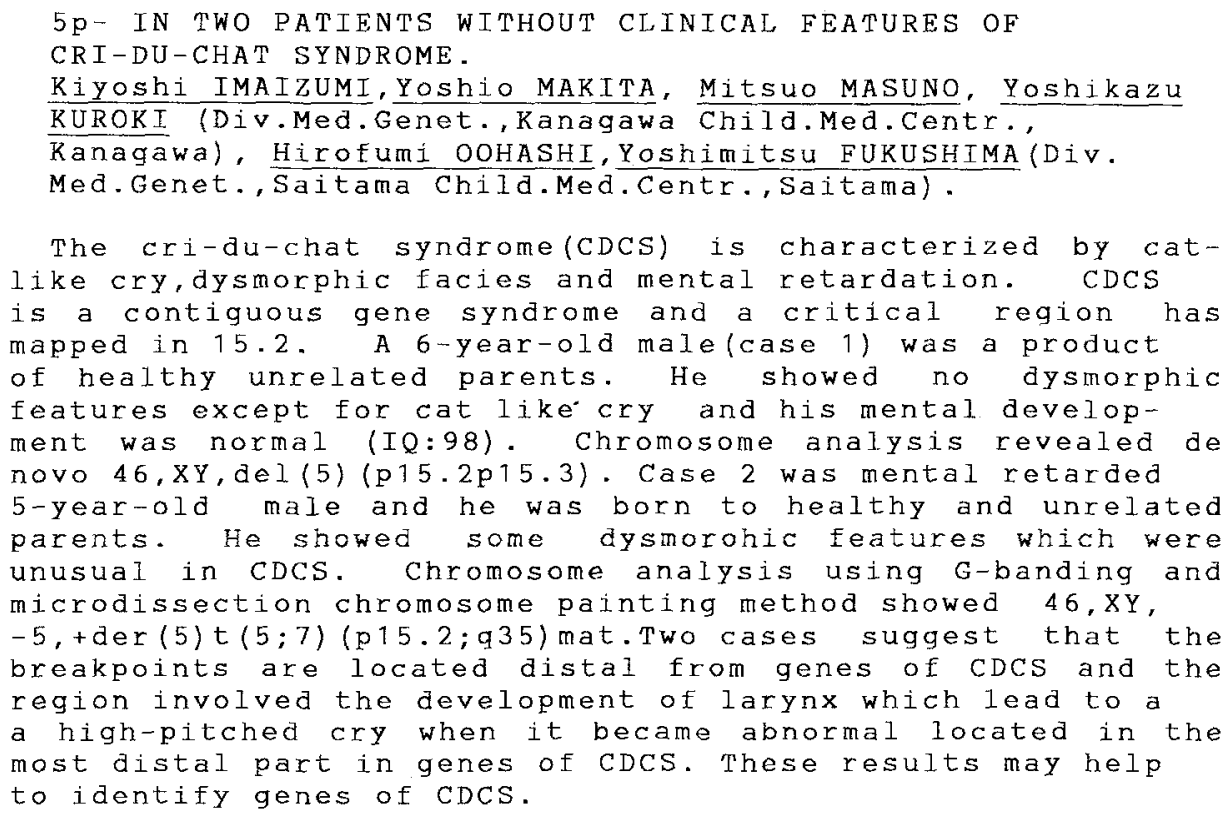




\section{2-D 4}

\section{A CASE OF INTERSTITIAL DELETION OF 5q21.2-q31.1 ASSOCIATED WITH BEALS CONTRACTURAL ARACHNODACTYLY SYNDROME.}

M. Masuno, K. Kurosawa, Y. Makita, K. Kagami ${ }^{1}$, T. Kawano ${ }^{1}$, G. Nishimura2, K. Imaizumi and Y. Kuroki (Div. of Med. Genet., Kanagawa

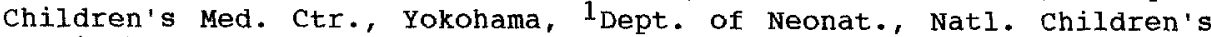
Hospital, Tokyo, and 2Dept. of Radiol., Shimizu Municipal Hospital, Shimizu)

Beals contractural arachnodactyly syndrome (CCA; MIM No *121050) is characterized by joint contractures, arachnodactyly, and crumpled ears. Recently, fibrillin 2 gene (FBN2; a candidate gene for CCA) was mapped to chromosome 5q23-q31 and was shown to be linked with CCA (Nature 352:330$334,1991)$. Here we present a case of CCA with del(5) (q21.2q31.1). The proposita was the second product of a 28-year-old gravida 3, para 1 , ab 1 mother and an unrelated 28-year-old father. She was born at 40 weeks of gestation. Birth weight was $3,230 \mathrm{~g}$, length $48.0 \mathrm{~cm}$, and OFC $34.0 \mathrm{~cm}$. She had hemitruncus, patent ductus arteriosus (PDA), patent foramen ovale, congenital contractures of elbow, knee, and hip joints, arachnodactyly, camptodactyly, dysplastic ears, and club foot, and died at 81 days of age. The clinical and chromosomal findings in our patient seem to support previous reports that a gene for CCA is linked to 5q21-q33 and that FBN2 is a candidate gene for CCA.

\section{2-D 5}

$A$ case of $5 q$ proximal trisony derived from paternal insertion der ins $(7 ; 5)$.

Koji Inui, Hiroko Tsukanoto, Atsuko Kashiwagi, Shintaro Okada (Department of pediatrics, Osaka University, Faculty of Medicine)

The patient was 3 years old born to 39 -year-old father and 29-year-old mother. His peculiar face (hypertelorism, antinongoloid slant, flat nasal bridge, bulbous nose) was noticed at 3 months of age and a chromosomal abnormality was suspected. His growth and psychomotor development were severly retarded. He was hypotonic and could walk alone at 2 years and 4 months of age. 3 -year-old, he was diagnosed as $5 \mathrm{q}$ proximal trisomy $(46, X Y,-7,+\operatorname{der}(7)$ dir ins $(7 ; 5)(p 15.1 ; q 14.2$ q22.1) derived from paternal chromosome 7 . Father has a balanced direct insertion $(7 ; 5)$ and these choromosomes were also transmitted to his phenotypically nornal daughter. The cases of $5 q$ proximal trisomy gere very rare. Comparing our case with reported cases and distal trisomy of chromosone 5 , our case was typical of proximal $5 \mathrm{~g}$ trisomy and different from the diatal type. 


\section{2-D 7}

TISSUE SPECIFIC MOSAICISM IN A PATIENT WITH PARTIAL TETRASOMY 9. MaShio KITATANI*, Mamoru OZAKI*, Hiromi KINOSITA**, Eikan KO**. Hiroaki TAKAHASHI *, **, (*Clinical Genetics, Human Genetics, Medical Research Institute, **0epartment of Pediatrics, Kanazawa Medical University, Ishikawa)

We report on a malformed female infant with a $46, X X / 47, X X,+p s u$ dic $(9)$ (pter $\rightarrow$ cen $\rightarrow q 12:: q 12 \rightarrow$ pter) constitution. The infant had growth retardation, psychomotor retardation, congenital heart disease (anomalous return of left vena cava superior. idiopathic dilatation of pulmonary artery), hypertelorism. bulbous nose, micrognathia, wide spacel nipples, sacral dimple and clinodactyly. No other skeletal anomalies nor genital anomalies were present. Cytogenetic analysis of the infant showed the spernumerary chromosome in $100 \%$ of peripheral lymphocyte metaphases examined and in $0 \%$ of shin fibroblasts. Tissue specific mosaicism was found in eight previous cases. Either no supernumerary chromosome was found in the skin or greatly reduced percentages were noted in all of the nine cases. Selective genetic pressure based on a functional disadvantage of partial tetrasomy 9 in the shin in proposed. Cordocentesis confirmation of any partial tetrasomy $g$ cells noted in amniotic fluid would appear to offer the best chance of prenatal detection.

\section{2-D 8}

CYTOGENETIC STUDY OF SEVERE CASE OF PALLISTFR-KILLTAN SYNDROME USING FLUORESCENCT IN SITU HYBRIDISATION(FISH). SAHAR M.GAMAL ${ }^{*}$ T. HASEGAWA ${ }^{*}, \underline{Y} \cdot$ SATOH $^{* *}, \underline{\text { K. ENDO }}{ }^{* * *}$ (Div.Clin.Genet. ${ }^{*}$,Div.Sur ${ }^{* *}$ Div.Clin.Path. ", Shizuoka Children's Hospital), H.SATOH \& T.WATANABE" ( Path. Dept., Tokyo Inst.Med.Scin.).

Classically, the supernumerary isochromosome 12p characterizing Pallister -Killian syndrome patients is detected in cultured skin fibroblasts but not in cultured blood lymphocytes. The proband of this study was a one day female presented with major chriteria of Pallister-Killian syndrome. She had severe congenital malformations in the form of cleft palate,poly -dactely, severe laryngomalacia \& anal atresia. FISH was applied on chromosome preparates from both cultured blood lymphocytes and skin fibroblasts as well as buccal smears of this patient, using chromosome 12 specific $\alpha$-satellite probe. The percentage of cells showing +ve signals for iso $12 \mathrm{p}$ in those samples was about $20 \%, 62 \% 870 \%$ respectively. At the age of one year the percentage dcreased to about $5 \%$ in blood and $40 \%$ in buccal smears. The extraordinary high percentage of iso 12p containing cell present in blood may be correlated to the severity of the malformations present in our patient. 


\section{2-D 9}

A MALE NEONATE WITH $r(13)$ THOUGHT TO BE COMPOSED OF PARTTAL TRISOWY 13 ADDED TO 13q-

Keiko IWASAKI, Tomoko HASEGANA (Div. Clin. Genet. Shizuoka Childrenś Hospital, Shizuoka), Koichi ENDO (Div. Clin. Path. S.C.H.,Shizuoka)

Ring chromosome is included under the category of deletion syndrome of the same chromosome because of losses of both ends of the arms. We experienced a new case of ring chromosome 13 with a severe phenotype. The patient was a newborn male, suspected to have gastrointestinal atresia. Systemic edema, hirsutism, microphthalmia, lowset ears, atresia of the external ear, webbed neck, atresia ani, rectosemidermal fissura, hypospadias, shawl scrotum and congenital heart defect were present, and the patient died at 8 days old. Chromosomal analysis showed the karyotype to be $46, X Y, r(13)$. In this case, the phenotypes were severe for ring chromosome, some anomalies were rather more characteristic of trisomy 13 than of $13 \mathrm{q}^{-}$, and the G-band staining pattern was tought to indecate partial trisomy.

\section{2-D 10}

A CASE OF $45, \mathrm{X} / 47, \mathrm{XY},+13$. Tsutomu YAMANAKA ${ }^{1}$, Chieni HAYAKAWA ${ }^{1}$, Shinichi SONTA' ('Dept. Pediatr. Central Hosp., '2 Dept. Genet. Deve1op. Res., Aichi Pref. Colony, Kasugai), Fumio HAYAKAWA, Kuniyoshi KuNO (Dept. Pediatr., Kosei Hosp., Anjo) and Hideki WATANABE (Dept. Uro1., Josai Hosp., Nagoya)

The case of a 5 -year-old boy with a $45, \mathrm{X} / 47, \mathrm{XY},+13$ karyotype is presented. He was born at term with a birthweight of $2480 \mathrm{~g}$ and displayed ambiguous genitalia. Chromosome analysis of 1ymphocytes disclosed $47, \mathrm{XY},+13$. The prognosis was expected poor but he had no major anomalies and developed fairly well. He sat without support at 13 months, spoke a word at 16 months and walked by himself at 18 months. He was operated on for hypospadia and retentio testis of left side. Laparotomy revealed 1-streak gonad and it was removed. On the secound operation of hypospadia, skin fibroblasts were analysed for chromosome study and $45, \mathrm{X}(74$ ce 11 s $) / 47, \mathrm{XY},+13(26$ ce11s) karyotype was showed. This karyotype is compatible with his few clinical findings of trisomy 13 and well development. 
2-D 11

DOES DELLTION MOSAICISY EXIST IN PRADER-WTLLI SYNDRONE ?

Takazuni KOZAKI,Keiko TAKAHASHI,Hideyuki UMII,Yoshimori ISHIHARA and Tadashi KAJII (Dept.of Chromosone Analysis, SRL, Inc., Tokyo)

We analysed blood sanples from 928 patients with possible Prader-Hilli syndrome, referred during the $35 / 12$ year period from January 1990 to May 1993 , using the high-resolution chromosone analysis ( 850 band level). Pive metaphases each were screened,and 192 cases had nicroscopically detectable deletion at 15q11-q13. Another 53 cases appeared to be nornal/deletion mosaics. Of the latter, 10 cases were further studied with fluorescence in situ hybridaization (PISH) of metaphase chromosones, using Oncor PWS(region A) and AS(region B) cosmid probes. Five cases had a chronosome 15 without region A or region B signals,an indication that these cases had a 15q11.2 deletion. The remaining 5 cases showed region $A$ and region $B$ signals on both chronosones 15 . In view of these finding, it was concluded that norwal/deletion mosaicisa either does not exist, or if it does,it is rare anong the patients with the Prader-Willi syndrome.

\section{2-D 12}

SUBMICROSCOPIC DELETION AT CHROMOSOME 16P13.3 AS A CAUSE OF RUBINSTEIN-TAYBI SYNDROME.

M. Masuno, K. Kurosawa, Y. Makita, K. Imaizumi, Y. Kuroki, F . Petrij 1, J. G. Dauwerse 1, and M. H. Breuning 1 (Div. of Med. Genet., Kanagawa Children's Med. Ctr., Yokohama and

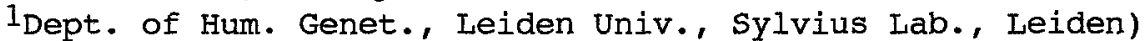

Rubinstein-Taybi syndrome (RTS; MIM No *180849) is characterized by broad thumbs, great toes, characteristic facies, and mental retardation. Recently, we have found submicroscopic interstitial deletions within $16 \mathrm{p} 13.3$ in 6 of 24 RTS patients living in the Netherlands (Am. J. Hum. Genet. $52: 249-254,1993$ ). Herein, we studied 17 Japanese patients with RTS, ranging in age from 1 to 16 years, using FISH with RT1 cosmid probe $(165237)$. All patients had normal chromosomes by GTG banding technique. Only one 14-year-old patient had a deletion of RT1 cosmid. Her length was $136.7 \mathrm{~cm}$ $(-3.9 \mathrm{SD})$, weight $38.0 \mathrm{~kg}(-1.7 \mathrm{SD})$, head circumference 50.4 cm $(-2.7$ SD). She could express few words. MRI showed hypogenesis of corpus callosum and dilated ventricles. Further analysis of RTS patients by using single-copy probes from RT1 cosmid might answer the question as to the presence or absence of etiologic heterogeneity in RTS. 


\section{2-D 13}

TWO CASES OF SMITH-MAGENIS SYNDROME ShOKO TSUNODA, Ryoji UMEzU, Mitsunori MURATA (Dept.Pediatr.Tokyo Women's Medical College Daini Hospital) Keiko SUZUKI, Akemi YAMAUCHI, Kayoko SAITO, Keiko SHISHIKURA, Haruko SUZUKI, Yukio FUKUYAMA (Dept.Pediatr.Tokyo Women's Medical College) Yoshimitsu FUKUSHIMA (Div.Med.Genet.Saitama Children's Medical Center)

Smith-Magenis syndrome(SMS) is a multiple malformation syndrome with an interstitial deletion of (17) (pl1.2). Recently SMS and Charcot-Marie-Tooth disease type 1A(CMTIA) were postulated as a new contiguous-gene syndrome. We present two children with SMS. The cese 1 was a 5-year-old boy with midface hypoplasia, short broad fingers. At the age of 3 years his hyperactivity and self-mutilating became severe. He has typical clinical manifestations of SMS. The case 2 was a 23month-old girl. She showed decreased sensitivity to pain, suggesting peripheral neuropathy. This was of interest to us because case 2 may represent a case of the contiguous-gene syndrome of SMS and CMT1A. Electron microscopic examination of muscle and peripheral nerve specimens was performed in case 2 .

\section{2-D 14}

FLUORESCENCE IN SITU HYBRIDIZATION STUDY IN FAMILIAL MILLERDIEKER SYNDROME. Yuji YOKOYAMA, Koji NARAHARA, Shinsuke NINOMIYA, Satoko ITOH, Yoshiki Seino(Dept. of Pediatr.okayama University Medica1 Schoo1., Okayama), Kaori MASUKO, Kazuhisa HONGOU, Shinichi YAGI, Toru KONISHI(Dept. of Pediatr.Toyama Medical and Pharmaceutical University,Faculty of Medicine., Toyama)

We report on familial Miller-Dieker Syndrome(MDS). The proband had a microcephaly, frontal bossing, low set ears, micrognathia, in addition to lissencephaly. The chromosomal study of peripheral blood lymphocytes by high resolution banding failed to show the deletion of $17 \mathrm{p}$. Fluorescence in situ hybridization(FISH) using the cosmid probe from the Miller-Dieker syndrome critical region in 17p13.3(Oncor,Inc.) indicated that the father carried a pericentric inversion of chromosome 17 . The proband was considered to carry a recombinant chromosome 17 , del (17p) and dup (17q), associated with paternal pericentric inversion of chromosome 17, inv(17)(p13.1q25.1). The paternal grandmother and one of his sisters had the same inversion. The detection of deletion by FISH was useful in genetic counceling of family members. This case emphasizes the importance in molecular diagnosis for MDS. 


\section{2-D 15}

A CASE OF DIGEORGE SYNDROME COMPLICATED BY 22q11 DELETION. Hiroshi KATSUMORI $^{1}$, Yoshimitsu FUKUSHIMA ${ }^{1,2}$, Kayoko SAITO ${ }^{1}$, and Yukio FUKUYAMA ${ }^{1}{ }^{1}{ }^{1}$ Dept. Pediatr., Tokyo Women's Med. Collage, Tokyo, ${ }^{2}$ Div. Med. Genet., Saitama Children's Med. Center, Saitama)

DiGeorge syndrome(DGS) is a disease whose major signs are thymic hypoplasia, parathyroid hypoplasia, and abnormality in the cardiac large artery. It has been considered to be caused by abnormal development of the $3 \mathrm{rd}$ and 4 th branchial pauches around week 4 to 6 of gestation. Studies in recent years have shown cases of the disease with 22q11 deletion at the chromosomal level, and the majority of these cases have demonstrated reciprocal translocation between chromosome 22 and other chromosomes. There have been only a few reports on intermediate deletion of 22q. We encountered a patient with DGS complicated by intermediate deletion of the $22 q 11$ band, which was detected by high-performance chromosomal differentiation. The patient was a 3-year-old girl who was born by normal delivery. Heart failure was observed soon after birth, and she was diagnosed as having persistent truncus arteriosus. At radical heart surgery at one month after birth, the thymus was not observed, and T cell hypofunction was present. She showed hypocalcemia with reduced parathyroid hormone and characteristic countenance(hypertelorism, flat nasal bridge, micrognathia, and fish-like mouth). High-performance differentiation of chromosomes revealed 46,XX,del(22)(q11.1q11.21). It has recently become possible to detect deletion at the molecular level in the 22q11 band by FISH method not only in DGS but also in velo-cardio-facial syndrome and conotruncal anomaly. Assessment by the FISH method is also considered necessary for patients in whom the deletion is not clear by high-performance differentiation.

\section{2-D 16}

A patient with irregular shaped pupils, hypoplasia of corpus callosum and de novo reciprocal translocation $[46, X Y, t(1 ; 4)(q 21 ; q 25)]$

Y. Makita, M. Masuno, K. Imaizumi and Y. Kuroki. (Division of Medical Genetics. Kanagawa Children's Medical Center. Yokohama)

Rieger syndrome(MIM *180500) is characterized by malformation of the anterior chamber of the eye, hypodontia and failure of involution of the periumbilical skin. It is generally inherited as an autosomal dominant trait. Recently, Rieger syndrome is mapped to chromosomal 4, candidate site is 4q25 or 4q27(J. Med. Genet. 29: 256-258 (1992)) .

The baby was born after a normal pregnancy and his father's age was 42 years old and mother was 37 years old, respectively. He suffered from following complications, irregular shaped pupils, umbilical hernia, bilateral vesico-ureteral regargitation, gall stones and infantile spasms. Brain CT showed hypoplasia of corpus callosum and agenesis of anterior commissure. Chromosomal analysis revealed de novo reciprocal translocation $[46, X Y, t(1 ; 4)(q 21 ; q 25)]$, which contained one of candidate sites of Rieger syndrome. Further studies about eye anomalies of this patient may show the gene(s) of Rieger syndrome is(are) located in his breakpoint $4 \mathrm{q} 25$. 


\section{2-D 17}

CONSTITUTIONAL ANALYSIS OF A MARKER CHROMOSOME DERIVED FROM MATERNAL TRANSLOCATION BETWEEN 5p and 13q BY USING CHROMOSOME MICRODISSECTION-PAINTING METHOD. Keiko WAKUI, Akira YAMAGISHI, Hirofumi OHASHI, Yasuhide MAKIYAMA, Hiroshi NISHIMOTO, and Yoshimitsu FUKUSHIMA (Saitama Children's Med. Ctr.)

A new born female patient had following clinical features: open meningomyelocele, hydrocephaly, Chiari II malformation, unclassified tumor in the ventricle, dolichocephaly, frontal bossing, wide frontal suture, hypertelorism, large nose, micrognathia, side-set nipples, and tapering finger. Chromosome analysis revealed that she had an excess marker chromosome. Its size was slightly smaller than Ggroup chromosomes. Her mother had a balanced translocation between $5 \mathrm{p} 15.3$ and 13q14.1. The marker chromosome was derived from 3:1 disjunction of maternal meiosis. Fluorescence in situ hybridization with $5 \mathrm{p}$ painting probe, which was obtained by microdissection of normal 5p and PCR amplification (Deng et al, 1992), revealed that the marker chromosome had no signal of 5p. Thus the marker chromosome seemed to be formed of mainly a part of 13pter-q14.1. FISH analysis with all human telomere probe (Oncor) revealed that there was no $\operatorname{der}(5)$ in the mother. Thus the rearrangement of the mother was reciprocal translocation and the karyotype of the patient was interpreted as $47, X X,+\operatorname{der}(13) t(5 ; 13)(p 15.3 ; q 14.1)$ mat.

\section{2-D 18}

A patient with $5 \mathrm{p}$ monosomy and $14 \mathrm{q}$ trisomy derived from maternal translocation

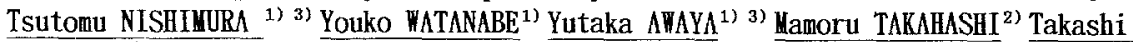

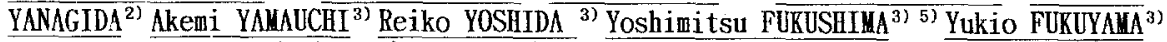
Toshiro NISHIKATI ${ }^{\text {) }}$ (Div. ${ }^{15}$ Pediatr. ${ }^{2)}$ Obstet. Seibo Hospital, Tokyo. Dept. ${ }^{3)}$ Pediatr. 4) Pathol. Tokyo Momen's Med. College. ${ }^{5)}$ Div. Med. Genet. Saitama Children's Med. Center)

The patient, a female neonate, was born at 40 weeks gestation with birth weight $1946 \mathrm{~g}$. The father was 34 years old and mother 31 , both healthy, they have two healthy children. The mother had a history of hydatid mole once and two spontaneous abortions. The following abnormalities were noticed: Wide frontal suture, metopic hemangioma, microphthalmus, bilateral cleft lip and palate, short neck, overlapping fingers of both hands, 11 ribs, andCHD(VSD, PDA). She died of heart failure at 14 days of age. In addition to the above malformations, agenesis of corps callosm, coarctation of the aorta, incomplete separation of the two lobes of the left lung and persistent left superior vena cavae were observed on autopsy. Chromosome analysis revealed a structual aberration of the short arm of chromosome 5 in the patient. The father is karyotypically normal, but the mother had a balanced reciprocal trancelocation between $5 \mathrm{p}$ and $14 \mathrm{q}[\mathrm{t}(5 ; 14)(\mathrm{p} 13 ; \mathrm{q} 24.3)]$ The patient had the derivative chromosome 5 and was affected with both $5 \mathrm{p}$ partial monosony and 14q distal partial trisony. Despite a through search of the literature, this seems to be the first combination of $5 \mathrm{p}$ partial monosomy and 14q distal partial trisomy. 


\section{2-D 19}

CAMPOMELIC DYSPLASTA AND SEX REVERSAL ASSOCIATED WITH DE NOVO $t(12 ; 17)$ TRANSLOCATION. Shinsuke NINOMIYA, Kouji NARAHARA, Kazushiro TSUJI, Yuji YOKOYAMA, Satoko ITOH, Tsunenori MATSUBARA, Yosiki SEINO (Dept. Pediatr., Okayama Univ. Med. Sch., Okayama), Yusuke NAKAMURA (Dept. Biochem., Cancer Institute, Tokyo)

Campomelic dysplasia (CMD) is a congenital disorder, characterized by shortening and bowing of lower extremities, hypoplastic scapulae, micrognathia, tracheomalacia and talipes equinovarus. Sex reversal has been reported in about half of genotypically male cases. Three independent reports of $\mathrm{CMD}$ associated with constitutional structural abnormalities involving $17 \mathrm{q}$ have confirmed assignment of the CMD 1ocus to the distal part of $17 \mathrm{q}$. We describe another case of CMD with sex reversal associated with a de novo reciprocal translocation, $46, X Y$, $t(12 ; 17)(q 21.2 ; q 23.3)$. The patient had all the typical features of CMD except for lower limb bowing, and sex reversal occurred in spite of the intact SRY gene. The present case indicates that the CMD locus can be localized on the band 17q23.3. Although CMD is established as an autosomal recessive disorder, the phenotypic variability in CMD cases suggests that it may represent a contiguous gene syndrome. cloning of the breakpoint in this patient is in progress.

2-D 20

A MEDIAN NODULE OF THE UPPER LIP: AN AUTOSOMAL DOMINANT TRAIT. Masato TSUKAHARA, Isabel FERNANDEZ(Dept. Pediatr. Yamaguchi Univ. Sch. Med., Yamaguchi) and Yoshitsugu SUGIO(Dep. Pediatr. Ogori Daiichi Hospital, Yamaguchi)

We describe a total of 16 individuals, in three families, with a median nodule of the upper lip. In family 1, the proposita, an 8-month-old infant girl, was otherwise phenotypically normal except a median nodule of the upper lip. The proposita's elder brother and mother, both phenotypically normal, also had the similar nodule of the upper lip. On the mother's side, the proposita's great-grandmother, great-grandaunt, grandfather, greataunt, two aunts and one female cousin, all had a median nodule of the upper lip. In family 2 , the proposita, the mother and maternal grandfather had a median nodule of the upper lip. In family 3 , the propoista, the father and paternal grandfather had a median nodule of the upper lip. Analysis of three families indicates that the condition is an autosomal dominant trait.. 


\section{2-D 21}

CONGENITAL HEART DEFECTS IN THE AARSKOG SYNDROME. Isabel FERNANDEZ G, Masato TSUKAHARA, Hideki YOSHII (Dept. Pediatr. Yamaguchi Univ. Sch. Med., Yamaguchi)

The Aarskog syndrome is characterized by short stature, hypertelorism, broad, short hands, clinodactyly of the fifth finger, cutaneous syndactyly, hyperextension of the proximal interphalangeal joints, inguinal hernia(s), cryptorchidism, and shawl scrotum, being also associated in previous reports with ocular manifestations, mental retardation, cleft lip and/or palate, umbilical changes, dolichomegasigmoid, and anomalous cerebral venous drainage. We report on ten Japanese individuals from three families with the syndrome. Uncommon association with congenital heart defects as pulmonary stenosis and ventricular septal defect with spontaneous closure were detected respectively in two of them as an additional feature. An extensive search of the literature was achieved being remarkable the fact that from 169 non Japanese individuals only two were found to have congenital heart defects, while from 30 Japanese individuals reported until this moment four (including ours) displayed such a cardiac anomalies. This could lead us to think about the possibility of a higher association of congenital heart defect in Japanese Aarskog individuals.

\section{2-D 22}

A boy with Rothmund Thomson syndrome.

Hiroshi NAKAI, Manami KUMAGAI, Akira OZAWA, Kouichiro IKE and Toshio OHARA (Dept. Pediatr., Iwate Prefecture Central Hospital)

A boy with Rothmund Thomson syndrome was reported. He was born in June 30,1986 . His parents had no consanguinity. Clinical features of the patient were short stature, poikiloderma (telangioectasia, pigmentation, skin atrophy) especially on his face and hands.

No abnormal findings were detected in routine blood, serum, immunological examinations, chromosome(G-band, sister chromatid exchange, fragility), $\mathrm{ACTH}, \mathrm{LH}, \mathrm{FSH}, \mathrm{T}_{3}, \mathrm{~T}, \mathrm{TSH}$, free $\mathrm{T}_{4}$, somatomedin-C, brainMRI , and growth hormon excreation tests ( 1 -DOPA, insulin and TRH,LH-RH loading tests respectively). Only in arginin loading, milddy low response was revealed. As for cultured skin fibroblasts from the case, unscheduled DNA synthesis and recovery of RNA synthesis were within normal ranges, however after UV irradiation, cell survival curve was declined slightly.

Although he needs to be protected from UV or direct sun light exposure, using $0.04 \mathrm{mcg} / \mathrm{Kg}$ of body weight/day of vitamin D derivative (alphacalcidol:Alpharol $\mathbb{B}$ ), he shows no abnormal findings in serum $\mathrm{Ca}$, P, ALP values nor rickets signs. now. 
A CASE OF PSEUDODIASTROPHIC DYSPLASIA

Ayako MUTO, Yoshiyuki IWAMATSU, Maki IMANO, Tomoichi IMAIZUMI, Shigeru NAGAKI, Yukio FUKUYAMA (Department of Pediatrics, Tokyo Women's Medical College, Tokyo) and Gen NISHIMURA (Department of Radiology, Shimizu City Hospital, Shizuoka)

We report a case of pseudodiastrophic dysplasia which has not been reported previously in our country, in a female infant with chief complaint of delay of development. When she was admitted at 5 months of age, her responses to light and sound were poor. Examination revealed increased anteroposterior trunk diameter compared with right to left, ulnar deviation of the hands, clubfeet and short limbs. Movement of the extremities against gravity was not seen. A roentgenogram revealed that the ilia appeared wide in transverse diameter and short in vertical diameter with a narrow greater sciatic notch, horizontal acetabular roofs, metaphyseal flaring of long bones, scoliosis, clubfeet, rhizomelic shortening and facial dysmorphism (flat nasal bridge, hypertelorism and micrognathia). There was no platyspondyly or elbow dislocation, which are important findings of PDD, but it was thought that these would be progressive with age. The diagnosis of PDD was made. PDD has been was reported in only 9 cases in the world. Two of these were sisters, suggesting autosomal recessive inheritance. This case improved slowly with movement of the feet after discharge from our hospital, and she was able to turn over in bed. She died at 7 months, however, after beeing found in the early morning lying in her cot not breathing.

\section{2-D 24}

A FAMILY WITH FG SYNDROME

Rumiko KATO, Norio NIIKAWA (Dept. Hum. Genet., Nagasaki Univ. Sch. Med., Nagasaki), Toshiro NAGAI (Kiyose Metropolitan Child. Hosp., Tokyo), Yoshimitsu FUKUSHIMA (Saitama Child. Med. Ctr., Iwatsuki)

FG syndrome is an X-linked recessive multiple malformation syndrome. We report here new familial cases of FG syndrome. Patient 1 (propositus) was a newborn infant, patient 2 a 5-year-old boy (elder brother of Patient 1), and patient 3 an uncle (maternal younger brother). Clinical manifestations common to the three patients included a peculiar facies with macrocephaly, frontal cowlick, hypertelorism and a long philtrum. Other findings were agenesis of corpus callosum, neonatal hypotonia and anal atresia in patients 1 and 2, strabismus and syndactyly in patient 2 , and patent ductus arteriosus and undescended testes in patient 3. Karyotypes of the three patients were all normal $46, X Y$. The mother of patients 1 and 2 represented a peculiar facies characteristic for FG syndrome but had no other features, and the maternal grandmother had no abnormal manifestations. Both of these females were thought to be carriers. Phenotypic difference in the two carrier females may be explained by variable expression due to $X$-inactivation, or germline mosaicism in the grand mother. This family may provide important information for a mapping of the putative gene responsible for FG syndrome. 


\section{2-D 25}

A CASE OF PARTINGTON SYNDROME

Takaya TOHMA, Yasutsugu CHINEN, Yoshinori IZUMIKAWA,

Kenji NARITOMI, and Kiyotake HIRAYAMA

(Dept. Pediat., Univ. Ryukyus, Okinawa)

A family of X-linked Silver-Russel syndrome with skin pigmentation has been reported by Partington $(1985,1986)$ (MIM312780). Here we added another family of Partington syndrome.

The propositus, a four-years-old boy, had short stature (-3.7SD), prominent forehead, triangular face, relative macrocephaly, large mouth, clinobrachydactyly of 5 th fingers, mental retardation, generalized hyperpigmented skin and asthmatic attack in infancy. Because the mother and maternal grandmother also had mild mental retardation, short stature and irregular less severe skin pigmentation, $\mathrm{X}$-linked dominant mode of inheritance was suggested. The propositus had an almost same phenotype compared to the case of Partington except mental retardation.

This case was suggested as the second report of Partington syndrome. It is not clear whether Partington syndrome is independent clinical entity or expression of genetic heterogeneity of Silver-Russel syndrome (MIM 27005).

\section{2-D 26}

HEMATOLOGICAL SCREENING OF THE X-LINKED $\alpha$-THALASSAEMIA/MENTAL RETARDATION (ATR-X) SYNDROME IN THE INSTITUTIONALIZED MALES WITH MENTAL RETARDATION. Ryozo KASAI (Asahigawa Jidoin Hosp., Okayama), Kouji NARAHARA, Kazushiro TSUJI, Yuji YOKOYAMA, Tsunenori MATSUBARA and Yoshiki SEINO (Dept. Pediatr., Okayama Med. Schl. Univ., Okayama).

The ATR-X syndrome, which is characterized by severe mental retardation, short stature, microcephaly, chracterstic face and genital abnormality in addition to $\alpha$-thalassaemia and hemoglobin $\mathrm{H}(\mathrm{HbH})$ disease, is a newly defined cause of $\mathrm{X}$-linked mental retardation. In order to estimate the prevalence of this syndrome in the retarded population, we screened for $\mathrm{HbH}$ inclusions in 188 institutionalized males with severe mental handicaps. At least 5,000 red cells per an individual were examined for the presence of $\mathrm{HbH}$ inclusion after staining with $1 \%$ methylene-blue. Twelve of the 188 patients $(6.4 \%)$ had mild anemia, but in none of the 188 patients hemoglobin $\mathrm{H}$ disease was detected. The present study suggests that the frequency of the ATR- $X$ syndrome may be very low in the Japanese mentally retarded population. Further hematological screening will be needed to know the exact frequency. 


\section{2-D 27}

DYSMORPHIC FEATURES AND AGE - RELATED BEHAVIORS IN WLLIAMS SYNDROME Kiyotaka TOMIWA, Kazuhiro SHIRAISHI, Koji TANIKAWA, Misa HASEBE, Junko 0CHI, Tomoko MIYAJIMA, Yasufumi KASAI (Dep.Paedi., Med.Cent.Child...Shiga)

$\leftarrow$ Dysmorphic and behavioral features in Williams syndrome are reviewed in 18 cases ( 10 male, 8 female aged 1 to 21 years). Heart murmurs were the initial signs in 7 cases. Most of them were referred to public health centres because of motor delay in infancy. Diagnosis was made at about 4 years of age. All had characteristic elfin-like faces (eye brow flare,periorbital \& cheek fullness, anteverted nares,prominent lip) and hoarse low piched voice. Supuravalvular AS and peripheral PS was noted in 11 and 3 cases respectively. Mean DQ was 50. Speech-language score was higher than cognitive score in all cases. Major behavioral problems in young patients were failure to thrive, fret and hypersensi tivity to sounds. Hyperacousis was often so severe that they masked the ears in panic. The ear-masking was frequently seen especialy in young patients and can be said to be a pathognomonic behavior in this conditions. Cocktail party speech was also unique. It was noted in all school age patients and necessitates speech and educational guidances. other problems include attention deficit, hyperkinesia and urinary frequency. One patients had posterior urethral vulve and another had a diverticulum of the bladder. A 21 year-old female patients had psycho -somatic reactions due to maladaption.

\section{2-D 28}

A CASE OF COSTELLO SYNDROME.

kImiko MIYAKAWA (Dept. Life Science, Niigata women's College, Niigata), Kensei IMADA, Masahisa SATHO, Yoshihiko ODA (Dept.Pediatrics, Niigata City Hospital, Niigata)

In 1971, Costello described a new syndrome in two patients with a unique malformation pattern of postnatal growth deficiency, mental retardation and nasal papillomata. Here, we report a similar child with this condition which we refer to as the Costello syndrome.

This 16-year-old girl was born at 37 weaks of geststion to a 24-year-old mother. Father was 28-year-old at that time and there is not any consanguinity between them. Delivery was spntaneous and vaginal with apgar score of 7 . Her birth weight $3340 \mathrm{~g}$. Heart murmur, congenital stridor, respiratory difficult, poor feeding and suck were noted from the birth. she had curly hair, large low-set years, thick lips, high arched palate, depressed nasal bridge, short neck, shield chest, spoon-shaped nail and dark skin colour. Her height was $83.9 \mathrm{~cm}(-3 \mathrm{SD})$ and $12.1 \mathrm{~kg}(-2 \mathrm{SD})$ at 3 years. Hyperkeratosis of the skin was appeared at abaut 2.5 yaers. Achanthosis nigricnns and papillomata were also noted at 8 years.

Costello syndrome shares some physical findings with Noonan syndrome and CFC syndrome. Noonan syndrome or CFC syndrome has very wide and variable expression, consequently, certain cases of Costello syndrome may have been misdiagnosed in the past. 


\section{2-D 29}

TEN PATIENTS WITH KABUKI MAKE-UP (NIIKAWA-KUROKI) SYNDROME

Miyako OGUNi (Dept. Pediatrics, Tokyo Homen's Medical College, Tokyo), Hiroshi MARUYAMA (Dept. Pediatrics, Tokyo Homen's Medical College, Tokyo, and Mastudo Clinic, Chiba), Hirokazu OGUNI, Kayoko SAITO and Yukio FukUYAMA (Dept. Pediatrics, Tokyo Women's Medical College, Tokyo)

The term Kabuki make-up syndrome was first coined by Kuroki and Ni ikawa, working independently, in 1981. Characteristics of this syndrome include a peculaiar facial appearance: eversion of the lower lateral eyelid, arched eyebrows with the lateral one third having sparse or dispersed hair, a depressed nasal tip, and prominent ears. Skeletal anomalies and dermatoglyphic abnormalities are very common. We experienced 10 cases of this syndrome. Six were female and four were male, and their ages ranged from 7 to 23 years. Our 10 patients all had a characteristic facial appearance with skeletal and dermatoglyphic anomalies, compatible with Kabuki makeup syndrome. Cleft palate ras present in three cases, congenital cardiac anomalies in two, epilepsy in eight, and failure to thrive and delayed development in six. A chromosomal anomaly was found in one patient $(45, X)$. Among the 10 patients, one had xeroderma pigmentosum (XP A was ruled out by detailed DNA examination), and three had abundant ephelides.

\section{2-D 31}

AN ATYPICAL CASE OF CHRONIC GRANULOMATOUS DISEASE.

Masahiko TSUDA, Takeshi SAKIYAMA, Chiaki WATANABE, Hisashi SHIMIZU, Ichiro INANA, Misao OWADA (Dept. Pediatr., Nihon Univ. School of Med., Tokyo) and Katsuko KAKINUMA ( Tokyo Metropolitan Institute, Tokyo)

A boy with atypical chronic granulomatous disease is presented. This patient showed perianal abscess at the age of one month. Diagnosis of chronic granulomatous disease was established at the age of seven month. NBT test was negative and $\mathrm{O}_{2}$ production was zero. Although he often suffered from perianal abscess, inguinal lymphadenitis, stomatitis, and skin abscess, he has never suffered from severe infection since he was given sulfamethoxazole-trimethoprim. Immunoblot analysis showed that $91 \mathrm{kDa}$ large subunit of cytochrome $b_{558}$ was deficient in this patient. However $22 \mathrm{kDa}$ small subunit was not deficient, but the amount was decreased. It is believed that the stable expression of either of the two subunits depend upon the other. Thus, our patient has typical clinical symptoms and very unique biochemical features. RT-PCR analysis showed no major deletion indicated the possibility of a point mutation. Further analysis is now undertaken and it would be helpful to understand the interaction of the two subunits. 


\section{2-D 32}

A CLINICAL STUDY OF INTRACTABLE EPILEPSY IN A CHILD WITH RING 20 CHROMOSOME. Yukitoshi TAKAHASHI, Hidemoto KUBOTA, Hideo SHIGEMATSU, Yushi INOUE, Tateki FUJIWARA, Kazuichi YAGI, Masakazu SEINO (National Epilepsy Center, Shizuoka Higashi Hospital, Shizuoka)

Our investigation in a 9-year-old boy with a karyotype $46, \mathrm{XY} /$ $46, X Y, r(20)$ (p13q13.33) revealed intractable frontal lobe epilepsy, mental retardation (FSIQ:59), incomplete GH deficiency, frontal cortical dysplasia on MRI images, and impulsive behavioral disorders. The epilepsy was characterized by complex motor automatism in sleep and in playing TV games. Ictal EEGs of spontaneous seizures indicated the epileptic origin in frontal regions. EEGs in playing TV games showed induction of bilateral diffuse theta rhythm, and the theta rhythm was followed by same ictal EEG pattern as spontaneous seizure at induced seizure. This theta rhythm was evoked by several tasks using higher brain functions, for example, several kinds of TV games, and calculations. These findings suggest the existence of mechanisms for seizureinduction by tasks using higher brain functions in this patient. As the results, the existence of seizure-induction mechanisms and the dysfunction of frontal lobe on the basis of cortical dysplasia might contribute to the intractability of epilepsy in our patient with ring 20 chromosome.

\section{2-D 33}

ULTRASOUND SCREENING OF NEWBORN INEANTS FOR KIDNEY AND URINARY TRACT ABNORMALITIES. Akira MATSUI* Tsunehisa TAKENAKA* * (Dept. Pediat., and Obstet \& Gynecol。, Isesaki Municipal Hospital, Gunma) and Yasushige MATSUO, Masamiti HAYASHI, Hidetosi YAMANAKA (Dept. Urol., Gunma Univ。, Gunma)

For the purpose of early detection and early treatment of kidney and urinary tract abnormalities, ultrasound screening of newborn infants for them has been done. A total of 2,768 newborn infants, born at Isesaki. Municipal Hospital from October 1988 to August 1993 were examined by ultrasound. All scans were performed between 2 to 5 days after birth, using an Aloka SSD 650 ultrasonic scanning system equipped with a 5-MHz linear transducer. If abnormal scans were found, serial ultrasound study and uroradiologic examinations were carried out. 33 newborn infants (1.19\%) showed kidney and urinary tract abnormalities. Vesicoureteral reflux was found in 16 cases, hydronephrosis in 7 , duplicated ureters in 4, unilateral multicystic kidney in 5 , and simple renal cyst in l. In addition, adrenal hemorrhage was found in 4 cases and neuroblastoma in 1 . A total of 9 cases received surgical operation. ultrasound may be useful for early detection and early treatment of silent kidney and urinary tract abnormalities. 


\section{2-D 34}

FIFTEEN YEAR EXPERIENCE OF NEYBORN SCREENING PROGRAM IN OSAKA CITY. Yutaka HASE (Dept. Pediatr., 0saka Kita Citizen's Hospital), Satoshi KUSUDA, Tashou KIN, Hisashi KAWAWAKI, Tuneo TSURUHARA, Yuuko FUKUDA (Dept. Pediatr., Osaka Children's Medical Center), Yukinobu 0SASA, Takashi YAMAIRI (Dept. Pediatr., Osaka Sumiyoshi Citizen's Hospital), Toshiaki OURA (0saka Municipal Rehabilitation Center for the Disabled)

In Osaka City, newborn screening program for PKU, MSUD, homocystinuria, histidinemia and galactosemia started in April 1977. By March $1992,492,171$ neonatas were screened and the recall rate was $1.0 \%$. Congenital hypothyroidism $(\mathrm{CH})$ and congenital adrenal hyperplasia(CAH) were added in April 1979 and January 1989 , respectively. The number and the recall rate of them were $441,649,0.7 \%$ and $99,121,0.3 \%$, respectively.

The following are the results of newborn screening in 0saka City for 15 years: two each with classical PKU and $\mathrm{BH}_{4}$ deficiency with PTPS deficiency have been identified; no MSUD detected; no homocystinuria, four cases with persistent hypermethioninemia(HM) which include two cases with the deficiency of hepatic methionine adenosyltransferase, six cases of transient HM and three cases with HM due to liver disorders; ninety-six histidinemia detected; two classical galactosemia, and five with 4-epimerase deficiency identified, but many cases with elevated blood galactose levels were caused by liver disorders or due to carrier state of 4-epimerase deficiency. Additionally, two cases with G-6-PD deficiency have been detected from positive Beutler test. Eighty-eight cases with $\mathrm{CH}$ and five cases with $\mathrm{CAH}$ were detected, and the discovery rate were $1 / 5,000$ and $1 / 19,800$, respectively.

\section{2-D 35}

\section{ISOLATION OF HUMAN GENES ASSOCIATED WITH CDG ISLAND FROM CHROMOSOME 6 SPECIFIC COSMID CLONES. Ichiro TAKAHASHI,Reiko TANUMA, Makoto HIRATA, Katsuyuki HASHIMOTO(Div, Genetic Resources, National Institute of Health, Tokyo)}

To identify certain genes on human chromosome 6 and construct a high-resolution map,Saito et al.(Am.J.Hum.Genet.50,65-70,1992) isolated 68 RFLP markers on chromosome 6. As these markers were cloned into the cosmid pWEX15, an insert DNA containing NotI site(s) would give a few bands by NotI digestion. In this way we found 11 of 68 clones had NotI site(s). After examination on existence of other CG enzyme sites, we determined the EcoRI fragments containing the NotI site on 6 clones and cloned into pBluescript II KS-. We tried to sequence the cloned EcoRI fragments according to the dideoxy chain termination method using automatic sequencer(ABI,model 371A). The clone cCI6-84(D6S182) was shown to contain the corresponding sequence to the human $90 \mathrm{kDa}$ heat shock protein beta(HSPCB) by comparison the sequences of 5'upstream (335 bp)and exon 3(346 bp) regions. It is suggested that HSPCB is located on $6 \mathrm{p} 12$, since cCl6-84 was previously mapped to that region.

Northern blot analysis showed that at least cCI6-4 (D6S136)and cCI6-71(D6S175) include transcribable regions. Then we determined the sequence of $2220 \mathrm{bp}$ in cCI6-71 and $1399 \mathrm{bp}$ in cCI6-4 . DNA homology search showed that the sequences have no homologous sequence in those registered to DDBJ/GenBank. 


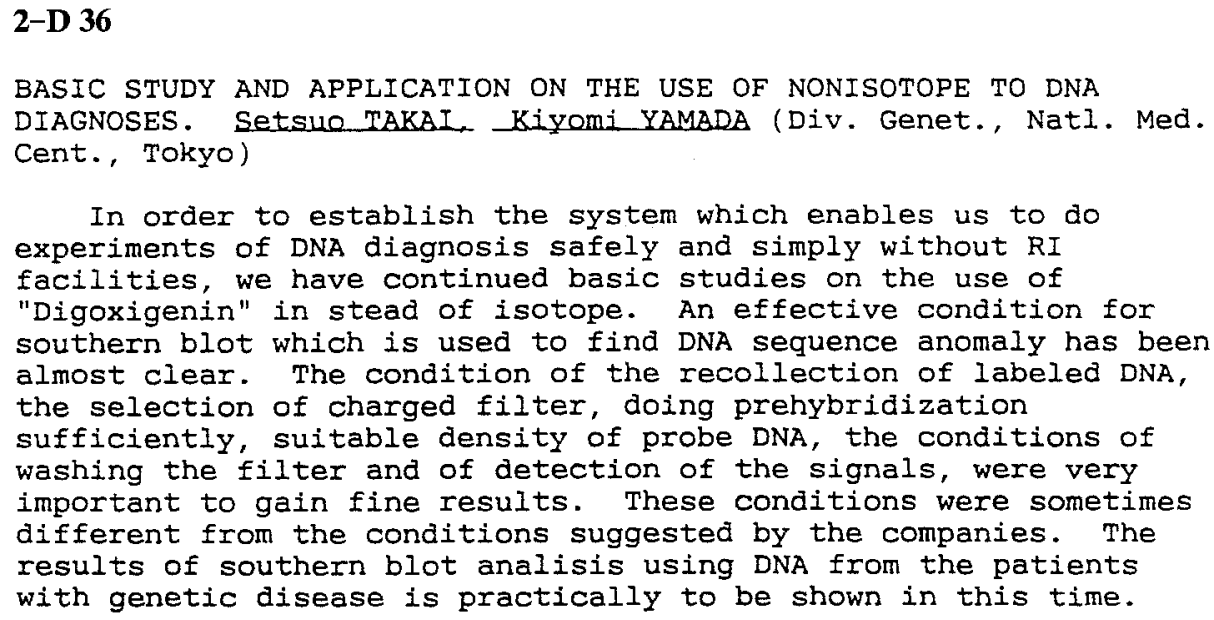

\section{2-D 37}

CONSTRUCTION OF A9 CELLS CONTAINING A SINGLE HUMAN

CHROMOSOME, WHOSE PARENTAL ORIGIN IS KNOWN. Kohzoh MITSUYA, Hiroshi UEJIMA, Hiroyuki KUGOH and Mitsuo OSHIMURA. (Dept. of Mol. \& Cell Genet., School of Life Sciences, Faculty of Medicine, Tottori Univ., Tottori)

A growing body of evidence has accumulated in favor of the biological importance of "Genomic imprinting", or parental allele-specific expression of genes. To establish an in vitro assay system for such imprinted genes, we have constracted mouse A9 clones containing a single human chromosome whose parental origin is known. Normal human fibroblasts were transfected with pSV2bsr plasmid DNA by the calcium phosphate precipipate method. Following fusion of BSH (Blasticidin S hydrochloride)resistant human fibroblasts and mouse A9 cells, microcell-mediated chromosome transfer was performed to isolate mouse A9 clones containing a single human chromosome tagged with pSV2bsr. Thus, A9 cells containing chromosomes 1 (1clone), 2(3clones), 4(4clones), 5(2clones), 6(1clone), 7(5clones), 8(3clones), 10(9clones), 11(3clones), 15(3clones), 16(4clones), 18(2clones), 20(1clone) or X(1clone) were obtained. Restriction fragment length phormorphic analysis revealed that 3 A9(bsr11)clones contained either paternal or maternal chromosome, i.e., 2 patenrnal and 1 maternal origin. We are now in progress of examination for genes such as IGF2, that has been known to be imprinted. 


\section{2-D 38}

DEVELOPMENT OF SEQUENCED TAGGED SITES (STS) FROM HUMAN CHROMOSOMAL REGION 14q22-32.1

Shuichi IGARASHI(1), Osamu ONODERA (1), Hajime TANAKA (1), Tatsuya KISHINO(2), Nobuyuki SOEJIMA (2), Michael WALTER (3), Norio NIIKAWA (2), Shoji TSUJI (1) (1) Dept. Neurology, Brain Research Institute, Niigata Univ. (2) Dept. human genet., Nagasaki Univ. School of Med. (3) Dept. Genet., University of Cambridge

The gene for early onset familial Alzheimer's disease (14q24.3) and the gene for Machado-Joseph disease (14q24.3-32.1) have been mapped to the long arm of chromosome 14 by linkage analyses. we have developed STSs by microdissection of human chromosome 14q22-32.1 region. Human chromosomal region,14q22-32.1, were microdissected under an inverted microscope. DNAs were digested with Sau3Al, amplified with the primer-linker method coupled to polymerase chain reaction, and subcloned into pUC18. So far we have characterized 330 microclones, of which 277 microclones are shown to contain inserts with a mean insert size of 300bp. We have determined partial nucleotide sequences and generated primer pairs to develop STS. The chromosomal locations were determined using a hybrid cell panel. 13 primer pairs have been shown to amplify genomic DNA segment on human chromosome 14. 7 primer pairs amplified repetitive sequences. These STSs derived from human chromosome 14q22-32.1 should be useful for the construction of the physical map, isolation of YAC clones and eventually to identify genes for early onset familial Alzheimer disease and Machado-Joseph disease.

\section{2-D 39}

STRUCTURAL ANALYSIS OF cDNAS FOR HUMAN MITOCHONDRIAL TRIFUNCTIONAL PROTEIN: CAUSATIVE ENZYME COMPLEX OF LONG-CHAIN

\section{FATTY ACID $\beta$-OXIDATION DISORDER}

Takehiko Kamijo, ${ }^{*}$ Atsushi Komiyama,* and Takashi Hashimoto $\$$

Department of *Pediatrics and ${ }^{\S}$ Biochemistry,

Shinshu University School of Medicine, Matsumoto, Nagano 390, Japan

Mitochondrial long-chain enoyl-CoA hydratase/3-hydroxyacyl-CoA dehydrogenase/3-ketoacyl$\mathrm{CoA}$ thiolase trifunctional protein is a causative enzyme complex of long-chain fatty acid $\beta$ oxidation disorder. We cloned, sequenced, and expressed the following cDNAs for the $\alpha-$ and $\beta$-subunits of human trifunctional protein. The 2,690-bp cDNA clone had a 2,289-bp open reading frame encoding a $82,958-\mathrm{Da}$ precursor and a 78,969-Da mature subunit ( $\alpha$-subunit). Expression of this cDNA in mammalian cells yielded a polypeptide with the long-chain enoylCoA hydratase and long-chain 3-hydroxy acyl-CoA dehydrogenase activities. The 1,991-bp cDNA clone had a 1,422-bp open reading frame encoding a 51,293-Da precursor and a 47,484-

Da mature subunit ( $\beta$-subunit). Expression of this cDNA in mammalian cells yielded a polypeptide with the long-chain 3-ketoacyl-CoA thiolase activity. 


\section{2-D 40}

Genomic organization of the mouse Lmp-2 gene Fumio KISHI ${ }^{1}$, Yoshinori SUMINAMI ${ }^{2}\left({ }^{1}\right.$ Dept. Pediatr., ${ }^{2}$ Dept. Obstet. Gynec., Yamaguchi Univ. Sch. Med., Ube) and John J. MONACO (Dept. Microbiol. Immunol., Virginia Commonwealth Univ., Richmond)

Major histocompatibility complex (MHC) class-I molecules present antigenic peptide fragments to cytotoxic $T$ cells. The peptides are generated in the course of antigen processing from endogenously synthesized cytosolic proteins, and transported into the endoplasmic reticulum to associate with an MHC class-I molecule. So far, at least four genes, $L m p-2,7$ and Tap-1, 2, have been identified between the $P b$ and $O b$ genes of the MHC class-II region. The genomic organizaion of mouse $L m p-2$, a gene that encodes a subunit of a large intracellular protein complex, was studied. A genomic clone has been isolated that covers the entire mouse $L m p-2$ gene. We have determined the nucleotide sequence of the region encompassing the whole Lmp-2 gene and three exons of the Tap-I gene, which spans $8 \mathrm{~kb}$ in the mouse genome. The two genes are situated in opposite directions. The transcription start points of the two genes, identified by primer extention analysis, are only $118 \mathrm{bp}$ apart. Both promoter regions upstream from the transcription start points have neither TATA consensus sequence nor other upstream regulatory elements, like an interferon-response element, in spite of their interferon-inducible expression. The Lmp-2 sequence from an non-obese diabetic (NOD) mouse, a model animal for autoimmune diabetes, was compared with that from a Balb/c mouse.

\section{2-D 41}

AN RNA SPLICING MUTATION IN HUMAN CILIARY NEUROTROPHIC FACTOR GENE. Ryosuke Takahashi, Hidemi Misawa (Dept. Neurol., Tokyo Metropolitan Institute for Neuroscience, Tokyo), Hidehiro Yokoji, Michiyuki Hayashi (Dept. Neurol., Tokyo Metropolitan Neurological Hospital, Tokyo) Jianguo Hu and Takeo Deguchi (BML, Inc., Saitama )

We report an RNA splicing mutation in the human gene that encodes ciliary neurotrophic factor (CNTF), a multifunctional protein that affects a variety of neurons. In the mutant allele, transition from $G$ to $A$ in the intron produced a novel splice acceptor site and an mRNA species coding for a truncated protein of 62 amino acids. Analysis of tissue samples from various genotype subjects and transfection of CNTF minigenes into cultured cells demonstrated that the mutant allele expresses only the mutant mRNA species. Of the 303 Japanese tested, five (2\%) mutant homozygote subjects were found among patients with neurological diseases who had shown no apparent 
2-E 1

MOLECULAR ANALYSIS OF RH POLYPEPTIDES DETECTED IN VARIOUS RH PHENOTYPES. Eiji KAJII, Fuminori UMENISHI and Shigenori IKEMOTO (Dept. Legal Med. \& Hum. Genet., Jichi Medical School, Tochigi)

Rh-related cDNA clones from donors with general $\mathrm{RhD}$-positive and $\mathrm{RhD}$-negative $\mathrm{Rh}$ phenotypes and rare $\mathrm{Rh}$ phenotypes (including Rhnull and -D-) were amplified by the polymerase chain reaction (PCR). Direct sequencing based on the PCR suggested the presence of both the RhPI-related and RhPII-related cDNAs in all donors. The RhPI and $\mathrm{RhPII} \mathrm{cDNAs}$ encoding two different $\mathrm{Rh}$ polypeptides had been cloned and reported by us. To confirm that the RhPII gene is present, we attempted to amplify the RhPII-specific region in genomic DNA using the PCR method. The RhPII-specific region were detected in all donors. Subcloning of the amplified Rh-related cDNAs revealed five kinds of $\therefore$ DNAs consisted of the RhPI, RhPII, and their variants. These cDNAs were of identical size and demonstrated the open reading frames composed of 1251 nucleotides from which 417 amino acid residues were inferred. It was shown that both the RhPI-related cDNA and the RhPII-related cDNA existed in all donors. These data sustain the three genes theory for the inheritance of the $\mathrm{Rh}$ blood group system and suggested that some posttranslational alteration of the $\mathrm{Rh}$ polypeptide or another protein is needed to stabilize the $\mathrm{Rh}$ polypeptide in the membrane.

\section{2-E 3}

A MUTATION IN THE PIT1 GENE IN THREE GENERATIONS : GENOMIC IMPRINTING MAY ACCOUNT FOR UNAFFECTED MUTATION CARRIERS. Nobuhiko OKAMOTO Yoshinao WADA, Shinobu IDA Ryoichi KOGA, Keilchi OZONO, Hide-aki CHIYO Akira HAYASHI (Osaka Med. Ctr. and Res. Inst. for Maternal and Child Health), Ke-ita TATSUMI (Dept. of Lab. Medicine, Osaka Univ. Med. School)

The combined deficiency of pituitary hormones, thyrotropin, growth hormone and prolactin, caused by the defective PIT1 gene manifests in homozygous or heterozygous state. This is the third case having an allele with the Arg271Trp mutation which occurs in the POU homeodomain of the gene. The mutation produces clinical symptoms in heterozygotes by a dominant-negative effect on the action of the normal PIT1 gene product (Radovick et al. 1992). However in this family, the proband has apparent manifestations of hormone deficiencies, but her father, grandmother and aunts have the same mutation without clinical symptoms. The phenotypic expression of the mutation is not explained by simple mode or dominat-negative effect but possibly by genomic imprinting. Considerable variations in the clinical manifestations of the reported cases suggest that the complex systems or multiple factors are involved in the expression of the PIT1 gene and the action of its product. 
2-E 4

PCCB GENE MISSENSE AND SPLICING MUTATIONS IN A COMPOUND HETEROZYGOTE FOR PROPIONIC ACIDEMIA. Ioshihiro OHURA ${ }^{1}$, Kuniaki NARISAWA ${ }^{2}$, Keiya TADA ${ }^{1}$. (Depts. Pediatrics ${ }^{1}$ and

Biochemical Genetics ${ }^{2}$, Tohoku University School of Medicine, Sendai)

Propionic acidemia is an autosomal recessive disease resulting from deficiency of propionylCoA carboxylase (PCC) activity. The $\alpha$ and $\beta$ subunits of $P C C$ (structure, $\alpha_{6} \beta_{6}$ ) are encoded by the PCCA and $P C C B$ genes, respectively. The human $P C C B$ CDNA was sequenced in full and shown to encode a pre- $\beta$ subunit of 539 amino acids. By PCR and sequence analysis, we found two different mutations in a $\beta$-subunit deficient Japanese patient. One mutation was inherited from the mother; this was a $C^{1283}$ to $T$ transition(C1283T) which substituted threonine ${ }^{428}$ for isoleucine. By PCR-ASO hybridization method, the C1283T mutation was found in 5 of 16 mutant alleles and was not detected in 50 normal Japanese subjects. This suggests that this C1283T mutation causes disease, and may be a common mutation in $\beta$ subunit deficient Japanese patients. The second mutation was an inframe 57-bp deletion leading to the deletion of 19 amino acid from the $\beta$-polypeptides. Analysis of the genomic DNA revealed a four-bp deletion from bp3 to bp 6 of the intron just downstream of the deleted exon. This deletion disrupted the consensus 5' splice signal and led to exon skipping.

\section{2-E 5}

THE EFFECT OF ATOMIC BOMB RADIATION ON THE GENETIC INSTABILITY OF TANDEM-REPETITIVE-ELEMENTS IN HUMAN GERM CELLS. Mieko KODAIRA, Junko KANEKO, and Chiyoko SATOH. (Dept. of Genetics, Radiation Effects Research Foundation, Hiroshima)

We have been studying the effects of the atomic bomb radiation on the germ line mutation rates. Frequencies of germline mutations at 6 minisatellite loci, $\lambda T M-18$, ChdTC-15, Pc-1, CEB-1, $\lambda M S-1$, and $\lambda g 3$ were examined in 50 exposed families in each of which at least one of parents was exposed to the A-bomb (64 children) and 50 control families ( 60 children) by using Southern blot analysis. Fifteen mutations at the $C E B-1$ locus and 12 mutations at the $\lambda M S-1$ locus and 1 mutation at the $\lambda g 3$ locus were detected among 124 children. The mutation rates per gamete in the exposed parents were $6.1 \%$ at the $C E B-1$ locus and $1.5 \%$ at the $\lambda M S-1$ locus, whereas those in the non-exposed parents were $6.0 \%$ at both of the $C E B-1$ and the $\lambda M S-1$ loci. A single mutation at the $\lambda g 3$ locus was derived from the exposed father. No significant difference was observed in the mutation rate at each of the 3 loci between the 2 groups of parents. These results suggest that A-bomb exposure seems not to affect the germline instabilities at the CEB-1 locus, the $\lambda M S-1$ locus and the $\lambda g 3$ locus. 


\section{2-E 6}

高コリンエステラーゼ活性を有する 8 家系. 日高和夫、井内岩夫、山崎害子（川崎医科 大学生化学). Ten instances of hyper serum cholinesterase detected in eight Japanese families. Kazuo HIDAKA, Iwao IUCHI, Toshiko YAMASAKI(Dept. of Biochem., Kawasaki Med. School)

血清コリンエステラーゼ（EC 3.1.1.8，C h E ）の遗伝子 $\mathrm{E}_{1}$ は染色体 $3 \mathrm{q} 21-25$ 上に ある。高 C h E 活性保因者にサクシニルコリンの常用量を投与してもその作用が無效であ る。私共はここ数年で、肝、腎機能障害に無関係の高 C h E 活性例を 8 家系（10名）を 検出した。その遺伀生化学的成績は次の通りであった。1) 高C h E活性は 487〜878(正 常 : 160 250 $\mu \mathrm{mol} / \mathrm{ml} / \mathrm{hr}$ )で正常值の上限の 3〜 4 倍の高值を示した。 2 ）家族調査で 高 Ch E 活性の遺伝性が認められた。3）アイソザイム電気泳動で $\mathrm{C}_{4}$ の他に $\mathrm{C}_{5}$ 位置に高 活性を示す band が出現した。4） $\mathrm{C}_{5}$ の band は $\mathrm{C}_{4}$ のそれに比べ熱に不安定であった。 5 ）高活性を示す $\mathrm{C}_{4}$ およびC 5 に対応する蛋白が存在した。6）4つの exon での遺伝子 解析では異常が諗められなかった。現在、intron および5'一と $3^{\prime}$ 一の非翻訳領城を検 索中である。

\section{2-E 7}

TRINUCLEOTIDE REPEAT INSTABILITY WAS NOT DETECTED IN THE CHILDREN OF ATOMIC BOMB SURVIVORS. Chiyoko SATOH, Kazuki YASUNAGA (Dept. Genet., Radiation Effects Research Foundation, Hiroshima)

In a pilot study to compare various types of DNA as potential targets for the detection of germinal mutations in the children of atomic bomb survivors, 50 exposed and 50 control families were examined for trinucleotide repeat expansion mutations. This type of mutations result in 6 human genetic diseases. The expansions show remarkable variation both within the cells of a single individual and among affected members of a single family which have been interpreted as mitotic and meiotic instability, respectively. We examined with PCR analysis the regions with the triplet repeats in the $F M R-1, A R$, and $D M$ genes causative for fragile $\mathrm{X}$ syndrome, spinobulbar muscular atrophy and myotonic dystrophy, respectively, of 64 children of the exposed family (one or both parents were exposed to an average dose of $1.8 \mathrm{~Sv}$ ) and 60 children of the control families and compared the repeat numbers with those of their parents. No mutations were detected in a total of 177 regions derived from 65 germ cells of exposed parents and 443 regions from 183 germ cells of non-exposed parents, that is, no effects of atomic bomb radiation on the instability of the triplet repeats in the germ cells were observed. 


\section{2-E 8}

DNA FINGER PRIN TING WIT H MULTILOCUS PROBE Myo IN HY DATIDIFORM MOLE WITH A COEXISTENT FETUS. Mitsuyo TANEMURA, Noriko KATO, Atsushi ARA KAWA, Tadashi IIDA, Setsuo OKADA, Kenji SUZUMORI, Kaoru SUZUMORI, Yoshiaki YA GAMI (Dept. Obstet. Gynecol., Nagoya City Univ. Med. School, Nagoya)

Hydatidif orm moles can be classified into two entities, complete and partial. Two cases of pregnant women with suspected partial mole were presented. Ultrasound examinations revealed a placenta with suspected molar mass and a live fetus in these cases. These pregnancies were terminated by dilation and curettage. DNA was prepared using standard techniques from molar tissue, normal placenta, fetus, maternal and paternal blood. We analyzed DNA fingerprints of each sample by multilocus probe Myo, and 5 single-locus probes after digestion with restriction endonuclease TaqI and Hinfl. In both cases, each polymorphic band in molar tissues could be identified as being of paternal but not maternal origin, though normal placenta and fetus had polymorphic bands of parental origin. Additionally some polymorphic bands of paternal origin were not observed in molar tissues, indicating that endoreduplication of a normal haploid sperm or fertilization by dispermy to an anuclear oocyte with no effective genome could form the complete hydatidiform mole (androgenesis). The differentiation between partial mole and twin pregnancy consisting of a combination of a normal pregnancy and complete hydatidiform mole is sometimes difficult based only on gross appearance and histopathology. This method can be used to obtain a differential diagnosis between the se entities.

\section{2-E 9}

DISSEMINATION OF GERMLINE MUTATION CAUSING SUPPRESSION OF SOMATIC MUTATION. Masayuki HAKODA, Sakura HAYASIMOTO, Naoyuki KAMATANI, Sadao KASHIWAZAKI (Inst. Rheum., Tokyo Women's Med.Col., Tokyo) and Tsukasa KOJIMA (Clin. Chem. Toranomon Hosp., Tokyo)

We have been studying in vivo somatic mutations at autosomal adenine phosphoribosyl transferase (APRT) locus by cloning T cells resistant to 2,6diaminopurine. It has been revealed that mutant $T$ cells exist at the frequency of as high as $1.3 \times 10^{-4}$. Southern blot analysis showed that approximately $80 \%$ of mutant T cells lost normal alleles, which is expressed as loss of heterozygosity (LOH). Recently, we have identified a heterozygote (OY) with low $(1 / 5 \sim 1 / 10)$ mutant T cell frequency. Major gene alteration (probably a partial deletion) was observed in the germline APRT allele in this heterozygote. In the APRT-mutant T cell clones obtained from this heterozygote, LOH was not observed. In another nonrelated heterozygote (TF), the same major alteration was identified in the germline APRT gene. The frequency of mutant T cells deficient in APRT in this heterozygote was also low as observed in heterozygote OY. No LOH was observed in mutant T cell clones. Although APRT locus has not any relevance to oncogenesis, loss of normal alleles is an important mechanisms for the inactivation of suppressor oncogenes. Thus, the similar class of genetic defect leading to the suppression of $\mathrm{LOH}$ may relate to the different risks for the development of malignant tumors among individuals. 


\section{2-E 10}

ANALYSIS OF SRY GENE IN 46, XY SEX REVERSAL PATIENTS BY PCR DIRECT SEQUENCING.

Taku IIDA $^{1,2}$, Rie KOMAKI $^{1}$, Yutaka NAKAHORI ${ }^{1}$, Yasuo NAKAGOME${ }^{1}$ ('Dept. Hum. Genet., Tokyo Univ., Tokyo, 2Dept. Obstet. and Gynecol., Tokyo Univ., Tokyo)

A number of $\mathrm{XY}$ males have been reported in whom no translocation involving the SRY (sex determining region Y) gene have been detected. The sequence analysis could reveal mutations in some of them.

We performed the PCR direct sequencing analysis of SRY in 20 patients who have either a 46, XY karyotype or mosaicism with Y chromosomal short arm and show the female external genitalia.

A 380 bp region including the HMG (high mobility group) conserved region was amplified and sequenced using the streptavidin-magnet beads method.

In one of all the patients' DNAs, was point mutation in the SRY observed.

\section{2-E 11}

IDENTIFICATION OF NEW CDNA CLONES ENCODING RH POLYPEPTIDES. Fuminori UMENISHI, Eiji KAJI and Shigenori IKEMOTO (Dept. Legal Med. \& Hum. Genet., Jichi Medical School, Tochigi)

We previously reported two cDNA clones (RhPI and RhPII cDNAs) encoding $\mathrm{Rh}$ polypeptides that consisted of an open reading frame with 1251 nucleotides. A result of the heterozygous patterns in direct sequencing suggested the presence of additional $\mathrm{Rh}$ related cDNA clones besides the above two clones. We attempted the isolation of Rh poiypeptide cDNA clones using PCR method from mRNAs of the erythroid cells cultured by the selective two-phase liquid culture system and reticulocytes. Four Rh-related cDNAs were isolated other than the RhPI and RhPII cDNAs (RhPI-1, RhPI-2, RhPII-1, and RhPII-2, tentatively designated), and showed one or several nucleotide substitutions compared with the original clones. We further isolated two RhPI-related isoforms that were the shortened forms of RhPI cDNA. These nucleotide deletions by alternative splicing produce unexpected structural peptides resulting in the generation of a new open reading frame by frameshift translations and in the reverse orientation of topology. Although it is as yet unclear that these Rh-related polypeptides and isoforms encode which of $\mathrm{Rh}$ antigens, multiple Rh-related mRNAs may be essential to the expression of $\mathrm{Rh}$ antigenicity. 


\title{
2-E 12
}

\author{
PHYSICAL MAPPING OF THE SHORT ARMS OF HUMAN ACROCENTRIC \\ CHROMOSOMES. \\ Kosuke SAKAI, Jun KUDOH, Shinsei MINOSHIMA, Nagakura HARA, Yimin WANG \\ and Nobuyoshi SHIMIZU (Department of Molecular Biology, Keio University School \\ of Medicine, Tokyo)
}

It has been shown that the short arms of acrocentric chromosomes are mainly composed of several different clusters of tandemly repeated sequences such as rRNA gene (rDNA) and $\beta$ satellites. We have shown rDNA clusters as a 3-Mb DNA band on a pulsed-field gel after digesting human genomic DNA with Eco RV or Sse 83871 , each of which does not cut within rDNA clusters. We purified DNA from 320 rDNA positive cosmid clones, which were derived from chromosome 22-specific cosmid library, and digested with Eco RV. Eight clones which were susceptible to Eco RV were further analyzed as candidates for boundary clones of the rDNA cluster. Physical mapping of these clones allocated one clone to $3^{\prime}$ flanking to the rDNA cluster. This clone contained both unique and tandemly repeated sequence. This novel tandem repeat sequence together with known short arm sequences were used for the analyses of the short arm structure. It was demonstrated that the rDNA cluster was linked with a cDNA clone pUNC 724 at the distal junction which was further linked to the $\beta$ satellite tandem repeats.

\section{2-E 13}

TELOMERE LENGTH IN LEUKEMIC CELL LINES. Hiroshi OHMURA Mitsuo OSHIMURA (Dept. Mol. Cell Genet., Tottori Univ., Yonago) and Jun MINOWADA (Fujisaki Cell Center, Hayashibara Biochemical Laboratories, Inc., Okayama)

Telomere is the structure which is located on both ends of individual chromosomes in eukaryotes. The DNA sequence of the telomere consists of tandem repeat of TTAGGG in man. Telomere reduction is associated with cell senescence and immortalization. We examined the telomere length in leukemic cell lines and peripheral blood samples.

- AML, T-ALL and CML(BC) cell lines showed shorter telomere length than that of the normal lymphocytes.

- PreB-ALL cell lines showed longer telomere length than that of the normal lymphocytes.

- The telomere length of the normal lymphocytes showed no significant difference from those of B-ALL, MLL cell lines and MDS, CML(CP) samples.

- $C M L(B C)$ cell lines showed shorter telomere length than that of $C M L(C P)$ samples.

- Some cell lines had variable telomere length, even though they were established from the same patient.

Thus, the telomere length in leukemic cell lines is unique for the leukemic type, and the frequency of chromosome abnormality was not associated with the telomere length in cells. 


\section{2-E 14}

A FAMILY WITH LESCH-NYHAN SYNDROME: SPLICING ERROR BECAUSE OF A POINT MUTATION AT THE 3' END OF INTRON. Yasukazu YAMADA ${ }^{2}$, Haruko GOTO $^{1}$, Shozo TAMURA ${ }^{2}$, and Nobuaki OGASAWARA ${ }^{1}\left({ }^{1}\right.$ Department of Genetics, Institute for Developmental Research, Aichi Prefectural Colony, Kasugai, Aichi, and ${ }^{2}$ Tamura Clinic, Shinjuku-ku, Tokyo)

Deficiency of a purine salvage enzyme, hypoxanthine guanine phosphoribosyltransferase (HPRT, EC 2.4.2.8), is associated with two distinct clinical disorders which are inherited as an X linked recessive trait. Complete deficiency of HPRT leads to Lesch-Nyhan syndrome, whereas partial deficiency causes a severe form of gout. We report here the identification of a point mutation at the consensus region for splicing of the HPRT gene in a Japanese family with Lesch-Nyhan syndrome.

A single nucleotide substitution of $G$ to $T$ at the 3 '-end of intron 3 in the splicing consensus region has been identified in one allele of the HPRT gene from a mother predicted to be a heterozygous Lesch-Nyhan carrier. By utilizing a $B f a$ I restriction site which was lost in the mutation as an indicator, family study was carried out, and the mother and her daughtor were identified as heterozygotes but the mother's sister did not have the mutant allele. The mutation generated splicing error and resulted in two types of abnormal mRNA. The major altered mRNA, named Type I, skipped the exon 4 and is predicted to produce a protein deleted of 22 amino acid residues. The other, Type II, having a 9-bp deletion at the 5'-end of exon 4, can result in a protein lacking 3 amino acids, from codon 107 to 109.

\section{2-E 15}

IDENTIFICATION OF POINT MUTATIONS IN THE ALPHA-GALACTOSIDASE A GENE EXON 7 IN TWO PATIENTS OF FABRY DISEASE

Yasushi MIYAKITA(1), Hajime TANAKA(2), Osamu ONODERA(2), Isao HOZUMI(2), Akihiro YOKOYAMA(1), Tohru IZUMI(1), Akira SHIBATA(1), Shouji TSUJI(2).

(1)First Department of Internal Medicine, Niigata University School of Medicine,Niigata (2)Department of Neurology, Brain Research Institute, Niigata University, Niigata

We have analyzed alpha-galactosidase $A$ gene from two patients with Fabry disease using PCR-SSCP analysis. The analysis revealed two aberrantly migrating bands derived from the exon 7 in two unrelated hemizygotes. Direct sequencing analysis revealed two different point mutations. One hemizygote had an A-to- $C$ transversion in exon 7 (codon 410) which substitutes a proline(CCA) for a threonine(ACA) and creates an Mval restriction site. The other had a different point mutation in exon 7 , which was $T-$ to-C and $\mathrm{C}-$ to-T transitions at codon 387 which substitutes a proline(CCT) for a leucine(CTC) and destroyed an Alul site. Since previously reported exonic point mutations of the alpha-galactosidase $A$ gene in Fabry disease have been found only in exon 1,2 or 6 , this is the first report of point mutations in exon 7. 


\section{2-E 16}

A new nonsense point mutation of the a-galactosidase A gene in exon 6 in a case of Fabry disease

Hitoshi Osaka, Seiji Kimura (Dept. Ped., Yokohama City Univ., Yokohama) Chiaki Kawanishi, Ken Inoue, Hideki Onishi, Yoshiteru Yamada, Kyoko Suzuki, Tokiji Hanihara, and Kenji Kosaka (Dept. Psy., Yokohama City Univ., Yokohama)

A 17-year-old Japanese male developed normally until 10-year-old when he experienced foot pain. It occurred with high fever or after exercise, and persisted for a few minutes. The intensity of the pain increased gradually, and so he was referred to our hospital at the age of eleven years. His mother had also experienced weak foot pain in childhood and she had bilateral cataracta. Physical examination revealed that he had angiokeratoma on the scrotum. No neurological or ophthalmological abnormalities were detected. A $\alpha$-Gal A activity of white blood cells from the patient was not detected, so the diagnosis of Fabry disease was made. We performed reverse transcription and cDNA amplification of the patient's $\alpha$-Gal A mRNA, and three PCR products overlapping each other in the $\alpha$-Gal A coding region were prepared. CDNA sequencing revealed a single base substitution, C-to- $T$, at nucleotide position 901 . It changed codon 301 from CGA to TGA, resulting in the replacement of a codon for arginine with a termination codon. We found no other base substitution in the entire coding region of the patient's $\alpha-\mathrm{Gal} A$ cDNA. This mutation was also confirmed in DNA. His mother was heterozygous for this point mutation.

\section{2-E 17}

STEROID SULFATASE GENE STUDY IN TWO FAMILIES WITH X-LINKED ICHTHYOSIS Kazuo NOMURA, Ha jime NAXANO, Kaoru UMEK1, Atsushi KON, Daisuke SAHAMURA, Isao HASHIMOTO (Dept. Dermatol., Hirosaki Univ. , Hi rosaki)

$X-1$ inked ichthyosis (XLI) is a hereditary skin disaese caused by steroid sulfatase (STS) deficiency. Usually, entire deletion of STS gene in $X$ chromosome is observed in the affected individuals. In this study, we examined STS gene in two families with XLI using PCR and Southern blot. Three sets of oligonucleotide primers were prepared for amplifying exon1.5 and 10 in the STS gene which consitsts of 10 exons. In the family 1, the DNA was not amplified in exon10 in two affected individuals, whereas DNA was amplified in exon 1 and 5 in all the members. In the family 2, the DNA was amplified in exon 1,5 and 10 in all the members including affected individuals and a career. The STS activity of the proband was 25 . which was about $20 \%$ of that of normal male (generally, the STS activity is almost 0 in the affected individual). The Southern blot analysis showed Sall polymorphic pattern in the family 1. The results suggested there is a partial deletion or point mutation in the STS gene in these two families with XLI. 


\section{2-E 18}

MUTATIONS OF THE ORNITHINE TRANSCARBAMYLASE (OTC) GENE IN MALE PATIENTS WITH LATE ONSET OTC DEFICIENCY. Atsushi NISHIYORI', Makoto YOSHINO', Yasuyuki TOKUNAGA ${ }^{1}$, Toshinobu MATSUURA ${ }^{2}$, Ryuuji HOSHIDE ${ }^{2}$, Ichiro MATSUDA $^{2}$ and Tateo KUNO ${ }^{3}$ ('Dept. Pediatr, Kurume Univ., ${ }^{2}$ Dept. Pediatr. Kumamoto Univ., ${ }^{3}$ Dept. Pediatr. Saga Medical Univ.)

Hemizygous male patients with ornithine transcarbanylase (OTC) deficiency virtually always develop its manifestations in the neonatal period or in the early infancy. In contrast to these classical patients, we reported three male patients with unusually late onset. Analyses of the OTC gene in these three patients revealed a $G$ to $A$ substitution in exon 2, resulting in the substitution of a ${ }^{40} \mathrm{Arg}$ to His in patient 1 and another unrelated male, patient 3 . A $T$ to $G$ substitution in exon 2, which caused a ${ }^{55} \mathrm{Tyr}$ to Asp substitution, was found in patient 2. Transmission of the ${ }^{40} \mathrm{Arg}$ to His mutation through the paternal 1 ineage was demonstrated by the identification of the identical mutation in a six year-old boy with hyperammonemia in the pedigree of patient 1 . These findings suggest that these mutations may be 1 ikely to be associated with the late onset disease, and demonstrate that the mutant OTC gene can be transmitted through a paternal lineage.

\section{2-E 19}

MOLECULAR ABNORMALITY OF ERYTHROCYTE PYRUVATE KINASE DEFICIENCY IN THE AMISH

Hitoshi KANNO, Shiro MIWA (Okinaka Memorial Institute for Medical Research, Tokyo), Samir K. BALLAS (Jefferson Medical College, Philadelphia), Hisaichi FUJII (Dept. of Blood Transfusion Medicine, Tokyo Women's Medical College) and Herbert S. BOWMAN (Harrisburg Hospital, Harrisburg)

Pyruvate kinase (PK) deficiency is the most common hereditary non-spherocytic hemolytic anemia (HNSHA) due to a glycolytic enzyme defect. In 1963, Bowman and Procopio described five PK deficient kindred found in the Amish deme in Pennsylvania. Previous reports showed that all the Amish PK variants descended from a common ancestor, therefore, the patients are likely to be homozygous with the identical mutation. The clinical manifestation of the Amish PK variant was often severe, sometimes death occurred in the neonates or between the ages of one and three. We identified a point mutation of the human PK gene, 1436 CGC to CAC in an Amish family with erythrocyte PK deficiency associated with HNSHA. The mutation causes a single amino acid substitution from Arg to His at the 479th amino acid residue of human R-type PK. The substituted Arg residue located in the $\mathrm{C}$ domain of PK, that is essential for both the intersubunit contact and the allostericity of the $R, L$ and $M_{2}$-type isozymes. Since PK demonstrates the catalytic activity only in dimer or tetramer, it is rational that the structural alteration causes a drastic decrease of PK activity in the erythrocyte. 
GENETIC SCREENING OF HUMAN ERYTHROCYTE AMP DEAMINASE DEFICIENCY. Nobuaki OGASAWARA ${ }^{1}$, Yasukazu YAMADA ${ }^{1}$, Haruko GOTO ${ }^{1}$, and Takaji MURASE ${ }^{2}$ ( ${ }^{1}$ Department of Genetics, Institute for Developmental Research, Aichi Prefectural Colony, Kasugai, Aichi, and ${ }^{2}$ Aichi Red-Cross Blood Center, Seto, Aichi)

Erythrocyte specific AMP deaminase (EAMPD) deficiency identified firstly by us, is clinically completely asymptomatic. The inheritance is autosomal recessive and the heterozygote frequency is estimated at about $1 / 30$. A point mutation of $\mathrm{C}$ to $\mathrm{T}$ resulting in an amino acid change of Arg to Cys had been identified on the EAMPD gene $(A M P D-3)$. The mutation was homogeneous in two partial and two complete deficiency. As the identified mutation (1717TC) seems to be very frequent at least in Japanese, we screened mutant genes, to clarify the existence and frequency of other mutations.

In screening about 2600 blood samples, 61 samples showed about a half of the enzyme activity of control. In one allele of the 45 individuals, the identified mutation (1717TC) was detected by the analysis of genomic PCR amplification and digestion at the Pst I site created in only the mutant gene. By the sequence analysis of the other 16 samples diagnosed as heterozygous, 9 heterogeneous mutations were identified in one allele of the 12 individuals. However, mutations in the remained 4 samples were unknown.

Thus, the EAMPD deficiency in Japanese seems to be associated with $75 \%$ major homogeneous mutation and $25 \%$ other heterogeneous mutations.

\section{2-E 21}

MOLECULAR CHARACTERIZATION OF GENE EXPRESSION IN HUMAN LACTATE DEHYDROGENASE-A DEFICIENCY. Hiroaki MIYAJIMA, Yoshitomo TAKAHASHI, Takako SHIMIZU, Tadashi KAMATA, Masahiro SERIZAWA, Kuniko ISHIKAWA and Eizo KANEKO (Dept. Med., Hamamatsu Univ. Sch. Med., Shizuoka)

A 34-year-old male complained of muscle pain and pigmenturia after severe exertion from age of eleven. Con sanguinity could not be found through four generation. His youger brother also experienced recurrent rhabdomyolysis during exercise. Neither muscle wasting nor weakness was detectable. The activity of lactate dehydrogenase (LDH) in the muscle was decreased less than $8 \%$ of nomal value. The isozyme pattern of the muscle LDH revealed only one band of B 4 . The levels of blood lactate did not rise on anaerobic exercise, while a marked increase of pyruvate was found. These laboratory data were similar to those of his brother. Northem blot analysis showed that the ratio of LDH-A transcript to B-actin transcript in the patient was similar to that in a normal subject. The size of the reverse transcription-polymerase chain reaction product corresponding to exon 6 was decreased. The direct sequencing of this product revealed a deletion of 20 nucleotides. The deletion occurred at short sequence repeat (TTGG), suggesting that "slipped mispaining" during DNA synthesis might be involved in deletion formation. This mutation results in a frame-shift translation and premature termination. The predicted incomplete LDH-A contains only 259 instead of 331 amino acids. Immunofluorescence staining showed the presence of LDHA protein within the cytoplasm. These findings suggest that LDH-A mRNA is transcribed in a truncated form and an incomplete LDH-A protein lacking the subunit contact subdomain could not assemble into a tetrameric structure that has an enzymatic activity. 


\section{2-E 22}

Molecular characterization of two galactosemia mutations (type 1) in Japanese Jiro ASHINO, Yoshiyuki OKANO, G.Isshiki (Dept. of Pediatr., Osaka City Univ. Med. School., Osaka) Itujin SUYAMA (Osaka Municipal Rehabil. Cent. for the Disabled, Osaka) and Takeshi YAMAZAKI (Osaka Rosai Hosp., Osaka)

We found the two mutations of galactose-1-phosphate uridyl transferase (GALT) gene in two Japanese patients with GALT deficiency. GALT cDNA was amplified from transformed lymphoblast by RT-PCR method, and was subcloned into M13mp 18 for DNA sequencing. The missense mutation was a $\mathrm{G}$ to $\mathrm{A}$ transition at nucleotide 720 of the GALT gene, resulting in the substitution of Arg by His at the codon 231 (R231H). The GALT activity of R231H mutant construct reduced to $15 \%$ of normal control using a COS cell expression system. We found a splicing mutation which showed a $38 \mathrm{bp}$ deletion from nucleotide 281 to 318 of the GALT cDNA. We observed an A to $G$ transition at nucleotide 38 in exon 3 by genome DNA analysis. There was the pyrimidine tract in the region before this mutation as well as in the orginal acceptor splice site. Therefore, this mutation was the cause of new splice acceptor site (AA - AG). We examined the frequency of $\mathrm{R} 231 \mathrm{H}$ and the splicing mutation in 7 Japanese families $(15$ alleles) using dot-blot hybridization. $\mathrm{R} 231 \mathrm{H}$ mutation was found only in both alleles of a proband, and the splicing mutaion also was found in both alleles of another proband. The two patients with R231H/R231H, Del38/Del38 showed less than 1\% of normal control by GALT analysis of lymphoblast, and typical clinical galactosemia type 1 .

\section{2-E 23}

Gene Muation and Serum $\beta$-galactosidase in $G_{M 1}$ gangliosidosis juvenile type

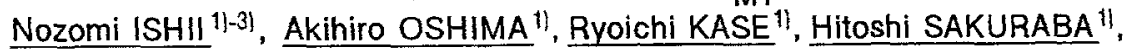
Yukio Fukuyama $^{3 /}$, Yoshiyuki SUZUKI" ("Dept. Clinical Genetics, Tokyo Metropolitan Institute of Medical Science, Tokyo, ${ }^{21}$ Dept. Pediatrics, Tokyo Metropolitan Komagome Hospital, Tokyo, ${ }^{31}$ Dept. Pediatrics, Tokyo Women's Medical College, Tokyol

$G_{M 1}$ gangliosidosis is a genetic disease with lysosomal $\beta$-galactosidase deficiency caused by mutations of the gene coding for this enzyme. In this study, however, iuvenile $G_{M 1}$ gangliosidosis patients with a common mutation, R201C (201 Arg $\rightarrow$ Cys), were found to show apparently normal enzyme activity in plasma or serum. Serum enzyme activity increased 3- to 10-fold in normal subjects after 3.5-h clotting, but this increase was not observed in the patients homozygous for this mutation. $\beta$-galactosidase assay is not always reliable for the diagnosis of hereditary $\beta$-galactosidase deficiency, unless it is conducted under the wellcontrolled condition. 


\section{2-E 24}

OTHER MUTATIONS OF $\beta$-HEXOSAMINIDASE $\alpha$ GENE IN JAPANESE PATIENTS WITH INFANTILE TAY-SACHS DISEASE: ONE SPLICING MUTATION AND FIVE MISSENCE MUTATIONS.

Akemi TANAKA, Hiroshi MURAKAMI, and Gen ISSHIKI (Dept. Pediat., Osaka City Univ. School of Med.)

Tay-Sachs disease is caused by genetic abnormalities of $\beta$-hexosaminidase $\alpha$ subunit gene. The major mutation (a G-toT transversion at the acceptor splice site of intron 5) of infantile Tay-Sachs disease among Japanese patients was reported by our group in 1993. It was found in $80 \%$ of the mutant alleles of the patients from various part of Japan. In this report, six mutations in five Japanese patients with infantile Tay-Sachs disease were newly characterized, and four of them were novel mutations. These alleles account for $50 \%$ of the rest of the mutant alleles. One base substitution at the donor splice site of intron 3 (G-to-T) caused a skipping of exon 3 in the mutant cDNA of case 1. Case 2, 3, and 4 had a point mutation with amino acid substitutions of C458Y, L484P, and R504C, respectively. There was a double mutation of S302G and R504H in case 5. Two of them (R504C and R504H) have been reported in other ethnic groups but others have not. These two mutations were at the mutation hot spot with $\mathrm{CpG}$ sequence. All the cases exept case 1 had the major mutation in another allele. These results suggested that these mutations exept "the major mutation" are sporadic and still unspreaded.

\section{2-E 25}

HUMAN N-ACETYLGALACTOSAMINE-6-SULFATE SULFATASE: MOLECULAR CLONING AND STRUCTURAL ANALYSIS. Yoshihiro NAKASHIMA, Shunji TOMATSU, Toshinori HORI, Hideki IWATA, Tatsuya OGAWA, Atsushi YAMAGISHI, Atsushi UCHIYAMA, Seiji FUKUDA, Kazuko SUKEGAWA and Tadao ORII. (Dept. Pediatrics, Gifu Univ., Gifu)

Mucopolysaccharidosis IV A (MPS IV A) results from a genetic deficiency of the lysosomal hydrolase, $\mathrm{N}$-acetylgalactos amine-6-sulfate sulfatase (GALNS). To begin to investigate MPS IV A patients precisely at the genome level, we elucidated the entire structure of the human GALNS gene from a series of overlapping clones isolated from human genomic library.

The gene is about $50 \mathrm{~kb}$ in length and contains 14 exons. The $5^{\prime}$-flanking region lacks a characteristic TATA box or CCAAT box, but has high $\mathrm{G}+\mathrm{C}$ content, containing four $\mathrm{GC}$ boxes common to a hous ekeeping promoter. Main transcription sites at nucleotides -58 and -22 were identified within 722 nucleotides upstream of the translation start site by primer extension analysis. The $5^{\prime}$-flanking region exhibited promoter activity by transient expression using a CAT assay. Further deletion analys is to determine a defined promoter showed the core region was located between positions -98 to -1 upstream of the ATG codon. It suggests that one GC box in this region would be a binding site of a regulatory element. 
2-E 26

MOLECULAR BASIS OF MUCOPOLYSACCHARIDOSIS TYPE IV A (ANALYSIS OF COMMON DOUBLE DELETION FOR GALNS GENE) Toshinori HORI, Shunii TOMATSU, Atsushi UCHIYAMA, Yoshihiro NAKASHIMA, Seiji FUKUDA, Kazuko SUKEGAWA, Tadao ORII (Department of Pediatrics, Gifu University, School of Medicine)

Mucopolysaccharidosis IVA ( MPS IVA) is an autosomal recessive disorder caused by a deficiency in Nacetylgalactosamine-6-sulfate sulfatase (GALNS). Studies on the molecular basis of MPS IVA have been facilitated following purification of GALNS, cloning of the full-length cDNA, identification of the first two exonic point mutations, chromosomal assignment to $16 \mathrm{q} 24$, and isolation of GALNS gene. We report here the first evidence of a new common molecular lesion which may be a hot spot for double deletion in the GALNS gene. Using the cDNA probe, Southern blot analysis of GALNS gene in unrelated 20 patients revealed the gene rearrangement in 4 Japanese patients. Further DNA analysis with genomic restriction mapping and Southern blot by genomic probes revealed that two independent regions of nearly 8.0 - and 6.0 - $\mathrm{kb}$ fragments including some exons, respectively, were deleted homozygously in a severe phenotype in one Japanese MPS IVA patient. This similar double gene deletion pattern has been also observed in a heteroallelic state among only 3 Japanese patients. These results suggest that this deletion might define a severe phenotype. This unique type of mutation is the first document of a common double deletion as a single gene. We isolated the mutant fragments with deletions from the fibroblasts genomic library of the homozygous patient, decided breakpoints, and analyzed his family by PCR method. But the precise mechanism of occurrence of this large structural change has yet to be clarified. Further molecular investigations into MPS IVA patients would also help us better understanding of accurate frequency of this deletion event and difference in races.

\section{2-E 27}

MOLECULAR BASIS OF MUCOPOLYSACCHARIDOSIS IVA

Seiji FUKUDA, Shun $j i$ Tomatsu, Tatsuya OGAWA, Hideki IWATA, Yoshihiro NAKASHIMA, Toshinor i HORI, Atsushi YAMAGISHI, Atsushi UCHTYAMA, Kazuko SUKEGAWA, Yuko FUKUDA, Tadao OR I I Department of Pediatrics, Gifu University School of Medicine Mucopolysaccharidos is IVA results from genetic deficiency of lysosomal N-acetylgalactosamine-6-sufate sulfatase (GALNS). To investigate the molecular bas is of MPSIVA, we performed mutation screening on PCR fragments derived from 21 patients, using MDE heteroduplex and SSCP-MDE method and identified 12 new mutations on GALNS gene.

Specific bands with abnormal mobility were subcloned into plasmid vector, of which entire sequence was determined on several clones. Some expression vector pCAGGS containing the mutated cDNA were transfected into the enzyme deficient fibroblasts using 1 iposomes and the GALNS activities of the cell was assayed 120 hour after transfection.

At present, sixteen different mutations have already been detected in 21 patients. Most of them were various, and widely spread on GALNS gene. We have already confirmed some exonic mutations were associated with the disease by demonstrating deficient GALNS actvities in cells transfected with expression vector including each mutation. As concerns the others detected by mutation screening system, the activities encoded by them are also under investigation. 


\section{2-E 28}

IDENTIFICATION OF VERY-LONG-CHAIN ACYL-COA DEHYDROGENASE DEFICIENCY IN PATIENTS PREVIOUSLY DIAGNOSED WITH LONG-CHAIN ACYL-COA DEHYDROGENASE DEFICIENCY.

Seiji YAMAGUCHI ${ }^{1,2}$, Yasuhiro INDQ $^{1,3}$, Paul M. COATES $^{4}$, Takashi HASHIMOTO ${ }^{5}$, Kay TANAKA $^{!}$ (1.Department of Genetics, Yale University, CT 06510; 2. Department of Pediatrics, Gifu University School of Medicine; 3.Department of Pediatrics, Kumamoto University School of Medicine; 4.Division of Gastroenterology and Nutrition, Children's Hospital of Philadelphia, PA 19104; 5.Department of Biochemistry, Shinshu University School of Medicine, Matsumoto, Nagano 390)

Long chain acyl-CoA dehydrogenase (LCAD) deficiency is a disorder of fatty acid B-oxidation. Its diagnosis has been made based on the reduced activity of palmitoyl-CoA dehydrogenation, e.g. in fibroblasts. We previously showed that in immunoblot analysis, a LCAD band of normal size and intensity was detected in fibroblasts from all LCAD- deficient patients tested. In the present study, we amplified via PCR and sequenced LCAD CDNAs from three of these LCAD-deficient cell lines, and found perfectly normal LCAD sequence in two of them, indicating that at least these patients were not deficient in LCAD. The third patient was homozygous for an $A$ to $C$ substitution at 997 , although it is unknown whether or not $997-\mathrm{C}$ is a normal polymorphism. While the LCAD sequence data were puzzling, a new enzyme, very long chain acyl-CoA dehydrogenase (VLCAD), was recently identified. Since VLCAD also has high activity with palmitoyl-COA as substrate, it was possible that defective VLCAD may cause reduced palmitoyl-CoA dehydrogenating activity. We performed immunoblot analysis of VLCAD in six "LCAD-deficient" patients; VLCAD was negative in three of them, two of whom had a normal LCAD cDNA squence. These results indicated that a considerable number of the patients who had previously been diagnosed of having LCAD deficiency in fact have VLCAD deficiency.

\section{2-E 29}

MOLECULAR DEFECTS IN PHENYLALANINE HYDROXYLASE (PAH) GENE DETECTED BY PAHmRNA ANALYSIS FROM LYMPHOBLASTS IN ORIENTALS. Yoshiyuki OKANO, Gen ISSHIKI (Dept. of Pediatr., Osaka City Univ. Med.School, Osaka), Yutaka HASE (Osaka Kita Citizen's Hosp., Osaka), and Toshiaki OURA (Osaka Municipal Rehabil. Cent. for the Disabled, Osaka)

The low levels of mRNA analysis in non-expressing tissues can be detected by reverse transcription and nested PCR. We analyzed PAHmRNA from EB transformed lymphoblasts of Japanese PKU patients, and identified two exonic deletions in PAH genes. Amplified PAHcDNAs were short compared with normal PAHcDNA after nested $\mathrm{PCR}$, and the deletions were found in exon 5 and 6 , and exon 11. The deletion of exon 5 and 6 showed new RFLP with Xmn1, Bglll, and BamH1-EcoR1 by southern hybridization analysis reported by Trefz et al., indicating there was the deletion of more than $10 \mathrm{~kb}$ genome DNA including exon 5 and 6 . In genome DNA analysis, the patient with exon 11 deletion showed normal sequence in exon 11 and neighbouring introns except for Y356X mutation, which was a $C$ to $A$ transition at the 3 rd nucleotide in exon 11 (tacagTAC[ - A]TG). Y356X mutation effected the acceptor splice site of exon 11, and became the cause of splicing mutation of exon 11. The analysis of PAHmRNA from lymphoblast is useful for molecular characterization of PKU mutations. 


\section{2-E 30}

MOLECULAR ANALYSIS OF AUTOSOMAL RECESSIVE CHRONIC GRANULOMATOUS DISEASE WITH P47- OR P67-PHOX DEFICIENCY.

M. IWATA, I. MATSUDA (Dept. Ped., Kumamoto Univ., Kumamoto), H. NUNOI (Inst. of Med. Sci., Univ. of Tokyo), S. TSURUTA (Shizuoka Pref. Children's Hosp.), S.TATSUZAWA (Nat. Children's Hosp.), J. KOMIYAMA (Dept. Ped., Shinshu Univ.), T. NAKANO (Dept. Ped., Mie Univ.),

H. NIWA (Izumi-Sano City Hosp., Osaka), H.IMAISHI (Osaka NTT Hosp.), S.OGA (Dept. Ped., Kyushu Univ.), T. CHO (the 2nd Dept. Med., Nigata Univ.)

Chronic Granulomatous Disease (CGD) is a rare inherited disease due to defect in superoxide generating system in phagocytes(NADPH oxidase). This enzyme system consists of five protein components; i.e.,the membrane bound cytochrome b558 ;gp91-, p22-phox, cytosolic factors; p47-, p67phox and rac p21. Any defect or dysfunction in these components except rac p21 causes CGD.

We found 6 CGD patients with p47-phox deficiency and 5 with p67-phox deficiency in Japan and analyzed by direct sequencing method. All of the patients with p47-phox deficiency had a GT dinucletide deletion, suggesting that this region is a hot mutation spot for this type of CGD. Of 5 patients with p67-phox deficiency, one patient had a 186 base pairs deletion and another had a 2 base pairs insertion. However the other three cases had no mutation within a cording region except 2 point mutations due to polymorphism. Further analysis is required for the latter 3 patients. This is the first report on genetical analysis of p67-phox deficient CGD.

\section{2-E 31}

MOLECULAR ANALYSIS OF HOLOCARBOXYLASE SYNTHETASE DEFICIENCY. Yoko AOKI ${ }^{1}$, Yoichi SUZUKI ${ }^{1}$, Yoshinori ISHIDA ${ }^{1}$, Yasushi CHIBA ${ }^{2}$, Akihiro IWAMATSU $^{3}$, Kuniaki NARISAWA' (Dept. 'Biochem. Genet. and 'Pediatr., Tohoku Univ. School of Medicine, Sendai; ${ }^{J}$ Kirin Brewery Co. Ltd., Central Laboratories of Key Technology, Yokohama)

Holocarboxylse synthetase (HCS) deficiency is an autosomal recessive disorder characterized by combined organic aciduria, metabolic ketoacidosis, and dermatitis, all of which are improved by administration of biotin. Previous studies demonstrated high Km values of HCS for biotin in cultured cells from the patients. However, the molecular basis of HCS deficiency has not been reported. We have recently isolated human HCScDNA clones, which provided the tools for investigating the molecular pathogenesis. We studied one Japanese sib case (patent1 and patient2), and found two distinctive mutations, one base transition (T710C) and one base deletion of a $G$ at base position 782 by analysing HCS mRNA of patient1. The genomic analysis confirmed the heterozygosity of the affected sibs. The $\mathrm{T} 710 \mathrm{C}$ mutation causes amino acid substitution from $\mathrm{Leu}^{237}$ to $\mathrm{Pro}^{237}$, while one base deletion results in a frame shift followed by a premature termination, suggesting that those mutations are causative. 


\title{
2-E 32
}

\author{
AN ASSOCIATION STUDY BETWEEN ALCOHOLISM AND THE DOPAMINE \\ TRANSPORTER GENE \\ Yoshihi ro KONO. Hiroshi YONEDA, Toru ISHIDA. Yasuhi ro NONOMURA. \\ Yasuhi ro INAYAMA. Jun $\mathrm{KOH}$, Ryuichi ro HIROTA. Yasushi INADA. \\ Hi royuki ASABA, Toshiaki SAKAI (Dept. Neuropsychiatry, Osaka Med. Coll., \\ Takatsuki, Osaka) and Hiroyuki IMAMICHI (Shin-abuyama Hospi tal, Takatsuki, \\ Osaka )
}

Giros et al (1992) have recently isolated a cDNA clone for the human dopamine transporter (DAT) which cocaine binds to and blocks. Vandenbergh et al (1992) have reported a $40-$ bp repeat in the 3 ' untranslated region of this cDNA and variable numbers of the repeat ranging from 3 to 11 copies. We investigated this variable number tandem repeat (VNTR) for 50 unrelated Japanese alcohol ics and 58 biologically unrelated controls. Genomic DNAs were prepared from peripheral white blood cells using standard method. The 40-bp repetitve el ement in the 3' untranslated region was ampl if ied by PCR. The PCR products were separated by agarose gel electrophores is, and 11 (A1 : 485bp), 10 (A2: $445 \mathrm{bp}), 9(\mathrm{~A} 3: 405 \mathrm{bp})$ and $7(\mathrm{~A} 4: 325 \mathrm{bp})$ copies of the $40-\mathrm{bp}$ repeat were found. The allele frequencies did not show any significant differences between the alcoholics and the controls. This result suggests that the DAT gene may not directly cause alcoholism.

\section{2-E 34}

An association study between bipolar affective disorder and serotonin 2 receptor DNA marker

Hiroshi YONEDA, Toru ISHIDA, Yasuhiro NONOMURA, Yasuhiro INAYAMA, Yoshihiro KONO, Jun KOH, Ryuichiro HIROTA, Yashusi INADA, TOShiaki SAKAI (Dept. Neuropsychiat., Osaka Medical College, Takatsuki)

Serotonin(5HT) receptors play an important role in the central nervous system. They were subtyped pharmacologically and each subtype may be associated with psychiatric disorders or psychiatric symptoms. In affective disorders, chronic administration of antidepressants decreases the density of $5 \mathrm{HT}$ receptors. We investigated genetic association between bipolar affective disorder and polymorphic 5HT2 receptor gene. The subjects were 83 bipolar affective disorders and 96 normal controls. The 5HT2 receptor gene located on the chromosome 13, showed a MspI polymorphic site at codon 102. Genomic DNA corresponding to the 5HT2 receptor gene was amplified by PCR. Digestion of the 342 bp PCR product with MspI yielded 2 alleles. There were no significant differences between the patients and controls in the allele frequencies and the frequencies of the genotypes. We found no association between bipolar affective disorder and serotonin 2 receptor gene. These results indicated that 5HT2 receptor does not directly relate to developing bipolar affective disorder. 


\section{2-E 35}

An association study between schizophrenia and dopamine D2 receptor gene (DRD2)

Toru ISHIDA, Hiroshi YONEDA, Yasuhiro NONOMURA, Yasuhiro INAYAMA,

Yoshihiro KONO, Ryuichi TAKAHATA, Jun $\mathrm{KOH}$, Ryuichiro HIROTA,

Yashushi INADA and Toshiaki SARAI (Dept. Neuropsychiat., Osaka

Medical College, Takatsuki)

The hyperactivity of dopaminergic system is one of the major etiological hypotheses of schizophrenia. The major support for this hypothesis is that all effective antipsychotic drugs bind to dopamine receptors and improve acute schizophrenic symptoms. We investigated the allelic association between schizophrenia and polymorphic dopamine D2 receptor gene (DRD2). The subjects were 60 schizophrenics and 58 normal controls. The D2 receptor gene is located on the long arm of chromosome 11 (11q22-23). The DRD2 ( $\lambda$ hD2G1) reveals a TaqI polymorphism with two alleles (i.e. 6.6 and $3.7 \mathrm{~kb}$ ). There were no significant differences between the patients and controls in the allele frequencies and the frequencies of the genotypes. We found no association between schizophrenia and dopamine D2 receptor gene. These results indicated that dopamine D2 receptor gene does not directly relate to developing schizophrenia.

\section{2-E 36}

ASSOCIATION STUDY OF SCHIZOPHRENIA WITH BDNF (BRAIN DERIVED NEUROTROPHIC FACTOR) POLYMORPHISM

Xiao Yan DAI ${ }^{1\}}$, Tsukasa SASAKI ${ }^{1)}$, Shoji KUWATA $^{21}$, Mineko HATTORI $^{1)}$, Rimmei FUKUDA $^{1)}$, Yoichi SHIBATA $^{21}$, Hajime KAZAMATSUR $\bar{I}^{1)}$, Shinichiro NANKO ${ }^{1)}$

1) Dept. of Psychiatry, Teikyo Univ. Sch. of Med.

2) Dept. of Transfusion Med., Univ. of Tokyo Sch. of Med.

The recent possible neurodevelopmental etiology of schizophrenia makes nerve growth factor (NGF) family genes interesting candidate loci. BDNF is a member of NGF, and has a role in the development, migration and differentiation of the neural cells. Dinucleotide repeat polymorphism within the intron of the BDNF(Prosche et al.1992) was examined using the PCR amplification method. Four alleles were demonstrated in acrylamide gel with silver-staining. The frequencies of the alleles in 60 unrelated Japanese schizophrenias and 60 healthy volunteers did not differ between the two groups. The result did not indicate the relationship between schizophrenia and BDNF polymorphism. 
2-E 37

A POINT MUTATION OF THE AMYLOID PRECURSOR PROTEIN GENE IN SCHIZOPRENIA

KOH Jun, YONEDA Hiroshi, ISHIDA Toru, NONOMURA Yasuhiro, INAYAMA Yasuhiro, KONO Yoshihiro, TAKAHATA Ryuichi, HIROTA Ryuichiro, INADA Yasuyuki, SAKAI Toshiaki. (Department of Neuropsychiatry, Osaka Medical College, Takatuki, Osaka)

A point mutation at exon 17 codon 713 in the amyloid precursor protein (APP) gene causes an amino-acid substitution (Ala-Val). We investigated this mutation in schizophrenia by PCR method.

We examined 94 schizophrenic cases. We extracted DNA from blood samples by phenol method and amplified the exon 17 of the APP gene by PCR. PCR products were digested by Mae-III. The mutation creates a MaeIII restriction site. Mae-III digests were electrophoresed in $3 \%$ agarose gel and stained with ethidium bromide. We investigated the mutation by PCR-SSCP method.

94 schizophrenic cases did not show the point mutation. These results indicates that the point mutation of APP gene may not be a main etiological factor of schizophrenia.

\section{2-E 38}

AN ASSOCIATION BETWEEN SPORADIC LATE-ONSET ALZHEIMER'S DISEASE AND APOC-II GENE

Yasuhiro NONOMURA, Hi roshi YONEDA, Toru ISHIDA, Yasuhiro INAYAMA, Yoshihiro KONO, Jun KOH, Ryuichiro HIROTA, Yasushi INADA, Toshiaki SAKAI Dept. Neuropsychiat., Osaka Med. Coll., Takatsuki, Osaka

Pericak-Vance et al.(1991) reported that late-onset familial Alzheimer's disease (AD) was linked to the long arm of chromosome 19. Schellenberg et al. (1992) also reported that early-onset familial $\mathrm{AD}$ was not 1 inked to apolipoprotein $\mathrm{C}-\mathrm{I}$ ( $\mathrm{APOC}-\mathrm{II})$ gene (chromosome 19) but late-onset familial AD was 1 inked to APOC-I gene. We studied an association between APOC-I and sporadic late-onset $\mathrm{AD}$. The subjects were 22 late-onset sporadic $\mathrm{AD}$ cases which were diagnosed according to the criteria of NINCDS-ADRDA, and 66 normal controls. We extracted DNA from blood samples and amplified the intron 3 of the APOC-II gene by use of PCR method. PCR products were electrophoresed in $3 \%$ agarose gel and stained by ethidium bromide. We detected the two bands: $375 \mathrm{bp}$ (1) and $335 \mathrm{bp}$ (2). Allele frequencies of (1), (2) of sporadic late-onset $\mathrm{AD}$ and normal controls were $0.364,0.636$ and 0.205 , 0.795. We found a genetic association in allele frequencies of (1) between $A P O C-I I$ and sporadic late-onset $A D$. These results suggest that sporadic late-onset $\mathrm{AD}$ cases may be caused by the APOC-II gene. 


\section{2-E 39}

GENE ANALYSIS OF EARLY-ONSET FAMILIAL ALZHEIMER'S DISEASE.

Kouzin KAMINO, Keiko NAGANO, Aoi YOSHIIWA, Tomohiro KATSUYA, Tetsuro MIKI, Toshio OGIHARA (Dept. Geriat. Med., Osaka Univ. Med. Sch. Osaka) and Kunio I-i (Dept. 1st. Pathol., Tokushima Univ. Med. Sch, Tokushima)

Early-onset Familial Alzheimer's disease, which shows an autosomal dominat inheritance, is thought to be monogenic disease with genetic heterogeneity. Mutations of APP (A4/b amyloid precursor protein) gene have been found as causative gene in some pedigrees. Most of the families, however, have no mutation of this gene and revealed negative linkage in the region of this gene. Recently, another locus of the disease was found in long arm of chromosome 14 (14q24.3) that is speculated to be major locus of the disease. We performed linkage analysis for 6 pedigrees of the disease concerning the locus of APP and 14q24.3. OS-1 family, which possesses a mutation of APP gene, revealed no recombination in APP gene locus, but negative linkage with markers in 14q24.3. The other 5 families are not linked with APP locus, but suggestive linkage with D14S43 ( $\mathrm{Z}=1.17$ at $\mathrm{q}=0.001$ ). A $c$-fos gene was analysed by SSCP, but no mutation was detected in the patients. And base changes were found in intron 2 and around exon 4 that would be useful DNA markers of $c-f o s$ gene locus.

\section{2-E 40}

GENETIC ANALYSIS FOR A SEARCH FOR GENE ASSOCIATED WITH MOYAMOYA DISEASE, Noriyuki HACHIYA, Yukio TAKIZAWA (Dept. Public Health, Akita Univ. Sch. Med., Akita) and Toshitaka OMURA, (Saitama Inst. Public Health, Urawa)

A genetic epidemiological study was conducted on Moyamoya disease (Spontaneous occlusion of the circle of Willis), which is a cerebrovascular disorder characterized by unusual cerebral angiographic appearances. Among 48 cases, male to female ratio was 1:3.8 and a bimodal age distribution represented that $35.5 \%$ was less than twenty years old and $37.5 \%$ was between forty to fifty-nine. A molecular approach was performed to determine genetic loci involving susceptibility to the disease. In a case-control study, the frequency of RFLP was compared at the D21S15 and D21S17 loci between DNA isolated from blood samples of 32 unrelated Japanese possessing the abnormality and that of 68 controls. The working hypothesis was genetic locus on chromosome 21 might have any role to develop the unique cerebrovascular malformation, because several cases of Down's syndrome have been reported to be associated with Moyamoya disease-like abnormality. No association, however, was found between the MspI nor BglII RFLP and the occurrence of disease. 
2-F 1

JAPANESE FAMILIAL AMYOTROPHIC LATERAL SCLEROSIS ASSOCIATED WITH A NOVEL POINT MUTATION IN Cu/Zn SUPEROXIDE DISMUTASE GENE. M. AOKI ${ }^{1}, \underline{M}$. OGASAWARA ${ }^{2}, \underline{Y}$. MATSUBARA ${ }^{2}, \underline{\text { K. NARISAWA }}{ }^{2}, \underline{S}$. NAKAMURA $^{1}, \underline{Y}$. ITOYAMA ${ }^{1}$ and ${\underline{K} . A B E^{1}}^{1}$ (Department of Neurology ${ }^{1}$, and Department of Biochemical Genetics ${ }^{2}$, Tohoku Univ. Sendai)

Amyotrophic lateral sclerosis (ALS) is a progressive neurological disorder that commonly results in death shortly after the diagnosis. Although the pathophysiologic process of ALS remains unknown, about 5 to $10 \%$ of cases are familial. We identified a novel point mutation (A to $G$, which resulted in an amino acid substitution of histidine ${ }^{46}$ to arginine) in exon 2 of the $\mathrm{Cu} / \mathrm{Zn}$ SOD (SOD1) gene in two Japanese familial ALS (FALS), and the segregations of the mutation were confirmed in the other family members. We found no this substitution in 27 Japanese sporadic ALS patients nor 57 unrelated normal Japanese control subjects. Moreover, the enzymatic activities of $\mathrm{C} w / \mathrm{Zn}$ SOD of peripheral red blood cell lysate were reduced to about $80 \%$ in the affected members, compared with other non-affected family members. This FALS was characterized by the relatively slow progression and should be a new subtype of FALS.

\section{2-F 2}

A NOVEL MUTATION IN CU/Zn SUPEROXIDE DISMUTASE GENE IN JAPANESE FAMILIAL AMYOTROPHIC LATERAL SCLEROSIS Ryoichi NAKANO ${ }^{1}$, ShUZO SATO', Takashi INUZUKA', Yoshiaki HONMA ${ }^{4}$, Hitoshi TAKAHASHI ${ }^{3}$, Fusahiro IKUTA ${ }^{3}$, Kenji SAKIMURA ${ }^{2}$ and Shouji TSUJI' ${ }^{1}$ Dept. Neurol., ' ${ }^{2}$ Dept. Neuropharmacol. and ${ }^{3}$ Dept. Pathol. Brain Res. Inst., Niigata Univ. ${ }^{4}$ Dept. Neurol., Sado General Hospital

Several missense mutations of $\mathrm{Cu} / \mathrm{Zn}$ superoxide dismutase (SOD1) gene have been reported as a putative cause of familial amyotrophic lateral sclerosis (FALS). We have studied 9 patients from 8 independent FALS families and some cases with disease related to FALS. Five exon portions of SOD1 gene were amplified by PCR, followed by sequencing analysis by cycle sequencing method. We identified a novel missense mutation in exon 1 in two Japanese cases of FALS. This mutation results in ${ }^{4} \mathrm{Ala}$-toThr substitution. No mutations were found in other disease patients. This results suggests that the missense mutation in SOD1 gene is also a cause of FALS in some families in Japan. 


\section{2-F 3}

X-LINKED RECESSIVE BULBOSPINAL NEUROPATHY: CLINICAL FEATURES AND ANDROGEN RECEPTOR GENE MUTATIONS. Manabu DOYU, Gen SOBUE, Noriko SHIMADA, Koji YAMAMOTO, Eiichiro MUKAI, Takeshi YASUDA, Teruhiko KACHI and Terunori MITSUMA (4th. Dept. Int.Med., Aichi Medical Univ., Nagakute, Aichi )

$\mathrm{X}$-linked recessive bulbospinal neuronopathy(X-BSNP) is an adult form of motor neuronopathy characterized by slowly progressive bulbar and spinal muscular atrophy. In this report, we describe several clinical features of X-BSNP and correlated them with the AR gene mutations and the number of $C A G$ repeat $((C A G) n)$. 66 patients of X-BSNP from 56 families and their siblings were the subjects of this study, PCR products for $\mathrm{CAG}$ repeat region of $\mathrm{AR}$ gene was subjected to the direct cycle sequensing to determine the number of (CAG)n. To examine the tissue expression of the ARmRNA and their size of (CAG)n, RT-PCR was performed on the various tissues of biopsed and autopsed materials. Northern blot analysis for ARmRNA was also performed. Age at onset, severity of muscular weakness and ADL adjusted by the age and the presence of gynecomastia was well correlated with the number of (CAG)n. Suppression of plasma gonadotrophin (FSH, LH) and testosterone levels following to the administration of the synthetic androgen (fluoxymesterone) was significantly weaker in X-BSNP patients as compared with controls, suggesting that androgen action was aberrantly expressed in the patients. The degree of testosterone suppression was correlated with (CAG)n. ARmRNA with elongated size of (CAG)n was expressed in wide variety of tissues including the testis, scrotal skin, peripheral nerves, muscles, liver etc.

\section{2-F 4}

THE GENE FOR MACHADO-JOSEPH DISEASE MAPS TO CHROMOSOME $14 \mathrm{q}$. Yoshihisa TAKIYAMA ${ }^{1}, 2$, Hajime TANAKA ${ }^{2}$, Shingo KAWASHIMA 1 , Hirosuke SAKAMOTO ${ }^{1}$ Kotaro ENDO ${ }^{2}$, Mitsuo YOSHIDA ${ }^{\top}$, Shoji TSUJI ${ }^{2}$ and Masatoyo

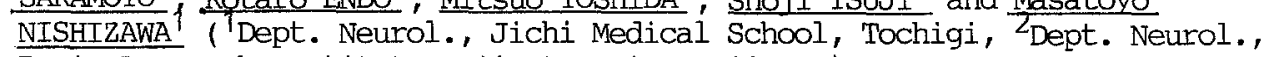
Brain Research Institute, Niigata Univ., Niigata)

Machado-Joseph disease (MJD) is an autosomal dominant, neurodegenerative disorder involving predominantly cerebellar, pyramidal, extrapyramidal, motor neuron, and oculomotor systems. With the use of highly polymorphic microsatellite DNA polymorphisms, we undertook genetic linkage analysis in a single large Japanese MJD family of 5 generations. DNA was obtained with informed consent from 41 individuals including 19 affected persons. We found that the MJD locus is tightly linked to chromosome 14q DNA markers D14S48 and D14S55. The maximal lod score between MJD and D14S48 was 4.43 at a recombination fraction $(\theta)=0$. Multipoint linkage analysis gave an even higher likelihood of linkage at D14S48 ( $\left.z_{\max }=6.96\right)$. Recombination events between the MJD locus and D14S48/D14S55 were not observed in this family. Our data demonstrate that the MJD locus is on the long arm of chromosome 14. As multiple recombination events were found between the MJD locus and both D14S53 and D14S45, the gene for MJD is thus located in the 29 cMo region between D14S53 and D14S45. 


\section{2-F 5}

Title: The gene for Machado-Joseph disease maps to human chromosome 14q. Authors: Endo K (1), Tanaka H (1), Takiyama Y (2), Kawashima $S$ (2), Sakamolo H (2), Karube Y (2), Shimazaki H (2), Soutome M (2), Yoshida M (2), Nishizawa M (2), Yuasa T (3), Horikawa Y (4), Oyanagi K (5), Nagai H (6), Kondo T (7), Segawa M (8), Nomura $Y(8)$, Yoshida E (9), Sakurai $N(10)$, Fukuhara $N(11)$, Makibuchi $T(11)$, Inuzuka $T(1)$, Onodera O (1), Tsuji S (1) Affillatlons: (1) Dept. of Neurol. Institute Niigata Univ. (2) Dept. of Neurol. Jichi Med. School (3) Dept. of Neurol. Faculty of Med., Tokyo Med. and Dent. Univ. (4) Dept. of Neurol. Shinrakuen Hosp. (5) Center of Materials of Brain Desease Niigata Univ. (6) Dept. of Neurol., Suibara Hosp. (7) Dept. of Neurol., Agano Hosp. (8) Segawa Neurol. Clinic for Children (9) Dept. of Neurol., Tokai Memorial Hosp. (10) Dept. of Neurol., Faculty of Med., Nagoya Univ. (11) Dept. of Neurol., Natl. Sanatorium Saigata Hosp.

Text: Machado-Joseph disease is an autosomal dominant, multisystem, neurodegenerative disorder involving predominantly cerebellar, pyramidal, extrapyramidal, motor neuron and oculomotor systems. Although it was first reported in families of Portuguese-Azorean descent, MJD has also been described in non-Azorean families from various countries, being one of the most common hereditary spinocerebellar degenerations. Previous efforts to map the gene for MJD have failed to show significant linkage. With use of recently developed microsatellite DNA polymorphism we performed detailed genetic linkage analysis on 36 members of 6 families including 14 affected individuals mainly from Niigata prefecture Japan. We have found significantly high lod scores to several microsatellites on the chromosome 14q (D14S42, D14S43, D14S53, D14S55, D14S48, D14S45, D14S51). The LINKMAP (LINKAGE) program was used to calculate lod scores for various locations for the MJD gene relative to fixed positions. The highest lod score of 3.814 was obtained at 2.2 centiMorgan (cMo) centromeric to D14S55. Absence of recombination events were involving D14S48/D14S55 and the presence of linkage disequilibrium at D14S48 further support the localization of the MJD gene. Since multiple recombination events were observed between the MJD locus and D14S45, the gene for the MJD is located in the region of $29.1 \mathrm{cMo}$ from D14S53 and D14S45.

\section{2-F 6}

LINKAGE ANALYSIS OF HEREDITARY SPINOCEREBELLAR DEGENERATION Akemi WAKISAKA(Dept. Pathol., Hokkaido Univ., Sapporo), Hidenao SASAKI. Kunio TASHIRO(Dept. Neurol., Hokkaido Univ., Sapporo), Takeo KATO(Dept. Med., Yamagata Univ., Yamagata) and_Michihiro YOSHIDA(Chromo. Res. Inst, Hokkaido Univ., Sapporo)

Hereditary oliv-pontocerebellar atrophy (OPCA) is revealed genetically heterogeneous neuro-degenerative disorders in Japanese. Out of 19 OPCA families 11 were proved to be SCA1 whereas 8 were SCA2 by close linkage with D6S89 and IGF1, respectively. Eight polymorphic markers on $6 \mathrm{p}$ were investigated for fine mapping of SCA1. These markers were tightly linked with each other and with SCA1 also. The segregation and mult-ipoint linkage analysis showed that most likely gene order is cenD6S109-D6S274-D6S288-SCA1-AM10GA-D6S89-EDN1-D6S202-F13A1-tel. The expansions of (CAG) trinucleotide repeats which located about $50 \mathrm{~kb}$ telomeric to D6S288 were demonstrated in the affected members from 9 SCAl families while not in healthy members and in other 2 SCA1 families. The former shares same D6S274D6S288 haplotype other than that of the latter. These results indicate that; 1) the cause of SCA1 is not exclusively due to the expansion of trinucleotide rep eats, 2) only the SCA1 patients with expanded (CAG) shows founder effect.

The linkage analysis of 8 Japanese SCA2 families indicates SCA2 gene is located much closer to D12S105 than IGF1. 


\section{2-F 8}

LINKAGE STUDY IN DRPLA(DENTATORUBRAL AND PALLIDOLUYSIAN ATROPHY. NObuhiro MURAYAMA, Yuji TANAKA, Ikuko KONDO(Dept Hygiene, Ehime Univ, Ehime), Akira SANo(Dept Psy.,Ehime Univ.), Masao YAMADA, Shigeo NAGAFUCHI, Keiko TADOKORO(Nat. Child. Hosp., Tokyo), Mie TARAHASHI (Dept. Psy., Kochi Med School, Kochi), Osamu KOMURE(Dept Psy, Kobe Univ, Kobe) and Ichiro KANAZAWA(Dept. Nerol. Univ. of Tokyo, Tokyo)

Hereditary dentatorubral and pallidoluysian atrophy(DRPLA) is an autosomal dominant neurodegenertive disease. Clinical signs and symptoms vary greatly from patients to patients and it is sometimes difficult to differentiate a patients with DRPLA from Huntington's disease(HD). However, DRPLA is distinct from HD. We used linkage analysis of localized he gene for DRPLA in 14 families with the aid of polymorphic DNA markers. The loci for $\mathrm{F} 8 \mathrm{VWF}$ and $\mathrm{CD} 4$ gave the highest positive lod scores of 3.3 and 3.6 , respectively, at recombination fractions of 0.07 and 0.00 . These data suggest that the gene for DRPLA is assigned to chromosome $12 \mathrm{p}$ (p12-pter).

\section{2-F 9}

DIRECT SEQUENCE ANALYSIS OF PUTATIVE ADRENOLEUKODYSTROPHY (ALD) GENE IN JAPANESE ALD PATIENTS

Osamu ONODERA(1), Ryouko KOIKE(1), Syuuichi IGARASHI(1), Hiroyuki TABE(1), Kiyotoshi KANEKO(2), Tadashi MIYATAKE(2), Jean MOSSER(3), Claude-Olivier SARDE(3), Jean-Louis MANDEL(3), Syouji TSUJI(1)

(1) Department of Neurology, Brain Research Institute, Niigata University, Niigata

(2) Department of Neurology, Tokyo Medical and Dental University, Tokyo

(3) INSERN U184, LGME/CRNS, Faculte de Medicine, Strasburg.

We have analyzed the putative ALD gene from five Japanese ALD patients who have been revealed to have no large deletion or insertion of putative ALD gene by Southern blot hybridization analysis. To find the point mutations of putative ALD gene in those ALD patients, we analyzed their genomic DNAs by a direct sequence method using an ALF automated DNA sequencer. The analysis revealed a one sequence variation in an exon 9. All five ALD patients had a G-to-A transition in an exon 9 (codon 660) that substitutes a Glutamine (CAG) for an Arginine (CGG). We observed this variation in two normal Japanese male either, so this transition will not cause the ALD. There were no other variations in an exon 2 to an exon 10 that contained highly homologous sequences between human $70 \mathrm{~K}$ peroxisomal menbrane protein. 


\section{2-F 10}

ANALYSIS OF PUTATIVE ADRENOLEUKODYSTROPHY (ALD) GENE IN JAPANESE ALD PATIENTS. Ryoko KOIKE, Osamu ONODERA, Hiroyuki TABE, Shoji TSUJI (Dept. Neurol., Niigata Univ., Niigata), Kiyotoshi KANEKO, Tadashi MIYATAKE (Dept. Neurol., Tokyo Med. Dent. Univ., Tokyo), Jean MOSSER, Claude-Oliver SARDE and Jean-Louis MANDEL (Lab. Génét. Mol. CNRS, INSERM U184, Inst. Chimie Biol., Fac. Méd., Strasbourg, France)

ALD is an X-linked recessive neurological disease. Recently a putative ALD gene has been identified by positional cloning (Mosser et al. 1993). To investigate if the putative ALD gene is responsible for the pathogenesis of ALD, we have analyzed the gene of 37 Japanese ALD patients. The probe for each exon was generated by PCR amplification of genomic DNA and used for Southern blot analysis. We identified partial deletions of the putative ALD gene in 2 patients with a milder adult phenotype of ALD (cerebello-brainstem dominant type). One patient had a partial deletion of $0.5 \mathrm{~kb}$ involving exon 1 and intron 1 , and the other had a deletion spanning at least exons 3 through 6 . The results confirm the identity of this gene as the ALD gene. Furthermore, the presence of deletions of the ALD gene in patients with milder clinical form raises the possibility that clinical phenotypes of ALD are not determined solely by the genotypes.

\section{2-F 11}

IDENTIFICATION OF A NONSENSE MUTATION IN ALD PROTEIN CDNA FROM A PATIENT WITH ADRENOLEUKODYSTROPHY Atsushi UCHIYAMA, Yasuyuki SUZUKI, Atsushi IMAMURA, Toshiyuki FUKAO, Kouzen SOU, Shunji TOMATSU, Nobuyuki SIMOZAWA, Seiji YAMAGUCHI*, Naomi KONDO, and Tadao ORII(Dept. Pediatr., Gifu Univ. Sch. Med., Gifu, *Dept. Pediatr,, Shimane Med.Univ., Izumo)

$\mathrm{X}$-linked Adrenoleukodystrophy(ALD) is a metabolic disorder with very-long-chain fatty acids and is classified into two phenotypes. One is child cerebral ALD, which forms rapidly progressive adrenocortical insufficiency. The other is called adrenomyeloneuropathy (AMN),which shows more slowly progressive spinal form. Recently putative gene of ALD(ALDprotein CDNA) was cloned and some of the patients were shown to have large deletion in the gene by Aubourg et al. Here we have efficiently found a point mutation ( $2154 \mathrm{C}$ to T) in an AMN patient using RT-PCR method combined with Mutation Detection Enhancement gel. This mutation substituts a termination codon for glutamine at position 590(Q590STOP) and also delets Pst I site, hence other 8 ALD patients' cDNAs were invesitigated by the restriction enzyme assay, but none of them had the mutation. To our knowledge, this is the first evidence of the point mutation of ALDprotein cDNA. 


\section{2-F 12}

\section{MOLECULAR ANALYSIS OF PELIZAEUS-MERZBACHER DISEASE IN A JAPANESE FAMILY}

Akiko IWAKI ${ }^{1}$, Tamaki MURAMOTO ${ }^{2}$, Hiroyasu FURUMI ${ }^{1}$, Maria L. DARIO-DELEON ${ }^{1}$, Toru IWAKI 2 , Jun TATEISHI ${ }^{2}$, Yasuyuki FUKUMAKI ${ }^{1}$ (1 Institute of Genetic Information, Kyushu University, ${ }^{2}$ Department of Neuropathology, Faculty of Medicine, Kyushu University, Fukuoka)

Pelizaueus-Merzbacher disease (PMD) is a neurodegerative disorder characterized by abnormal formation of myelin that wraps large axons in the central nervous system. Two clinical forms of PMD are inherited in an X-inked recessive manner: one is present at birth, the so-called connatal variant of Seitelberger, and the other is the classic form, an infantile variant with a more protracted course. We analyzed expression and the structure of the proteolipid protein (PLP) gene of the Japanese patients with connatal type of PMD and observed followings, 1) Western blot analysis demonstrated no PLP in the brain specimen in the patient. 2) RT-PCR revealed that PLP transcripts and an alternaive spliced variant, DM20 transcripts were also detected in the brain tissue. 3) Northern blot analysis of the brain demonstrated that the amount of messages for PLP and MBP, specific proteins for oligodendrocytes was significantly reduced while that of an astrocyte-specific protein, GFAP was not. 3) Direct sequencing of the PLP gene revealed a $G$ to $T$ transition in exon $V$, which leads to glycine to cystein substitution at residue 220.4 ) Allele-specific oligonucleotide hybridization demonstrated the close association of this mutation and the PMD phenotype in the family members and no allele with the mutation in $100 \mathrm{X}$-chromosomes of normal Japanese. These results indicated that the mutation in residue 220 is responsible for the pathogenesis of this disorder and PLP could have two major roles in myelination and differentiation of oligodendrocytes in the central nervous system.

\section{2-F 13}

Charcot-Marie-Tooth neuropathy type $1 \mathrm{~B}$ is associated with point mutations of the myelin Po gene. K. Hayasaka ${ }^{1}$, M. Himoro ${ }^{1}$, P.F. Chance ${ }^{2}$, W. Satoh ${ }^{1}$, G. Takada ${ }^{1}$, K, Uyemura $^{3}$, N. Shimizu ${ }^{3}$ T.D. Bird ${ }^{4}$ and P.M. Conneally ${ }^{5}{ }^{1}$ Akita University, Akita, Japan, ${ }^{2}$ University of Utah, Salt Lake City, Utah, ${ }^{3}$ Keio University, Tokyo, Japan, ${ }^{4}$ University of Washington, Seattle, Washington, and ${ }^{5}$ Indiana University, Indianapolis, Indiana)

Charcot-Marie-Tooth neuropathy type 1 (CMT1) is the most common inherited peripheral neuropathy and is characterized clinically by slowly progressive distal muscle weakness, absent deep tendon reflexes, mild sensory impairment, and pes cavus deformity of the foot. Most cases show dominant inheritance. CMT1 loci map to chromosome 17 (CMT1A), chromosome 1 (CMT1B), another unknown autosome (CMT1C) and the X chromosome (CMTX). CMT1A is the most frequent subtype of CMT1 which has been demonstrated to be associated with a large DNA duplication of $17 \mathrm{p} 11.2$ including the peripheral myelin protein-22 gene (PMP22) or a point mutation of PMP22. CMT1B has been reported only in four families. Myelin protein zero (Po), the major structural protein of peripheral myelin, is another integral myelin membrane protein like PMP22. The locus of the Po gene has been mapped to chromosome 1q22-q23 in the region of the CMT1B locus.

In this study we have investigated $P o$ as a candidate gene in two farmilies with CMT1B and demonstrated the presence of two different point mutations in the Po gene (a glutamate substitution for lysine 96 or aspartate 90). These mutations are located in the extracellular domain responsible for the function of Po as an adhesion molecule. Our results strongly suggest that Po is a gene responsible for CMT1B neuropathy. 


\section{2-F 14}

Abnormalities of NFl gene in patients with Neurofibromatosis 1(NF1). Nobuaki HATTA, Takahiko HORIUCHI, Mitsuru MATSUMOTO, Shigeru FUJITA, Yuzuru KOBAYASHI(The First Dept. Int. Med., Ehime Univ., Ehime) Francis S. COLLINS (Univ. of Michigan., USA)

Neurofibromatosis 1 (NF1) is one of the most common inherited disorders and characterized by the abnormalities in multiple tissues derived from the neural crest. Few cases of NF1 have been reported presenting with abnormalities in the NF1 gene. Moreover, no mutations of NF 1 gene have been identified in Japanese. In the present report, we describe 4 independent mutations of NF1 gene in 5 cases of 25 unrelated Japanese NF1 patients. Polymerase chain reaction(PCR)/single strand conformation polymorphism(SSCP) analysis of exon 28 to 36 revealed a 4-bp deletion in exon 30 in one patient, nonsense mutations at the same codon for $R-1947$ in exon 31 in two patients, and a 1-bp deletion in exon 32 in one patient. Reverse transcriptase(RT)-PCR/SSCP analysis of GTPase activating protein related domain(GRD) revealed a 5-bp deletion in exon 23 in one patient. As the deletion mutations resulted in frameshifts with premature translational termination, truncations of NF1 gene product occur in a11 5 patients with NF1 mutations. The three deletion mutations were all novel. The nonsense mutations at $R-$ 1947 observed in two patients have been reported previously in three unrelated Caucasians, indicating that this is the hotspot for NFl gene common among different ethnic groups.

\section{2-F 15}

MOLECULAR GENETIC STUDY USING C-DNA PLMM1, LOCATED ON CHROMOSOME 7, IN 4 FAMILIES WITH TUBEROUS SCLEROSIS

Reiko MORITA, Kayoko SAITO, Michiko HARA, Maki IMANO, Makiko OSAWA, Takayo HARADA, Mayumi MISHIMA, Haruko SUZUKI, Keiko SHISHIKURA, Yoshito HIRAYAMA, and Yukio FUKUYAMA(Dept.

Pediatr., Tokyo Women's Medical College, Tokyo)

Four patients with tuberous scierosis(TSC) and their families were studied using pLMM1, which is located on chromosome 7, to obtain a restriction fragment length polymorphisms(RFLPs) by Southern blotting and to detect the pLMM1 mutation.

In one of the families, the TSC patient had a younger brother with congenital myotonia of Becker type(CM-B). TSC has heterogeneity and its gene loci exist on chromosomes 9(TSC1), 11(TSC2), and 12(TSC3), whereas the locus of $C M-B$ is presumed to be on 7 . There have been no reports of families with both TSC and CM-B patients to date. Our results suggest the possibilitiy of a contiguous gene syndrome of TSC and CM-B in one of the 4 families studied. 


\section{2-F 16}

DNA AMPLIFICATION IN FRAGILE X SYNDROME. Kunikazu KISHI (Sch. Health Sci., Kyorin Univ., Tokyo), Masatake YAMAUCHI (Div. Genet., Natl. Inst. Rad. Sci., Chiba), Naohiko SERI (Kazusa DNA Res. Inst., Chiba), Akira HOMMA, Ri-ichi IMAMURA (Tokyo Metropol. Inst. Gerontol., Tokyo), Koichi SEKIZAWA (Sch. Health Sci., Kyorin Univ., Tokyo) and Tada-aki HORI (Div. Genet., Natl. Inst. Rad. Sci., Chiba)

Fragile $\mathrm{X}$ syndrome [fra (X)] is characterized cytogenetically by a high frequency of chromosome breaks at Xq27.3 when their cells are cultured under the conditions that perturb deoxypyrimidine pools. The mutation has been shown to be the amplification of a trinucleotide sequence CCG and the abnormal methylation of a CPG island in FMR-1 gene. In the present study, we examined the mutation in 12 male patients with fra (X), who expressed Xq27.3 in $5 \%$ or more of the metaphases. DNA samples from the patients were digested to completion with Pstl or EcoRI+Eagl, and analyzed using DNA probe pPCRfxl. All the patients were shown to have longer DNA fragments, in both Pstl and EcoRI+Eagl digested samples, compared with normal controls, reflecting the amplification of the CCG repeat and the hypermethylation of the CpG island in the FMR-1 gene. Some of the patients showed methylation mosaicism in which unmethylated as well as methylated fragments were detected in EcoRI+Eag1 digested samples.

\section{2-F 17}

DYNAMIC MUTATIONS AND FOUNDER CHROMOSOMES IN FRAGILE X SYNDROME Tada-aki HORI, Masatake YAMAUCHI (Div. Genet., Natl. Inst. Radiol. Sci., Chiba), Naohiko SEKI (Kazusa DNA Res. Inst., Chiba), Shin NAGATA (Dep. Obst. Gyn., Natl. Fukuoka Ctr. Hosp., Fukuoka), Kaoru SUZUMORI (Dep. Obst. Gyn., Nagoya City Univ. Nagoya), Kunikazu KISHI (Sch. Health Sci., Kyorin Univ., Tokyo), Ikuko KONDO (Lab. Hyg., Ehime Univ. Sch. Med), Grant R. SUTHERLAND and Robert I. RICHARDS (Dep. Cytogenet. Mol. Genet., Adelaide Children's Hospital, Adelaide, Australia)

It has recently been suggested a few founder chromosomes are responsible for most fragile $X$ mutations in Caucasian populations. To examine the origins of the fragile $X$ mutations in the Japanese population, we analyzed haplotypes of FRAXA locus in 35 unrelated fragile $X$ chromosomes and 125 normal $X$ chromosomes in the Japanese males, by using two polymorphic $A C$ repeats, FRAXAC1 and FRAXAC2. It is likely that the evidence for founder fragile $X$ chromosomes in the Japanese population will be similar to that in Caucasians, although different haplotypes are involved. The distribution of normal allele size of $p(C C G) n$ repeat among the $X$ chromosomes in the Japanese popualtion is very similar to that reported for Caucasians, except that the most frequent copy number $(n=28)$ is one copy less than that in Caucasians and that there is an additional peak at 35 copies. There is no significant correlation between FRAXAC alleles and the number of $p(C C G) n$ repeat in nonfragile $X$ chromosomes. Alleles with more than 31 copies do not segregate with either of fragile $X$ haplotypes. 


\section{2-F 18}

FRAGILE X SYNDROME CARRYING BOTH A CGG AMPLIFICATION AND AN FMR-1 DELETION. Yo NIDA, Naohisa SHINTANI, Ichiro OHNO, Tohru YOKOI, Noboru TANIGUCHI (Dept. Pediatrics, Kanazawa Univ., Ishikawa), Tamotsu SATO (Medical Intelligence Center, Kanazawa Univ. Hosp., Ishikawa) and Kazumi IKAWA (Ishikawa health service, Ishikawa)

Recently, the fragile $X$ gene (FMR-1) was isolated and it was revealed that vast majority of patients with fragile $\mathrm{X}$ syndrome showed both amplification of the (CGG)n repeat and hypermethylation of the $\mathrm{CpG}$ island at the 5' UTR of FMR-1 gene. But some authors reported gene deletion of FMR-1 also caused fragile X syndrome. We examined a 4 y.o. mentally retarded boy, he had a typical clinical feature of fragile $X$ syndrome and cytogenetic expression of FRAXA in $11 \%$ of his peripheral lymphocytes. Southem blot analysis showed he had both a full mutation and a deletion of FMR-1 gene, and RT-PCR revealed his peripheral leukocytes expressed no mRNA of FMR-1. Thus, both alleles were functionally null. Peripheral leukocytes DNA was digested by EcoRI and probe with $3^{\prime}$ adjacent DNA fragment of (CGG)n repeat showed he had an $8.0 \mathrm{~kb}$ full mutation band and a $5.0 \mathrm{~kb}$ shorter band compared with normal $5.2 \mathrm{~kb}$ band. Pst digest showed a $3.8 \mathrm{~kb}$ and a $4.8 \mathrm{~kb}$ band instead of normal $1.0 \mathrm{~kb}$ band. Hence full mutation band of EcoRI digest was $8.0 \mathrm{~kb}$, (CGG)n repeat amplified to $2.8 \mathrm{~kb}$. Then, the $3.8 \mathrm{~kb}$ PstI fragment included this amplified triplet repeat and $4.8 \mathrm{~kb}$ Pst fragment should be a same allele of $5.0 \mathrm{~kb}$ EcoRI fragment. It was suggested that the deleted $200 \mathrm{bp}$ included the normal PstI site. EcoRI digest of his mother DNA showed a $5.6 \mathrm{~kb}$ pre-mutation band and a $6.4 \mathrm{~kb}$ full mutation band with $5.2 \mathrm{~kb}$ normal one, but we couldn't detect a shorter $5.0 \mathrm{~kb}$ band. It indicated that deletion of the DNA detected in the patient was de novo. We are now going to clone this deleted $5.0 \mathrm{~kb}$ EcoRI fragment and determine what part of FMR-1 gene is truly deleted.

\section{2-F 19}

\section{Linkage dysequilibrium between CGG repeat numbers in FMR-1 and CA repeat numbers in the loci flanking the CGG repeat}

Tadao ARINAMI, Midori ASANO, Hideo HAMAGUCHI (Dept. Med. Genet., Univ. Tsukuba)

To better understand mutations in normal alleles of $F M R-1$, family studies to observe new mutations in normal alleles and haplotype analyses with microsatellite markers flanking the repeat, FRAXACI/FRAXAC2, to confirm the mutation rate estimated from the family studies and founder chromosomes in the fragile $X$ syndrome were carried out. The family studies detected one new mutation in a total of 303 meioses. However, the mutation rate was not in accordance with the expected or observed heterozygosities in the population or with linkage disequilibrium observed between the repeat numbers and the haplotypes of the markers flanking the CGG. The fact that the haplotype in the chromosome in which the new mutation was found was the same as one of those frequently found in the Japanese fragile $X$ chromosomes suggests the presence of a subgroup in normal alleles that is more liable to mutate than others. 


\section{2-F 20}

Comparison between cytogenetic and molecular genetic survey for the fragile $X$ in a Japanese mentally retarded population.

Yvonne HOFSTEE*, Tadao ARINAMI, Hideo HAMAGUCHI (Dept. Med. Genet., Univ. Tsukuba, * Present affiliation: Stichting Klinisch Genetisch Centrum, Leiden)

To examine the reliability of cytogenetic analyses for the estimation of the prevalence of the fragile $X$ syndrome, the CGG repeat in the FMR-1 gene was assayed by Southern blot hybridization, and the data thus obtained was compared with the cytogenetic data from an institutionalized mentally retarded population consisting of 305 males and 129 females. The DNA analysis detected six unrelated full mutations among 296 unrelated alleles in the males and two full mutations among 129 unrelated alleles in the females. These findings were completely consistent with the cytogenetic data obtained eight years ago. No premutation was found in 546 unrelated X chromosomes in the mentally retarded patients as well as 826 unrelated X chromosomes in the controls. These data suggest that the estimates of the prevalence of the fragile $\mathrm{X}$ syndrome based on cytogenetic data in the population studies are almost reliable.

\section{2-F 21}

A BRAZILIAN FAMILY WITH THE $3271(\mathrm{~T} \rightarrow \mathrm{C})$ MUTATION IN MITOCHONDRIAL DNA.

Yu-ichi GOTO, Ikuya NONAKA (National Center Hospital for Mental, Nervous and Muscular Disorders, NCNP, Tokyo), Satoshi HORAI (National Institute of Genetics, Mishima) and Suely K. MARIE (Sao Paulo Univ., Sao Paulo, Brazil)

The second most common mutation associated with MELAS (mitochondrial myopathy, encephalopathy, lactic acidosis and stroke-like episodes) in Japan is the 3271 mutation. This mutation was found in a Brazilian family of Portuguese and Italian descent indicating that this mutation also exists in a race other than Japanese. The propositus had mild clinical manifestation atypical of MELAS suggesting that patients with the 3271 mutation exhibit heterogeneous phenotypic expressions as seen in the 3243 mutation. 


\section{2-F 22}

MITOCHONDRIAL DNA MUTATIONS IN PATIENTS WITH CEREBELLER ATAXIA

E.MIYATA ${ }^{1}$, H.KOGA ${ }^{1}$, K.OHNO ${ }^{2}$, M.TANAKA ${ }^{2}$, T.OZAWA ${ }^{2}$ and H.YAMAMOTO ${ }^{1}$

Department of Neurology Fujita Health University School of Medicine,Aichi,Japan,

Department of Biomedical Chemistry ,Faculty of Medicine Nagoya University,Aichi,Japan 2.

Cerebellar ataxia is one of the common symptoms in mitochondrial encephalomyopathy, especially in cases of myoclonus-epilepsy with ragged-red fiber (MERRF). An A-to-G transition at nucleotide position 8344 and a C-to-G transition at nucleotide position 8356 of mitochondrial DNA (mtDNA), that are associated with MERRF, are reported in a patient with spinocerebellar degeneration without ragged-red fibers. On the other hand, a T-to-G transition at 8993 in the ATPase 6 gene is observed in a family with several neurological deficits including cerebellar ataxia. Kageyama et al. reported prominent degeneration in the olivo-ponto-cerebellar system in an autopsied case of unclassified mitochondrial myopathy. In order to investigate the involvement of mutations of mtDNA and it's relation to pathomechanisms of cerebellar ataxia, we screened the nucleotide mutations at positions 8344 and 8993 in 66 cases ( 50 sporadic and 16 hereditary) of cerebellar ataxia. We also determined the total nucleotide sequences of mtDNA in two other patients (Patients 1 and 2) with cerebellar ataxia. The grandmother and the mother of Patient 1 and the mother of Patient 2 were affected by cerebellar ataxia.

No point mutations at nucleotide positions 8344 and 8356 were observed among 66 patients.Only one patient who showed hypercardiomyopathy and retinitis pigmentosa, the point mutation at nt 8993 was obsereved. Seven nonsynonymous mutations were observed in the protein-coding region of mtDNA of the two patients with hereditary cerebellar ataxia. These mutations, however, were frequently observed in control subjects. Three nonsynonymous mutations, which were observed only in Patient 1, were frequently observed in control subjects. But fursher Three other nonsynonymous mutations, which were observed only in Patient 2, were rarely observed in control subjects. In addition, these three mutations would change the amino acids which were conserved among mammalian species. The role of the rare nonsynonymous mutations observed in Patient 2 in the development of cerebellar ataxia was not clear and should be further investigated. We suggest that mtDNA is partisipated with atypical cereballer ataxia with other complications ,epsecially retinitis pigmentosa.

\section{2-F 23}

FAMILIAL MITOCHONDRIAL ENCEPHALOMYOPATHY ASSOCIATED WITH DEAF-MUTISM, OPHTHALMOPLEGIA, LEUKODYSTROPHY AND PARTIAL CYTOCHROME C OXIDASE DEFICIENCY.

Masanori NAKAGAWA, Hirohisa YAMADA, Itsuro HIGUCHI, Yoshio KAMINISHI, Mitsuhiro OSAME (3rd Dept. Int. Med., Kagoshima Univ., Kagoshima) and Yasushi ISASHIKI (Dept. Ophthalmol., Kagoshima Univ, kagoshima)

We report two sisters ( 36 and 32 year-old) with familial deaf-mutism, progressive external ophthalmoplegia, leukodystrophy and mitochondrial myopathy. Their T2-weighted brain MRI demonstrated diffuse symmetrical high intensity areas in the white matter. Their muscle biopsies showed ragged-red fibers and cytochrome c oxidase ( $\mathrm{CCO}$ )-negative fibers. CCO activity in biopsied muscle decreased to about $30 \%$ of normal control. They had no deletion of mitochondrial DNA and no point mutation in mitochondrial tRNA. Their brother was diagnosed to have KugelbergWelander disease, grand mal seizure and urinary dysfunction. Their parents and grandparents had consanguinity. Three relatives were found to have deaf-mutism without accompanying a ophthalmoplegia. This rare combination of mitochondrial encephalomyopathy and familial deaf-mutism might be caused by a nuclear DNA mutation in these sisters. 


\section{2-F 24}

A FAMILY OF CHRONIC PROGRESSIVE EXTERNAL OPHTHALMOPLEGIA WITH AN ASYMPTOMATIC MOTHER WITH MITOCHONDRIAL ABNORMALITIES IN SKELETAL MUSCLE Masashi AKAIKE, Hisaomi KAWAI, Seiji OKAZAKI, Makoto KUNISHIGE, Kenji YOKOI, Takao MITSUI, Yoshihiko NISHIDA and Shiro SAITO (1st Dept. of Int. Med., School of Med., The Univ. of Tokushima., Tokushima)

The modes of inheritance of Kearns-Sayre syndrome(KSS) and chronic progressive external ophthalmoplegia(CPEO) have not been established, since most cases are sporadic. We studied skeletal muscle pathology and mitochondrial DNA(mtDNA) in a sporadic patient (proband) with KSS/CPEO and examined muscle mitochondrial function in asymptomatic family members. The proband was a 56-year-old male who had bilateral ptosis, external ophthalmoplegia, retinal pigmentation, heart block and exercise intolerance. An aerobic exercise test of $15 \mathrm{~W}$ for 15 minutes with an ergometer induced a marked increase in serum lactate levels. Biopsied deltoid muscle revealed ragged red fibers, cytochrome oxidase $(\mathrm{COX})$-negative fibers and mitochondrial abnormalities by electron microscope. Analysis of muscle mtDNA revealed a 4,977-bp deletion between nt. 8,483 and 13,459 . None of the other family members had symptoms similar to those of the proband. However, aerobic exercise tests showed a marked increase in serum lactate levels in the proband's mother. Histology of her biopsied deltoid muscle revealed ragged red fibers, COXnegative fibers, and mitochondria with morphological abnormalities. These findings suggest that the mitochondrial myopathy of the proband was inherited from the asymptomatic mother, which may account for the transmission of many sporadic KSS/CPEO cases.

\section{2-F 25}

CHRONIC PROGRESSIVE EXTERNAL OPHTHALMOPLEGIA AND THE DNA ABNORMALITY

Koji ABE, Tsuyosi KAMEYA, Masashi AOKI, and Yasuto ITOYAMA Department of Neurology, Tohoku University School of Medicine, Sendai

Three unrelated families with chronic progressive external ophthalmoplegia (CPEO) are reported in addition to a sporadic case. Familial CPEO shows an autosomal dominant inheritance, and the penetrances are almost $100 \%$. That suggests primary genetic abnormality responsible for the disease is in the nuclear DNA, but not in the mitochondrial DNA. Eye lid ptosis is their first symptom, and they have no heart or retinal abnormality. Aerobic muscle excercise test shows elevation of plasma pyruvate and lactate levels in the sporadic case, but not in the familial cases. Enzyme activity of muscle mitochondrial electron transfer system shows decreases in both sporadic and familial cases. Histochemical study shows a decrease of cytochrome $\mathrm{C}$ oxidase activity in the biopsied muscles. Southern blot analysis shows an evident deletion of mitochondrial DNA in muscle of the sporadic case, but not in the familial cases. Putative DNA deletion was not amplified by PCR analysis of the familial cases. These results suggest that the mechanism causing CPEO may be different between sporadic and familial cases. 


\section{2-F 26}

RAPID DIAGNOSIS AND QUANTIFICATION OF mIDNA USING PCR-SSCP. Yoshinori IANNO, Makoto YONEDA, Hajime TANAKA, Keiko TANAKA and Shoij TSUJI (Dept. Neurol., Brain Res. Inst., Niigata Univ.)

In most cases, the mutations of mitochondrial encephalomyopathies are present as a heteroplasmic state. Although the Southern analysis and PCR-RFLP analysis are widely used for the quantitation of the mutant mtDNA, quantitative analysis of the ratio of mutant and wild type mtDNAs is difficult because of the possibilities of partial digestion by restriction enzymes or the heteroduplex formation during PCR amplification.

Therefore, to overcome these problems, we have devised a novel method for the quantitative analysis of mutant mtDNA using PCR-SSCP (single strand conformation polymorphism) method. We have used primer pairs of nt. 3,210-3,229 and nt. 3,3243,305 for the detection of 3,243 mutation (MELAS), and the primer pairs of 8,293 8,312 and $8,381-8,400$ for the detection of 8,344 mutation (MERRF). The best temperature to detect 3,243 mutant mtDNA (MELAS) was $4^{\circ} \mathrm{C}$ for the electrophoresis using $0.5 \times \mathrm{MDE}$ gel containing $10 \%$ glycerol, and that for detection of 8,344 mutation (MERRF) was $37^{\circ} \mathrm{C}$.

The standard curve for the quantitation of mutant mtDNAs is linear from 0 to $100 \%$ with a correlation coefficient of 0.999 for the 3,243 mutation, and 0.991 for the 8,344 mutation. The percentages of mutant mtDNA in several tissues of 2 autopsied cases of MELAS are $82-95 \%$. The mutant mtDNAs in skeltal muscles of 6 MERRF cases are present at $89-94 \%$. This method is very simple and a useful method to accurately quantitate mutant mtDNA using small amount of samples.

\section{2-F 27}

DNA Diagnosis for Pyruvate Dehydrogenase Deficiency in Female Patients with Congenital Lactic Acidemia.

Junko MATSUDA, Michinori ITO, Etsuo NAITO, Ichiro YOKOTA, Yasuhiro KURODA. (Dept. of Pediatrics. Sch. of Medicine, Univ. of Tokushima.)

Defect in pyruvate dehydrogenase (PDH) complex is a major cause of congenital lactic acidemia. Most cases with PDH complex deficiency result from a mutation in the PDH $\alpha$ subunit $(E / \alpha)$. The gene for E1 $\alpha$ is located on the $X$ chromosome. The diagnosis for El $\alpha$ deficiency is usually established by the measurment of PDH complex activity of the cultured cellis. However, the heterozygous female patients with Eladeficiency are misdiagnosed, when the normal $X$ chromosome is expressed in the cultured cells. Therefore, for reliable diagnosis of Eld deficiency in female patients, it is essential to define the underlying gene mutation. Then, we used the method of SSCP and direct sequencing for DNA diagnosis of Ela deficiency. We examined 11 female patients with congenital lactic acidemia, whom we could not find any defect by the measurement of the enzyme activity of their cultured cells. Five of the 11 female patients had abnormal migration patterns compared with controls. Two of the 5 patients had missense mutations resulting in a changed amino acid residue in the E1d subunit (G89S and G291R). Then, we concluded that SSCP analysis followed by direct sequencing in female lactic acidemic patients was a useful method for the diagnosis of Eld deficiency. 


\section{2-F 28}

PRENATAL DIAGNOSIS IN A FAMILY WITH MITOCHONDRIAL ACETOACETYLCOA THIOLASE DEFICIENCY : THE USE OF POLYMERASE CHAIN REACTION FOLLOWED BY HETERODUPLEX DETECTION METHOD. Akihiro WAKAZONO, Toshiyuki FUKAO, Kouzen SOU, Seiji YAMAGUCHI*, Tadao ORII (Dept. Pediatr., Gifu Univ. Sch. Med., Gifu , *Dept. Pediatr., Shimane Med. Univ., Izumo)

Mitochondrial acetoacetyl-CoA thiolase deficiency is an organic aciduria, inherited by autosomal recessive trait, affected in isoleucine and ketone body catabolisms. We have been analyzed molecular basis of this disorder at both protein and gene levels. A socalled common mutation was not detected and genetic heterogeneity was noted. This time,we described prenatal diagnosis in a Caucasian family. Proband (GK16) was previously identified as a compound heterozygote of IVS8(+1) g to $t$ and A301P. Fetus DNA from amniocytes was PCR-amplified followed by heteroduplex detection on a MDE gel. The fetus was identified to a carrior of IVS8 $(+1)$ mutation. We confirmed the diagnosis by immunoblot analysis of amniocyte extract, gene analysis with a blood paper after her delivery. This is the first report that the prenatal diagnosis was made in this disorder at the gene level.

\section{2-F 29}

\section{GENE MUTATIONS OF MITOCHONDRIAL ACETOACETYL-COA} THIOLASE DEFICIENCY: GENOTYPE/PHENOTYPE RELATIONSHIP Toshiyuki FUKAO, Akihiro WAKAZONO, Kousen SOU, Seiji YAMAGUCHI*, Tadao ORII (Dept. Pediatr., Gifu Univ. Sch. Med., Gifu) Takashi Hashimoto (Dept. Biochem., Shinshu Univ. Sch. Med., Matsumoto)

*present address: Dept Pediatr., Shimane Med. Sch., Izumo

Mitochondrial acetoacetyl-CoA thiolase (T2) deficiency is an organic aciduria of isoleucine catabolism, which shows autosoml recessive traits. We have been analyzed molecular basis of $\mathrm{T} 2$ deficiency with more than half patients reported in the world, at both the protein and the gene levels. At the protein level, 7 different types of CRM was noted in pulse-chase experiments of 16 fibroblasts with this disorder. At the gene level, we have identified 14 gene mutations in $12 \mathrm{~T} 2$ deficient patients. The gene mutations were various and no so-called common mutation was detected. Clinical features of these 16 patients were kindly provided by physicians following these patients. Thus fur, we could not find relationship between genotype ( gene mutations and CRM types ) and clinical phenotype. 
2-F 30

MATERNALLY-INHERITED DIABETES MELLITUS AND MITOCHONDRIAL GENE MUTATION-IN THE VIEW POINT OF MELAS-

Hideki ONISHI (Dept. Psychiat., FUJISAWA Hosp., Kanagawa)

Hitoshi OSAKA (Dept. Pediat., Yokohama City Univ., Kanagawa)

Ken INOUE, Chiaki KAWANISHI, Tokiji HANIHARA, Hideki NAGATOMO, Yoshiteru YAMADA, Tomohiro MIYAKAWA, Kyoko SUZUKI and Kenji KosAKA (Dept. Psychiat., Yokohama City Univ. ,Kanagawa)

Three MELAS (Mitochondrial myopathy, encephalopathy, lactic acidosis, and stroke-like episodes) patients with diabetes mellitus (DM) were analysed to investigate the relationship with the mitochondrial(mt) DNA mutation. All the patients analysed had an A-to-G substitution in the nucleotide pair 3243 of the mtDNA in a heteroplasmic fashion. Two cases had DM and oligosymptonatic relatives in the maternal side and were negative in the islet cell antibody. No DM or oligosymptomatic relatives was observed in the paternal side. They received sulfonylurea treatment first and then received insulin treatment. These data suggest that DM is caused by the mtDNA mutation. It is necessary to check glucose tolerance regularly for MELAs patients. And mtDNA should be checked when DM was maternally inherited.

\section{2-F 31}

ANALYSES OF THE PERIPHERIN/RDS AND RECOVERIN GENES IN JAPANESE RETINITIS PIGMENTOSA PATIENTS. Masamichi SAGA (Keio Health Counseling Center, Dept. Ophthalmol., Keio Univ. Sch. Med., Tokyo ), Yukihiko MASHIMA, Kiyoshi AKEO, Yoshihisa OGUCHI (Dept. Ophthalmol., Keio Univ. Sch. Med., Tokyo ), Jun

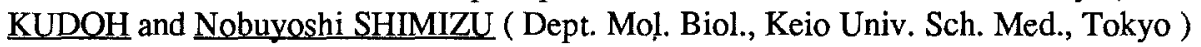

Recently, several mutations in the peripherin/retinal degeneration slow (RDS ) gene have been reported as the cause of retinitis pigmentosa or macular dystrophy. Furthermore, a new retina specific gene, recoverin, has been cloned and its nucleotide sequence has been published. We have analyzed exon 1 and exon 2 of the peripherin/RDS and most of the coding region of the recoverin genes in Japanese retinitis pigmentosa patients, including 16 autosomal dominant families and 7 autosomal recessive families without rhodopsin gene mutations, with polymerase chain reaction-single strand conformation polymorphism method. We identified a novel mutation in codon 214 of the peripherin/RDS gene replacing TGC ( Cys ) to TCC ( Ser) in three patients of the same family with autosomal dominant retinitis pigmentosa. The cysteine residue at codon 214 is conserved among other mammals and this mutation was not found in 40 normal unrelated individuals. Thus, this mutation appears to be the cause of retinitis pigmentosa in this family. There were no other mutations either in both the peripherin/ RDS and recoverin genes. 


\section{2-F 33}

POLYMORPHISMS IN THE PHOSDUCIN GENE

Fumino ARA, Keiko FUJIKI, Yoshihiro HOTTA, Mutsuko HAYAKAWA, Atsushi

KANAI (Dept. of Ophthalmol., Juntendo Univ., Tokyo), George INANA (Bascom

Palmer Eye Institute, Miami, FL)

Phosducin is a soluble phosphoprotein highly expressed in the retina. It has been thought to have an important role in phototransduction. We have found interesting polymorphisms in the phosducin gene while investigating this gene for mutations in retinal degenerative diseases. We analyzed the complete coding sequence of the phosducin gene in autosomal dominant and recessive retinitis pigmentosa (ADRP and ARRP), Usher's syndrome type II (US II), other retinal disease cases and controls. We found 5 kinds of nucleotide substitutions. Three of them are in the non-coding regions, and two of them change amino acid residues. These changes may be related to the disease, but further analysis is needed. One of the nucleotide substitutions in the non-coding region is a rare polymorphism. The other two are polymorphisms $(G-9 \rightarrow A, A 1131 \rightarrow G)$ which define a specific haplotype. The frequency of this haplotype is different in the disease and control groups and in the American and Japanese populations, though only the difference between the American and Japanese groups is statistically significant. These polymorphisms showed to be useful for linkage analysis because they are identified by restriction enzyme digestion.

\section{2-F 34}

FREQUENCY OF POLYMORPHISMS IN THE RHODOPSIN GENE IN RETINITIS PIGMENTOSA PATIENTS AND NORMAL CONTROLS IN JAPAN

Keiko FUJIKI, Hiroyuki KAWANO, Yoshihiro HOTTA, Misako TAKEDA, Fumino ARA, Mutsuko HAYAKAWA, Atsushi KANAI (Dept. of Ophthalmol., Juntendo Univ., Tokyo),Tomoko HASHIMOTO, Jun-Ichi FURUYAMA (Dept. of Genet., Hyogo Coll. Med., Hyogo and George INANA (Bascom Palmer Eye Institute, Miami, FL)

We have analyzed the rhodopsin gene of Japanese patients with autosomal dominant $(\mathrm{AD})$ and autosomal recessive (AR) retinitis pigmentosa (RP) and detected two kinds of point mutations cosegregated with ADRP (Fujiki et al., 1992). In addition, the single nucleotide ( $\mathrm{nt}$ ) substitutions at nt269 (5' non-coding region) and nt5145 (4th intron) were extremely frequent in RP patients. In the present study, these variants were compared with 61 unrelated RP patients and 67 normal controls. There was no significant difference in the variant frequencies in the two groups, and there was no deviation from Hardy-Weinberg's law in each genotype. Therefore, it was concluded that these variants did not correlate with RP. The frequency of A269 $\rightarrow$ $\mathrm{G}$ and $\mathrm{G} 5145 \rightarrow \mathrm{A}$ in our data was $52 \%$ and $36 \%$, respectively. These values were higher than that in the American population as reported by Sung et al., 1991 (14 $\%$ for nt269 and infrequent for nt5145). However, another variant of C5321 $\rightarrow$ A ( 3 . non-coding region) was $5 \%$ in our data which was lower than $13 \%$ in the USA. These differences might be due to population differences. These polymorthisms are useful as DNA markers for linkage analysis. 


\section{2-F 35}

INVESTIGATION OF VON WILLEBRAND DISEASE: THE FIRST CASE OF HOMOZYGOUS TYPE IIC. Hisamitsu UNO ${ }^{1}$, Tomio YAMAZAKI ${ }^{2}$, Muneou SUZUKI 1 , Hitoshi MATSUOKA $^{1}$, Akira YOSHIOKA ${ }^{3}$, and Hirohito TSUBOUCHI ${ }^{1}$, ( ${ }^{1}$ 2nd. Dept. Int. Med., Miyazaki Med. School, Miyazaki, ${ }^{2}$ 1st. Dept. Int. Med., Nagoya Univ., Nagoya, 3 Dept. Pediat. Nara Med. Univ., Nara)

Type II von Willebrand disease (vWD) is a qualitative abnormality of von Willebrand factor $(\mathrm{vWF})$ which is characterized by the absence of the largest, or the largest and intermediate-sized plasma vWF multimers. Type IIC vWD is a very rare variant subtype in which only nine families have been previously described. The multimers of the propositus were composed of the increased smallest multimer and progressively decreased larger multimers, with each multimer replaced by single band instead of normal triplet structure. The coagulopathy and multimer analysis of the propositus' first relatives suggested that the propositus is homozygous for type IIC vWD gene. To assure the homozygosity of the propositus, linkage analysis in vWF gene was carried out within the family using polymorphism of variable number of tandem repeat (VNTR) within intron 40, and of BstEII and HaelII sites in exon 28. VNTR patterns demonstrated the homozygosity of the propositus. Furthermore, the digestion of $v W F$ by $S$. aureus V-8 protease which produced two distinct fragments of $v W F$, i. e. a C-terminal SpII and a series of N-terminal SpIII fragments, showed abnormalities of SpIII, indicating that the molecular abnormality of vWF in type IIC vWD resides in the $\mathrm{N}$-terminal portion. However, the sequence analysis of exon 28 showed no base substitution.

\section{2-F 36}

GENE ANALYSIS OF THROMBASTHENIA WITH TWO TYPE SPLICE SITE MUTATIONS. Sadahiko IWAMOTO, Eiji KAJII, Shigeneori IKEMOTO (Dept. Legal Med. and Human Genet., Jichi Medical School, Tochigi)

Splice site mutations often result in many kinds of genetic disorders. We performed molecular analysis in siblings with Glanzmann's thrombasthenia whose platelets defected glycoprotein IIb (GPIIb). GPIIb mRNA and genomic DNA were amplified by polymerase reaction and were analysed their sequences. The sequence analysis showed that the siblings were compound heterozygotes of two GPIIb gene defects. The father's allele involves skipping exon 28 secondary to a base substitution at the splicing donor site of exon 28 (CAGlgtgagt $\rightarrow$ TAGlgtgagt) as an amber mutation. The exon skipping results in a GPIIb isoform, GPIIb ${ }^{-28}$, which was identical with the isoform previously isolated from HEL cell. The transcription level of GPIIb ${ }^{-28}$ was identical with wild type allele. The mother's allele appears to involve decreasing GPIIb mRNA level in platelet secondary to a base substitution at the splicing acceptor site of exon $6(\mathrm{cag} / G \rightarrow$ caalG). The mother's pathogenic allele was not detected with mRNA form in the platelets. Our results indicate that the GPIIb ${ }^{-28}$ is not expressed on platelet membrane as a stable GPIIb/IIIa complex nor left as a monomer in peripheral platelets. 


\section{2-F 37}

DETECTION OF MISSENSE MUTATIONS IN THE CARDIAC $\beta$-MYOSIN HEAVY CHAIN GENE FROM PATIENTS WITH HYPERTROPHIC CARDIOMYOPATHY.

Akinori KIMURA, Takehiko SASAZUKI (Dept. Genet., Med. Inst. Bioreg., Kyushu Univ., Fukuoka), Hirofumi NISHI, Haruhito HARADA, Yoshinori KOGA, Hironori TOSHIMA (3rd Dept. Int. Med., Kurume Univ. Schl. Med., Kurume), RESERCH COMMITTEE FOR IDIOPATHIC CARDIOMYOPATHY, JAPAN.

Hypertrophic cardiomyopathy (HCM) ia an autosomal dominant inherited disease characterized by cardiac hypertrophy of unknown etiology and is a major cause of sudden deathS in young adults. To elucidate the molecular defects in HCM, we have analyzed the structure of cardiac $\beta$-myosin heavy chain (MHC) gene from 164 patients with HCM. Thirteen different missense mutations in the cardiac $\beta$-MHC gene was found in 20 patients (12\%). These mutations were found at the evolutionary conserved amino acid residue among various $\mathrm{MHCs}$ and co-segregated with the disease in respective multiplex families, suggesting that they were the causes of cardiac hypertrophy in these patients. In contrasst, linkage study of HCM with genetic markers in 40 multiplex families demonstrated that there were at least 11 families $(27.5 \%)$ showing negative linkage to the $C M H I$ locus (cardiac MHC gene locus), i.e. non-myosin families. Among the 11 non-myosin fmilies, at least 2 families showed negative linkages to the $C M H 2$ locus which is another disease locus recently identified in Caucasian non-myosin families. These obsevations suggest that there are at least 3 disease locus for Japanese familial HCM.

\section{2-F 38}

GENETIC ANALYSIS OF TWO JAPANESE FAMILIES WITH WERNER'S SYNDROME USING MICROSATELLITE MARKERS. Noriaki MITSUDA,Jun NAKURA,Koichi KIHARA,Lin JE,Keiko NAGANO,Kouzin KAMINO,Tetsuro MIKI,Toshio OGIHARA(Dept.Geriat. Med.,Osaka Univ. Med. Sch.,Osaka.)

Werner's syndrome(WRN), a heritable progeroid syndrome, is a rare autosomal recessive disease. The incidence of WRN in Japanese is higher than that in Caucasian. The genetic defect in WRN is unknown, but recently WRN locus was mapped to the short arm of chromosome 8,8p11.2. We confirm that WRN locus is located between two DNA markers, D8S87 and ANK1. The genetic distance between them is approximately $10 \mathrm{cM}$. We typed two unrelated families which contains 4 patients and 3 healthy siblings using microsatellites on the short arm of chromosome 8 and made haplotypes. 2 of 3 healthy persons were diagnosed as carriers. In conclusion, we can identify the mutation haplotype through the generations in each pedigrees using microsatellite DNA markers on the short arm of chromosome 8 . 


\section{2-F 39}

GENETIC MAP AROUND WERNER'S SYNDROME (WRN) REGION ON THE SHORT ARM OF CHROMOSOME 8. Jun NAKURA, Koichi KIHARA, Lin YE, Noriaki MITSUDA, Kouzin KAMINO, Toru OHTA*, Yoshihiro JNNO*, Norio NIIKAWA*, Yusuke NAKAMURA**, Tetsuro MIKI, Toshio OGOHARA (Dpt. Geriat. Med., Osaka Univ. Med. Sch., Osaka, *Dpt Hum. Genet., Nagasaki Univ. Sch. Med., Nagasaki, ** Cancer Inst., Tokyo)

Werner's syndrome (WRN) is a rare autosomal recessive disorder and causative genetic defect of WRN is still unknown. Positive lod scores between the WRN locus and two microsatellite markers, ANK1 and D8S87, on the short arm of chromosome 8 have been confirmed that the WRN locus was mapped to 8p11.2-p12. To clone the WRN gene, we collected DNA samples of more than $40 \mathrm{WRN}$ patients mainly from first or second cousin marriage, and performed homozygosity mapping. We have typed affected individuals and their family members by using microsatellite markers isolated from our microdissected library and from Genome Data Base (GDB). Lod scores were calculated using a computor program LINKAGE V5.1. A peak lod score of 18.4 at a recombination fraction of 0.001 was obtained with one of the microsattelite marker cloned in our laboratory, and this marker also revealed association with the WRN locus. For the purpose of making detailed genetic map around WRN locus and of cloning the gene, we are isolating microsatellite markers from YAC clones containing this marker region, and are isolating candidate genes from cosmid libraries constructed from DNA of the YAC clones.

\section{2-F 40}

STUDY OF THE HUP2 GENE IN THE PATIENTS WITH WAARDENBURG SYNDROME Zentaro YAMAGAIA, Sumio IIJIMA, Shinichi SHINOZAKI, TOShihiro MIYAMURA, AKio ASAKA (Dept. Of Health sciences, Yamanashi Medical University) and Moyra Smith (Dept. of Pediatrics, UC Irvine)

Waardenburg syndrome is an autosomal dominat disorder characterized by dysmorphology, pigmentary disturbances and sensorineural deafness. The mouse mutant Splotch has been postulated to be homologous to human waardenburg syndrome type I (WSI). The phenotype in splotch is due to a deletion in exon 5 of the Pax3 gene. Baldwin et al (1992) and Tassabehji et al (1992) demonstrated 2 different mutations in exon 2 of the HuP2 gene. We have carried out analysis of HuP2 gene in 3 individuals in a 3 generation pedigree with WSI and two Japanese patients with WSI. No mutation occurred in exon 2 in this family. We examined exon 5 of HuP2 gene since it corresponds to exon 5 of the Pax3 gene which carries a deletion in Splotch. We utilized oligonuceotide primers derived from published sequence of exon 5 of the Pax 3 gene to derive PCR product from genomic DNA. Analysis of somatic cell hybrids revealed that the human PCR product was dependent on the presence of human chromosome 2 . We carried out sequence analysis of the PCR product derived from 2 affected individuals and 1 normal individual and demonstrated an $A$ to $T$ mutation in exon 5 in the WSI individuals. We did additional studies and indicated analysis of Japanese patients with WSII which was not found any mutation in HuP2 gene by PCR SSCP. 


\section{AUTHOR INDEX}

AW: Award Lecture. S: Symposia. P: Special Symposium. W: Workshop. N and V: Luncheon and Evening Seminar. Others: General Contribution.

$\mathbf{A}$

\begin{tabular}{|c|c|}
\hline ABE, $K$. & $2-\mathrm{F} 1$ \\
\hline ABE, Koji & $2-F 25$ \\
\hline ABE, Kuniya & $1-F 34,1-F 38$ \\
\hline ABE, Kyohko & $1-\mathrm{E} 16,1-\mathrm{F} 12$ \\
\hline ABE, Masako & $1-E 41$ \\
\hline ABE, Tatsuo & 1-D6, 1-D10, 1-E12 \\
\hline AKAGI, Kiwamu & $1-F 37$ \\
\hline AKAIKE, Masashi & $2-F 24$ \\
\hline AKANE, Atsushi & $\mathrm{S} 6-\mathrm{C} 17$ \\
\hline AKAO, Yukihiro & $1-\mathrm{E} 9$ \\
\hline AKAZA, Tatsuya & $1-E 35$ \\
\hline AKEO, Kiyoshi & $2-\mathrm{F} 31$ \\
\hline AMEMIYÄ, Hiroshi & 1-E19 \\
\hline ANDO, Juko & $\mathrm{N} 1-\mathrm{B} 6$ \\
\hline AOKI, M. & $2-\mathrm{F} 1$ \\
\hline AOKI, Masashi & $2-F 25$ \\
\hline AOKI, Yoko & 1-D17, 2-E31 \\
\hline ARA, Fumino & 2-F33, 2-F34 \\
\hline ARAHATA, Kiichi & $\mathrm{W} 2-\mathrm{B} 9, \mathrm{~W} 2-\mathrm{B} 10$ \\
\hline ARAI, Eiko & $1-\mathrm{D} 21$ \\
\hline ARAKAWA, Atsushi & $2-E 8$ \\
\hline ARAKI, Shukuro & $\mathrm{P} 2-\mathrm{A} 35$ \\
\hline ARIGA, Tadashi & $1-\mathrm{D} 24$ \\
\hline ARINAMI, Tadao & $\begin{array}{l}\text { 1-E20, 1-E21, 1-E24, } \\
\text { l-F14, 2-F19, 2-F20 }\end{array}$ \\
\hline ARIYAMA, Takeshi & $1-D 6$ \\
\hline ARTZT, Karen & $1-F 34$ \\
\hline ASAKA, Akio & $1-F 27,2-F 40$ \\
\hline ASAKAWA, Shuichi & $\mathrm{S} 7-\mathrm{A} 26$ \\
\hline ASANO, Midori & $2-\mathrm{F} 19$ \\
\hline ASHINO, Jiro & $2-\mathrm{E} 22$ \\
\hline AWAYA, Yutaka & 2-D18 \\
\hline AZUMA, Takeshi & $1-\mathrm{E} 38$ \\
\hline \multicolumn{2}{|l|}{ B } \\
\hline BALLAS, S.K. & 2-E19 \\
\hline BEST, R.G. & $1-\mathrm{D} 37$ \\
\hline BIRD, T.D. & $2-\mathrm{F} 13$ \\
\hline BOWMAN, H.S. & $2-E 19$ \\
\hline BREUNING, M.H. & $2-\mathrm{D} 12$ \\
\hline BUMS, J. & L3-A 18 \\
\hline \multicolumn{2}{|l|}{$\mathrm{C}$} \\
\hline CHANCE, P.F. & $2-F 13$ \\
\hline CHEN, Harold & S2-B2 \\
\hline CHEN, Yu-chen & $1-\mathrm{E} 30$ \\
\hline
\end{tabular}

$\begin{array}{ll}\text { CHIBA, Yasushi } & \text { 1-D17, 2-E31 } \\ \text { CHINEN, Yasutsugu } & 2-\mathrm{D} 25 \\ \text { CHIYO, Hide-aki } & 2-\mathrm{E} 3 \\ \text { CHO, T. } & 2-E 30 \\ \text { CHUMAKOV, Ilya } & \text { 1-D20 } \\ \text { COATES, Paul M. } & 2-\mathrm{E} 28 \\ \text { COHEN, Daniel } & \text { 1-D20 } \\ \text { COLLINS, F.S. } & \text { 2-F14 } \\ \text { CONNEALLY, P.M. } & \text { 2-F13, L2-A7, P1- } \\ & \text { A30 }\end{array}$

D

$\begin{array}{ll}\text { DAI, Xiao Yan } & \text { 2-E36 } \\ \text { DARIO-DELEON, } & \text { 2-F12 } \\ \text { M.L. } & \\ \text { DAUWERSE, J.G. } & \text { 2-D12 } \\ \text { DEGUCHI, Takeo } & \text { 2-D41 } \\ \text { DOHI, Hiroshi } & \text { 1-D1 } \\ \text { DONG, Rei-ping } & \text { 1-E36 } \\ \text { DOYU, Manabu } & \text { 2-F3 }\end{array}$

E

\begin{tabular}{|c|c|}
\hline EGUCHI, I. & $1-\mathrm{F} 3$ \\
\hline EKI, Toshihiko & $1-E 28$ \\
\hline $\begin{array}{l}\text { EMANUEL, S. } \\
\text { Beverly }\end{array}$ & 1-D22 \\
\hline EMI, Mitsuru & W1-A11 \\
\hline ENDO, Fumio & $\mathrm{S} 3-\mathrm{C} 4, \mathrm{~S} 4-\mathrm{A} 16$ \\
\hline ENDO, $\mathrm{K}$. & 2-D8, 2-F5 \\
\hline ENDO, Koichi & $2-\mathrm{D} 9$ \\
\hline ENDO, Kotaro & $2-F 4$ \\
\hline ESAKI, Yukio & $1-E 34$ \\
\hline ETO, Yoshikatsu & S8-B20, V1-B11 \\
\hline \multicolumn{2}{|l|}{$\mathbf{F}$} \\
\hline $\begin{array}{l}\text { FERNANDEZ, G. } \\
\text { Isabel }\end{array}$ & $2-\mathrm{D} 21,2-\mathrm{D} 20$ \\
\hline FRIEDMANN, T. & L3-A18, P2-A39 \\
\hline FUJII, Hisaichi & 2-E19 \\
\hline FUJIKI, Keiko & 2-F33, 2-F34 \\
\hline FUJIKI, Norio & 1-E38, W4-, W4-A22 \\
\hline FUJITA, Kiyoshi & $1-F 24$ \\
\hline FUJITA, Shigeru & $2-\mathrm{F} 14$ \\
\hline FUJIWARA, Tateki & 2-D32 \\
\hline FUKAO, Toshiyuki & $2-\mathrm{F} 11,2-\mathrm{F} 28,2-\mathrm{F} 29$ \\
\hline FUKUDA, Rimmei & 2-E36 \\
\hline FUKUDA, Seiji & 2-E25, 2-E26, 2-E27 \\
\hline FUKUDA, Yuuko & $2-\mathrm{D} 34$ \\
\hline
\end{tabular}




\begin{tabular}{|c|c|c|c|}
\hline FUKUI, Yoshinori & $1-\mathrm{E} 34$ & HARADA, Naoki & $1-\mathrm{F} 12$ \\
\hline FUKUMAKI, & $2-\mathrm{F} 12$ & HARADA, Shoji & $1-F 18$ \\
\hline Yasuyuki & & HARADA, Takayo & $1-F 8,2-F 15$ \\
\hline $\begin{array}{l}\text { FUKUSHIMA, } \\
\text { Hirofumi }\end{array}$ & $\mathrm{S} 9-\mathrm{C} 21$ & $\begin{array}{l}\text { HARADA, } \\
\text { Yoshi-nobu }\end{array}$ & $1-\mathrm{D} 11$ \\
\hline $\begin{array}{l}\text { FUKUSHIMA, } \\
\text { Hisao }\end{array}$ & $1-F 6$ & $\begin{array}{l}\text { HARIHARA, Shinji } \\
\text { HASE, Yutaka }\end{array}$ & $\begin{array}{l}1-\mathrm{F} 18 \\
2-\mathrm{D} 34,2-\mathrm{E} 29\end{array}$ \\
\hline $\begin{array}{l}\text { FUKUSHIMA, } \\
\text { Masakatsu }\end{array}$ & $1-\mathrm{E} 18$ & $\begin{array}{l}\text { HASEBE, Misa } \\
\text { HASEGAWA, }\end{array}$ & $\begin{array}{l}\text { 2-D27 } \\
\text { 2-D8, 1-F40, 2-D9, }\end{array}$ \\
\hline $\begin{array}{c}\text { FUKUSHIMA, } \\
\text { Yoshimitsu }\end{array}$ & $\begin{array}{l}\text { 1-D30, 1-D33, 1-D 36, } \\
\text { 2-D2, 2-D3, 2-D13, } \\
\text { 2-D15, 2-D 17, 2-D18, } \\
\text { S3-C2 }\end{array}$ & $\begin{array}{l}\text { Tomoko } \\
\text { HASHIBA, Katsuko } \\
\text { HASHIMOTO, Isao } \\
\text { HASHIMOTO, }\end{array}$ & $\begin{array}{l}\mathrm{S} 2-\mathrm{B} 4 \\
1-\mathrm{E} 29 \\
2-\mathrm{E} 17 \\
2-\mathrm{D} 35\end{array}$ \\
\hline $\begin{array}{l}\text { FUKUYAMA, } \\
\text { Jun-ichi }\end{array}$ & $1-\mathrm{E} 1,1-\mathrm{E} 3,1-\mathrm{F} 11$ & $\begin{array}{c}\text { Katsuyuki } \\
\text { HASHIMOTO, }\end{array}$ & 2-D39, 2-E28, 2-F29 \\
\hline $\begin{array}{l}\text { FUKUYAMA, } \\
\text { Kouzou }\end{array}$ & P2-A37 & $\begin{array}{l}\text { Takashi } \\
\text { HASHIMOTO, }\end{array}$ & 1-E1, 1-E3, 1-E4, \\
\hline $\begin{array}{l}\text { FUKUYAMA, } \\
\text { Yoshimitsu }\end{array}$ & $2-\mathrm{D} 24$ & $\begin{array}{c}\text { Tomoko } \\
\text { HATA, Akira }\end{array}$ & $\begin{array}{l}1-\mathrm{E} 40,2-\mathrm{F} 34 \\
1-\mathrm{E} 17, \mathrm{~S} 3-\mathrm{C} 2\end{array}$ \\
\hline $\begin{array}{l}\text { FUKUYAMA, } \\
\text { Yukio }\end{array}$ & $\begin{array}{l}\text { 1-F8, 2-D2, 2-D } 15, \\
\text { 2-D23, 2-D29, 2-E23, } \\
\text { 2-F15, W2-B7 }\end{array}$ & $\begin{array}{l}\text { HATA, Jun-ichi } \\
\text { HATSUSE, Hiromi } \\
\text { HATTA, Nobuaki }\end{array}$ & $\begin{array}{l}1-\mathrm{F} 7 \\
1-\mathrm{E} 26 \\
2-\mathrm{F} 14\end{array}$ \\
\hline FURUICHI, Masato & $\mathrm{S} 1-\mathrm{A} 5$ & HATTORI, Masahira & $\mathrm{S} 6-\mathrm{C} 15, \mathrm{~S} 7-\mathrm{A} 25$ \\
\hline FURUKAWA, Ken & $1-F 22$ & HATTORI, Mineko & 2-E36 \\
\hline $\begin{array}{l}\text { FURUKAWA, } \\
\text { Tetsuo }\end{array}$ & W2-B9 & $\begin{array}{l}\text { HATTORI, } \\
\text { Shinzaburo }\end{array}$ & $\mathrm{S} 3-\mathrm{C} 4$ \\
\hline $\begin{array}{l}\text { FURUMI, Hiroyasu } \\
\text { FURUSE, Masanori }\end{array}$ & $\begin{array}{l}2-\mathrm{F} 12 \\
\text { S5-B18 }\end{array}$ & $\begin{array}{l}\text { HAYAKAWA, } \\
\text { Chiemi }\end{array}$ & 2-D10 \\
\hline $\begin{array}{l}\text { FURUYAMA, } \\
\text { Jun-ichi }\end{array}$ & $\mathrm{l}-\mathrm{E} 4,1-\mathrm{E} 40$ & $\begin{array}{l}\text { HAYAKAWA, } \\
\text { Fumio }\end{array}$ & 2-D10 \\
\hline $\begin{array}{c}\text { FUSHIMI, Kiyohide } \\
\text { G }\end{array}$ & $1-D 14$ & $\begin{array}{l}\text { HAYAKAWA, } \\
\text { Mutsuko } \\
\text { HAYASAKA, K. }\end{array}$ & $\begin{array}{l}2-\mathrm{F} 33,2-\mathrm{F} 34 \\
2-\mathrm{F} 13\end{array}$ \\
\hline GAMAL, S.M. & 2-D8 & HAXASHI, Akira & $2-\mathrm{E} 3$ \\
\hline GOTO, Haruko & 2-E14, 2-E20 & HAYASHI, Ken & $1-\mathrm{D} 32$ \\
\hline GOTO, Jun & $\mathrm{P} 1-\mathrm{A} 31$ & HAYASHI, & 2-D41 \\
\hline GOTO, Toshihiro & $1-\mathrm{D} 28$ & Michiyuki & \\
\hline $\begin{array}{c}\text { GOTO, Yu-ichi } \\
\mathbf{H}\end{array}$ & $2-\mathrm{F} 21$ & $\begin{array}{l}\text { HAYASHI, Yasuhide } \\
\text { HAYASIMOTO, } \\
\text { Sakura }\end{array}$ & $\begin{array}{l}1-\mathrm{D} 39,1-\mathrm{E} 14 \\
2-\mathrm{E} 9\end{array}$ \\
\hline $\begin{array}{l}\text { HACHIYA, } \\
\text { Noriyuki }\end{array}$ & $2-\mathbf{E} 40$ & $\begin{array}{l}\text { HIDA, Akiko } \\
\text { HIDAKA, Kazuo }\end{array}$ & $\begin{array}{l}1-\mathrm{D} 27 \\
2-\mathrm{E} 6\end{array}$ \\
\hline HAGIWARA, Yoko & $1-F 5$ & HIGUCHI, Itsuro & $2-F 23$ \\
\hline HAKODA, Masayuki & $1-\mathrm{F} 26,2-\mathrm{E} 9$ & HIMORO, M. & $2-\mathrm{F} 13$ \\
\hline HAMADA, Hirofumi & $\mathrm{S} 4-\mathrm{A} 15$ & HIRAI, Momoki & $1-\mathrm{D} 29,1-\mathrm{D} 35, \mathrm{l}-\mathrm{F} 18$ \\
\hline HAMADA, Hiromi & $1-\mathrm{F} 14$ & HIRAISHI, & $1-\mathrm{F} 7$ \\
\hline $\begin{array}{l}\text { HAMAGUCHI, } \\
\text { Hideo }\end{array}$ & $\begin{array}{l}1-\mathrm{E} 19,1-\mathrm{E} 20,1-\mathrm{E} 21, \\
1-\mathrm{E} 22,1-\mathrm{E} 23,1-\mathrm{E} 24, \\
1-\mathrm{F} 14,2-\mathrm{F} 19,2-\mathrm{F} 20\end{array}$ & $\begin{array}{l}\text { Yoshiyuki } \\
\text { HIRAKAWA, } \\
\text { Kohichi }\end{array}$ & $1-\mathrm{E} 12, \mathrm{I}-\mathrm{E} 13$ \\
\hline HANDA, Masafumi & $1-\mathrm{F} 11$ & HIRAKAWA, Shun & $1-\mathrm{F} 31$ \\
\hline HANIHARA, Tokiji & 2-E16, 2-F30 & HIRAMATSU, Ryoji & $1-E 41$ \\
\hline HARA, Michiko & $2-\mathrm{F} 15$ & HIRANO, Chiaki & $1-\mathrm{E} 24$ \\
\hline HARA, Nagakura & 2-E12 & HIRATA, Makoto & 2-D35 \\
\hline HARADA, Haruhito & $2-\mathrm{F} 37$ & HIRATA, Yukimasa & $1-\mathrm{E} 33$ \\
\hline
\end{tabular}




\begin{tabular}{|c|c|c|c|}
\hline $\begin{array}{l}\text { HIRA YAMA, } \\
\text { Kiyotake }\end{array}$ & 2-D25 & $\begin{array}{l}\text { IKEYA, Kiyoko } \\
\text { IKOMA, Fumihiko }\end{array}$ & $\begin{array}{l}\text { 1-F8, W2-B7 } \\
1-\mathrm{E} 4\end{array}$ \\
\hline HIRAY AMA, Mikio & W4-A22 & IKUTA, Fusahiro & $2-\mathrm{F} 2$ \\
\hline HIRAYAMA, Mitsue & 1-E35 & IKUTA, Koichi & $1-F 36$ \\
\hline $\begin{array}{l}\text { HIRAYAMA, } \\
\text { Nakami }\end{array}$ & $1-\mathrm{D} 23$ & $\begin{array}{l}\text { IMADA, Kensei } \\
\text { IMAIZUMI, K. }\end{array}$ & $\begin{array}{l}\text { 2-D28 } \\
\text { 2-D4, 2-D12, 2-D16 }\end{array}$ \\
\hline HIROTA, Ryuichiro & $\begin{array}{l}\text { 2-E32, 2-E34, 2-E35, } \\
\text { 2-E37, 2-E38 }\end{array}$ & IMAIZUMI, Kiyoshi & $\begin{array}{l}\text { 1-D30, 1-F30, 2-D3, } \\
\text { S2-B1 }\end{array}$ \\
\hline HOFSTEE, Yvonne & $2-\mathrm{F} 20$ & IMAIZUMI, & $2-\mathrm{D} 23$ \\
\hline HOMMA, Akira & $2-\mathrm{F} 16$ & Tomoichi & \\
\hline HONDA, Yutaka & $1-$ E33 & IMAIZUMI, Yoko & $1-\mathrm{F} 29$ \\
\hline HONG, Gi Hyun & 1-E37 & IMAMICHI, & $2-E 32$ \\
\hline HONGOU, Kazuhisa & 2-D14 & Hiroyuki & \\
\hline HONMA, Yoshiaki & $2-F 2$ & IMAMURA, Atsushi & $2-F 11$ \\
\hline HORAI, Satoshi & 2-F21, S1-A1 & IMAMURA, Ri-ichi & $2-F 16$ \\
\hline HORI, Hitomi & $1-\mathrm{D} 15$ & IMAMURA, Takashi & $1-\mathrm{D} 16$ \\
\hline HORI, Katsuji & P2-A37 & IMAMURA, Toshiro & S5-B16 \\
\hline HORI, Masahiro & S9-C18 & IMANISHI, Tadashi & $1-E 29$ \\
\hline HORI, Tada-aki & $\begin{array}{l}\text { I-D11, 1-F16, 2-F16, } \\
2-\mathrm{F} 17\end{array}$ & $\begin{array}{l}\text { IMANO, Maki } \\
\text { IMOTO, Natsuki }\end{array}$ & $\begin{array}{l}\text { 2-D23, 2-F15 } \\
\text { 1-E24 }\end{array}$ \\
\hline HORI, Toshinori & 2-E25, 2-E26, 2-E27 & INADA, Yasushi & 2-E32, 2-E34, 2-E38 \\
\hline HORII, Akira & S15-B17 & INANA, George & 2-F33, 2-F34 \\
\hline HORIIKE, Shigeo & 1-E12 & INANA, Ichiro & $2-\mathrm{D} 31$ \\
\hline HORIKAWA, Izumi & 1-D12, 1-E7 & INAYAMA, & 2-E32, 2-E34, 2-E35, \\
\hline HORIUCHI, Atsushi & 1-D6 & Yasuhiro & $2-E 37,2-E 38$ \\
\hline $\begin{array}{l}\text { HORIUCHI, } \\
\text { Takahiko }\end{array}$ & $2-\mathrm{F} 14$ & $\begin{array}{l}\text { INAZAWA, Johji } \\
\text { INDO, Yasuhiro }\end{array}$ & $\begin{array}{l}\text { 1-D6, 1-D10, W3-C9 } \\
\text { 2-E28, S8-B22 }\end{array}$ \\
\hline HOSHIDE, Ryuuji & $2-\mathrm{E} 18$ & INOUE, Ken & $2-\mathrm{E} 16,2-\mathrm{F} 30$ \\
\hline HOTTA, Yoshihiro & 2-F33, 2-F34 & INOUE, Yushi & 2-D32 \\
\hline HOZUMI, Isao & $2-\mathrm{E} 15$ & INOUE, Kiyoshi & $1-\mathrm{D} 10$ \\
\hline HU, Jianguo & 2-D41 & INUI, Koji & $1-F 6,2-D 5$ \\
\hline $\mathbf{I}$ & & $\begin{array}{l}\text { INUZUKA, Takashi } \\
\text { ISASHIKI, Yasushi }\end{array}$ & $\begin{array}{l}2-\mathrm{F} 2 \\
2-\mathrm{F} 23\end{array}$ \\
\hline ICHIKAWA, Hitoshi & 1-D18, 1-D19 & ISHIDA, Toru & 2-E32, 2-E34, 2-E35, \\
\hline ICHIKAWA, & $1-E 35$ & & 2-E37, 2-E38 \\
\hline Yohichi & & ISHIDA, Yoshinori & 1-D17, 2-E31 \\
\hline IDA, Shinobu & $2-E 3$ & ISHIHARA, & $1-F 36$ \\
\hline IGARASHI, Shuichi & 2-D38, 2-F9 & Hisamitsu & \\
\hline IGARASHI, & $1-F 40$ & ISHIHARA, Yasushi & $1-\mathrm{E} 40$ \\
\hline Takeyasu & & ISHIHARA, & 2-D11 \\
\hline IIDA, Reiko & $1-\mathrm{F} 21$ & Yoshimori & \\
\hline IIDA, Tadashi & $2-\mathrm{E} 8$ & ISHII, Masatoshi & $1-\mathrm{F} 35$ \\
\hline IIDA, Taku & 2-E10 & ISHII, Nozomi & $2-E 23$ \\
\hline IIJIMA, Sumio & $1-\mathrm{F} 27,2-\mathrm{F} 40$ & ISHIKAWA, & $2-E 21$ \\
\hline IKAGAWA, Shuji & 1-E39 & Kumiko & \\
\hline IKAWA, Kazumi & 2-F18 & ISHIKAWA, Takeru & $1-E 39$ \\
\hline IKE, Kouichiro & $2-\mathrm{D} 22$ & ISHIKAWA, & $1-\mathrm{E} 20$ \\
\hline IKEDA, Hiroyuki & S8-B21 & Yoshihide & \\
\hline IKEDA, Joh-E & S7-A27 & ISHIKIRIY AMA, & $1-\mathrm{F} 16$ \\
\hline $\begin{array}{l}\text { IKEMOTO, } \\
\text { Shigenori }\end{array}$ & 2-E1, 2-E11, 2-F36 & $\begin{array}{l}\text { Satoshi } \\
\text { ISHIMATU, Takashi }\end{array}$ & $1-E 5$ \\
\hline IKEUCHI, Tatsuro & $\begin{array}{l}\text { 1-D14, 1-D18, 1-D19, } \\
\text { 1-D21, 1-D 34, 1-E5, } \\
\text { 2-D1 }\end{array}$ & $\begin{array}{l}\text { ISHIZAKI, Kanji } \\
\text { ISHIZUKA, Mitsuru } \\
\text { ISOBE, Masaharu }\end{array}$ & $\begin{array}{l}1-E 13 \\
1-D 1 \\
1-D 15\end{array}$ \\
\hline
\end{tabular}




\begin{tabular}{|c|c|c|c|}
\hline ISSHIKI, Gen & 2-E22, 2-E24, 2-E29 & KAMINO, Kouzin & 1-D9, 1-F25, 2-E39, \\
\hline ITO, Koji & $1-\mathrm{E} 37$ & & 2-F38, 2-F39 \\
\hline ITO, Michinori & $2-F 27$ & KAMOSHITA, & $1-$ E14 \\
\hline ITO, Shigenori & $1-\mathrm{F} 23,1-\mathrm{F} 24$ & Shigehiko & \\
\hline ITOH, Satoko & 1-E2, 2-D14, 2-D19 & KANAGAE, Yumi & S4-A14 \\
\hline ITOYAMA, Yasuto & $2-\mathrm{F} 1,2-\mathrm{F} 25$ & KANAI, Atsushi & 2-F33, 2-F34 \\
\hline IUCHI, Iwao & 2-E6 & KANAMORI, Masao & $1-\mathrm{E} 8$ \\
\hline IWAKI, Akiko & $2-\mathrm{F} 12$ & KANAZAWA, & 2-F8, $\mathrm{A} 12-, \mathrm{P} 1-\mathrm{A} 31$ \\
\hline IWAKI, Konomi & $1-\mathrm{D} 15$ & Ichiro & \\
\hline IWAKI, Toru & $2-F 12$ & KANEKO, Eizo & $2-\mathrm{E} 21$ \\
\hline IWAMATSU, & $1-\mathrm{D} 17,2-\mathrm{E} 31$ & KANEKO, Hiroto & 1-E13 \\
\hline Akihiro & & KANEKO, Junko & $1-\mathrm{F} 19,2-\mathrm{E} 5$ \\
\hline IWAMATSU, & $2-\mathrm{D} 23$ & KANEKO, Kiyotoshi & $2-\mathrm{F} 9,2-\mathrm{F} 10$ \\
\hline Yoshiyuki & & KANEKO, Yasuhiko & S5-B15 \\
\hline IWAMOTO, & $2-F 36$ & KANNO, Hitoshi & $2-E 19$ \\
\hline Sadahiko & & KANO, Michiko & $1-\mathrm{D} 29$ \\
\hline IWASAKI, Keiko & $1-\mathrm{F} 40,2-\mathrm{D} 9$ & KARUBE, Y. & $2-\mathrm{F} 5$ \\
\hline IWATA, Hideki & 2-E25, 2-E27 & KASAI, Ryozo & $2-\mathrm{D} 26$ \\
\hline IWATA, Misa & $2-\mathrm{E} 30,1-\mathrm{F} 23$ & KASAI, Yasufumi & $2-\mathrm{D} 27$ \\
\hline IWATANI, Noritaka & $1-\mathrm{F} 1$ & KASAMA, Midoriko. & $1 F-F 10$ \\
\hline IZUMI, Tohru & $2-\mathrm{E} 15$ & KASE, Ryoichi & 2-E23 \\
\hline $\begin{array}{l}\text { IZUMIKAWA, } \\
\text { Yoshinori }\end{array}$ & 1-D7, 2-D25 & $\begin{array}{l}\text { KASHIWAGI, } \\
\text { Atsuko }\end{array}$ & 2-D5 \\
\hline $\mathbf{J}$ & & $\begin{array}{l}\text { KASHIWAZAKI, } \\
\text { Sadao }\end{array}$ & 1-F26, 2-E9 \\
\hline $\mathrm{JE}$, Lin & $2-F 38$ & KATAGIRI, Yukiko & $1-F 31$ \\
\hline JHANWAR, S.C. & 1-E6 & KATAYAMA, & $1-\mathrm{F} 31$ \\
\hline JINNO, Yoshihiro & 1-D3, 1-D7, 1-D9, 1- & Susumu & \\
\hline & D13, 1-D24, 1-F33, & KATO, Noriko & $2-E 8$ \\
\hline & $2-F 39$ & KATO, Rumiko & $1-D 3,2-D 24$ \\
\hline JUJI, Takeo & 1-E20, 1-E25, 1-E29, & KATO, Shingo & $1-F 7$ \\
\hline & 1-E33, 1-E35 & KATO, Takeo & $2-F 6$ \\
\hline & & KATOH, Motonobu & $1-\mathrm{D} 12$ \\
\hline $\mathbf{K}$ & & KATSUMATA, & S9-C19 \\
\hline KACHI, Teruhiko & $2-\mathrm{F} 3$ & Yoshinao & \\
\hline KAGAMI, K. & 2-D4 & KATSUMORI, & 2-D15 \\
\hline KAGEYAMA, & $1-\mathrm{E} 5$ & Hiroshi & \\
\hline Yukio & & KATSUYA, & $1-\mathrm{F} 25,2-\mathrm{E} 39$ \\
\hline KAJII, Eiji & 2-E1,2-E11, 2-F36 & Tomohiro & \\
\hline KAJII, Tadashi & 2-D11 & KAWAHARA, & $1-\mathrm{D} 28$ \\
\hline KAKINUMA, & $2-\mathrm{D} 31$ & Hidetoshi & \\
\hline Katsuko & & KAWAI, Hisaomi & $2-F 24$ \\
\hline KAKUDO, Kennichi & $1-E 40$ & KAWAKAMI, & $1-$ E26 \\
\hline KAMATA, Tadashi & 2-E21 & Masaya & \\
\hline $\begin{array}{l}\text { KAMATANI, } \\
\text { Naoyuki }\end{array}$ & 1-F26, 2-E9, S8-B23 & $\begin{array}{l}\text { KAWAMURA, } \\
\text { Machiko }\end{array}$ & $1-\mathrm{E} 14$ \\
\hline KAMEYA, Tsuyoshi & $2-F 25$ & KAWANISHI, & 2-E16,2-F30 \\
\hline KAMIGUCHI, & $1-\mathrm{D} 31,1-\mathrm{F} 32$ & Chiaki & \\
\hline Yujiroh & & KAWANO, Hiroyuki & 2-F34 \\
\hline KAMIJO, Takehiko & $2-D 39$ & KAWANO, T. & 2-D4 \\
\hline $\begin{array}{l}\text { KAMIKAWAJI, } \\
\text { Nobuhiro }\end{array}$ & 1-E32, 1-E36 & $\begin{array}{l}\text { KAWASAKI, } \\
\text { Kazuhiko }\end{array}$ & 1-E28, S7-A26 \\
\hline KAMINISHI, Yoshio & $2-F 23$ & $\begin{array}{l}\text { KAWASHIMA, } \\
\text { Shingo }\end{array}$ & $2-\mathrm{F} 4,2-\mathrm{F} 5$ \\
\hline
\end{tabular}




\begin{tabular}{|c|c|}
\hline $\begin{array}{l}\text { KAWAWAKI, } \\
\text { Hisashi }\end{array}$ & 2-D34 \\
\hline $\begin{array}{l}\text { KAZAMATSURI, } \\
\text { Hajime }\end{array}$ & $2-\mathrm{E} 36$ \\
\hline KIDA, Mitsushiro & $1-F 39$ \\
\hline KIHARA, Kazunori & $1-\mathrm{E} 5$ \\
\hline KIHARA, Koichi & 2-F38, 2-F39 \\
\hline KIKUCHI, Shuichi & $1-\mathrm{E} 19$ \\
\hline KIMURA, Akinori & 1-E34, 2-F37, S1-A2 \\
\hline KIMURA, Seiji & 2-E16 \\
\hline KIMURA, Tomoatsu & $\mathrm{S} 3-\mathrm{C} 5$ \\
\hline KIMURA, Yasukazu & $1-\mathrm{F} 20$ \\
\hline KIN, Tashou & 2-D34 \\
\hline KINOSITA, Hiromi & $2-\mathrm{D} 7$ \\
\hline KISHI, Fumio & 2-D40 \\
\hline KISHI, Koichiro & $1-\mathrm{F} 21$ \\
\hline KISHI, Kunikazu & $2-\mathrm{F} 16,2-\mathrm{F} 17$ \\
\hline KISHINO, Tatsuya & $\begin{array}{l}\text { 1-D3, 1-D24, 2-D38, } \\
\text { 1-D7 }\end{array}$ \\
\hline KITATANI, Mashio & $2-\mathrm{D} 7$ \\
\hline KITOH, Yoshihiko & $1-\mathrm{F5}$ \\
\hline KO, Eikan & $2-\mathrm{D} 7$ \\
\hline KOBASHI, Gen & $1-\mathrm{E} 17$ \\
\hline $\begin{array}{l}\text { KOBAYASHI, } \\
\text { Kazuhiro }\end{array}$ & $1-\mathrm{D} 27$ \\
\hline $\begin{array}{l}\text { KOBAYASHI, } \\
\text { Kimiko }\end{array}$ & 1-E21, 1-E23, 1-E24 \\
\hline KOBAYASHI, M. & $1-F 9$ \\
\hline $\begin{array}{l}\text { KOBAYASHI, } \\
\text { Noboru }\end{array}$ & $1-\mathrm{D} 40,1-\mathrm{E} 25$ \\
\hline $\begin{array}{l}\text { KOBAYASHI, } \\
\text { Yuzuru }\end{array}$ & $2-\mathrm{F} 14$ \\
\hline KODAIRA, Mieko & $2-\mathrm{E} 5$ \\
\hline KODAMA, Terutaka & $1-\mathrm{D} 27$ \\
\hline KOGA, H. & $2-\mathrm{F} 22$ \\
\hline KOGA, Ryoichi & 2-E3 \\
\hline KOGA, Yoshinori & $2-F 37$ \\
\hline $\mathrm{KOH}$, Jun & $\begin{array}{l}\text { 2-E32, 2-E34, 2-E35, } \\
\text { 2-E37, 2-E38 }\end{array}$ \\
\hline KOHLI, Yoshihiro & $1-\mathrm{E} 38$ \\
\hline KOHSAKA, Takao & $1-\mathrm{E} 25$ \\
\hline KOIKE, Ryoko & $1-\mathrm{F} 3,2-\mathrm{F} 10,2-\mathrm{F} 9$ \\
\hline KOJIMA, Tsukasa & 2-E9 \\
\hline KOMAKI, Rie & 1-D27, 2-E10 \\
\hline KOMHE, Satoshi & 1-F8, W2-B7 \\
\hline $\begin{array}{l}\text { KOMIYAMA, } \\
\text { Atsushi }\end{array}$ & 2-D39 \\
\hline KOMIY AMA, J. & $2-\mathrm{E} 30$ \\
\hline KOMORIYA, Keiji & $1-\mathrm{E} 31$ \\
\hline KON, Atsushi & $2-\mathrm{E} 17$ \\
\hline KONDO, Eri & W2-B7 \\
\hline KONDO, H. & 1-F3 \\
\hline KONDO, Ikuko & 2-F8, 2-F17 \\
\hline KONISHI, Hiroshi & $1-F 30$ \\
\hline
\end{tabular}

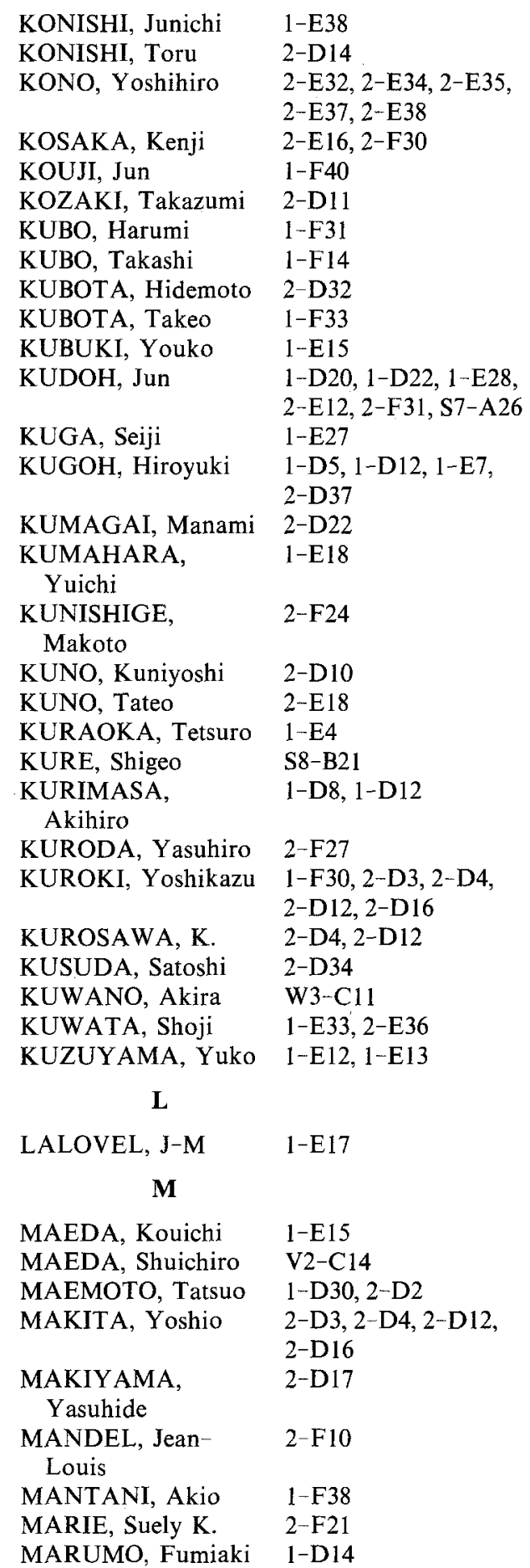




\begin{tabular}{|c|c|c|c|}
\hline $\begin{array}{l}\text { MARUYAMA, } \\
\text { Hiroshi }\end{array}$ & 2-D29 & $\begin{array}{l}\text { MINOSHIMA, } \\
\text { Shinsei }\end{array}$ & $\begin{array}{l}1-\mathrm{D} 1,1-\mathrm{D} 4,1-\mathrm{D} 20 \\
1-\mathrm{D} 22,1-\mathrm{E} 28,2-\mathrm{E} 12\end{array}$ \\
\hline MASAKI, T. & $1-F 9$ & & S7-A26 \\
\hline MASEKI, Nobuo & S5-B15 & MINOURA, Shigeki & $1 \mathrm{~F}-\mathrm{F} 10$ \\
\hline MASHIMA, & $2-\mathrm{F} 31$ & MINOWADA, Jun & $2-\mathrm{E} 13$ \\
\hline Yukihiko & & MISAWA, Hidemi & 2-D41 \\
\hline MASUKO, Kaori & 2-D14 & MISAWA, Shinichi & $1-\mathrm{E} 12,1-\mathrm{E} 13$ \\
\hline MASUNO, Mitsuo & $\begin{array}{l}\text { 2-D3, 2-D4, 2-D12, } \\
\text { 2-D16 }\end{array}$ & $\begin{array}{l}\text { MISHIMA, Mayumi } \\
\text { MITA, Tetsuo }\end{array}$ & $\begin{array}{l}1-\mathrm{F} 8,2-\mathrm{F} 15 \\
1-\mathrm{D} 5\end{array}$ \\
\hline $\begin{array}{l}\text { MATSUBARA, } \\
\text { Tsunenori }\end{array}$ & 2-D19, 2-D26 & $\begin{array}{l}\text { MITSUDA, Noriaki } \\
\text { MITSUI, Takao }\end{array}$ & $\begin{array}{l}\text { 1-D9, 2-F38, 2-F39 } \\
\text { 2-F24 }\end{array}$ \\
\hline MATSUBARA, Y. & $2-\mathrm{Fl}$ & MITSUMA, Terunori & $2-\mathrm{F} 3$ \\
\hline MATSUDA, Ichiro & 2-E18, 2-E30, S3-C4 & MITSUYA, Kohzoh & 1-D5, 1-E7, 2-D37 \\
\hline MATSUDA, Junko & $2-F 27$ & MITSUYAMA, & $1-\mathrm{D} 1$ \\
\hline MATSUI, Akira & 2-D33 & Susumu & \\
\hline MATSUI, Ichiro & $1-\mathrm{D} 40$ & MITUNAGA, & $1-E 29$ \\
\hline MATSUI, Kiyoshi & $1-\mathrm{F} 24$ & Shigeki & \\
\hline MATSUI, Naomi & $1-\mathrm{E} 25$ & MIURA, Akiko & $1-\mathrm{F} 20$ \\
\hline MATSUKI, & $1-\mathrm{F} 22$ & MIWA, Shiro & $2-\mathrm{E} 19$ \\
\hline Takasumi & & MIYAJIMA, Atsushi & $1-\mathrm{D} 23$ \\
\hline MATSUMOTO, & $1-\mathrm{F} 24,1-\mathrm{F} 28$ & MIYAJIMA, Hiroaki & $2-\mathrm{E} 21$ \\
\hline Hideo & & MIYAJIMA, & 2-D27 \\
\hline MATSUMOTO, & $2-\mathrm{F} 14$ & Tomoko & \\
\hline Mitsuru & & MIYAKAWA, & $2-\mathrm{D} 28$ \\
\hline MATSUMOTO, & $1-\mathrm{D} 3$ & Kimiko & \\
\hline Naomichi & & MIYAKAWA, & $2-\mathrm{F} 30$ \\
\hline MATSUO, Masafumi & $1-\mathrm{F} 5$ & Tomohiro & \\
\hline MATSUO, Nobutake & $1-\mathrm{F} 7$ & MIYAKITA, Yasushi & $2-\mathrm{E} 15$ \\
\hline MATSUO, Yasushige & 2-D33 & MIYAMURA, & $1-\mathrm{F} 27,2-\mathrm{F} 40$ \\
\hline $\begin{array}{l}\text { MATSUOKA, } \\
\text { Hitoshi }\end{array}$ & $1-\mathrm{E} 15,2-\mathrm{F} 35$ & $\begin{array}{l}\text { Toshihiro } \\
\text { MIYATA, E. }\end{array}$ & $2-\mathrm{F} 22$ \\
\hline MATSUOKA, Tarou & $1-\mathrm{F} 6$ & MIYATAKE, & $2-\mathrm{F} 9,2-\mathrm{F} 10$ \\
\hline $\begin{array}{l}\text { MATSUSHITA, } \\
\text { Ikumi }\end{array}$ & $1-\mathrm{D} 27$ & $\begin{array}{l}\text { Tadashi } \\
\text { MIYAZAKI, Emiko }\end{array}$ & $1-\mathrm{E} 18$ \\
\hline MATSUSHITA, Sho & 1-E30, 1-E31, 1-E39 & MIYAZAKI, & $1-\mathrm{F} 35,1-\mathrm{F} 36$ \\
\hline $\begin{array}{l}\text { MATSUURA, } \\
\text { Nariaki }\end{array}$ & $1-\mathrm{E} 40$ & $\begin{array}{c}\text { Jun-ichi } \\
\text { MIYAZAKI, }\end{array}$ & $1-\mathrm{E} 20$ \\
\hline $\begin{array}{l}\text { MATSUURA, } \\
\text { Toshinobu }\end{array}$ & $2-\mathrm{E} 18, \mathrm{~S} 3-\mathrm{C} 4$ & $\begin{array}{l}\text { Ryunosuke } \\
\text { MIYAZAKI, Tokiko }\end{array}$ & $1-\mathrm{F} 24,1-\mathrm{F} 28$ \\
\hline MATSUYA, Kunio & $1-\mathrm{E} 37$ & MIZOI, Yasuhiko & $1-\mathrm{F} 23,1-\mathrm{F} 24$ \\
\hline $\begin{array}{l}\text { MATUBARA, } \\
\text { Yoichi }\end{array}$ & $\mathrm{S} 8-\mathrm{B} 21$ & $\begin{array}{l}\text { MIZUNO, Kunihiko } \\
\text { MOMOI, M. }\end{array}$ & $\begin{array}{l}1-\mathrm{D} 27 \\
1-\mathrm{F} 3\end{array}$ \\
\hline MIHARU, Norio & 1-D37 & MONACO, John J. & 2-D40 \\
\hline MIIKE, Teruhisa & $1-\mathrm{F} 1$ & MORI, Masataka & $1-\mathrm{F} 37$ \\
\hline MIKAMO, Kazuya & AW1-A20, 1-D31 & MORIMURA, Tatsuo & $1-\mathrm{E} 1$ \\
\hline MIKI, Tetsuro & $\begin{array}{l}\text { 1-D3, 1-E18, 1-F4, } \\
\text { 1-F25, 2-E39, 2-F38, } \\
\text { W2-B8 }\end{array}$ & $\begin{array}{l}\text { MORITA, Mitsuo } \\
\text { MORITA, Reiko } \\
\text { MOSSER, Jean }\end{array}$ & $\begin{array}{l}\text { 1-E41 } \\
1-\mathrm{F} 8,2-\mathrm{F} 15, \mathrm{~W} 2-\mathrm{B} 7 \\
2-\mathrm{F} 9,2-\mathrm{F} 10\end{array}$ \\
\hline MIMURA, Hiroko & $1-\mathrm{F} 11$ & MUKAI, Eiichiro & $2-\mathrm{F} 3$ \\
\hline MIN, Wei-ping & $1-\mathrm{E} 36$ & MURAKAMI, & 2-E24 \\
\hline MINESHITA, & 1-D28 & Hiroshi & \\
\hline Takahiro & & MURAKAMI, Masae & $1-\mathrm{E} 2$ \\
\hline MINETA, Toshihiro & P2-A37 & $\begin{array}{l}\text { MURAMOTO, } \\
\text { Tamaki }\end{array}$ & $2-\mathrm{F} 12$ \\
\hline
\end{tabular}




\begin{tabular}{|c|c|c|c|}
\hline MURASE, Takaji & 2-E20 & NAKANO, Teruaki & $1-\mathrm{E} 27,2-\mathrm{E} 30$ \\
\hline MURATA, Mitsunori & 2-D13 & NAKAO, Makoto & $1-\mathrm{E} 13$ \\
\hline $\begin{array}{l}\text { MURAYAMA, } \\
\text { Nobuhiro }\end{array}$ & 2-F8 & $\begin{array}{c}\text { NAKAOKA, } \\
\text { Yoshiharu }\end{array}$ & 1-D37, 1-F32 \\
\hline MUTO, Ayako & 2-D23 & NAKASHIMA, & $1-\mathrm{D} 16$ \\
\hline MUTO, Shinya & $1-F 28$ & Hitoshi & \\
\hline MUTOH, Ayako & $2-\mathrm{D} 2$ & NAKASHIMA, & 2-E25,2-E27 \\
\hline Macer, D.R.J. & W4-A21 & Yoshihiro & \\
\hline $\mathbf{N}$ & & $\begin{array}{l}\text { NAKASHIMA, } \\
\text { Yoshiro }\end{array}$ & $2-\mathrm{E} 26$ \\
\hline NADANO, Daita & $1-\mathrm{F} 21$ & NAKATA, Katsunori & $1-\mathrm{E} 21$ \\
\hline $\begin{array}{l}\text { NAGAFUCHI, } \\
\text { Shigeo }\end{array}$ & $1-\mathrm{D} 2,1-\mathrm{D} 39,2-\mathrm{F} 8$ & $\begin{array}{l}\text { NAKATA, Ken } \\
\text { NAKAZAKI, }\end{array}$ & $\begin{array}{l}\text { S3-C5 } \\
\text { W4-A22 }\end{array}$ \\
\hline NAGAI, Toshiro & 2-D24, N2-C7 & Shigeaki & \\
\hline NAGAKI, Shigeru & $2-\mathrm{D} 23$ & NAKAZATO, & $\mathrm{S} 3-\mathrm{C} 4$ \\
\hline NAGANO, Keiko & $\begin{array}{l}\text { 1-D9, 1-F25, 2-E39, } \\
2-\mathrm{F} 38\end{array}$ & $\begin{array}{l}\text { Hitoshi } \\
\text { NAKURA, Jun }\end{array}$ & \\
\hline $\begin{array}{l}\text { NAGATA, Satoru } \\
\text { NAGATA, Shin }\end{array}$ & $\begin{array}{l}2-\mathrm{D} 1 \\
2-\mathrm{F} 17\end{array}$ & $\begin{array}{l}\text { NAMIKAWA, } \\
\text { Chisato }\end{array}$ & $1-\mathrm{E} 17, \mathrm{~S} 3-\mathrm{C} 2$ \\
\hline $\begin{array}{l}\text { NAGATOMO, } \\
\text { Hideki }\end{array}$ & $2-F 30$ & $\begin{array}{l}\text { NAMIKI, Mikio } \\
\text { NANBA, Eiji }\end{array}$ & $\begin{array}{l}\text { 1-D27 } \\
\text { S8-B19 }\end{array}$ \\
\hline NAITO, Etsuo & $2-\mathrm{F} 27$ & NANKO, Shinichiro & 2-E36 \\
\hline $\begin{array}{l}\text { NAKAGAWA, } \\
\text { Masanori }\end{array}$ & $2-\mathrm{F} 23$ & $\begin{array}{l}\text { NARAHARA, Kouji } \\
\text { NARISAWA, K. }\end{array}$ & $\begin{array}{l}\text { 2-D14, 2-D19, 2-D26 } \\
\text { 2-F1 }\end{array}$ \\
\hline $\begin{array}{l}\text { NAKAGAWA, } \\
\text { Yuzuki }\end{array}$ & 1-D5, 1-D12 & $\begin{array}{l}\text { NARISAWA, } \\
\text { Kuniaki }\end{array}$ & $\begin{array}{l}\text { 1-D17, 2-E4, 2-E31, } \\
\text { S8-B21, V1-B13 }\end{array}$ \\
\hline $\begin{array}{l}\text { NAKAGOME, } \\
\text { Yasuo }\end{array}$ & $\begin{array}{l}\text { 1-D25, 1-D26, 1-D27, } \\
2-\mathrm{E} 10\end{array}$ & $\begin{array}{l}\text { NARITA, Naoko } \\
\text { NARITOMI, K. }\end{array}$ & $\begin{array}{l}1-\mathrm{F} 5 \\
\mathrm{~S} 2-\mathrm{B} 3\end{array}$ \\
\hline NAKAHARA, Kouji & $1-\mathrm{E} 2$ & NARITOMI, Kenji & $2-\mathrm{D} 25$ \\
\hline NAKAHORI, & 1-D25, 1-D26, 1-D27, & NEEL, J.V. & $1-\mathrm{F} 19$ \\
\hline Yutaka & 2-E10, S6-C16 & NEMOTO, Yoshiaki & $1-\mathrm{E} 27$ \\
\hline NAKAI, Hiroshi & $2-\mathrm{D} 22$ & NIDA, Yo & $2-F 18$ \\
\hline NAKAI, Hiroyuki & $1-\mathrm{E} 12,1-\mathrm{E} 13$ & NIHO, Yoshiyuki & $1-\mathrm{E} 27$ \\
\hline $\begin{array}{l}\text { NAKAJIMA, } \\
\text { Tamiko }\end{array}$ & $1-\mathrm{F} 22$ & NIIKAWA, Norio & $\begin{array}{l}\text { 1-D } 7,1-\mathrm{D} 9,1-\mathrm{D} 13, \\
1-\mathrm{D} 24,1-\mathrm{D} 30,1-\mathrm{D} 33\end{array}$ \\
\hline $\begin{array}{l}\text { NAKAJIMA, } \\
\text { Yoshiyuki }\end{array}$ & 1-E19 & & $\begin{array}{l}\text { 1-D36, 1-E16, 1-F1, } \\
\text { 1-F12, 1-F33, 2-D24, }\end{array}$ \\
\hline $\begin{array}{l}\text { NAKAMURA, } \\
\text { Hajime }\end{array}$ & $1-\mathrm{F} 5$ & NIIRO, Hiroaki & $\begin{array}{l}2-\mathrm{D} 38,2-\mathrm{F} 39,1-\mathrm{D} 3 \\
1-\mathrm{E} 27\end{array}$ \\
\hline NAKAMURA, Misa & $1-\mathrm{E} 4,1-\mathrm{E} 40$ & NIKAWA, Norio & W1-A9 \\
\hline NAKAMURA, S. & $2-\mathrm{F} 1$ & NINOMIYA, & 1-E2, 2-D14, 2-D19 \\
\hline $\begin{array}{l}\text { NAKAMURA, } \\
\text { Takako }\end{array}$ & $1-F 18$ & $\begin{array}{c}\text { Shinsuke } \\
\text { NINOMIYA, }\end{array}$ & $\mathrm{S} 3-\mathrm{C} 1$ \\
\hline $\begin{array}{l}\text { NAKAMURA, } \\
\text { Takamichi }\end{array}$ & 1-E17 & $\begin{array}{l}\text { Yoshifumi } \\
\text { NISHI, Hirofumi }\end{array}$ & $2-F 37$ \\
\hline $\begin{array}{l}\text { NAKAMURA, } \\
\text { Yusuke }\end{array}$ & $\begin{array}{l}\text { 1-D6, 1-D13, 1-D21, } \\
\text { I-D33, 1-D35, 2-D19, }\end{array}$ & $\begin{array}{l}\text { NISHIDA, } \\
\text { Yoshihiko }\end{array}$ & $2-F 24$ \\
\hline & $\begin{array}{l}\mathrm{A} 12-, \mathrm{W} 1-\mathrm{A} 11, \mathrm{~W} 3- \\
\mathrm{C} 8\end{array}$ & $\begin{array}{l}\text { NISHIKAWA, } \\
\text { Toshiro }\end{array}$ & 2-D18 \\
\hline $\begin{array}{l}\text { NAKANAGA, } \\
\text { Masao }\end{array}$ & $\mathrm{I}-\mathrm{F} 21$ & $\begin{array}{l}\text { NISHIMOTO, } \\
\text { Hiroshi }\end{array}$ & 2-D17 \\
\hline NAKANO, Hajime & 2-E17 & NISHIMUKAI, & $1-E 25$ \\
\hline NAKANO, Keiichiro & $1-E 37$ & Hiroaki & \\
\hline NAKANO, Ryoichi & $2-\mathrm{F} 2$ & NISHIMURA, G. & 2-D4 \\
\hline
\end{tabular}




\begin{tabular}{|c|c|c|c|}
\hline NISHIMURA, Gen & 2-D23, N2-C6 & OHKI, Misao & 1-D18, 1-D19, SI-A4, \\
\hline NISHIMURA, M. & 1-F9 & & S7-A25 \\
\hline \multirow{2}{*}{$\begin{array}{l}\text { NISHIMURA, } \\
\text { Tsutomu }\end{array}$} & \multirow[t]{2}{*}{$2-\mathrm{D} 18$} & OHMURA, Hiroshi & 2-E13 \\
\hline & & OHNO, Ichiro & $2-\mathrm{F} 18$ \\
\hline \multirow{2}{*}{$\begin{array}{l}\text { NISHIMURA, } \\
\text { Yasuharu }\end{array}$} & \multirow{2}{*}{ 1-E30, 1-E31, 1-E39 } & OHNO, K. & $2-\mathrm{F} 22$ \\
\hline & & OHNO, Kousaku & $\mathrm{P} 2-\mathrm{A} 38$ \\
\hline NISHIO, Hisahide & $1-F 5$ & OHNO, M. & $1-\mathrm{F} 9$ \\
\hline \multirow{2}{*}{$\begin{array}{l}\text { NISHIWAKI, } \\
\text { Kunihiko }\end{array}$} & \multirow[t]{2}{*}{$1-\mathrm{F} 33$} & OHSHIMA, Hiroyuki & $1-E 5$ \\
\hline & & OHTA, Masumi & 1-D29, 1-D35 \\
\hline NISHIYORI, Atsushi & $1-F 37,2-E 18$ & OHTA, Tohru & 1-D24,1-E16 \\
\hline \multirow{2}{*}{$\begin{array}{l}\text { NISHIZAWA, } \\
\text { Masatoyo }\end{array}$} & \multirow{2}{*}{$2-\mathrm{F} 4, \mathrm{P} 1-\mathrm{A} 33$} & OHTA, Toru & $1-\mathrm{D} 9,2-\mathrm{F} 39$ \\
\hline & & OHURA, Toshihiro & $2-E 4$ \\
\hline NIWA, T. & $2-E 30$ & OISHI, Hidetsune & $1-\mathrm{D} 32$ \\
\hline NODA, Kazuo & $1-\mathrm{F} 12$ & OKA, Yoshitomo & $1-F 36$ \\
\hline NOGUCHI, Atsuo & $1-\mathrm{E} 29$ & OKABE, Ichiro & $\mathrm{W} 1-\mathrm{A} 10$ \\
\hline NOGUCHI, Shiro & 1-E41 & OKADA, Setsuo & 2-E8 \\
\hline NOGUCHI, Yuichi & $1-\mathrm{E} 19$ & OKADA, Shintaro & $1-F 6,2-D 5$ \\
\hline NOMURA, Kazuo & 2-E17 & OKAMOTO, Etsuji & $1-\mathrm{D} 37,1-\mathrm{F} 32$ \\
\hline NOMURA, Yoshiko & W2-B9 & OKAMOTO, & 2-E3 \\
\hline NONAKA, Ikuya & $2-\mathrm{F} 21$ & Nobuhiko & \\
\hline NONOMURA, Y. & $1-\mathrm{F} 9$ & OKANO, Tetsuroh & $1-D 36$ \\
\hline \multirow{2}{*}{$\begin{array}{l}\text { NONOMURA, } \\
\text { Yasuhiro }\end{array}$} & \multirow{2}{*}{$\begin{array}{l}\text { 2-E32, 2-E34, 2-E35, } \\
\text { 2-E37, 2-E38 }\end{array}$} & OKANO, Yoshiyuki & 2-E22, 2-E29 \\
\hline & & OKAZAKI, Seiji & $2-\mathrm{F} 24$ \\
\hline NORINAGA, Ryoko & $2-\mathrm{D} 1$ & OKUBO, Kousaku & S7-A28 \\
\hline NOSE, Koichiro & $1-\mathrm{D} 28$ & OMINE, Hideo & $1-F 19$ \\
\hline NUNOI, $\mathrm{H}$. & 2-E30 & OMOTO, Keiichi & 1-F18 \\
\hline \multirow{2}{*}{\multicolumn{2}{|c|}{$\mathbf{0}$}} & OMURA, Toshitaka & $2-\mathrm{E} 40$ \\
\hline & & ONISHI, Hideki & 2-E16, 2-F30 \\
\hline OCHI, Junko & $2-\mathrm{D} 27$ & ONO, Keiro & S3-C5 \\
\hline ODA, Yoshihiko & $2-\mathrm{D} 28$ & ONODERA, O. & $1-F 3$ \\
\hline $\begin{array}{l}\text { OGASAWARA, } \\
\text { Hideyuki }\end{array}$ & $1-\mathrm{E} 5$ & ONODERA, Osamu & $\begin{array}{l}\text { 2-D38, 2-E15, 2-F9, } \\
\text { 2-F10 }\end{array}$ \\
\hline OGASAWARA, M. & $2-\mathrm{F} 1$ & OOHASHI, Hirofumi & 2-D3 \\
\hline \multirow{2}{*}{$\begin{array}{l}\text { OGASAWARA, } \\
\text { Mayumi }\end{array}$} & \multirow[t]{2}{*}{$1-\mathrm{E} 17$} & OOMORI, Yasue & $1-E 33$ \\
\hline & & OPITZ, J.M. & L4-A29, P1-A34 \\
\hline $\begin{array}{l}\text { OGASAWARA, } \\
\text { Nobuaki }\end{array}$ & 2-E14, 2-E20 & ORII, Tadao & $\begin{array}{l}\text { 2-E25, 2-E26, 2-E27, } \\
2-\mathrm{F} 11,2-\mathrm{F} 28,2-\mathrm{F} 29\end{array}$ \\
\hline OGAWA, Kiyoshi & $1-\mathrm{D} 36$ & OSAKA, Hitoshi & $2-\mathrm{E} 16,2-\mathrm{F} 30$ \\
\hline OGAWA, Tatsuya & $2-E 25,2-E 27$ & OSAME, Mitsuhiro & $2-F 23$ \\
\hline \multirow[t]{3}{*}{ OGIHARA, Toshio } & 1-D9, 1-E18, 1-F4, & OSASA, Yukinobu & $2-\mathrm{D} 34$ \\
\hline & \multirow{2}{*}{$\begin{array}{l}\text { 1-F25, 2-E39, 2-F38, } \\
2-F 39\end{array}$} & OSAWA, Makiko & $2-\mathrm{F} 15, \mathrm{~W} 4-\mathrm{A} 23$ \\
\hline & & OSHIMA, Akihiro & $2-E 23, P 2-A 36$ \\
\hline OGUCHI, Yoshihisa & $2-\mathrm{F} 31$ & OSHIMURA, Mitsuo & 1-D12, 1-D5, 1-D8, \\
\hline OGUCHI, Hirokazu & 2-D29 & & 1-E7, 2-D37, 2-E13 \\
\hline OGUNI, Miyako & $2-\mathrm{D} 29$ & OTSUKA, Takako & $1-F 1$ \\
\hline $\mathrm{OH}$, Myoung-don & $1-E 37$ & OTSUKA, Takeshi & $1-E 27$ \\
\hline OHAMA, Koso & 1-D37, 1-F32 & OURA, Toshiaki & 2-D34, 2-E29 \\
\hline OHARA, Toshio & $2-\mathrm{D} 22$ & OWADA, Misao & 2-D31 \\
\hline \multirow[t]{2}{*}{ OHASHI, Hirofumi } & \multirow{2}{*}{$\begin{array}{l}\text { 1-D30, 1-D33, 1-D36, } \\
\text { 2-D17 }\end{array}$} & OZAKI, Mamoru & 2-D7 \\
\hline & & OZAWA, Akira & $2-\mathrm{D} 22$ \\
\hline OHASHI, Humihiro & 2-D2 & OZAWA, T. & $2-F 22$ \\
\hline OHIRA, Miki & $1-\mathrm{D} 18$ & OZONO, Keiichi & $2-\mathrm{E} 3$ \\
\hline OHIRA, Miyuki & S7-A25 & & \\
\hline
\end{tabular}




\section{P}

PARK, Myoung Hee 1-E37

PETRIJ, F. 2-D12

$\mathbf{R}$

RICHARDS, R.I. 2-F17

\section{$\mathbf{S}$}

SAGA, Masamichi

SAHASHI, Ko

SAIJO, Kaoru

SAITO, Fumiko

SAITO, Izumu

SAITO, Kayoko

SAITO, Shiro

SAITO, Susumu

SAITO, Toshiuki

SAITO, Kayoko

SAITOU, Naruya

SAKAI, Kosuke

SAKAI, Toshiaki

SAKAKI, Tsukasa

SAKAKI, Yoshiyuki

SAKAMOTO, A.

SAKAMOTO, $\mathrm{H}$.

SAKAMOTO,

Hiromi

SAKAMOTO, Hirosuke

SAKIMURA, Kenji

SAKIYAMA,

Takeshi

SAKIYAMA, Yukio

SAKUMA, Izumi

SAKURABA,

Hitoshi

SAMURA, Osamu

SANO, Akira

SARDE, Claude-

Olivier

SASABE, Yutaka

SASAKI, Hidenao

SASAKI, Hiroshi

SASAKI, Makoto

SASAKI, Sei

SASAZAKI,

Takehiko

SATHO, Masahisa

2-F31
W2-B9
1-D21
1-D14, 1-D18, 1-D19,
1-D21, 1-D34
S4-A14
1-F8, 2-D13, 2-D15,
2-D29, 2-F15
2-F24
1-D35
1-D11
W2-B7
1-F17
1-D22, 2-E12, S7-
A26
2-E34, 2-E35, 2-E37,
2-E38
2-E36
1-D18, 1-D19, 1-E16,
S7-A25
1-F9
2-F5
I-F11
2-F4
2-F2
2-D31
1-D24
1-F8, W2-B7
2-E23
1-D37
2-F8
2-F9, 2-F10
1-F31
2-F6
1-D3
S3-C2
1-D14
S5-B18, 1-E32, 1-
E34, 1-E36, 2-F37
2-D28

\begin{tabular}{|c|c|}
\hline SATO, Chiaki & $1-$ E35 \\
\hline SATO, Koichi & $1-\mathrm{E} 17$ \\
\hline SATO, Shuzo & $2-F^{2}$ \\
\hline SATO, Tamotsu & $2-F 18$ \\
\hline SATOH, Chiyoko & $\begin{array}{l}\text { 1-F19, 1-F20, 2-E5, } \\
2-\mathrm{E} 7\end{array}$ \\
\hline $\mathrm{SATOH}, \mathrm{H}$. & 2-D8 \\
\hline SATOH, W. & $2-\mathrm{F} 13$ \\
\hline SATOH, Y. & 2-D8 \\
\hline SAWADA, Tadashi & $1-E 3,1-E 4$ \\
\hline $\begin{array}{l}\text { SAWAMURA, } \\
\text { Daisuke }\end{array}$ & $2-\mathrm{E} 17$ \\
\hline SEGAWA, Masaya & W2-B9 \\
\hline SEINO, Masakazu & $2-\mathrm{D} 32$ \\
\hline SEINO, Yoshiki & $\begin{array}{l}\text { 1-E2, 2-D14, 2-D19, } \\
\text { 2-D26 }\end{array}$ \\
\hline SEKI, Chinatsu & $2-\mathrm{D} 2$ \\
\hline SEKI, Naohiko & $\begin{array}{l}\text { 1-D11, 1-F16, 2-F16, } \\
\text { 2-F17 }\end{array}$ \\
\hline $\begin{array}{l}\text { SEKIGUCHI, } \\
\text { Mutsuo }\end{array}$ & S1-A5 \\
\hline SEKIYA, Takao & $1-E 14$ \\
\hline SEKIZAWA, Koichi & $2-F 16$ \\
\hline SERIU, Taku & $1-\mathrm{E} 13$ \\
\hline $\begin{array}{c}\text { SERIZAWA, } \\
\text { Masahiro }\end{array}$ & $2-\mathrm{E} 21$ \\
\hline SHIBATA, Akira & $2-\mathrm{E} 15$ \\
\hline SHIBATA, Yoichi & 1-E33, 2-E36 \\
\hline SHIBUYA, Atsushi & $1-$ E35 \\
\hline $\begin{array}{l}\text { SHIGEMATSU, } \\
\text { Hideo }\end{array}$ & 2-D32 \\
\hline $\begin{array}{l}\text { SHIKISHIMA, } \\
\text { Yasushi }\end{array}$ & $1-\mathrm{D} 28$ \\
\hline $\begin{array}{l}\text { SHIMADA, } \\
\text { Kazunori }\end{array}$ & $\mathrm{V} 2-\mathrm{C} 14$ \\
\hline SHIMADA, Noriko & $2-\mathrm{F} 3$ \\
\hline SHIMADA, Takashi & S4-A13 \\
\hline SHIMADA, Tsutomu & $1-\mathrm{D} 10$ \\
\hline SHIMAKURA, Yae & 1-E21, 1-E23, 1-E24 \\
\hline SHIMAZAKI, H. & $2-\mathrm{F} 5$ \\
\hline SHIMIZU, Hisashi & 2-D31 \\
\hline SHIMIZU, Kiichi & $1-\mathrm{D} 28$ \\
\hline SHIMIZU, Koji & $1-\mathrm{F} 18$ \\
\hline SHIMIZU, Motoyuki & $1-\mathrm{D} 12$ \\
\hline SHIMIZU, N. & $2-\mathrm{F} 13$ \\
\hline $\begin{array}{l}\text { SHIMIZU, } \\
\text { Nobuyoshi }\end{array}$ & $\begin{array}{l}\text { 1-D1, 1-D4, 1-D20, } \\
\text { 1-D22, 1-E28, 2-E12, } \\
\text { 2-F31, S7-A24, S7- } \\
\text { A26 }\end{array}$ \\
\hline SHIMIZU, Takako & $2-\mathrm{E} 21$ \\
\hline SHIMIZU, Toshiaki & 2-D1 \\
\hline $\begin{array}{l}\text { SHIMOZAWA, } \\
\text { Nobuyuki }\end{array}$ & AW2-A19, V1-B12 \\
\hline SHINDO, Hideki & $1-\mathrm{E} 1$ \\
\hline
\end{tabular}




\begin{tabular}{|c|c|}
\hline $\begin{array}{l}\text { SHINOHARA, } \\
\text { Tamiko }\end{array}$ & $1-\mathrm{D} 29, \mathrm{I}-\mathrm{F} 13$ \\
\hline $\begin{array}{l}\text { SHINOZAKI, } \\
\text { Shinichi }\end{array}$ & $1-\mathrm{F} 27,2-\mathrm{F} 40$ \\
\hline SHINTANI, Naohisa & $2-\mathrm{F} 18$ \\
\hline $\begin{array}{l}\text { SHIRAISHI, } \\
\text { Kazuhiro }\end{array}$ & 2-D27 \\
\hline SHIRAISHI, Tetsuya & $\mathrm{P} 2-\mathrm{A} 37$ \\
\hline SHIRASAWA, Senji & S5-B18 \\
\hline $\begin{array}{l}\text { SHISHIKURA, } \\
\text { Akihiro }\end{array}$ & 1-D19 \\
\hline $\begin{array}{l}\text { SHISHIKURA, } \\
\text { Keiko }\end{array}$ & 2-D13 \\
\hline SIEGFRIED, J.M. & $1-\mathrm{E} 6$ \\
\hline $\begin{array}{l}\text { SIMOZAWA } \\
\text { Nobuyuki }\end{array}$ & $2-F 11$ \\
\hline SMITH, Moyra & $2-F 40$ \\
\hline SOBUE, Gen & $2-\mathrm{F} 3$ \\
\hline SOEDA, Eiichi & $1-\mathrm{D} 20,1-\mathrm{E} 28$ \\
\hline SOEJIMA, Hidenobu & $\begin{array}{l}1-\mathrm{D} 3,1-\mathrm{D} 7,1-\mathrm{D} 13 \\
1-\mathrm{D} 24\end{array}$ \\
\hline SOEJIMA, Nobuyuki & $2-\mathrm{D} 38$ \\
\hline SOHDA, Satoshi & $1-\mathrm{F} 14$ \\
\hline SONODA, Takahiko & $1-\mathrm{E} 8$ \\
\hline SONTA, Shin-ichi & 2-D10, V2-C12 \\
\hline $\begin{array}{l}\text { SOTOZONO, } \\
\text { Yasuhiro }\end{array}$ & $\begin{array}{l}1-\mathrm{E} 1,1-\mathrm{E} 3,1-\mathrm{E} 4 \\
1-\mathrm{E} 40\end{array}$ \\
\hline SOU, Kousen & 2-F29 \\
\hline SOU, Kouzen & 2-F11,2-F28 \\
\hline SOUTOME, M. & 2-F5 \\
\hline SUBOG, Lee & $1-\mathrm{F} 18$ \\
\hline SUDO, Tohru & $1-\mathrm{E} 32$ \\
\hline $\begin{array}{l}\text { SUGAHARA, } \\
\text { Yoshie }\end{array}$ & $1-\mathrm{F} 11$ \\
\hline SUGIMOTO, Tohru & $1-\mathrm{E} 3,1-\mathrm{E} 4$ \\
\hline SUGIO, Yoshitsugu & $2-\mathrm{D} 20$ \\
\hline $\begin{array}{l}\text { SUKEGAWA, } \\
\text { Kazuko }\end{array}$ & $2-\mathrm{E} 26$ \\
\hline $\begin{array}{l}\text { SUMINAMI, } \\
\text { Yoshinori }\end{array}$ & 2-D40 \\
\hline SUOH, Hiroshi & W2-B9 \\
\hline $\begin{array}{l}\text { SUTHERLAND, G. } \\
\quad \text { R. }\end{array}$ & $2-\mathrm{F} 17$ \\
\hline SUTO, Yumiko & $1-\mathrm{D} 29,1-\mathrm{D} 35$ \\
\hline SUYAMA, Itujin & $2-\mathrm{E} 22$ \\
\hline SUZUKI, Haruko & 2-D13, 2-F15 \\
\hline SUZUKI, Juli & $1-\mathrm{D} 18$ \\
\hline SUZUKI, Keiko & 2-D13 \\
\hline SUZUKI, Koichi & $1-F 23$ \\
\hline SUZUKI, Kyoko & $2-\mathrm{E} 16$ \\
\hline SUZUKI, Mikio & $1-\mathrm{D} 5$ \\
\hline SUZUKI, Muneou & 1-E15,2-F35 \\
\hline SUZUKI, Noriyuki & $1-\mathrm{D} 5,1-\mathrm{D} 8$ \\
\hline SUZUKI, Tomokazu & $1-\mathrm{E} 41$ \\
\hline
\end{tabular}

\begin{tabular}{|c|c|}
\hline SUZUKI, Yasuhiko & $1-\mathrm{D} 10$ \\
\hline SUZUKI, Yasuyuki & $2-\mathrm{F} 11$ \\
\hline SUZUKI, Yoichi & 1-D17, 2-E31 \\
\hline SUZUKI, Yoshiyuki & $2-\mathrm{E} 23$ \\
\hline SUZUMORI, Kaoru & $\begin{array}{l}\text { 1-D32, 1-E17, 2-E8, } \\
2-\mathrm{F} 17, \mathrm{~S} 3-\mathrm{C} 2\end{array}$ \\
\hline SUZUMORI, Kenji & 2-E8 \\
\hline \multicolumn{2}{|l|}{$\mathbf{T}$} \\
\hline TABATA, Yoshiko & $1-\mathrm{E} 18$ \\
\hline TABE, Hiroyuki & $2-\mathrm{F} 9,2-\mathrm{F} 10$ \\
\hline TADA, Keiya & $2-\mathrm{E} 4$ \\
\hline TADOKORO, Keiko & $1-\mathrm{D} 39,2-\mathrm{F} 8$ \\
\hline TADOKORO, Kenji & $1-\mathrm{E} 29$ \\
\hline TAGUCHI, Takahiro & $1-\mathrm{E} 6$ \\
\hline TAKADA, Fumio & $1-\mathrm{E} 26$ \\
\hline TAKADA, G. & $2-\mathrm{F} 13$ \\
\hline $\begin{array}{l}\text { TAKAHASHI, } \\
\text { Ei-ichi }\end{array}$ & W3-C8 \\
\hline $\begin{array}{l}\text { TAKAHASHI, } \\
\text { Hiroaki }\end{array}$ & $2-\mathrm{D} 7$ \\
\hline $\begin{array}{l}\text { TAKAHASHI, } \\
\text { Hitoshi }\end{array}$ & $2-\mathrm{F} 2$ \\
\hline TAKAHASHI, Ichiro & 2-D35 \\
\hline $\begin{array}{l}\text { TAKAHASHI, } \\
\text { Katsushi }\end{array}$ & $1-\mathrm{E} 30,1-\mathrm{E} 31$ \\
\hline $\begin{array}{l}\text { TAKAHASHI, } \\
\text { Kazutoshi }\end{array}$ & S8-B21 \\
\hline $\begin{array}{l}\text { TAKAHASHI, } \\
\text { Keiko }\end{array}$ & 2-DII \\
\hline $\begin{array}{l}\text { TAKAHASHI, } \\
\text { Kiyoshi }\end{array}$ & $\mathrm{V} 2-\mathrm{Cl} 14$ \\
\hline $\begin{array}{c}\text { TAKAHASHI, } \\
\text { Mamoru }\end{array}$ & 2-D18 \\
\hline TAKAHASHI, Mie & $2-F 8$ \\
\hline TAKAHASHI, Norio & $1-F 19,1-F 20$ \\
\hline TAKAHASHI, Rei & $1-\mathrm{E} 1$ \\
\hline $\begin{array}{l}\text { TAKAHASHI, } \\
\text { Ryosuke }\end{array}$ & 2-D41 \\
\hline $\begin{array}{c}\text { TAKAHASHI, } \\
\text { Yoshitomo }\end{array}$ & $2-\mathrm{E} 21$ \\
\hline $\begin{array}{l}\text { TAKAHASHI, } \\
\text { Yukitoshi }\end{array}$ & 2-D32 \\
\hline $\begin{array}{l}\text { TAKAHATA, } \\
\text { Naoyuki }\end{array}$ & $\mathrm{S} 1-\mathrm{A} 3$ \\
\hline $\begin{array}{l}\text { TAKAHATA, } \\
\text { Ryuichi }\end{array}$ & 2-E35, 2-E37 \\
\hline TAKAI, Setsuo & $1-\mathrm{D} 23,2-\mathrm{D} 36$ \\
\hline $\begin{array}{l}\text { TAKAKU, } \\
\text { Fumimaro }\end{array}$ & S4-A17 \\
\hline TAKANO, Shinichi & $1-E 5$ \\
\hline TAKANO, Takako & $1-\mathrm{D} 25,1-\mathrm{D} 26,1-\mathrm{E} 20$ \\
\hline TAKANO, Toshiya & $1-\mathrm{F} 7$ \\
\hline TAKATA, Mizuho & $1-\mathrm{D} 4$ \\
\hline
\end{tabular}




\begin{tabular}{|c|c|}
\hline $\begin{array}{c}\text { TAKAYAMA, } \\
\text { Yoshinaga }\end{array}$ & $1-E 26$ \\
\hline TAKEDA, Misako & 2-F34 \\
\hline TAKEDA, Shin'ichi & $\mathrm{W} 2-\mathrm{B} 10$ \\
\hline TAKEDA, Takayuki & $1-D 2$ \\
\hline $\begin{array}{l}\text { TAKENAKA, } \\
\text { Tsunehisa }\end{array}$ & 2-D33 \\
\hline $\begin{array}{l}\text { TAKESHIMA, } \\
\text { Yasuhiro }\end{array}$ & $1 \sim \mathrm{F} 5$ \\
\hline TAKESHITA, Haruo & $1-\mathrm{F} 21$ \\
\hline TAKESHITA, Naoki & $1-\mathrm{F} 31$ \\
\hline $\begin{array}{l}\text { TAKESHITA, } \\
\text { Tsutao }\end{array}$ & $1-\mathrm{E} 34$ \\
\hline TAKEUCHI, Fujio & $1-\mathrm{E} 37$ \\
\hline $\begin{array}{l}\text { TAKIGUCHI, } \\
\text { Masaki }\end{array}$ & 1-F37 \\
\hline TAKITA, Hitoshi & $1-\mathrm{E} 24$ \\
\hline TAKIYAMA, Y. & $2-\mathrm{F} 5$ \\
\hline $\begin{array}{l}\text { TAKIYAMA, } \\
\text { Yoshihisa }\end{array}$ & $2-\mathrm{F} 4$ \\
\hline TAKIZAWA, Yukio & 2-E40 \\
\hline TAMAKI, Yoshihiro & $\mathrm{S} 9-\mathrm{C} 20$ \\
\hline TAMURA, Kohji & $1-\mathrm{E} 17$ \\
\hline TAMURA, Shozo & $2-\mathrm{E} 14$ \\
\hline TAMURA, Toshiya & $\begin{array}{l}\text { 1-D7, 1-D13,1-D24, } \\
1-F 1\end{array}$ \\
\hline $\begin{array}{l}\text { TANAHASHI, } \\
\text { Hiroshi }\end{array}$ & $\begin{array}{l}\text { 1-D } 18,1-\mathrm{D} 19, \mathrm{~S} 7- \\
\mathrm{A} 25\end{array}$ \\
\hline TANAKA, Akemi & 2-E24 \\
\hline TANAKA, H. & $2-\mathrm{F} 5$ \\
\hline TANAKA, Hajime & $\begin{array}{l}\text { 2-D38, 2-E15, 2-F4, } \\
\text { 2-F26, W1-A8 }\end{array}$ \\
\hline TANAKA, Junko & $1-\mathrm{F} 6$ \\
\hline TANAKA, Karo & 1-D26, 1-D27 \\
\hline TANAKA, Kay & 2-E28 \\
\hline TANAKA, Keiko & $2-F 26$ \\
\hline TANAKA, M. & $2-\mathrm{F} 22$ \\
\hline TANAKA, Yuji & $2-\mathrm{F} 8$ \\
\hline $\begin{array}{l}\text { TANEMURA, } \\
\text { Mitsuyo }\end{array}$ & 2-E8 \\
\hline TANI, Ei-ichi & $1-\mathrm{E} 1$ \\
\hline $\begin{array}{l}\text { TANIGUCHI, } \\
\text { Noboru }\end{array}$ & $2-\mathrm{F} 18$ \\
\hline TANIKAWA, Koji & $2-\mathrm{D} 27$ \\
\hline $\begin{array}{l}\text { TANIMURA, } \\
\text { Masako }\end{array}$ & $1-\mathrm{D} 40$ \\
\hline $\begin{array}{l}\text { TANIWAKI, } \\
\text { Masafumi }\end{array}$ & $1-\mathrm{E} 12, \mathrm{~W} 3-\mathrm{C} 10$ \\
\hline $\begin{array}{c}\text { TANIYAMA, } \\
\text { Tadayoshi }\end{array}$ & $1-\mathrm{D} 23$ \\
\hline TANNO, Yoshinori & $2-F 26$ \\
\hline TANUMA, Reiko & 2-D35 \\
\hline TASHIRO, Fumi & $1-\mathrm{F} 35,1-\mathrm{F} 36$ \\
\hline TASHIRO, Kousuke & $\mathrm{S} 7-\mathrm{A} 25$ \\
\hline
\end{tabular}

\begin{tabular}{|c|c|}
\hline TASHIRO, Kunio & $2-\mathrm{F} 6$ \\
\hline TATEISHI, Jun & 2-F12, P1-A32 \\
\hline TATENO, Hiroyuki & $1-\mathrm{D} 31$ \\
\hline TATSUMI, Keita & $2-\mathrm{E} 3$ \\
\hline TATSUZAWA, S. & 2-E30 \\
\hline TABUCHI, Kazuo & $\mathrm{P} 2-\mathrm{A} 37$ \\
\hline TERAI, Chihiro & $1-F 26$ \\
\hline TESTA, J.R. & $1-\mathrm{E} 6$ \\
\hline TODA, Tatsushi & Al2- \\
\hline TOHMA, Takaya & $2-\mathrm{D} 25$ \\
\hline TOKINO, Takashi & $1-\mathrm{D} 13$ \\
\hline $\begin{array}{l}\text { TOKUNAGA, } \\
\text { Katsushi }\end{array}$ & $\begin{array}{l}1-\mathrm{E} 20,1-\mathrm{E} 25,1-\mathrm{E} 29 \\
1-\mathrm{B} 33,1-\mathrm{E} 35,1-\mathrm{E} 37\end{array}$ \\
\hline $\begin{array}{l}\text { TOKUNAGA, } \\
\text { Yasuyuki }\end{array}$ & 2-E18 \\
\hline TOMATSU, Shunji & $\begin{array}{l}\text { 2-E25, 2-E26, 2-E27, } \\
2-\mathrm{F} 11\end{array}$ \\
\hline TOMIWA, Kiyotaka & $2-\mathrm{D} 27$ \\
\hline TOSHIMA, Hironori & $2-\mathrm{F} 37$ \\
\hline TOYAMA, Takanori & $1-\mathrm{E} 15$ \\
\hline TOYO-OKA, T. & $1-F 9$ \\
\hline $\begin{array}{l}\text { TSUBOUCHI, } \\
\text { Hirohito }\end{array}$ & $1-\mathrm{E} 15,2-\mathrm{F} 35$ \\
\hline TSUCHIYA, Shigeru & $1-\mathrm{E} 20,1-\mathrm{E} 21$ \\
\hline TSUDA, Masahiko & 2-D31 \\
\hline TSUJI, Kazushiro & $1-\mathrm{E} 2,2-\mathrm{D} 19,2-\mathrm{D} 26$ \\
\hline TSUJI, $\mathbf{S}$ & $1-\mathrm{F} 3,2-\mathrm{F} 5$ \\
\hline TSUJI, Shoji & $\begin{array}{l}\text { 1-D3, 2-D38, 2-F2, } \\
2-\mathrm{F} 4,2-\mathrm{F} 26, \mathrm{~W} 1-\mathrm{A} 8\end{array}$ \\
\hline TSUJI, Shouji & 2-E15 \\
\hline TSUJI, Syoji & 2-F9 \\
\hline TSUJIMOTO, G. & $1-\mathrm{F} 9$ \\
\hline $\begin{array}{l}\text { TSUJIMOTO, } \\
\text { Susumu }\end{array}$ & 1-D20 \\
\hline $\begin{array}{l}\text { TSUKAHARA, } \\
\text { Masato }\end{array}$ & 2-D20, 2-D21 \\
\hline $\begin{array}{l}\text { TSUKAHARA, } \\
\text { Toshifumi }\end{array}$ & $\mathrm{W} 2-\mathrm{B} 10$ \\
\hline $\begin{array}{l}\text { TSUKAMOTO, } \\
\text { Hiroko }\end{array}$ & $1-\mathrm{F} 6,2-\mathrm{D} 5$ \\
\hline TSUKITA, Shoichiro & $1-\mathrm{D} 24$ \\
\hline TSUMAKI, Noriyuki & $\mathrm{S} 3-\mathrm{C} 5$ \\
\hline $\begin{array}{l}\text { TSUNEKAWA, } \\
\text { Bunkichi }\end{array}$ & $1-\mathrm{D} 26$ \\
\hline $\begin{array}{l}\text { TSUNEMATSU, } \\
\text { Yukiko }\end{array}$ & S5-B14 \\
\hline $\begin{array}{l}\text { TSUNEYAMA, } \\
\text { Hatsue }\end{array}$ & $1-\mathrm{E} 35$ \\
\hline TSUNODA, Shoko & 2-D13 \\
\hline $\begin{array}{l}\text { TSURUHARA, } \\
\text { Tuneo }\end{array}$ & 2-D34 \\
\hline TSURUTA, S. & 2-E30 \\
\hline TSUZUKI, Teruhisa & $\mathrm{S} 1-\mathrm{A} 5$ \\
\hline
\end{tabular}


U

\begin{tabular}{|c|c|}
\hline UCHIDA, Atsuko & $1-\mathrm{F} 23$ \\
\hline $\begin{array}{l}\text { UCHIGATA, } \\
\text { Yasuko }\end{array}$ & $1-E 33$ \\
\hline $\begin{array}{l}\text { UCHIKAWA, } \\
\text { Makoto }\end{array}$ & $1-\mathrm{E} 35$ \\
\hline $\begin{array}{l}\text { UCHIYAMA, } \\
\text { Atsushi }\end{array}$ & $\begin{array}{l}2-\mathrm{E} 25,2-\mathrm{E} 26,2-\mathrm{E} 27, \\
2-\mathrm{F} 11\end{array}$ \\
\hline UEDA, Shoichi & $1-\mathrm{E} 5$ \\
\hline UEDA, Yutaka & 1-E12, 1-E13 \\
\hline UEHARA, Shigeki & $1-\mathrm{D} 32$ \\
\hline UEJIMA, Hiroshi & 1-D5, 1-E7, 2-D37 \\
\hline UMEKI, Kaoru & $2-\mathrm{E} 17$ \\
\hline $\begin{array}{l}\text { UMENISHI, } \\
\text { Fuminori }\end{array}$ & 2-E1, 2-E11 \\
\hline UMEZU, Ryoji & $2-\mathrm{D} 13$ \\
\hline UMII, Hideyuki & 2-D11 \\
\hline UNO, Hisamitsu & 1-E15, 2-F35 \\
\hline URANO, Haruyoshi & $1-\mathrm{F} 13$ \\
\hline USHIO, Yukitaka & $1-F 38$ \\
\hline USUI, Norihisa & 2-D2 \\
\hline $\begin{array}{c}\text { UYEMURA, } \mathrm{K} . \\
\text { W }\end{array}$ & $2-F 13$ \\
\hline WADA, Yoshinao & $2-E 3$ \\
\hline $\begin{array}{l}\text { WAGATSUMA, } \\
\text { Takashi }\end{array}$ & $1 F-F 10$ \\
\hline WAKASUGI, Shoji & $1-F 38$ \\
\hline $\begin{array}{l}\text { WAKAZONO, } \\
\text { Akihiro }\end{array}$ & 2-F28, 2-F29 \\
\hline WAKISAKA, Akemi & $2-F 6$ \\
\hline WAKUI, Keiko & $\begin{array}{l}\text { 1-D30, 1-D33, 1-D36, } \\
2-\mathrm{D} 17\end{array}$ \\
\hline WALTER, Michael & $2-\mathrm{D} 38$ \\
\hline WANG, Yimin & $\begin{array}{l}\text { 1-D4, 1-D20, 1-D22, } \\
2-\mathrm{E} 12, \mathrm{~S} 7-\mathrm{A} 26\end{array}$ \\
\hline WATAHIKI, Akira & $1-F 18$ \\
\hline $\begin{array}{l}\text { WATANABE, } \\
\text { Chiaki }\end{array}$ & 2-D31 \\
\hline $\begin{array}{l}\text { WATANABE, } \\
\text { Hideki }\end{array}$ & 2-D10 \\
\hline WATANABE, $T$. & 2-D8 \\
\hline $\begin{array}{l}\text { WATANABE, } \\
\text { Yoriko }\end{array}$ & $1-\mathrm{E} 16$ \\
\hline $\begin{array}{l}\text { WATANABE, } \\
\text { Yoshihisa }\end{array}$ & $1-\mathrm{E} 25$ \\
\hline $\begin{array}{l}\text { WATANABE, } \\
\text { Youko }\end{array}$ & 2-D18 \\
\hline $\begin{array}{c}\text { WERTELECKI, W. } \\
\mathbf{Y}\end{array}$ & $\mathrm{S} 2-\mathrm{B} 2$ \\
\hline $\begin{array}{l}\text { YABUTA, Keijiro } \\
\text { YAGAMI, } \mathrm{K} \text {. }\end{array}$ & $\begin{array}{l}2-\mathrm{D} 1 \\
1-\mathrm{Fg}\end{array}$ \\
\hline
\end{tabular}

\begin{tabular}{|c|c|}
\hline YAGAMI, Yoshiaki & 2-E8 \\
\hline YAGI, Kazuichi & 2-D32 \\
\hline YAGI, Shinichi & 2-D14 \\
\hline YAMADA, Hirofumi & $1-E 37$ \\
\hline YAMADA, Hirohisa & $2-F 23$ \\
\hline YAMADA, Kiyomi & $\begin{array}{l}\text { 1-D23, 1F-F10,2- } \\
\text { D36 }\end{array}$ \\
\hline YAMADA, Masao & $1-\mathrm{D} 2,1-\mathrm{D} 39,2-\mathrm{F} 8$ \\
\hline $\begin{array}{l}\text { YAMADA, } \\
\text { Yasukazu }\end{array}$ & 2-E14, 2-E20 \\
\hline $\begin{array}{l}\text { YAMADA, } \\
\text { Yoshihiro }\end{array}$ & $\mathrm{S} 9-\mathrm{C} 22$ \\
\hline $\begin{array}{l}\text { YAMADA, } \\
\text { Yoshiteru }\end{array}$ & $2-\mathrm{E} 16,2-\mathrm{F} 30$ \\
\hline $\begin{array}{l}\text { YAMAGATA, } \\
\text { Hidehisa }\end{array}$ & $1-F 4$ \\
\hline YAMAGATA, N. & $1-F^{3}$ \\
\hline $\begin{array}{l}\text { YAMAGATA, } \\
\text { Zentaro }\end{array}$ & $1-\mathrm{F} 27,2-\mathrm{F} 40$ \\
\hline YAMAGISHI, Akira & 2-D17 \\
\hline $\begin{array}{l}\text { YAMAGISHI, } \\
\text { Atsushi }\end{array}$ & 2-E25, 2-E27 \\
\hline $\begin{array}{l}\text { YAMAGISHI, } \\
\text { Fuminori }\end{array}$ & $1-\mathrm{D} 15$ \\
\hline $\begin{array}{l}\text { YAMAGISHI, } \\
\text { Hiroyuki }\end{array}$ & $1-\mathbf{F} 7$ \\
\hline $\begin{array}{l}\text { YAMAGUCHI, } \\
\text { Masatake }\end{array}$ & $1-\mathrm{F} 16$ \\
\hline YAMAGUCHI, Seiji & $2-\mathrm{E} 28,2-\mathrm{F} 28,2-\mathrm{F} 29$ \\
\hline YAMAIRI, Takashi & 2-D34 \\
\hline $\begin{array}{l}\text { YAMAKAWA- } \\
\text { KOBAYASHI, } \\
\text { Kimiko }\end{array}$ & $1-\mathrm{E} 22$ \\
\hline $\begin{array}{l}\text { YAMAKAWA, } \\
\text { Kazuhiro }\end{array}$ & 1-D6 \\
\hline $\begin{array}{l}\text { YAMAMOTO, } \\
\text { Fumiichiro }\end{array}$ & $1-\mathrm{F} 17$ \\
\hline YAMAMOTO, $\mathrm{H}$. & $2-F 22$ \\
\hline YАMAMOTO, Ken & $1-E 34$ \\
\hline YAMAMOTO, Koji & $2-F 3$ \\
\hline $\begin{array}{l}\text { YAMAMURA, } \\
\text { Ken-ichi }\end{array}$ & $\begin{array}{l}\text { 1-F34, 1-F35, 1-F37 } \\
1-\mathrm{F} 38, \mathrm{~V} 2-\mathrm{C} 13, \mathrm{~V} 2- \\
\mathrm{C} 14\end{array}$ \\
\hline $\begin{array}{l}\text { YAMANAKA, } \\
\text { Hisashi }\end{array}$ & $1-\mathrm{F} 26$ \\
\hline $\begin{array}{l}\text { YAMANAKA, } \\
\text { Naoki }\end{array}$ & $1-\mathrm{F} 4$ \\
\hline $\begin{array}{l}\text { YAMANAKA, } \\
\text { Tsutomu }\end{array}$ & $1-\mathrm{D} 32,2-\mathrm{D} 10$ \\
\hline YAMANE, Kazuaki & $1-E 34$ \\
\hline $\begin{array}{l}\text { YAMANOUCHI, } \\
\text { Yasuko }\end{array}$ & 1-D25, 1-E20 \\
\hline $\begin{array}{l}\text { YAMASAKI, } \\
\text { Toshiko }\end{array}$ & 2 \\
\hline
\end{tabular}




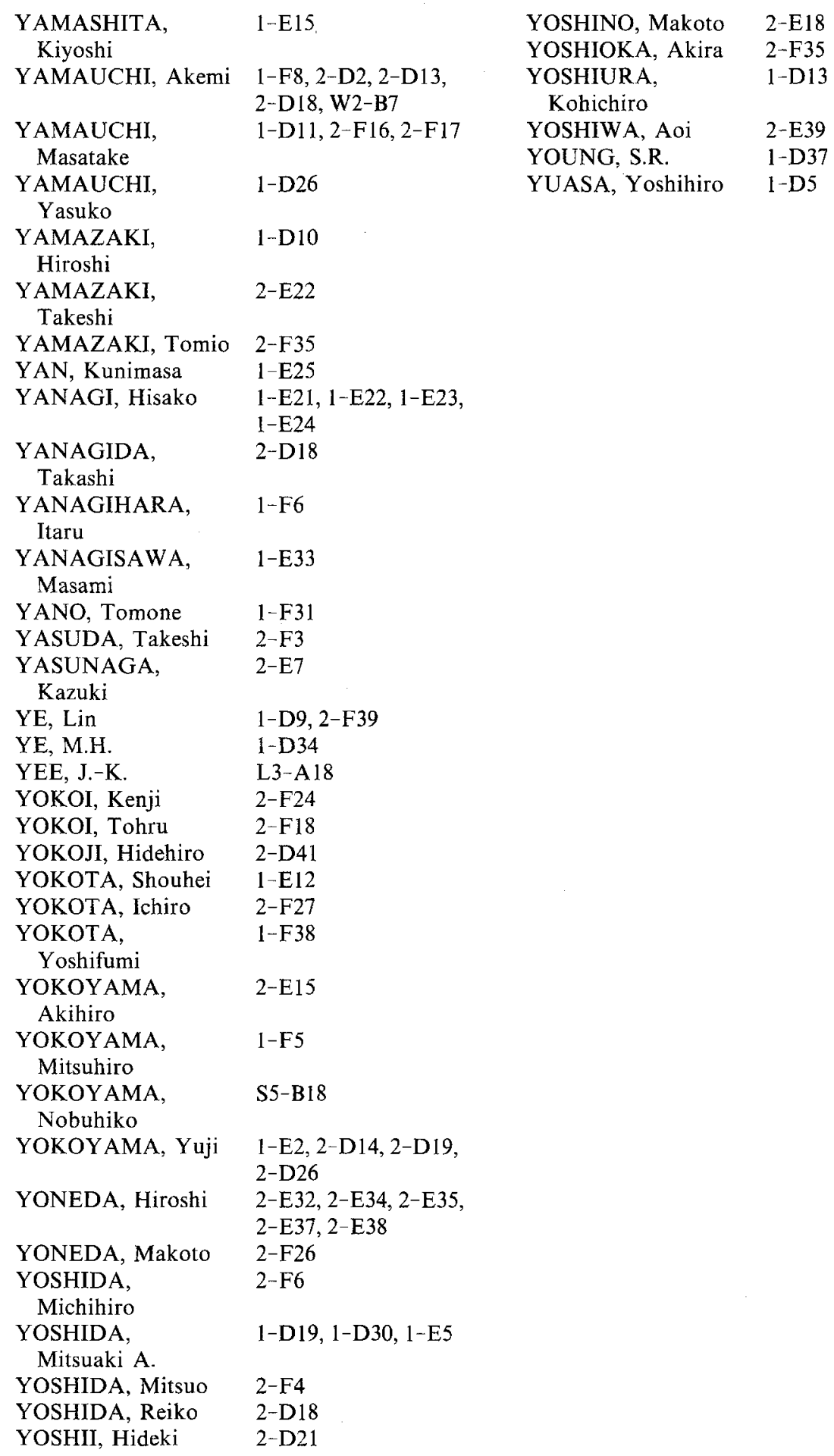




\section{SUBJECT INDEX}

\section{A}

\begin{tabular}{|c|c|}
\hline Aarskog syndrome & $2-\mathrm{D} 21$ \\
\hline $\mathrm{ABO}$ & $1-\mathrm{F} 17,1-\mathrm{F} 22$ \\
\hline A-bomb radiation & 2-E5 \\
\hline ACE & $1-E 18$ \\
\hline $\begin{array}{l}\text { acentric marker } \\
\text { chromosome }\end{array}$ & $1-\mathrm{D} 36$ \\
\hline acrocentric & $2-\mathrm{E} 12$ \\
\hline $\begin{array}{l}\text { acyl-CoA dehydro- } \\
\text { genase }\end{array}$ & $2-E 28$ \\
\hline adenovirus & S4-Al6 \\
\hline adenovirus vector & S4-A14 \\
\hline $\begin{array}{l}\text { adrenoleukodystro- } \\
\text { phy }\end{array}$ & $\begin{array}{l}2-\mathrm{F} 9,2-\mathrm{F} 10,2-\mathrm{F} 11, \\
\mathrm{~V} 1-\mathrm{B} 12\end{array}$ \\
\hline alcoholism & $2-E 32$ \\
\hline ALD & $2-F 9$ \\
\hline ALDP gene & $2-\mathrm{F} 10$ \\
\hline allergy & $1-$ E39 \\
\hline Alport syndrome & $\mathrm{S} 3-\mathrm{C} 4$ \\
\hline alternative splicing & $\begin{array}{l}\text { 1-E4, 1-E13, 1-E40, } \\
1-\mathrm{F} 38,2-\mathrm{E} 11\end{array}$ \\
\hline Alzheimer's disease & 2-E38, 2-E39 \\
\hline amelogenin & $1-\mathrm{D} 26$ \\
\hline aminocentesis & $1-\mathrm{F} 11$ \\
\hline Amish & $2-\mathrm{E} 19$ \\
\hline AML1-MTG8 & $\mathrm{S} 1-\mathrm{A} 4$ \\
\hline amniocentesis & $1-\mathrm{F} 13$ \\
\hline AMP deaminase & $2-\mathrm{E} 20$ \\
\hline $\begin{array}{l}\text { amyotrophic lateral } \\
\text { sclerosis }\end{array}$ & $2-\mathrm{F} 1$ \\
\hline analysis & S9-C21 \\
\hline ancestral event & $1-F 4$ \\
\hline $\begin{array}{l}\text { androgen receptor } \\
\text { gene }\end{array}$ & $2-\mathrm{F} 3$ \\
\hline androgenesis & 2-E8 \\
\hline anencephaly & P1-A34 \\
\hline aneuploidy & $1-\mathrm{D} 29$ \\
\hline angiotensinogen & $1-\mathrm{E} 17$ \\
\hline animal model & P2-A38 \\
\hline anti-sense & $1-F 36$ \\
\hline antigen presentation & 1-E30, 1-E39 \\
\hline $\begin{array}{l}\text { antigen-presenting } \\
\text { cell }\end{array}$ & S4-A15 \\
\hline $\begin{array}{l}\text { antisense } \\
\text { oligonucleotide }\end{array}$ & S5-B16 \\
\hline$A P C$ & $\mathrm{~S} 15-\mathrm{B} 17$ \\
\hline APO-C-II gene & 2-E38 \\
\hline apolipoprotein A-I & $1-\mathrm{E} 21$ \\
\hline apolipoprotein E & $1-\mathrm{E} 20$ \\
\hline apolipoprotein(a) & $1-$ E19 \\
\hline
\end{tabular}

\begin{tabular}{|c|c|}
\hline APP gene & $2-E 37$ \\
\hline APRT & $2-\mathrm{E} 9$ \\
\hline association & 2-E38 \\
\hline association study & 2-E32, 2-E34, 2-E35 \\
\hline ATL & $1-\mathrm{E} 15$ \\
\hline ATR-X syndrome & $2-\mathrm{D} 26$ \\
\hline $\begin{array}{l}\text { autosomal dominant } \\
\text { inheritance }\end{array}$ & $2-\mathrm{D} 20$ \\
\hline azoospermia & $1-\mathrm{D} 27$ \\
\hline \multicolumn{2}{|l|}{ B } \\
\hline $\begin{array}{l}\text { B/A4 amyloid } \\
\text { precursor protein } \\
\text { (APP) }\end{array}$ & $1-\mathrm{F} 25$ \\
\hline balanced carrier & $1-\mathrm{D} 32$ \\
\hline $\begin{array}{l}\text { balanced rearrange- } \\
\text { ments }\end{array}$ & $1-D 33$ \\
\hline Bayesian calculation & $1-\mathrm{F} 8$ \\
\hline $\begin{array}{l}\text { BDNF(brain derived } \\
\text { neurotrophic } \\
\text { factor) }\end{array}$ & $2-E 36$ \\
\hline Beals syndrome & $2-\mathrm{D} 4$ \\
\hline behavior & 2-D27 \\
\hline behavioral genetics & N1-B6 \\
\hline bioethics & W4-, W4-A23 \\
\hline biotin & 2-E31 \\
\hline $\begin{array}{l}\text { bipolar affective } \\
\text { disorder }\end{array}$ & 2-E34 \\
\hline $\begin{array}{l}\text { birth defects } \\
\text { monitoring }\end{array}$ & $1-\mathrm{F} 30$ \\
\hline bladder carcinoma & $1-\mathrm{E} 1$ \\
\hline body mapping & S7-A28 \\
\hline bone dysplasia & $\mathrm{N} 2-\mathrm{C} 6$ \\
\hline $\begin{array}{l}\text { branched chain keto } \\
\text { acid }\end{array}$ & S8-B22 \\
\hline breast cancer & WI-AII \\
\hline$b s r$ & $2-\mathrm{D} 37$ \\
\hline \multicolumn{2}{|l|}{ C } \\
\hline$c-\operatorname{erb} A \beta$ & $\mid-E 41$ \\
\hline$c-f o s$ & $2-E 39$ \\
\hline $\mathrm{C} 3$ & $1-E 25$ \\
\hline $\mathrm{C} 4$ & $1-E 35$ \\
\hline CAG & P1-A30 \\
\hline CAG repeat & $2-\mathrm{F} 3$ \\
\hline (CAG) repeat & $2-\mathrm{F} 6$ \\
\hline campomelic dysplasia & 2-D19 \\
\hline cancer gene therapy & S4-A15 \\
\hline cardiomyopathy & 2-F37 \\
\hline carrier detection & $1-F 8,2-F 38$ \\
\hline carrier female & $2-\mathrm{D} 24$ \\
\hline
\end{tabular}




\begin{tabular}{|c|c|c|c|}
\hline cat eye syndrome & $1-D 22$ & chromosome sorting & S7-A26 \\
\hline$(\mathrm{CCG}) \mathrm{n}$ & $1-F 16$ & chromosome & $1-E 9$ \\
\hline cDNA cloning & 1-D17, 1-E26, 2-D39 & translocation & \\
\hline cDNA sequence & $\mathrm{S} 7-\mathrm{A} 28$ & chronic granuloma- & 2-E30 \\
\hline Central Committee & S4-A17 & tous disease & \\
\hline centromere & $1-\mathrm{D} 36$ & chronic progressive & $2-\mathrm{F} 24,2-\mathrm{F} 25$ \\
\hline cerebellar ataxia & $2-\mathrm{F} 22$ & external & \\
\hline CGD & 2-D31 & ophthalmo- & \\
\hline CGG repeat in & $2-F 19$ & plegia & \\
\hline FMR-1 & & clinical dysmor- & N2-C6, N2-C7 \\
\hline $\begin{array}{l}\text { Charcot-Marie-Tooth } \\
\text { disease }\end{array}$ & $\mathrm{I}-\mathrm{D} 4,2-\mathrm{F} 13$ & $\begin{array}{l}\text { phology } \\
\text { clinical features }\end{array}$ & $1-F 3$ \\
\hline ChE gene & 2-E6 & clinical genetics & L4-A29, N2-C6 \\
\hline chemiluminescence & S9-C18 & clubfeet & $2-\mathrm{D} 23$ \\
\hline chidren's hospital & S2-B1 & CML & $1-\mathrm{E} 13$ \\
\hline children & 1-E24 & CNS & $\mathrm{P} 2-\mathrm{A} 39$ \\
\hline children of atomic & $2-\mathrm{E} 7$ & CNTF & $2-\mathrm{D} 41$ \\
\hline bomb survivors & & coagulation factor & $1-\mathrm{F} 23$ \\
\hline cholinesterase & 2-E6 & XIII & \\
\hline chondrodysplasia & $\mathrm{S3}-\mathrm{C} 5$ & codon 214 & 2-F31 \\
\hline chromosomal deletion & 2-D15 & COL4A5 gene & $\mathrm{S} 3-\mathrm{C} 4$ \\
\hline chromosomal & 1-D17 & collagen & $\mathrm{S} 3-\mathrm{Cl}$ \\
\hline localization & & colorectal & S5-B18 \\
\hline chromosome & $2-\mathrm{D} 3$ & tumorigenesis & \\
\hline chromosome 1 & $1-\mathrm{D} 2$ & comparative mapping & 1-D18, 1-D35 \\
\hline chromosome $10 \mathrm{q} 24.1$ & $1-\mathrm{D} 10$ & computer database & S2-B3 \\
\hline chromosome 11 & 1-D11,1-D12 & congenital heart & 2-D21 \\
\hline chromosome 11 q23 & 1-E9 & defects & \\
\hline chromosome 12 & $1-\mathrm{D} 14$ & consanguineous & S8-B19 \\
\hline chromosome $12 p$ & $2-\mathrm{F} 8$ & family & \\
\hline chromosome 14 & 1-D15, 2-D38, 2-F4, & consensus survey & W4-A22 \\
\hline & 2-F5, P1-A33 & contiguous-gene & $2-\mathrm{D} 13$ \\
\hline chromosome 21 & 1-D20, S1-A4 & syndrom & \\
\hline chromosome $21 \mathrm{q}$ & 1-D19 & coronary heart & $1-\mathrm{E} 19$ \\
\hline chromosome 22 & $1-\mathrm{D} 21$ & disease & \\
\hline chromosome 3 & 1-D6 & cosmid & 1-D12,1-D 15, 1-D20, \\
\hline chromosome $3 \mathrm{p}$ dele- & $1-\mathrm{E} 5$ & & W3-C8 \\
\hline tion & & cosmid clone & 1-D3 \\
\hline chromosome 4 & W2-B9 & cosmid clones & 2-D35 \\
\hline chromosome $4 \mathrm{q}$ & 2-D1 & cosmid contig & 1-E28, S7-A26 \\
\hline chromosome 6 & $1-\mathrm{D} 35$ & cosmid library & $1-\mathrm{D} 22$ \\
\hline chromosome 7 & $2-F 15$ & cosmid marker & $1-\mathrm{D} 8$ \\
\hline chromosome 8 & 1-D8, 1-D36 & Costello syndrome & 2-D28 \\
\hline chromosome 9 & A-12 & $\mathrm{CpG}$ island & $2-\mathrm{D} 35$ \\
\hline $\begin{array}{l}\text { chromosome } \\
\text { aberrations }\end{array}$ & 1-D31, AW1-A20 & $\begin{array}{l}\text { Creutzfeldt-Jakob } \\
\text { disease }\end{array}$ & P1-A32 \\
\hline $\begin{array}{l}\text { chromosome } \\
\text { abnormality }\end{array}$ & $1-\mathrm{F} 11,1-\mathrm{F} 13$ & $\begin{array}{l}\text { Cri-du-Chat } \\
\text { syndrome }\end{array}$ & 2-D3 \\
\hline chromosome analysis & $1-\mathrm{F} 10$ & crossing-over & $\mathrm{V} 2-\mathrm{C} 12$ \\
\hline chromosome bands & $1-\mathrm{D} 13$ & CTG expansion & $1-\mathrm{F} 3,1-\mathrm{F} 4$ \\
\hline chromosome deletion & 1-E6 & CTG repeat & S8-B19 \\
\hline chromosome painting & 1-D29 & $\mathrm{Cu} / \mathrm{Zn} \mathrm{SOD}$ & $2-\mathrm{F} 1$ \\
\hline $\begin{array}{l}\text { chromosome } \\
\text { rearrangement }\end{array}$ & $1-\mathrm{D} 30$ & $\begin{array}{l}\mathrm{Cu} / \mathrm{Zn} \text { superoxide } \\
\text { dismutase }\end{array}$ & $2-\mathrm{F} 2$ \\
\hline
\end{tabular}




\begin{tabular}{|c|c|}
\hline $\begin{array}{l}\text { curriculum for } \\
\text { student }\end{array}$ & $1-F 39$ \\
\hline CYP2C subfamily & $1-\mathrm{D} 10$ \\
\hline cytochrome b558 & 2-D31 \\
\hline cytogenetic map & W3-C8 \\
\hline cytogenetics & $1-\mathrm{D} 33$ \\
\hline cytokine & $\mathrm{S} 4-\mathrm{A} 15$ \\
\hline \multicolumn{2}{|l|}{$\mathbf{D}$} \\
\hline database & $1-\mathrm{D} 1$ \\
\hline deafness & $2-F 23$ \\
\hline defective virus & $1-\mathrm{E} 15$ \\
\hline deficiency & $2-\mathrm{E} 20$ \\
\hline $\operatorname{del}(5)(q 21.2 q 31.1)$ & $2-\mathrm{D} 4$ \\
\hline deletion & $2-\mathrm{F} 10$ \\
\hline development & $1-\mathrm{F} 34, \mathrm{~S} 3-\mathrm{Cl}$ \\
\hline DHPR gene & $\mathrm{S} 8-\mathrm{B} 21$ \\
\hline diabetes mellitus & $2-\mathrm{F} 30$ \\
\hline DiGeorge syndrome & $2-\mathrm{D} 15$ \\
\hline digital DNA typing & S9-C19 \\
\hline $\begin{array}{l}\text { dinucleotide repeat } \\
\text { polymorphism }\end{array}$ & $2-\mathrm{E} 36$ \\
\hline disease genes & $\mathrm{S} 7-\mathrm{A} 24$ \\
\hline disease-susceptibility & $\mathrm{S} 1-\mathrm{A} 2$ \\
\hline DMD & $1-\mathrm{F} 8$ \\
\hline $\mathrm{DMD} / \mathrm{BMD}$ & $1-\mathbf{F} 7$ \\
\hline DNA & V1-B11 \\
\hline DNA analysis & 2-F9, S8-B20 \\
\hline DNA diagnoses & $2-\mathrm{D} 36$ \\
\hline DNA diagnosis & $\begin{array}{l}2-\mathrm{F} 16,2-\mathrm{F} 27, \mathrm{~L} 2-\mathrm{A} 7 \\
\mathrm{P} 2-\mathrm{A} 35\end{array}$ \\
\hline DNA-finger print & $\mathrm{S} 9-\mathrm{C} 18$ \\
\hline DNA fingerprinting & 2-E8, S9-C22 \\
\hline DNA packing ratio & $1-\mathrm{D} 19$ \\
\hline DNA replication & S1-A5 \\
\hline DNA sequence & $1-F 23$ \\
\hline dominant & $2-\mathrm{D} 2$ \\
\hline $\begin{array}{l}\text { dominant negative } \\
\text { effect }\end{array}$ & $2-\mathrm{E} 3$ \\
\hline $\begin{array}{l}\text { dopamin D2 receptor } \\
\text { gene }\end{array}$ & 2-E35 \\
\hline $\begin{array}{l}\text { dopamine transporter } \\
\text { gene }\end{array}$ & 2-E32 \\
\hline double deletion & 2-E26 \\
\hline Down syndrome & 1-D20, S7-A25 \\
\hline DRPLA & $2-\mathrm{F} 8$ \\
\hline dual PCR & $1-F 31$ \\
\hline $\begin{array}{l}\text { Duchenne muscular } \\
\text { dystrophy }\end{array}$ & $\begin{array}{l}\text { 1-F6, W2-B7, W2- } \\
\text { B10 }\end{array}$ \\
\hline dynamic mutation & $2-\mathrm{F} 17$ \\
\hline dysmyelination & $2-\mathrm{F} 12$ \\
\hline dystrophic hamster & $1-F 9$ \\
\hline dystrophin & $\begin{array}{l}\text { 1-F9, W2-B7, W2- } \\
\text { B10 }\end{array}$ \\
\hline
\end{tabular}

\begin{tabular}{|c|c|}
\hline dystrophin gene & $1-F 5$ \\
\hline \multicolumn{2}{|l|}{$\mathbf{E}$} \\
\hline E5 variant & $1-\mathrm{E} 20$ \\
\hline educational program & I-F39 \\
\hline $\begin{array}{l}\text { endometrial } \\
\text { carcinoma }\end{array}$ & S5-B16 \\
\hline enhancer & $1-F 37$ \\
\hline epidemiology & $1-\mathrm{F} 30$ \\
\hline epitope & $1-E 36$ \\
\hline ERG & $\mathrm{S} 1-\mathrm{A} 4$ \\
\hline ES cell & $\mathrm{V} 2-\mathrm{C} 13$ \\
\hline essential hypertension & $1-\mathrm{E} 17$ \\
\hline ethics & W4-A21 \\
\hline ethidium bromide & 1-D34 \\
\hline evolution & $1-\mathrm{E} 29,1-\mathrm{F} 17$ \\
\hline exon skipping & $2-\mathrm{F} 36$ \\
\hline extraction & $\mathrm{S} 9-\mathrm{C} 21$ \\
\hline
\end{tabular}

Fabry disease

familial

2-E15, 2-E16

1-F25

disease(FAD)

familial amyloidosis $\quad \mathrm{V} 2-\mathrm{Cl} 14$

familial amyloidotic P2-A35 polyneuropathy

familial amyotrophic 2-F2 lateral sclerosis

familial combined hyperlipidemia

familial hypercholesterolemia

familial transmission

family

family history

family study 2-D21

fatty acid $\beta$-oxidation $2-$ D39

fatty acid oxidation 2-E28

FCMD A-12

fetal cells $\quad 1-\mathrm{F} 14$

FG syndrome 2-D24

fibroblast 2-D10

FISH

1-D5, 1-D7, 1-D 10,

1-D18, 1-D19, 1-D21,

1-D23, 1-D24, 1-D25,

1-D28, 1-D29, 1-D35,

1-D37, 1-E16, 2-D8,

2-D1 1, 2-D14, 2-D15, W3-C8, W3-C9, W3C 11

flow-sorted syndrome 1-D22

fluorescence in situ 1-D15 hybridization 
FMR-1

forensic application

forensic materials

forensic practice

founder chromosomes

Fragile X syndrome

frontal lobe epilepsy
FSHD
$\alpha$-L-fucosidase
$\quad$ G
galactose-1-phos-
phate uridyl trans-
ferase(GALT)
galactosemia; type 1
$\alpha$-galactosidase A
$\beta$-galactosidosis
GALNS
gastric cancer
Gaucher disease
GC content
gene
gene analysis
gene cloning
gene deletion
gene expression
gene mapping
gene mutation R21C
gene product
gene tagging
gene-targeting
gene targeting
gene therapy

gene transfer

gene trap

genetic cladogram

genetic counseling

genetic counselor

genetic diagnosis

genetic disease

genetic epidemiology

genetic heterogeneity

genetic linkage

genetic polymorphism

genetic service

genome

genome analysis

genome mapping
1-F16, 2-F18, S6-C16

$\mathrm{S} 9-\mathrm{C} 20$

S9-C21

S9-C22

2-F 17

1-F16, 2-F16,

2-F17, 2-F18, 2-F19,

2-F20, S6-C16

2-D32

W2-B9

1-F21

2-E22

2-E22

2-E15, 2-E16

P2-A36

2-E25

S15-B17

S8-B20, V1-B11

1-D13

2-D3

1-E41

2-E25

2-F 18

2-E21

1-D1, 1-D4, 1-D7, 1-

D14, P2-A38

2-E23

S1-A5

V2-C13

S5-B18

V2-C14

L3-A18, P2-A39, S4-

A13, S4-A14, S4-

A16, S4-A17, W2-

B10, W4-A21

S4-A13

$\mathrm{V} 2-\mathrm{C} 13$

1-F 19

S2-B2, W4-, W4-A23

$\mathrm{N} 2-\mathrm{C} 7$

W2-B9

1-F29, 1-F40, S2-B3

2-E40

2-D25

P1-A33

1-E19, 1-F21

S2-B1, S2-B2

S6-C15

S7-A26

1-D 33, S7-A25 genomic deletion $\quad$ W2-B7

genomic imprinting 1-F33, 2-E3

genotype $1-\mathrm{F} 22$

Gerstmann-Sträussler P1-A32 syndrome

glioma

GLUT 2

GM-CSF

Gm allotype 1-F24

$1-\mathrm{F} 28$

2-E23

GM1 gangliosidosis

GM 1-gangliosidosis

GM2-gangliosidosis

$\alpha$ subunit gene

growth hormone gene

growth retardation

GTPase activating

protein

guideline

P2-A36

2-E24

1-F1

2-D28

1-F38

S4-A 17

1-E8

H

\begin{tabular}{|c|c|}
\hline $\mathrm{H}-2 \mathrm{~K}$ & $1-F 34$ \\
\hline handicap & W4-A22 \\
\hline haplotype & $2-F 33$ \\
\hline HBsAg & $1-E 36$ \\
\hline HDL & $1-\mathrm{E} 21$ \\
\hline Helicobacter pylori & $1-\mathrm{E} 38$ \\
\hline hemoglobin $\mathrm{H}$ & $2-\mathrm{D} 26$ \\
\hline heredity & $\mathrm{W} 4-\mathrm{A} 22$ \\
\hline heteroduplex & $2-\mathrm{F} 28$ \\
\hline heterogeneity & 1-D40, S8-B22 \\
\hline$\beta$-hexosaminidase & 2-E24 \\
\hline $\begin{array}{l}\text { high-resolution } \\
\text { banding }\end{array}$ & $1-\mathrm{D} 34$ \\
\hline $\begin{array}{l}\text { high resolution } \\
\text { mapping }\end{array}$ & W3-C9 \\
\hline higher brain function & 2-D32 \\
\hline HLA & $\begin{array}{l}1-\mathrm{E} 30,1-\mathrm{E} 33,1-\mathrm{E} 36 \\
1-\mathrm{E} 38,1-\mathrm{E} 39, \mathrm{~S} 1-\mathrm{A} 2\end{array}$ \\
\hline HLA-class I & $1-\mathrm{E} 32$ \\
\hline HLA-DPB 1 & $1-\mathrm{E} 29$ \\
\hline HLA DR & $1-E 37$ \\
\hline HLA-DR51 & $1-\mathrm{E} 34$ \\
\hline HLA-DRBI & $1-\mathrm{E} 31$ \\
\hline $\begin{array}{l}\text { holocarboxylase } \\
\text { synthetase }\end{array}$ & $1-\mathrm{D} 17$ \\
\hline $\begin{array}{l}\text { holocarboxylase } \\
\text { synthetase deficiency }\end{array}$ & $2-\mathrm{E} 31$ \\
\hline $\begin{array}{l}\text { homozygosity } \\
\text { mapping }\end{array}$ & $A-12$ \\
\hline homozygote & $2-\mathrm{F} 35$ \\
\hline
\end{tabular}




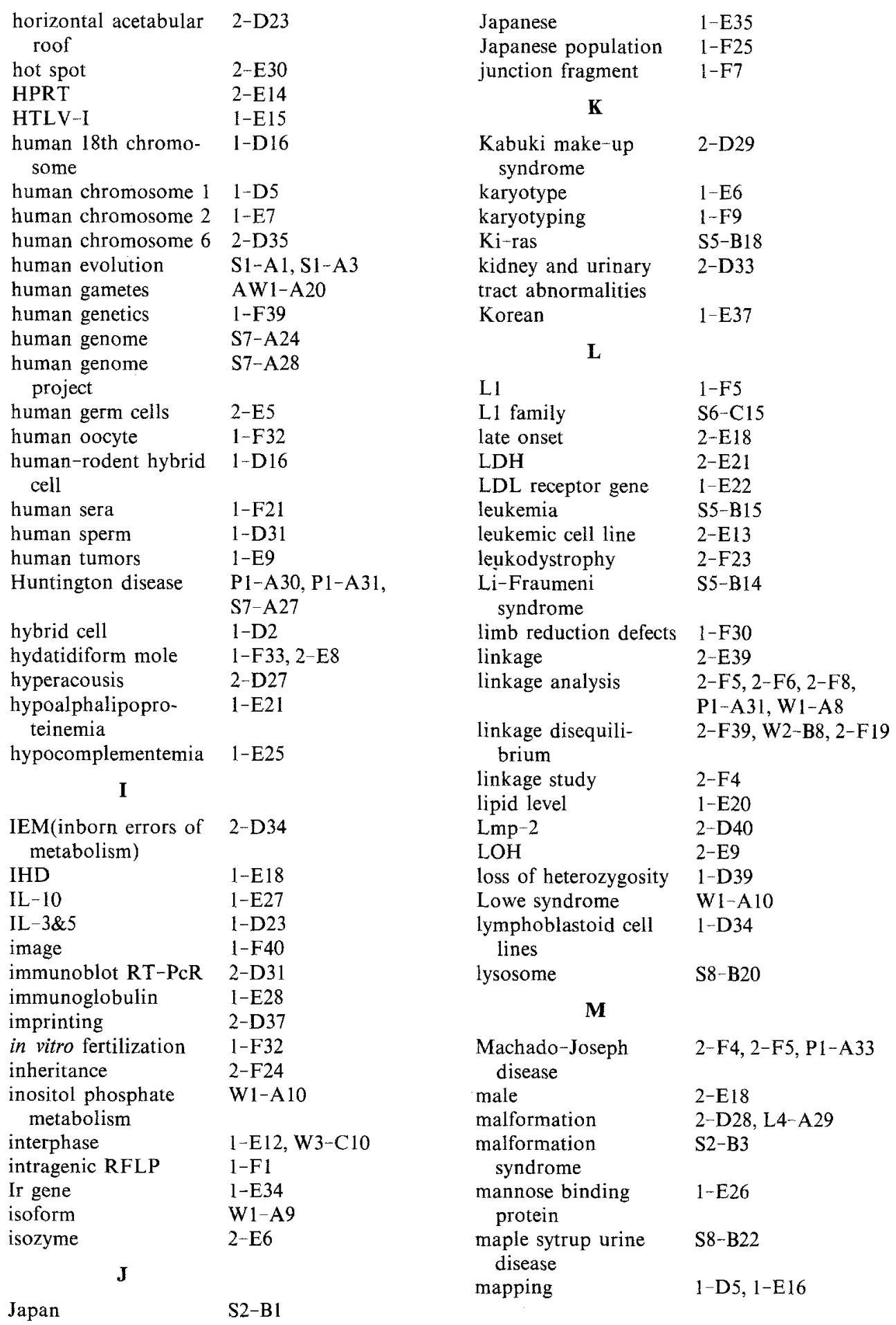




\begin{tabular}{|c|c|c|c|}
\hline $\begin{array}{r}\text { mapping and } \\
\text { sequencing }\end{array}$ & $\mathrm{S} 7-\mathrm{A} 24$ & $\begin{array}{l}\text { mosaicism } \\
\text { motif }\end{array}$ & $\begin{array}{l}\text { 1-F12, 2-D11, S3-C2 } \\
1-\mathrm{E} 31\end{array}$ \\
\hline marker chromosome & 2-D17 & mouse embryo & $1-F 31$ \\
\hline mass screening & $1-E 23$ & Moyamoya disease & $2-E 40$ \\
\hline maternal blood & $1-\mathrm{F} 14$ & MPS IVA & $2-E 26$ \\
\hline $\begin{array}{l}\text { maternal cell con- } \\
\text { tamination }\end{array}$ & $1-\mathrm{F} 12$ & $\begin{array}{l}\text { mt DNA } \\
\text { (mitochondrial }\end{array}$ & $2-F 22$ \\
\hline MCAD deficiency & V1-B13 & DNA) & \\
\hline MDE gel & 2-F11 & mucopolysaccha- & $2-\mathrm{E} 27$ \\
\hline median nodule & 2-D20 & ridosis IVA & \\
\hline medical genetics & 1-F40, S2-B4 & multi color FISH & W3-C9 \\
\hline MELAS & $2-F 21,2-F 30$ & multi-color FISH & 1-D6 \\
\hline membrane protein & AW2-A19 & mutation & 2-E7, 2-E9, 2-E14, \\
\hline $\begin{array}{l}\text { mental retardation } \\
\text { population }\end{array}$ & $2-\mathrm{F} 20$ & & $\begin{array}{l}\text { 2-E19, 2-E20, 2-E22, } \\
\text { 2-E27, 2-E31, 2-F1, }\end{array}$ \\
\hline mesothelioma & 1-E6 & & $2-\mathrm{F} 14,2-\mathrm{F} 28,2-\mathrm{F} 29$ \\
\hline metabolic disease & S4-A16 & & 2-F40, P2-A37, S1- \\
\hline metachromatic & V1-B11 & & $\mathrm{A} 5, \mathrm{~S} 8-\mathrm{B} 23$ \\
\hline leukodystrophy & & myelin & $2-\mathrm{F} 13$ \\
\hline methylmalonic & V1-B13 & myopathy MODY & $1-F 36$ \\
\hline acidemia & & myosin & $2-\mathrm{F} 37$ \\
\hline $\mathrm{MHC}$ & $1-\mathrm{F} 35,2-\mathrm{D} 40, \mathrm{~S} 1-\mathrm{A} 3$ & myotonic dystrophy & 1-F3, 1-F4, S8-B19, \\
\hline micro cell & 2-D37 & & W2-B8 \\
\hline microcell fusion & 1-E7 & $\mathbf{N}$ & \\
\hline microdeletion & 2-D14 & $\mathbf{N}$ & \\
\hline microdissection & $\begin{array}{l}\text { 1-D3, 1-D9, 1-D11, } \\
\text { 2-D38, S7-A27 }\end{array}$ & $\begin{array}{l}\mathrm{N}-m y c \text { gene } \\
\text { amplification }\end{array}$ & $1-\mathrm{E} 3$ \\
\hline $\begin{array}{l}\text { microdissection- } \\
\text { painting }\end{array}$ & 1-D30, 2-D17 & $\begin{array}{l}\text { NADPH oxidase } \\
\text { nervous system }\end{array}$ & $\begin{array}{l}\text { 1-E27, 2-E30 } \\
1-D 4\end{array}$ \\
\hline microdissection- & $2-\mathrm{D} 2$ & neural tube & $\mathrm{P} 1-\mathrm{A} 34$ \\
\hline painting method & & neuroblastoma & $1-E 3$ \\
\hline microsatellite & 1-D9, 1-D16, 2-F39 & neurodegenerative & W1-A8 \\
\hline minisatellite & $2-E 5$ & disease & \\
\hline $\begin{array}{l}\text { minisatellite variant } \\
\text { repeat }\end{array}$ & S9-C19 & $\begin{array}{l}\text { neurology } \\
\text { neuronal differen- }\end{array}$ & $\begin{array}{l}\mathrm{L} 2-\mathrm{A} 7 \\
1-\mathrm{E} 4\end{array}$ \\
\hline misdiagnosis & $1-\mathrm{F} 10$ & tiation & \\
\hline missense mutation & $2-F 37$ & neurotrophic factor & $2-\mathrm{D} 41$ \\
\hline mitochondria & 2-D39 & newborn & 2-D33, 2-D34 \\
\hline mitochondrial DNA & $\mathrm{S} 1-\mathrm{A} 3$ & newborn screening & $\mathrm{S} 2-\mathrm{B} 2$ \\
\hline mitochondrial disease & $2-\mathrm{F} 21$ & NF1 & $1-\mathrm{F} 38,2-\mathrm{F} 14$ \\
\hline mitochondrial DNA & $\begin{array}{l}\text { 1-F18, 2-F21, 2-F23, } \\
2-\mathrm{F} 25,2-\mathrm{F} 30, \mathrm{~S} 1-\mathrm{A} 1\end{array}$ & $\begin{array}{l}\text { Niemann-Pick } \\
\text { disease type C }\end{array}$ & P2-A38 \\
\hline $\begin{array}{l}\text { mitochondrial } \\
\text { encephalomyopathy }\end{array}$ & $2-\mathrm{F} 26$ & $\begin{array}{l}\text { NOD } \\
\text { non isotope }\end{array}$ & $\begin{array}{l}1-\mathrm{F} 35 \\
2-\mathrm{D} 36\end{array}$ \\
\hline mitochondrial & $2-F 24$ & non sense mutation & $2-\mathrm{E} 16,2-\mathrm{F} 11$ \\
\hline moesin & $1-\mathrm{D} 24$ & 0 & \\
\hline molecular analysis & 2-El & & \\
\hline molecular genetics & V1-B13 & oncogene & 1-E12, W3-C10 \\
\hline monkey & $1-E 29$ & one base deletion & $1-\mathrm{F} 6$ \\
\hline monocyte & $1-\mathrm{E} 27$ & opinion survey & W4 \\
\hline Morquio B disease & $\mathrm{P} 2-\mathrm{A} 36$ & ordering system & $1-\mathrm{D} 6$ \\
\hline mortality rate & $1-F 29$ & organic aciduria & $2-\mathrm{F} 29$ \\
\hline $\begin{array}{l}\text { mosaic partial } \\
\text { monosomies }\end{array}$ & $2-\mathrm{D} 1$ & $\begin{array}{l}\text { ornithine transcar- } \\
\text { bamylase deficiency }\end{array}$ & $2-\mathrm{E} 18$ \\
\hline
\end{tabular}




\begin{tabular}{|c|c|c|c|}
\hline osteoarthritis & $\mathrm{S} 3-\mathrm{C} 5$ & phylogenetic analysis & $\mathrm{S} 1-\mathrm{Al}$ \\
\hline $\begin{array}{l}\text { osteogenesis } \\
\text { impertecta }\end{array}$ & $\mathrm{S} 3-\mathrm{C} 2$ & $\begin{array}{l}\text { physical mapping } \\
\text { PIT1 }\end{array}$ & $\begin{array}{l}\text { 1-E28, 2-E12 } \\
2-\mathrm{E} 3\end{array}$ \\
\hline OTC & $1-F 37$ & plasmid & $1-\mathrm{D} 21$ \\
\hline$\beta$-oxidation & 2-E28 & pLMM & $2-\mathrm{F} 15$ \\
\hline \multicolumn{2}{|l|}{$\mathbf{P}$} & $\begin{array}{l}\text { poikiloderma } \\
\text { point mutation }\end{array}$ & 2-D22 \\
\hline$P_{0}$ & $2-\mathrm{F} 13$ & & $2-\mathrm{E} 37,2-\mathrm{F} 2,2-\mathrm{F} 22$ \\
\hline p53 & $\mathrm{P} 2-\mathrm{A} 37$ & polymerase chain & $\mathrm{S} 9-\mathrm{C} 19$ \\
\hline p53 gene & 1-E13, 1-E14 & reaction & \\
\hline $\begin{array}{l}\mathrm{p} 53 \text { germ-line } \\
\text { mutation }\end{array}$ & S5-B14 & $\begin{array}{l}\text { polymorphic marker } \\
\text { polymorphism }\end{array}$ & $\begin{array}{l}\text { 1-D3 } \\
1-\mathrm{E} 18,1-\mathrm{E} 30,1-\mathrm{F} 18\end{array}$ \\
\hline $\begin{array}{l}\text { Pallister-Killiam } \\
\text { syndrome }\end{array}$ & 2-D8 & & $\begin{array}{l}1-\mathrm{F} 23,1-\mathrm{F} 27,2-\mathrm{F} 33 \\
2-\mathrm{F} 34, \mathrm{~S} 1-\mathrm{A} 2\end{array}$ \\
\hline $\begin{array}{l}\text { parathyroid hormone- } \\
\text { related peptide }\end{array}$ & $1-\mathrm{E} 40$ & $\begin{array}{l}\text { population } \\
\text { positional cloning }\end{array}$ & $\begin{array}{l}\text { 1-F26 } \\
W 1-A 8, W 1-A 9\end{array}$ \\
\hline partial tetrasomy 9 & 2-D7 & & W1-A10,W1-A11 \\
\hline partial trisomy & $2-\mathrm{D} 9$ & pre B-cell ALL & $1-$ E14 \\
\hline $\begin{array}{l}\text { Partington syndrome } \\
\text { patient-parent }\end{array}$ & $\begin{array}{l}2-\mathrm{D} 25 \\
\mathrm{~S} 2-\mathrm{B} 4\end{array}$ & $\begin{array}{l}\text { predictive mutation } \\
\text { screening }\end{array}$ & S5-B14 \\
\hline associations & & pregnancy induced & $1-\mathrm{E} 17$ \\
\hline PAX & $1-D 7$ & hypertension & \\
\hline Pax 3 & $2-F 40$ & preimplantation & $1-\mathrm{F} 31$ \\
\hline \multirow{3}{*}{ PCR } & 1-E2, 1-E3, 1-E33, & diagnosis & \\
\hline & $\begin{array}{l}\text { 1-F22, 1-F24, 1-F27, } \\
2-\mathrm{E} 11,2-\mathrm{E} 17, \mathrm{~S} 9-\end{array}$ & $\begin{array}{l}\text { premature chromo- } \\
\text { some condensation }\end{array}$ & $1-F 32$ \\
\hline & $\mathrm{C} 20, \mathrm{~S} 9-\mathrm{C} 22$ & prenatal diagnosis & $1-\mathrm{F} 10,1-\mathrm{F} 11,1-\mathrm{F} 12$ \\
\hline $\begin{array}{l}\text { PCR direct } \\
\text { sequencing }\end{array}$ & $2-\mathrm{E} 10$ & & $\begin{array}{l}\text { 1-F13, 1-F14, 2-F28, } \\
\text { W4-A21 }\end{array}$ \\
\hline PCR-SSCP & 2-F27, S3-C4 & prevalence & $2-\mathrm{F} 20$ \\
\hline $\mathrm{PCR} / \mathrm{SSCP}$ & $2-\mathrm{F} 14$ & primate & $1-D 18$ \\
\hline PDH deficiency & $2-\mathrm{F} 27$ & prion & P1-A32 \\
\hline $\begin{array}{l}\text { Pelizaeus-Merzbacher } \\
\text { disease }\end{array}$ & $2-\mathrm{F} 12$ & $\begin{array}{l}\text { programmed cell } \\
\text { death }\end{array}$ & $1-\mathrm{E} 1$ \\
\hline pepsinogen & $1-\mathrm{F} 27$ & promoter & $2-E 25$ \\
\hline peptide & $1-\mathrm{E} 32$ & propionic acidemia & $2-E 4$ \\
\hline pericentric inversion & 2-D14 & propionyl CoA & $2-E 4$ \\
\hline peripheral neuropathy & 2-D13 & carboxylase & \\
\hline peripherin/RDS gene & $2-F 31$ & proteasome & $2-\mathrm{D} 40$ \\
\hline peroxisomal disorders & V1-B12 & proteolipid protein & $2-\mathrm{F} 12$ \\
\hline $\begin{array}{l}\text { peroxisome assembly } \\
\text { factor }\end{array}$ & AW2-A19 & $\begin{array}{l}\text { proximal insertion } \\
\text { psychology }\end{array}$ & $\begin{array}{l}2-\mathrm{D} 5 \\
\mathrm{~N} 1-\mathrm{B} 6\end{array}$ \\
\hline $\begin{array}{l}\text { personal } \\
\quad \text { identification }\end{array}$ & $\mathrm{S} 6-\mathrm{C} 17$ & $\begin{array}{l}\text { public perceptions } \\
\text { purine }\end{array}$ & $\begin{array}{l}\text { W4-A23 } \\
1-F 26, S 8-B 23\end{array}$ \\
\hline phenylalanine & 2-E29 & PWS & $2-\mathrm{D} 11$ \\
\hline hydroxylase & & PWS/AS & W3-C11 \\
\hline $\begin{array}{l}\text { phenylalanine } \\
\text { hydroxylase gene }\end{array}$ & S8-B21 & pyruvate kinase & 2-E19 \\
\hline phenylalanine & S8-B21 & $\mathbf{Q}$ & \\
\hline tolerance & & quantitation & $2-F 26$ \\
\hline phenylketonuria & $2-E 29$ & $\mathbf{R}$ & \\
\hline $\begin{array}{l}\text { phosducin } \\
\text { phosphoglucomutase }\end{array}$ & $\begin{array}{l}2-F 33 \\
1-F 19,1-F 20\end{array}$ & Ra-reactive factor & $1-\mathrm{E} 26$ \\
\hline
\end{tabular}




\begin{tabular}{|c|c|c|c|}
\hline radiation-reduced & $1-\mathrm{D} 12$ & single-locus probe & S9-C18 \\
\hline hybrid & & single strand DNA & $1-\mathrm{F} 7$ \\
\hline rare variant & $1-\mathrm{F} 20$ & electrophoresis & \\
\hline ras oncogene & S5-B16 & slipped mispairing & 1-E22, 2-E21 \\
\hline RB gene & $1-\mathrm{E} 1$ & Smith-Sagenis & 2-D13 \\
\hline rDNA & $2-\mathrm{E} 12$ & syndrome & \\
\hline reciprocal & 1-D32, 2-D16, V2- & somatic & S8-B23 \\
\hline translocation & $\mathrm{C} 12$ & somatic mutation & $\mathrm{S} 15-\mathrm{B} 17$ \\
\hline recombinant virus & S4-A 14 & South America & $1-F 28$ \\
\hline recombination & $1-F 19$ & Southern blotting & $2-\mathrm{E} 26$ \\
\hline recurrence & $\mathrm{S} 3-\mathrm{C} 2$ & sperm & $1-D 37$ \\
\hline renal cell carcinoma & $1-\mathrm{E} 5$ & spina bifida & $\mathrm{P} 1-\mathrm{A} 34$ \\
\hline repetitive sequences & $\mathrm{S} 6-\mathrm{C} 15$ & splice site mutation & $2-F 36$ \\
\hline reproductive failure & AW1-A20 & splicing error & $2-\mathrm{E} 14$ \\
\hline retinitis pigmentosa & 2-F31, 2-F34 & splicing mutation & $2-E 4,2-E 29$ \\
\hline retinoblastoma & $1-\mathrm{E} 2$ & $s r c$ gene & $1-E 4$ \\
\hline retrovirus & L3-A18 & SRY & $2-\mathrm{E} 10$ \\
\hline RFLP & 1-E38, 1-F24, 2-E40 & SSCP & 1-F6, 2-E15, 2-F26 \\
\hline $\operatorname{Rg}:-1,-2$ & $1-E 35$ & SSCP-MDE & $2-E 27$ \\
\hline $\mathrm{Rh}$ polypeptide & 2-E1, 2-E11 & steroid sulfatase & $2-\mathrm{E} 17$ \\
\hline Rheumatoid arthritis & $1-E 37$ & STS & 2-D38, S7-A25 \\
\hline rhodopsin gene & $2-F 34$ & submicroscopic & $2-\mathrm{D} 12$ \\
\hline RI & $2-\mathrm{D} 36$ & deletion & \\
\hline Rieger syndrome & 2-D16 & substitutions & $1-F 20$ \\
\hline ring 20 chromosome & $2-\mathrm{D} 32$ & SUP-PCR & S7-A27 \\
\hline ring chromosome 13 & $2-\mathrm{D} 9$ & support of the patient & S2-B4 \\
\hline $\begin{array}{l}\text { RNA splicing } \\
\text { mutation }\end{array}$ & 2-D41 & syndrome & L4-A29 \\
\hline Robin sequence & 2-D1 & \multicolumn{2}{|l|}{$\mathbf{T}$} \\
\hline $\begin{array}{l}\text { Rothmund Thomson } \\
\text { syndrome }\end{array}$ & $2-\mathrm{D} 22$ & $\begin{array}{l}\text { T cell-ALL } \\
\mathrm{T} / \mathrm{t} \text {-complex }\end{array}$ & $\begin{array}{l}1-E 14 \\
1-F 34\end{array}$ \\
\hline RT-PCR & I-E40 & $\mathrm{t}(8 ; 21)$ & S5-B15 \\
\hline $\begin{array}{l}\text { Rubinstein-Taybi } \\
\text { syndrome }\end{array}$ & 2-D12 & $\begin{array}{l}\text { TAM } \\
\text { tandemly-repetitive } \\
\text { nolymornhism }\end{array}$ & $\begin{array}{l}\text { 1-E16 } \\
\text { S6-C17 }\end{array}$ \\
\hline \multicolumn{2}{|l|}{$\mathbf{S}$} & TAP gene & $1-$ E33 \\
\hline SCA1 & $2-\mathrm{F} 6$ & Tay-Sachs disease & $2-\mathrm{E} 24$ \\
\hline schizophrenia & 2-E35, 2-E36, 2-E37 & telomere & $2-\mathrm{E} 13$ \\
\hline SCID & $1-\mathrm{D} 8$ & tetrasomy $9 p$ & 2-D7 \\
\hline screening & 1-E24, 2-D34 & thiolase & $2-\mathrm{F} 29$ \\
\hline segregation & $\mathrm{V} 2-\mathrm{C} 12$ & three genes theory & $2-\mathrm{E} 1$ \\
\hline selection & $1-\mathrm{F} 17$ & thrombasthenia & $2-F 36$ \\
\hline self peptide & 1-E31 & thyroid hormone & $1-E 41$ \\
\hline senescence & 1-E7 & tissue specific & $2-\mathrm{D} 7$ \\
\hline sequence-tagged-sites & 1-D13 & mosaicism & \\
\hline serotonin 2 receptor & $2-E 34$ & town geneticist & $\mathrm{N} 2-\mathrm{C} 7$ \\
\hline $\begin{array}{l}\text { serum } \beta \text {-galactosid- } \\
\quad \text { ase }\end{array}$ & 2-E23 & $\begin{array}{l}\text { transcriptional } \\
\text { control }\end{array}$ & $\mathrm{S} 3-\mathrm{C} 1$ \\
\hline severe malformation & 2-D8 & transformation & $2-\mathrm{E} 13$ \\
\hline sex ratio & 1-D37, 1-E8 & transgenic & $1-F 35$ \\
\hline sex reversal & 2-D19 & transgenic mouse & 1-E34, 1-F37 \\
\hline short limbs & $2-\mathrm{D} 23$ & translocation & 2-D18, 2-D19, S5- \\
\hline Silver-Russel & $2-\mathrm{D} 25$ & & $\mathrm{~B} 15$ \\
\hline syndrome & & transthyretin & $\mathrm{P} 2-\mathrm{A} 35, \mathrm{~V} 2-\mathrm{C} 14$ \\
\hline
\end{tabular}




trinucleotide
$\quad$ expansion
trinucleotide repeat
trinucleotide repeats
triplet repeat
trisomy 13
trisomy 14
tuberous sclerosis
tumor suppressor
tumor suppressor
genes

Turner

twin

type IIC

type IX collagen

U

$\begin{array}{ll}\text { ultrasound } & 2-\mathrm{D} 33 \\ \text { unknown } & 1-\mathrm{F} 28 \\ \text { upper lip } & 2-\mathrm{D} 20 \\ \text { urolithiasis } & 1-\mathrm{F} 26 \\ \text { UV-survival curve } & 2-\mathrm{D} 22\end{array}$

V

vector

viral vector

vital statistics

VNTR

VNTR markers

Von Hippel-Lindau syndrome

von Willebrand disease

\section{$\mathbf{W}$}

S6-C16

P1-A30, W2-B8

2-E7

P1-A31

2-D 10

1-D28

2-F 15

W1-A11

1-D39

2-D10

N1-B6

2-F35

S3-C5

-D33

$-\mathrm{F} 28$

$1-\mathrm{F} 26$

2-D22

L3-A 18

P2-A39, S4-A 13

$1-\mathrm{F} 29$

1-E2, S9-C20

S6- $\mathrm{Cl} 7$

1-E5

2-F35

2-F40

W1-A9

$1-\mathrm{D} 14$

1-D9, 2-F38, 2-F39

1-D28

2-D27

1-D39, 1-D40

1-D24

1-DI

$1-\mathrm{F} 33$

\section{$\mathbf{X}$}

$\mathrm{X}$-linked bulbospinal

2-F3

neuronopathy

$\mathrm{X}$-linked ichthyosis

2-E17

\author{
$\mathrm{X}$-linked mental 2-D26 \\ retardation \\ $\mathrm{X}$-linked recessive $\quad 2-\mathrm{D} 24$ \\ xeroderma 2-D29 \\ pigmentosum \\ $\mathrm{XY}$ female \\ 2-E10 \\ $\mathbf{Y}$ \\ $Y$ chromosome 1-D26, 1-D27 \\ $\mathrm{Y}$ specific and $\mathrm{X}-\mathrm{Y}$ 1-D25 \\ homologous \\ regions \\ YAC \\ 1-D2, 1-D 11, 1-D25, \\ 1-D26, 1-D27, 1-E12, \\ W3-C10, W3-C11
}

$\mathbf{Z}$

Zellweger syndrome

AW2-A19, V1-B12

\section{Others}

$13 q$ proximal trisomy $2-D 17$

$14 \mathrm{q}$ trisomy $2-\mathrm{D} 18$

$16 \mathrm{p} 13.3 \quad 2-\mathrm{D} 12$

$4 \mathrm{p}$ distal duplication 2-D2

4q25 2-D16

5p monosomy 2-D18

$5 \mathrm{q}+\quad 2-\mathrm{D} 5$

$5 q^{-} \quad 2-D 4$ 